\title{
Supply-demand balance in the atrium
}

Citation for published version (APA):

van Bragt, K. A. W. M. (2015). Supply-demand balance in the atrium. [Doctoral Thesis, Maastricht University]. Uitgeverij BOXPress. https://doi.org/10.26481/dis.20150703kb

Document status and date:

Published: 01/01/2015

DOI:

10.26481/dis.20150703kb

Document Version:

Publisher's PDF, also known as Version of record

\section{Please check the document version of this publication:}

- A submitted manuscript is the version of the article upon submission and before peer-review. There can be important differences between the submitted version and the official published version of record.

People interested in the research are advised to contact the author for the final version of the publication, or visit the DOI to the publisher's website.

- The final author version and the galley proof are versions of the publication after peer review.

- The final published version features the final layout of the paper including the volume, issue and page numbers.

Link to publication

\footnotetext{
General rights rights.

- You may freely distribute the URL identifying the publication in the public portal. please follow below link for the End User Agreement:

www.umlib.nl/taverne-license

Take down policy

If you believe that this document breaches copyright please contact us at:

repository@maastrichtuniversity.nl

providing details and we will investigate your claim.
}

Copyright and moral rights for the publications made accessible in the public portal are retained by the authors and/or other copyright owners and it is a condition of accessing publications that users recognise and abide by the legal requirements associated with these

- Users may download and print one copy of any publication from the public portal for the purpose of private study or research.

- You may not further distribute the material or use it for any profit-making activity or commercial gain

If the publication is distributed under the terms of Article $25 \mathrm{fa}$ of the Dutch Copyright Act, indicated by the "Taverne" license above, 


\section{SUPPLY-DEMAND BALANCE}

IN THE ATRIUM 
Copyright @ K.A.W.M van Bragt, Maastricht 2015

ISBN: $978-94-6295-232-4$

Cover and layout by Kelly van Bragt en Lyanne Polderman

Printed by Proefschriftmaken.nl || Uitgeverij BOXPress

Published by Uitgeverij BOXPress, 's-Hertogenbosch

All rights reserved. No part of this book may be reproduced, stored in a database or retrieval system, or published in any form or by any means, without prior permission in writing from the author. 


\title{
SUPPLY-DEMAND BALANCE IN THE ATRIUM
}

\author{
PROEFSCHRIFT
}

Ter verkrijging van de graad van doctor aan de Universiteit Maastricht, op gezag van de Rector Magnificus, Prof. Dr. L.L.G. Soete,

volgens het besluit van College van Decanen

in het openbaar te verdedigen op

Vrijdag 3 Juli 2015 om 10.00 uur

door

Kelly Anna Wilhelmina Maria van Bragt

Geboren op 23 januari 1985 te Roermond 


\section{PROMOTOR:}

Prof. Dr. U. Schotten

\section{CO-PROMOTOREN:}

Dr. S. Verheule

Dr. J.J. Luiken

\section{BEOORDELINGSCOMMISSIE:}

Prof. Dr. H.J.G.M. Crijns (voorzitter)

Prof. Dr. D.J.G.M. Duncker

Prof. Dr. F.W. Prinzen

This research is supported by the Cardiovascular Research Center Maastricht (CARIM), the Leducq Foundation (project ENAFRA) and EU (project EUTRAF).
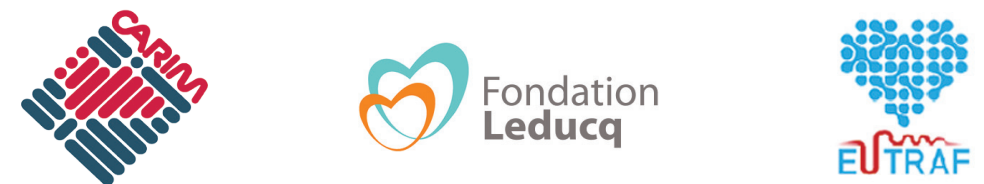
I looked for the dust in the air,

for that is where the words live,

tumbling lazy, remaining

just out of reach, and staying, staying,

staying, until something,

an unseen waft of air

causes them to drift right up to

your reach, gather into sentences,

one sentence, two sentences,

that's all you need to get started.

-Jimmy Breslin 

CHAPTER 1

CHAPTER 2

CHAPTER 3

CHAPTER 4

CHAPTER 5

CHAPTER 6

CHAPTER 7

APPENDIX
General introduction

Atrial tissue perfusion and ischemia in atrial

fibrillation

Anatomy of the atrial vasculature in pigs

Atrial supply-demand balance in healthy adult pigs:

coronary blood flow, oxygen extraction and lactate

production during acute atrial fibrillation

Dynamic regulation of atrial coronary blood flow:

description of supply-demand balance in healthy

adult pigs

The impact of persistent atrial fibrillation on the

atrial supply-demand balance

General discussion

Summary

Samenvatting

Valorization

About the author

List of publications

Dankwoord 
CHAPTER 1

8 


\section{General introduction \\ General introduction}

Kelly van Bragt

1
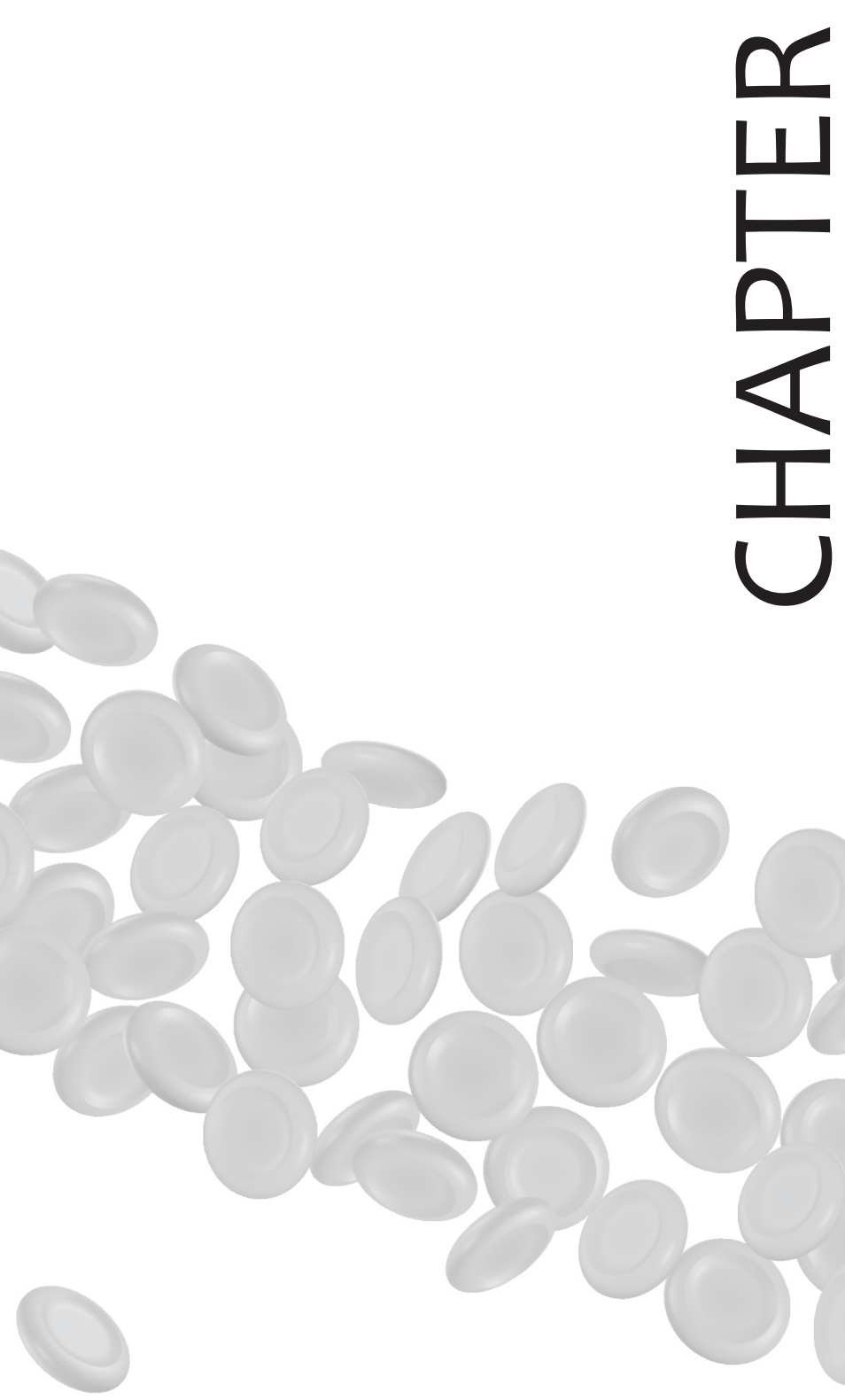


\section{GENERAL INTRODUCTION}

Atrial fibrillation (AF) is the most common arrhythmia in clinical practice, affecting $1 \%$ of the total population. The prevalence of AF increases with age (to $\sim 5 \%$ in people over 65 and $\sim 10 \%$ in people over $75^{1-3}$ ). The socio-economic burden related to AF is thus expected to increase with the aging of the general population. Chronic Ischemic heart disease is, amongst others, an important risk factor for $\mathrm{AF}^{1,4^{-10}}$. In acute myocardial infarction (AMI), about $10-15 \%$ of patients develop new-onset $A F^{11-16}$, a phenomenon that seems to be dependent on the involvement of atrial coronary branches 16-20. As an experimental correlate, the short- and long-term effects of the complete occlusion of an atrial artery on AF were investigated in-vivo ${ }^{21,22}$ and ex-vivo ${ }^{23,}{ }^{24}$. Several mechanisms, e.g. shortening of the action potential, slowing of conduction velocity and changes in calcium handling, were identified as potential mechanistic contributors to AF.

While these studies describe the role of atrial ischemia/infarction in the development of a substrate for AF, in this thesis, we describe another possible interrelation between ischemia and AF. We propose that AF in itself can cause (supply-demand) ischemia in the atria. This form of ischemia may form an important trigger for the remodeling processes that have been described as a result of AF. There is circumstantial evidence that supply-demand ischemia does indeed occur in the atria as a consequence of AF. The expression of hypoxic and angiogenic markers (e.g. HIF $\mathrm{HIF}_{2 a}$, VEGF) was shown in a goat model of $\mathrm{AF}^{25}$ and in atrial biopsies of AF patients 26-28. Some of the changes (electrical, contractile and structural remodeling) observed during chronic AF can be viewed as adaptive processes to conserve energy and lower the atrial oxygen demand to restore the atrial supply-demand balance. One of these processes, called myocardial hibernation was first described for fibrillating atria by Ausma ${ }^{29-33}$, and is reminiscent to ventricular remodeling in response to chronic low-flow ischemia.

\section{AIM OF THIS THESIS}

How the atrial supply-demand balance is controlled and under which circumstances a mismatch will occur is still to be investigated. The general aim of this thesis is to 
characterize the different regulatory mechanism of atrial oxygen supply-demand balance and determine whether or not there is supply-demand mismatch during acute and long-term AF. Atrial blood supply can be regulated at two levels: atrial coronary resistance and atrial oxygen extraction. Both are investigated in this thesis.

A detailed literature overview and background to the studies presented in this thesis are given in CHAPTER 2. The supply-demand mismatch during AF could in itself contribute to the self-perpetuation of AF and could therefore be a useful target for AF treatment.

We aimed to visualize and describe the atrial coronary anatomy and the regional distribution of atrial myocardial blood supply (CHAPTER 3). We secondly aimed to investigate the dynamic coronary flow regulation in time using Doppler flow probes around an atrial artery in healthy animals (CHAPTER 4). Here, dynamic atrial flow regulation was investigated during changes in atrial demand, such as an increase in atrial rhythm and atrial fibrillation.

In addition to the regulation of atrial flow, atrial oxygen supply is also determined by oxygen extraction. We investigated the contribution of the flow reserve vs the extraction reserve in maintaining the atrial supply-demand balance during sinus rhythm and acute changes in atrial rhythm in healthy animals (CHAPTER 5).

Finally, we aimed to address the long-term effect of AF on supply-demand balance in a model of AF in pigs (CHAPTER 6). In this model, 5 weeks of rapid atrial pacing mimics persistent AF and allows electrical, structural and contractile remodeling to take place. These forms of atrial remodeling may influence atrial demand and supply both in a negative and positive fashion. Whether or not this will disturb or maintain the total supply-demand balance is investigated here. In addition, a first analysis of vascular remodeling (perivascular fibrosis and capillary density) related to AF, an important aspect of structural remodeling in supply-demand ischemia, is described.

The final chapter of this thesis (CHAPTER 7) summarizes our findings and discusses the possible impact of these studies for future research and potential AF therapies. 


\section{CHAPTER 1}

\section{REFERENCES}

1. Krahn AD, Manfreda J, Tate RB, Mathewson FA, Cuddy TE. The natural history of atrial fibrillation: Incidence, risk factors, and prognosis in the manitoba follow-up study. Am J Med. 1995;98:476-484

2. Feinberg WM, Blackshear JL, Laupacis A, Kronmal R, Hart RG. Prevalence, age distribution, and gender of patients with atrial fibrillation. Analysis and implications. Archives of internal medicine. 1995;155:469-473

3. Go AS, Hylek EM, Phillips KA, Chang Y, Henault LE, Selby JV, Singer DE. Prevalence of diagnosed atrial fibrillation in adults: National implications for rhythm management and stroke prevention: The anticoagulation and risk factors in atrial fibrillation (atria) study. JAMA : the journal of the American Medical Association. 2001;285:2370-2375

4. Kannel WB, Benjamin EJ. Status of the epidemiology of atrial fibrillation. The Medical clinics of North America. 2008;92:17-40, ix

5. Rich MW. Epidemiology of atrial fibrillation. Journal of interventional cardiac electrophysiology : an international journal of arrhythmias and pacing. 2009;25:3-8

6. Schmitt J, Duray G, Gersh BJ, Hohnloser SH. Atrial fibrillation in acute myocardial infarction: A systematic review of the incidence, clinical features and prognostic implications. European heart journal. 2009;30:1038-1045

7. Nucifora G, Schuijf JD, Tops LF, van Werkhoven JM, Kajander S, Jukema JW, Schreur JH, Heijenbrok MW, Trines SA, Gaemperli O, Turta O, Kaufmann PA, Knuuti J, Schalij MJ, Bax JJ. Prevalence of coronary artery disease assessed by multislice computed tomography coronary angiography in patients with paroxysmal or persistent atrial fibrillation. Circulation. Cardiovascular imaging. 2009;2:100-106

8. Lip GY, Golding DJ, Nazir M, Beevers DG, Child DL, Fletcher RI. A survey of atrial fibrillation in general practice: The west birmingham atrial fibrillation project. The British journal of general practice : the journal of the Royal College of General Practitioners. 1997;47:285-289

9. Lokshyn S, Mewis C, Kuhlkamp V. Atrial fibrillation in coronary artery disease. International journal of cardiology. 2000;72:133-136

10. Cameron A, Schwartz MJ, Kronmal RA, Kosinski AS. Prevalence and significance of atrial fibrillation in coronary artery disease (cass registry). The American journal of cardiology. 1988;61:714717

11. Goldberg RJ, Seeley D, Becker RC, Brady P, Chen ZY, Osganian V, Gore JM, Alpert JS, Dalen JE. Impact of atrial fibrillation on the in-hospital and long-term survival of patients with acute myocardial infarction: A community-wide perspective. American heart journal. 1990;119:996-1001

12. Lehto M, Snapinn S, Dickstein K, Swedberg K, Nieminen MS, investigators O. Prognostic risk of atrial fibrillation in acute myocardial infarction complicated by left ventricular dysfunction: The optimaal experience. European heart journal. 2005;26:350-356 


\section{General introduction}

13. Madias JE, Patel DC, Singh D. Atrial fibrillation in acute myocardial infarction: A prospective study based on data from a consecutive series of patients admitted to the coronary care unit. Clinical cardiology. 1996;19:180-186

14. Berton G, Cordiano R, Cucchini F, Cavuto F, Pellegrinet M, Palatini P. Atrial fibrillation during acute myocardial infarction: Association with all-cause mortality and sudden death after 7-year of follow-up. International journal of clinical practice. 2009;63:712-721

15. Rathore SS, Berger AK, Weinfurt KP, Schulman KA, Oetgen WJ, Gersh BJ, Solomon AJ. Acute myocardial infarction complicated by atrial fibrillation in the elderly: Prevalence and outcomes. Circulation. 2000;101:969-974

16. Sakata K, Kurihara H, Iwamori K, Maki A, Yoshino H, Yanagisawa A, Ishikawa K. Clinical and prognostic significance of atrial fibrillation in acute myocardial infarction. The American journal of cardiology. 1997;80:1522-1527

17. James TN, Burch GE. The atrial coronary arteries in man. Circulation. 1958;17:90-98

18. Hod H, Lew AS, Keltai M, Cercek B, Geft IL, Shah PK, Ganz W. Early atrial fibrillation during evolving myocardial infarction: A consequence of impaired left atrial perfusion. Circulation. 1987;75:146-150

19. Kyriakidis M, Barbetseas J, Antonopoulos A, Skouros C, Tentolouris C, Toutouzas P. Early atrial arrhythmias in acute myocardial infarction. Role of the sinus node artery. Chest. 1992;101:944947

20. Alasady M, Shipp NJ, Brooks AG, Lim HS, Lau DH, Barlow D, Kuklik P, Worthley MI, Roberts-Thomson KC, Saint DA, Abhayaratna W, Sanders P. Myocardial infarction and atrial fibrillation: Importance of atrial ischemia. Circulation. Arrhythmia and electrophysiology. 2013;6:738-745

21. Yamazaki M, Avula UM, Bandaru K, Atreya A, Boppana VS, Honjo H, Kodama I, Kamiya K, Kalifa J. Acute regional left atrial ischemia causes acceleration of atrial drivers during atrial fibrillation. Heart rhythm : the official journal of the Heart Rhythm Society. 2013;10:901-909

22. Sinno H, Derakhchan K, Libersan D, Merhi Y, Leung TK, Nattel S. Atrial ischemia promotes atrial fibrillation in dogs. Circulation. 2003;107:1930-1936

23. Lin YK, Lai MS, Chen YC, Cheng CC, Huang JH, Chen SA, Chen YJ, Lin Cl. Hypoxia and reoxygenation modulate the arrhythmogenic activity of the pulmonary vein and atrium. Clinical science. 2012;122:121-132

24. Nishida K, Qi XY, Wakili R, Comtois P, Chartier D, Harada M, Iwasaki YK, Romeo P, Maguy A, Dobrev D, Michael G, Talajic M, Nattel S. Mechanisms of atrial tachyarrhythmias associated with coronary artery occlusion in a chronic canine model. Circulation. 2011;123:137-146

25. Thijssen VL, van der Velden HM, van Ankeren EP, Ausma J, Allessie MA, Borgers M, van Eys GJ, Jongsma HJ. Analysis of altered gene expression during sustained atrial fibrillation in the goat. Cardiovascular research. 2002;54:427-437

26. Gramley F, Lorenzen J, Jedamzik B, Gatter K, Koellensperger E, Munzel T, Pezzella F. Atrial fibrillation is associated with cardiac hypoxia. Cardiovasc Pathol. 2010;19:102-111

27. Xu Y, Sharma D, Du F, Liu Y. The role of toll-like receptor 2 and hypoxia-induced transcrip- 
tion factor-1alpha in the atrial structural remodeling of non-valvular atrial fibrillation. International journal of cardiology. 2013

28. Ogi H, Nakano Y, Niida S, Dote K, Hirai Y, Suenari K, Tonouchi Y, Oda N, Makita Y, Ueda S, Kajihara K, Imai K, Sueda T, Chayama K, Kihara Y. Is structural remodeling of fibrillated atria the consequence of tissue hypoxia? Circulation journal : official journal of the Japanese Circulation Society. 2010;74:1815-1821

29. Ausma J, Wijffels M, Thone F, Wouters L, Allessie M, Borgers M. Structural changes of atrial myocardium due to sustained atrial fibrillation in the goat. Circulation. 1997;96:3157-3163

30. Ausma J, Litjens N, Lenders MH, Duimel H, Mast F, Wouters L, Ramaekers F, Allessie M, Borgers $\mathrm{M}$. Time course of atrial fibrillation-induced cellular structural remodeling in atria of the goat. Journal of molecular and cellular cardiology. 2001;33:2083-2094

31. Dispersyn GD, Ausma J, Thone F, Flameng W, Vanoverschelde JL, Allessie MA, Ramaekers FC, Borgers M. Cardiomyocyte remodelling during myocardial hibernation and atrial fibrillation: Prelude to apoptosis. Cardiovascular research. 1999;43:947-957

32. Thijssen VL, Ausma J, Borgers M. Structural remodelling during chronic atrial fibrillation: Act of programmed cell survival. Cardiovascular research. 2001;52:14-24

33. Thijssen VL, Ausma J, Liu GS, Allessie MA, van Eys GJ, Borgers M. Structural changes of atrial myocardium during chronic atrial fibrillation. Cardiovasc Pathol. 2000;9:17-28 


\section{Atrial tissue perfusion and ischemia in atrial fibrillation in atrial fibrillation}

Kelly van Bragt

Hussein M. Nasrallah

Ulrich Schotten

Sander Verheule
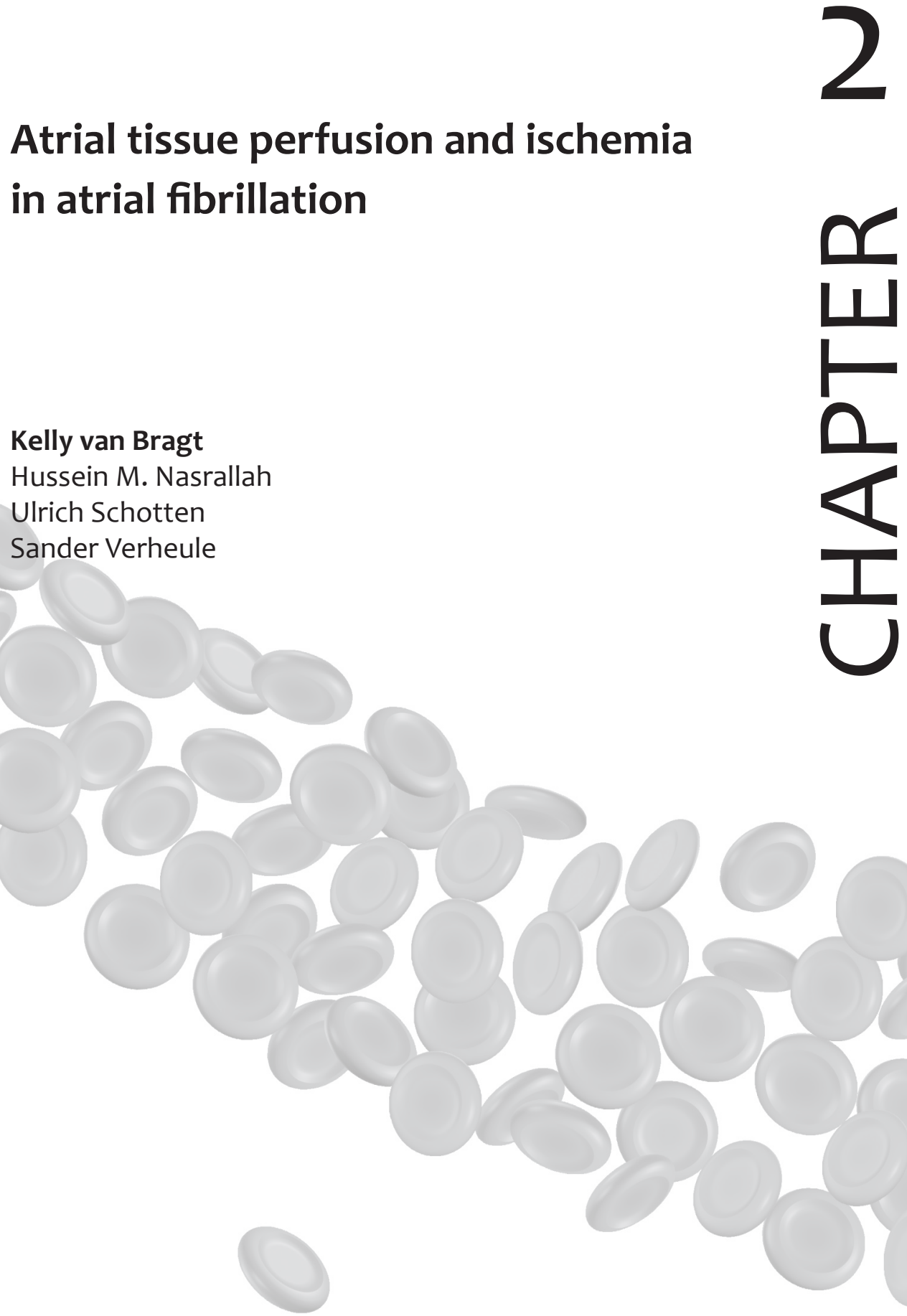

ل

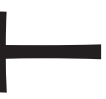

0

I

$\mathcal{U}$ 


\section{CHAPTER 2}

\section{ABSTRACT}

Atrial fibrillation (AF) is associated with atrial ischemia. The precise relationship, and specifically the causal relationship between ischemia and the remodeling, process during AF remains unclear. This review aims to gives an overview of the regulation of atrial blood supply and the effect of AF on atrial supply-demand balance. The atria are supplied by branches from the left and right coronary arteries, forming a very extensive capillary network. In order to maintain supply-demand balance, blood flow and oxygen extraction are regulated to match atrial oxygen demand. A reduction in atrial blood supply (e.g. myocardial infarction, coronary artery disease, vascular remodeling) or an increases in atrial demand (e.g. increased cardiac rhythm, increased blood pressure) can cause a disturbance in the balance, resulting in atrial ischemia. Many of these aspects have been under investigation, often with severe ischemia being the cause of atrial fibrillation. We propose a subtler role of supply-demand ischemia caused by AF. This supply-demand ischemia induces electrical, structural, vascular and metabolic remodeling, which might contribute to the perpetuation of AF. Further research is warranted to identify possible treatment options. 
1. INTRODUCTION

Atrial fibrillation (AF) is the most common sustained arrhythmia in clinical practice. Both in animal models and in many AF patients, the duration of AF episodes gradually increases with time. Over the past decades, it has become clear that AF itself causes electrical and structural changes in the atrial myocardium that result in stabilization of AF. Electrical remodeling consists of a decrease in action potential duration $(A P D), A F$ cycle length ( $A F C L)$, effective refractory period (ERP) and a reversal in the rate-dependence of the ERP. Electrical remodeling is a fast process. It takes place in the first few days of AF and a new steady state is reached after 3-5 days ${ }^{1}$ and is on itself is not sufficient for AF to become persistent. Structural remodeling takes weeks to months to develop and AF becomes more stable during this time. It comprises a variety of changes in cellular ultrastucture (e.g. mitochondrial swelling, glycogen accumulation, myolysis $)^{2,3}$, connexin distribution ${ }^{4}$ and increased extracellular matrix volume ${ }^{2}$. Overall, atrial myocytes dedifferentiate to a more neonatal phenotype ${ }^{5,6}$. These changes, also referred to as 'hibernation' are reminiscent of changes in ventricular myocytes during chronic low-flow ischemia. Indeed, many aspects of atrial remodeling can be interpreted as adaptations to energy shortage ${ }^{7}$. This is also compatible with observations in AF models in goats and in AF patients, where markers of hypoxia $\left(\mathrm{HIF}_{1 a}\right)$ and angiogenesis (VEGF) were detected ${ }^{8-12}$. We propose that supply-demand ischemia is a possible stimulus for atrial remodeling during AF. It will act on the atrial cardiomyocytes until a new steady-state supply-demand balance is created. Some factors of atrial supply-demand balance, e.g. atrial myocardial blood supply, have been under investigation since the early 1900's. This review aims to give a literature overview of the atrial coronary arteries and regulation of myocardial blood flow and describe the relationship between atrial fibrillation and atrial ischemia.

\section{ATRIAL CORONARY ANATOMY}

The atrium, like the ventricle, is supplied by branches from the left and right coronary arteries ${ }^{13-19}$ and has a very extensive capillary network (CHAPTER 3). The human atrial coronary anatomy was first described in the early 1900's by Keith and Flack, Gross, Crainicianu and Spalteholz 13, 14, 20, 21 . Several techniques, including the intracoronary injection of radiopaque substances or plastics, were used to visualize the 


\section{CHAPTER 2}

atrial anatomy post-mortem 14, 22 15, 23-27. In the early studies, nomenclature was not conclusive. Spalteholz referred to the atrial coronary arteries as rami (ramus is Latin for "branch") atrialis ${ }^{13}$. They were specified as dexter or sinister, depending on the origin from the left circumflex ( $L C x)$ or the right coronary artery (RCA) respectively, followed by anterior, intermediate or posterior depending on their origin from the LCx or RCA. However, not all hearts show well developed anterior, intermediate and posterior arteries. Therefore, many others chose for specific names for the most commonly observed atrial coronary arteries. For example, Gross used names that referred to the area an artery is supplying ${ }^{14}$.

\subsection{Number and size of the atrial coronary arteries in humans}

The RA is mainly supplied by the RCA, while the LA is mainly supplied by the left coronary artery ${ }^{19,28,29}$. The number and size of the atrial arteries, their branching points and the area they supply show considerable inter-individual variation ${ }^{17}$. Hromada et al reported 5 to 8 branches from both the left and right coronary artery supplying left and right atrium ${ }^{17}$. Busquet counted only major branches and found 2 to 6 on the right side ${ }^{18}$. Atrial branches are mostly $0.5-1 \mathrm{~mm}$ in diameter and their points of origin are found along the whole length of the coronary arteries ${ }^{19}{ }^{30}$. Atrial branches are often classified according to their regional origin as anterior, intermediate and posterior atrial branches ${ }^{15,16,29}$. However, not in all cases, branches will originate in all three regions of the coronary arteries ${ }^{15}$. Larger atrial arteries (diameter $>1 \mathrm{~mm}$ ) will originate mostly in the anterior portion of the coronary arteries and less in the intermediate and posterior parts ${ }^{30}$.

\subsection{Most commonly encountered atrial coronary arteries}

\subsubsection{The sinus node artery}

Because of the large variability in atrial branches, most authors choose to describe the course of the largest and most consistently found arteries. The artery supplying the sinoatrial node (SAN) area is one of the largest and most consistently found atrial arteries in man ${ }^{15}$. Since its first description, it has received many different names, for instance ramus ostii cavae superioris ${ }^{14}$, Keith-Flack artery ${ }^{21}$, the main atrial branch ${ }^{30}$ 
or most commonly the sinus node/ sinoatrial node artery ${ }^{18,31-33}$. The origin of the SAN artery is a branch of the RCA in approximately $60 \%$ of all cases. In $35 \%$ of the cases, the origin is exclusively from the left coronary artery (LCA) and in a small percentage (5\%), both the right and left coronary artery supply a branch to the SAN area. The SAN artery branched off in the proximal part (first $3 \mathrm{~cm}$ ) of the RCA or LCA in 90\% of the cases $15,18,25,31,34,35$. In cases where the SAN artery originates from the left, its origin was almost always from the LCX and in rare cases from the left main stem ${ }^{36,37}$. In addition to the branches from the right or left coronary artery, also branches from the rami bronchiales (arteries that supply the bronchi) have also been reported to supply the SAN ${ }^{17,29,38,39}$.

\subsubsection{Intermediate right atrial artery}

Usually there is at least one large artery originating from the area of the acute margin of the right ventricle ${ }^{15,18,40}$. The artery runs over the epicardium, and then divides into 2-3 smaller branches that continue intramurally through the atrial wall ${ }^{18}$. It may form anastomoses with branches from the sinus node artery in the area of the superior vena cava ${ }^{15}, 40$.

\subsubsection{Left atrial circumflex}

The left atrial circumflex artery ( $L A C x)$ is an artery that branches off from the proximal $L C x{ }^{15}, 37,40$. In a rare case, the $L A C x$ originates from the left main stem or the proximal left descending artery $(L A D){ }^{37}$. The $L A C x$ runs superior and parallel to the $L C X$, along the margin of the atrial free wall and terminates in the posterior LA (Figure 1) ${ }^{15}, 4^{0}$. Occasionally, it is nearly the size of the LCX itself ${ }^{40}$. The LACx gives off numerous branches to the LA, thereby supplying most of the LA wall 15, 37, 40. In 5-10\% of the cases, it also supplies the sinus node ${ }^{15}$. The LACX was found in $83 \%$ of the human hearts investigated by Tjandrawidjaja et al ${ }^{37}$. According to Gensini, on the other hand, most often the atrial branches originate directly from the LCx itself, not from a $\operatorname{LACx}{ }^{40}$. An explanation for this discrepancy might be the definition of the LACx. For example, when the branch runs parallel to the LCx, but the diameter of the potential LACX is rather small and an additional branch is found from the $L C x$, it might be discarded as LACX. 


\section{CHAPTER 2}

\subsection{Anastomoses}

An anastomosis is a connection between two vessels that does not contain capillaries. They can connect arteries with other arteries, veins with veins or even arteries with veins. Coronary anastomoses can occur within the myocardial wall (intramural anastomoses). Atrial arteries or veins that connect directly to the cardiac chambers, bypassing the capillary bed, are called cardiac luminal anastomoses. They are sometimes classified as a separate group, while other authors classify them as intramural anastomoses ${ }^{16,30}$. In addition, there are anastomoses that can connect coronary arteries to the extracardiac circulation (extracardiac anastomoses). Bronchial arteries and internal thoracic arteries supply the posterior pericardium or enter the pericardium as vasa vasorum of aorta, vena cava and pulmonary veins to form anastomoses with coronary arteries ${ }^{16,17,19,29,39,41}$. As mentioned above, arteries from the bronchial circulation are, for example, reported to supply the SAN ${ }^{29,39}$. Coronary anastomoses are formed during fetal development and persist under normal, non-pathological condition. However, these preexisting coronary anastomoses will develop into larger arteries under hypoxic stimulation, for example during coronary artery disease (CAD)

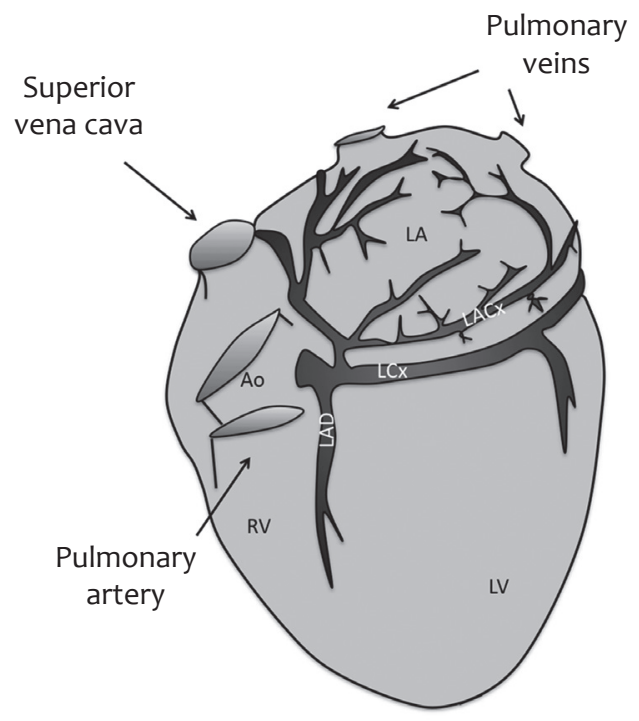

Figure 1: Representation of a left atrial circumflex artery modified from James and Burch, circulation, $1958^{15}$ 
or after a myocardial infarction (MI) through a process called arteriogenesis and thus contribute to the collateral circulation ${ }^{16,42-44}$.

\subsection{Atrial coronary anatomy in animals}

Descriptions of the atrial coronary anatomy can be found for many animal species such as Angora rabbits ${ }^{45}$, sheep ${ }^{46}$, North American beaver ${ }^{47}$, ostrich ${ }^{48}$, bonnet monkey ${ }^{49}$ or yak ${ }^{50}$. Of special interest are the animal species that are frequently used as models for cardiovascular disease, such as pig, dog and sheep. Often, only a very general description is given for the atrial coronary anatomy. Major anterior, intermediate and posterior branches were described, branching off from the RCA and LCX ${ }^{51-}$ 54 . The right and left coronary arteries give off branches that supply the right and left atrium, respectively $47,53,54$. The size of the atrial arteries is reported to be somewhat smaller in pigs than in dogs 53 . In addition, dogs have an extensive collateral network $55-57$. The number of collaterals found in swine hearts is more comparable to humans $51,52,55,56$. For this reason, pigs are often used as a model for chronic ischemia ${ }^{55}$. As in humans, the SAN in pigs, dogs and sheep is supplied by a branch from the RCA in the majority of cases ${ }^{46,51,52,54}$ and usually originates at the anterior portion of the RCA ${ }^{15}$, $18,25,31,34,35,46,51$. In the atria of sheep ${ }^{58}$ and pigs (CHAPTER 3 ) vessels do not seem to have overlap in perfusion area, indicating a high sensitivity for tissue damage during partial or complete blockade of an atrial vessel. In the dog it was shown, like in humans, that the area of the sinoatrial node can be supplied by more than one artery ${ }^{59}$.

\subsection{Role of atrial coronary arteries in AF treatment}

One of the strategies to treat $\mathrm{AF}$ is radiofrequency catheter ablation, creating transmural atrial lesions to prevent conduction of ectopic activity and to interrupt reentry pathways. At least two studies have shown that major atrial coronary arteries run through radiofrequency ablation lines in the pulmonary vein area, the LA roof, the LA anterior wall and the mitral isthmus of all patients investigated ${ }^{25,60}$. Damaging these atrial arteries could produce atrial infarctions and possibly result in an arrhythmogenic substrate. Some new ablation strategies take into consideration the course of mayor arteries in the atrial wall to prevent damage to atrial coronary arteries 25 , 61, 62. In addition to atrial infarction, radiofrequency ablation can cause endothelial 
dysfunction in atrial coronary arteries in the vicinity of the radiofrequency ablation line in pigs ${ }^{63}$. Also in patients, microvascular dysfunction and a proinflamatory reaction were observed after radiofrequency catheter ablation and this mechanism was linked to early recurrence of $\mathrm{AF}^{64,65}$.

\section{ATRIAL BLOOD FLOW MEASURING TECHNIQUES}

Several techniques are available to measure atrial blood flow. These techniques give information of either spatial aspect or time aspects of atrial coronary flow, but not both. Microsphere analysis gives information about the myocardial distribution of blood flow. The measurement is an average over the time of the microsphere injection. Techniques like electromagnetic flow probes ${ }^{66}$, Doppler flow probes ${ }^{67,68}$ and Doppler guide wires ${ }^{69}$ have made it possible to image real time blood flow through a vessel. This allowed researchers to see variations in blood flow pattern within one heartbeat to obtain insights into the mechanical forces acting on the atrial myocardial bed. Using a guide wire for flow measurements is a minimally invasive technique that can be used in patients. To measure blood flow, the vessel should be entered. Doppler and electromagnetic flow probes allow blood velocity measurement from the outside of a vessel. These flow probes can be used acutely after preparation of a vessel, or chronically implanted to measure blood flow in awake and standing or exercising animals ${ }^{67}$.

\section{PHASIC ATRIAL FLOW PATTERNS}

Coronary blood flow has a phasic pattern. This pattern is well studied in the ventricle. The atrial blood flow pattern, however, has hardly been investigated. Some atrial recordings were made in patients ${ }^{69,70}$, pigs ${ }^{71}$ and dogs ${ }^{68}$. During the atrial systole, a sharp decrease in atrial flow velocity has been observed. Atrial contraction, rather than the increase in atrial pressure, is responsible for this phasic decrease in the atrial flow ${ }^{68,72}$ (CHAPTER 4). The phasic nature of the LA arterial blood flow resembles the aortic pressure pattern. The atrial flow signal starts to increase after the atrial contraction and just before the start of ventricular contraction. A small decrease was seen at the moment of aortic valve opening and closure. LA flow patterns are highly similar in shape between humans, dogs and pigs (Figure 2A, B and C). To our know- 


\section{Atrial tissue perfusion and ischemia in atrial fibrillation}

A

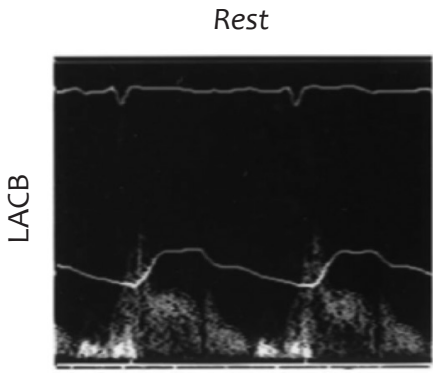

$100 \mathrm{bpm}$

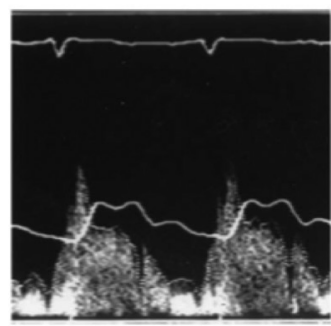

$120 \mathrm{bpm}$

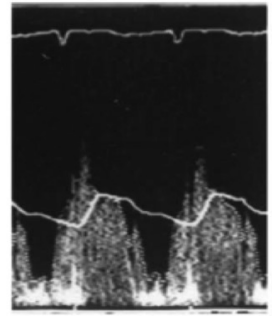

B

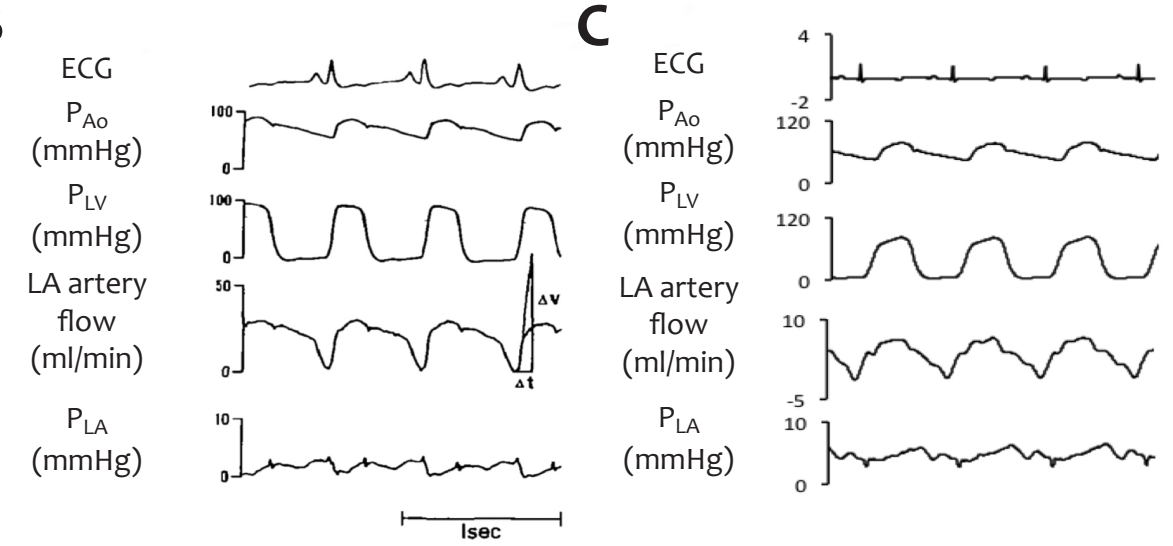

D

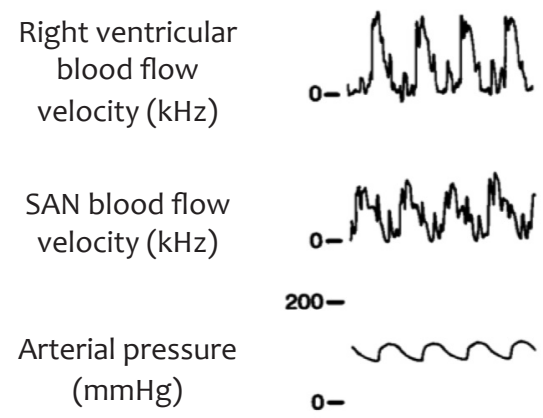

Figure 2: Representative example of the flow pattern in a left atrial branch of the circumflex artery (A) during sinus rhythm and pacing in patients under anaesthesia using a 15- $\mathrm{MHz}$ Doppler guide wire (From Skalidis et al, $2003^{69}$ ), (B) during sinus rhythm in the dog heart using a laser Doppler flow probe with an optical fiber during an open chest experiment (From Kajiya et al, $1989{ }^{68}$ ) and (C) during sinus rhythm in the pig using a Doppler flow probe during an open chest experiment (From van Bragt et al,CVR ${ }^{71}$ ). Example of blood flow measurements in a right ventricular branch and right atrial branch (Sinoatrial node of SAN artery) in an anesthetized dog (D) (From White et al, 1986 73 ). 


\section{CHAPTER 2}

ledge, data on the right atrial phasic flow pattern is limited. White et al described the flow patterns of sinus node artery, branching off from the RCA ${ }^{73}$. Also in the RA, atrial flow is out of phase with right ventricular flow and increases after atrial contraction (Figure 2D).

\section{REGIONAL DISTRIBUTION AND REGULATION OF ATRIAL MYOCARDIAL FLOW}

Most knowledge of atrial coronary flow distribution and regulation has been obtained in dogs. There is also some data available from miniature pigs ${ }^{74}$, horses 75 and baboons ${ }^{76}$. In the dog, the weight per atrium is about $10 \mathrm{~g}$ and together they constitute about $10 \%$ of the total heart weight $77-80$. During sinus rhythm, the atria receive about $5 \%$ of total coronary blood flow $77,81,82$. Thus, the atria receive less flow than the ventricles per gram of tissue. Myocardial blood flow is higher in the LA than in the RA and in the LV than in the RV 59,73,75, 81-84. Table 1 shows myocardial blood flow distributions in different studies during normal sinus rhythm in animals under anesthesia or in awake animals at rest. A large variation in baseline values can be observed. Possible explanations for these variations are baseline differences in heart rate and mean aortic pressure, differences in experimental procedure (awake vs anesthetized) and species differences. The influence of heart rate and mean aortic pressure on myocardial blood flow distribution is explained in the following section.

\subsection{Flow distribution to the different chambers of the heart}

Blood flow through a vessel is dependent on the pressure difference between the two ends of a vessel and on the vascular resistance. Like ventricular coronary arteries, the atrial myocardium is supplied by arteries that branch off from the aorta and the venous blood drains in the coronary sinus that drains into the RA lumen. Some of the atrial veins also drain directly into the LA and RA lumen as thebesian veins (CHAPTER 6). Therefore, aortic pressure and atrial pressure directly influence atrial myocardial perfusion. Atrial coronary artery resistance is regulated by atrial demand. The next section deals with the effect of changes in pressure and in atrial workload (atrial pacing, atrial fibrillation and exercise) on regional atrial myocardial perfusion. 


\section{Atrial tissue perfusion and ischemia in atrial fibrillation}

\begin{tabular}{|c|c|c|c|c|c|c|c|c|}
\hline & \multirow[t]{2}{*}{ Species } & \multirow{2}{*}{$\begin{array}{l}\text { Anesthetized } \\
\text { / Awake }\end{array}$} & \multirow{2}{*}{$\begin{array}{c}\text { HR } \\
\text { (bpm) }\end{array}$} & \multirow{2}{*}{$\begin{array}{c}\text { Mean } \\
\mathrm{P}_{\text {Ao }} \\
(\mathrm{mmHg})\end{array}$} & \multicolumn{4}{|c|}{$\begin{array}{l}\text { Myocardial blood flow } \\
(\mathrm{ml} /(\min * 100 \mathrm{~g}))\end{array}$} \\
\hline & & & & & RA & LA & RV & LV \\
\hline Neill et al, $1973^{81}$ & Dog & Anesthetized & $71 \pm 5$ & $95 \pm 7$ & $18 \pm 3$ & $30 \pm 4$ & $59 \pm 8$ & $72 \pm 4$ \\
\hline White et al, $1977^{60}$ & Dog & Anesthetized & $175 \pm 6$ & - & $83 \pm 7$ & - & $116 \pm 12$ & $150 \pm 10$ \\
\hline Neill et al. $1983^{82}$ & Dog & Anesthetized & $103 \pm 20$ & $91 \pm 9$ & $27 \pm 13$ & $47 \pm 24$ & $46 \pm 14$ & $67 \pm 17$ \\
\hline Smiseth et al, $1986^{83}$ & Dog & Anesthetized & $162 \pm 10$ & $157 \pm 11$ & - & $77 \pm 1$ & - & $148 \pm 10$ \\
\hline White et al, $1986^{84}$ & Dog & Anesthetized & $154 \pm 3$ & $104 \pm 5$ & $45 \pm 4$ & $75 \pm 11$ & $46 \pm 4$ & $84 \pm 7$ \\
\hline $\begin{array}{l}\text { Laughlin et al, } 1988 \\
74\end{array}$ & Minipig & Awake & $120 \pm 16$ & $136 \pm 4$ & $82 \pm 20$ & $89 \pm 26$ & - & - \\
\hline Bauman et al, $1993^{85}$ & Dog & Awake & $78 \pm 7$ & $110 \pm 5$ & $27 \pm 4$ & $35 \pm 4$ & $47 \pm 5$ & $90 \pm 9$ \\
\hline $\begin{array}{l}\text { Monohar et al, } \\
1994^{75}\end{array}$ & Horse & Awake & $42 \pm 1$ & $118 \pm 4$ & $19 \pm 4$ & $26 \pm 3$ & $44 \pm 6$ & $74 \pm 10$ \\
\hline
\end{tabular}

Table 1: Myocardial blood flow (ml/(min*100g)) in the right (RA) and left (LA) atrium and right (RV) and left (LV) ventricle. $\mathrm{HR}=$ heart rate (sinus rhythm) in beats per minute, Mean $\mathrm{P}_{\mathrm{Ao}}=$ mean aortic pressure in $\mathrm{mmHg}$.

\begin{tabular}{|c|c|c|c|c|c|c|c|}
\hline & \multirow[t]{2}{*}{ Species } & \multirow{2}{*}{$\begin{array}{c}\text { HR } \\
\text { (bpm) }\end{array}$} & \multirow{2}{*}{$\begin{array}{c}\text { Mean PAo } \\
(\mathrm{mmHg})\end{array}$} & \multicolumn{4}{|c|}{$\begin{array}{l}\text { Myocardial blood flow } \\
\qquad(\mathrm{ml} /(\min * 100 \mathrm{~g}))\end{array}$} \\
\hline & & & & RA app & RA body & LA app & LA body \\
\hline Bauman et al, $1989^{78}$ & Dog & pacing 120 & - & $20 \pm 3$ & $39 \pm 5$ & $38 \pm 7$ & $57 \pm 7$ \\
\hline Bauman et al, $1993^{85}$ & Dog & $78 \pm 7$ & $110 \pm 5$ & $15 \pm 3$ & $33 \pm 4$ & $30 \pm 5$ & $37 \pm 4$ \\
\hline Hoit et al, $1993^{87}$ & Dog & $88 \pm 20$ & $104 \pm 5$ & - & - & $148 \pm 48$ & $81 \pm 67$ \\
\hline
\end{tabular}

Table 2: Myocardial blood flow distribution in the right (RA) and left (LA) atrial appendage (app) and non-appendage (body) region. $\mathrm{HR}=$ heart rate (sinus rhythm) in beats per minute, Mean $\mathrm{P}_{\mathrm{AO}}=$ mean aortic pressure in $\mathrm{mmHg}$. 
5.1.1. Effect of changes in atrial and aortic pressure on atrial myocardial blood flow

Neill et al have described the effect of pressure manipulations on atrial flow in an open chest experiment in dogs ${ }^{82}$. They reported an increase in myocardial blood flow to all chambers when LA pressure increased from 8 to 12 or $20 \mathrm{mmHg}$ during mild and moderate mitral regurgitation. Most importantly, there was a redistribution of flow and the atria received a larger percentage of flow when LA pressure increased. Hypotension, established by controlled bleeding, resulted in a decrease in flow in all chambers. The relative distribution of total flow to the separate chambers was the same as during baseline. During atrial fibrillation, LA pressure increases $73,85,86$. Even when LA pressures were increased by volume loading to levels comparable to AF, LA myocardial blood flow was still higher during AF than during volume expansion ${ }^{85}$. This indicates that in addition to the effect of increased atrial pressure, other factors, such as the increase in atrial energy expenditure, contributes to a higher atrial myocardial blood flow.

5.1.2. Effect of changes in atrial workload on atrial myocardial blood flow

Atrial pacing increases atrial workload (CHAPTER 4). Creating AV block allows investigation of atrial flow during atrial pacing with controlled and low ventricular rate and visa versa. Atria pacing at rates above $200 \mathrm{bpm}$ resulted in an increase in atrial flow with no change in ventricular flow. As expected, ventricular pacing resulted in increased ventricular blood flow with no changes in atrial flow ${ }^{77,87}$. Atrial blood flow was also measured in conscious horses and dogs during rest and exercise. During exercise, the heart rate increases, with an increase in both atrial and ventricular workload. Exercise resulted in an increase of total myocardial blood flow depending on exercise intensity, as expected ${ }^{75,84}$. Interestingly, the increase in RA myocardial blood flow was much larger than in the other heart chamber. With this redistribution of total coronary flow, the differences in myocardial perfusion between LA and RA seen at rest disappear during exercise ${ }^{79,84}$.

During AF, the overall contractility is diminished, but locally very rapid electrical and mechanical activation rates increase the energy demand within the atrial myocyte. AF increases atrial blood flow even further than atrial pacing, with no (or only a mo- 
dest) effect on ventricular flow $73,85,87$. When a decrease in mean aortic pressure was observed during $\mathrm{AF}$, the increase in atrial flow was more modest and $\mathrm{AF}$ was not more potent than atrial pacing in increasing atrial blood flow ${ }^{86}$.

Results mentioned above show that atrial vascular resistance is regulated separately from ventricular coronary resistance to match local myocardial blood supply to myocardial demand under different conditions.

\subsection{Flow distribution within the atria}

Since myocardial workload is an important factor in blood flow supply, regional difference in flow distribution within the atrium were investigated in a small amount of studies (Table 2). Bauman showed that myocardial blood flow in the atrial appendage was lower than in the non-appendage region ${ }^{59,84}$. In a supine and standing position, both RA and LA appendage flow was lower than in the respective atrial body. During mild (heart rate $173 \pm 10$ ) and moderate exercise (heart rate 209 \pm 8 ), appendage flow exceeded myocardial flow in the non-appendage regions in both LA and RA ${ }^{84}$. As Bauman suggested, the appendage regions might be involved to a greater degree in atrial pump function and therefore acquiring more coronary blood flow than non-appendage regions during exercise ${ }^{79,88}$. In contradiction with the other results, Hoit et al found that LA appendage flow was higher, instead of lower, than in the LA body in sinus rhythm ${ }^{86}$. In addition, values for LA appendage flow were higher compared to other studies with a similar heartbeat. The contradictory findings may be explained by differences in experimental set up that have caused the appendage to call on its vasodilator response in the dogs examined by Hoit. During AF, a difference between right and left atrium was noticed. The different regions of the LA responded to AF as was seen during exercise. For the RA, total myocardial blood flow increased during $A F$, but appendage flow never exceeded flow in the non-appendage regions ${ }^{78}$.

\section{ATRIAL ISCHEMIA AND AF}

Ischemia occurs when oxygen supply is not sufficient to match oxygen demand. This may be due to a reduction in oxygen supply or an increase in demand. Atrial blood supply is dependent on atrial coronary arteries as described above. Involvement of atrial coronary arteries in chronic coronary artery disease or acute myocardial 


\section{CHAPTER 2}

infarction will cause atrial blood supply to decrease, resulting in a supply-demand mismatch. The complex interaction between AF and ischemia has been investigated experimentally and several mechanisms for the role of ischemia in AF and visa versa have been identified.

6.1. Acute severe atrial ischemia is a risk factor for AF

\subsubsection{Acute myocardial infarction}

Acute myocardial infarction (MI) is an important risk factor for atrial fibrillation ${ }^{89-92}$. $\mathrm{AF}$ is present in $10-20 \%$ of patients that are hospitalized with acute $\mathrm{MI}$ of which 7.2 $11.3 \%$ is new onset $A F{ }^{93-98}$. In addition to $A F$, also atrial flutter and sinus arrhythmias were observed after MI ${ }^{96,99-101}$. Most cases of new onset AF occur within the first few days after acute $\mathrm{MI}$ and the episodes are often transient $95,98,102$. However, $10 \%$ of the patients that develop new-onset AF post-MI do not convert to sinus rhythm spontaneously and they leave the hospital in AF ${ }^{95}$. Proposed mechanism by which acute $\mathrm{MI}$ causes AF are atrial ischemia and atrial MI, or right atrial overload due to right ventricular acute $\mathrm{MI}^{98}$. The number of occluded coronary arteries involved is significantly higher in the patients that do develop AF compared to non-AF patients after MI ${ }^{95}$, 98,103 . There are even a few case reports that describe an immediate cardioversion of AF to sinus rhythm after restoration of blood flow through angioplasty ${ }^{104,105}$. A study by Hod et al included 214 patients of which 7 (3\%) developed AF after MI. Their data indicated that all AF patients had a coexisting occlusion of 2 atrial arteries (AV node artery and proximal left circumflex artery), suggesting that acute left atrial ischemia could be the pathophysiologic mechanism of new onset AF after $\mathrm{MI}^{106}$. In addition, atrial infarctions are regularly observed in post mortem studies after $\mathrm{MI}(17-42 \%)^{107-}$ ${ }^{110}$. Most atrial infarctions are seen in the right atrium (RA), especially the right atrial appendage, but also the left atrium (LA) or both atria can be affected ${ }^{108,111,112}$. Since the atria are very thin, atrial infarctions are usually transmural. A study by Cushing et al showed that $43 \%$ (10 out of 23 ) of patients with proven atrial infarctions were in AF.

\subsubsection{Identifying mechanisms of ischemia-AF interaction}

To investigate the mechanism by which atrial ischemia is linked to AF, acute ischemia 
was experimentally induced in various animal models. Atrial ischemia resulted in an IK $\mathrm{K}_{\text {ATP }}$-dependent shortening of the action potential duration (APD) in isolated rabbit myocardial tissue strips ${ }^{113}$ and in both the ischemic and non-ischemic zone of isolated sheep hearts ${ }^{114}$. In addition, slowing of conduction velocity in the ischemic zone ${ }^{114-117}$ and an increase in dominant frequency ${ }^{114}$, conduction heterogeneity index ${ }^{115}, 117$ and AF duration ${ }^{115,116,118}$ were seen both in isolated hearts and whole animal experiments. Some studies show a slight increase in ERP at $3 \mathrm{~h}^{115}$ and $5 \mathrm{~h}$ of atrial ischemia ${ }^{115,}{ }^{116}$, but other studies report no change in ERP ${ }^{118}$. Also, an increase in ectopic activity was seen after occlusion of a LA branch in isolated sheep hearts ${ }^{114}$, but this was not confirmed during acute RA branch occlusion in anaesthetized dogs ${ }^{116}$.

The chronic effects of coronary artery occlusion and myocardial infarction were investigated. Cushing et al reported atrial extrasystole in addition to wandering pacemaker, atrial tachycardia and flutter after atrial infarction in dogs ${ }^{108}$. RA artery occlusion (atrial infarction, 1week) in dogs resulted in spontaneous atrial ectopic activity ${ }^{119}$. Underlying disturbances in calcium $\left(\mathrm{Ca}^{2+}\right)$ handling were recorded in isolated atrial myocytes, such as an increase in spontaneous $\mathrm{Ca}^{2+}$ sparks (confocal microscopy) during $\beta$-adrenergic stimulation, faster decay of caffeine-evoked $\mathrm{Ca}^{2+}$ transients and enhanced (by $\sim 73 \%) \mathrm{Na}^{2+}$ - $\mathrm{Ca}^{2+}$ exchange (NCX) current were found in dog with an atrial infarction compared to control animals. In addition to abnormal $\mathrm{Ca}^{2+}$ handling, also fibrosis was seen at the border zone of the infarcted area, resulting in conduction disturbances and reentry.

\subsection{Chronic low-flow ischemia is a risk factor for AF}

AF and coronary artery disease (CAD) often coexist. In fact, AF patients are more likely to have underlying chronic coronary artery disease than their aged-matched controls in sinus rhythm ${ }^{90,120}$. The prevalence of coronary artery disease in AF patients is $6.4-19.2 \%{ }^{22,121,122}$, and even higher (50\%) in patients who were originally diagnosed with "lone" $A F{ }^{120}$. Coronary artery disease, but also myocardial infarction and angina resulting from $C A D$, are identified as an important risk factor for $A F^{89,123}$. In addition, the presence of $A F$ in patients with $C A D$ is associated with a worse cardiovascular outcome ${ }^{37,124}$. 


\section{CHAPTER 2}

6.3. Subtle supply-demand ischemia caused by AF

6.3.1. Evidence for supply-demand mismatch in AF

During $A F$, the atrial oxygen demand is increased due to local rapid electrical and mechanical activation ${ }^{85}$. A decrease in cellular phosphocreatin (PCr) levels is a telltale sign of supply-demand ischemia ${ }^{125}{ }^{126}$. Indeed, in AF maintained by burst pacing in goats leads to a marked decrease $(60 \%)$ in $\mathrm{PCr}$. This decrease was already seen at one week of AF, and persisted during the ensuing months. However, after 4 months, $\mathrm{PCr}$ had returned to baseline levels. Throughout this entire time course, ATP levels remained similar to the baseline value, indicating that no severe ischemia occurred 127. In the same animal model, Thijssen et al confirmed a role for early ischemic stress in $\mathrm{AF}$, showing an increase in gene expression of hypoxia inducible factor $1 \alpha\left(\mathrm{HIF}_{1 \alpha}\right)$ only in the first week of atrial tachypacing -induced $\mathrm{AF}^{8}$. High levels of LA Vascular Endothelial Growth Factor (VEGF) were observed in patients with paroxysmal AF, but not in persistent AF patients. This supports a transient supply-demand mismatch during the stabilization of $A F^{11}$. Other patient studies indicate a more chronic supply-demand mismatch in AF. Analysis of right atrial appendage biopsies of persistent AF patients revealed an increase in hypoxic and angiogenic markers compared to sinus rhythm controls ${ }^{9}$. An increase in right atrial appendage $\mathrm{HIF}_{1 \alpha}$ was also observed with an increasing stabilization of AF from paroxysmal to persistent ${ }^{12}$. Protein levels of cytoplasmic $\mathrm{HIF}_{1 a}$, $\mathrm{HIF}_{2 a}$, vascular endothelial growth factor (VEGF), VEGF receptors (e.g. KDR) and phosphorylated KDR (pKDR) proteins were increased ${ }^{9}$. Ogi et al pooled data of paroxysmal and persistent AF patients and observed that $\mathrm{HIF}_{1 a}$ and VEGF were predominantly produced and co-localized in the endothelium of atrial arteries in the AF group ${ }^{10}$.

\subsubsection{Identifying mechanisms of ischemia- AF interaction}

Several ion-channels were investigated to determine the interaction between AF and supply-demand ischemia. A first candidate is the ATP-regulated potassium channels $\left(\mathrm{K}_{\mathrm{ATP}}\right)$, involved in atrial action potential duration and the effective refractory period.

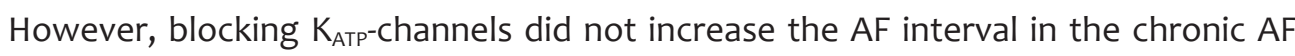
goat-model ${ }^{128}$. This can be explained by the fact that ATP levels remained completely 
normal during $\mathrm{AF}$ in the chronic $\mathrm{AF}$ goat model, while phosphocreatine was reduced in the first week of $\mathrm{AF}^{127}$. Another candidate ion-channel involved in atrial ischemia and $\mathrm{AF}$ is the sodium/proton exchanger (NHX). During a supply-demand mismatch, protons accumulate, which is known to activate the NHX ${ }^{129}$. Extrusion of protons from the cell leads an inward current of sodium $\left(\mathrm{Na}^{2+}\right)$, triggering on its turn the opposing $\mathrm{NCX}$ that will increase intracellular $\mathrm{Ca}^{2+}{ }^{130}$. Intracellular calcium overload is thought to be the cause of the downregulation of the L-type calcium current (ICa $\mathrm{L}_{\mathrm{L}}$. NHX blockade prevented AF-induced shortening of the ERP ${ }^{131}$ and AF-induced contractile dysfunction after $5 \mathrm{~h}$ of $\mathrm{AF}$ in the dog ${ }^{132}$. In a study in goats, however, AF-induced shortening of the ERP could not be prevented by NHX blockade ${ }^{133}$. In addition, different mechanisms seem to be involved in short-term vs. long-term atrial remodeling. In chronic AF models, NHX blockade could not prevent AF-induced ERP shortening in dogs after 7 days of $A F^{134}$ or reverse electrical remodeling in paroxysmal $A F$ (no effect on AF duration) or persistent AF (no effect on AF cycle length) in goats ${ }^{133}$. It can be concluded that the mechanisms involved in acute, severe ischemia are different from the chronic, subtle supply-demand ischemia induced by AF and blocking NHX or KATP-channels is not effective.

\subsubsection{Atrial remodeling as a consequence of supply-demand ischemia}

\subsubsection{Myocardial stunning}

One of the first signs during acute ventricular ischemia is 'stunning', this is the fast decline of ventricular contractility ${ }^{125}$. Similar findings are reported in the atria after an AF episode. A rapid decline in atrial contractility was seen already after 5 min of AF in goats ${ }^{135}$ and after $1 \mathrm{~h}$ in the atria of pigs ${ }^{136}$. Contractile function can still be restored after restoration of myocardial perfusion $3,7,49,125,137,138$. The presence of atrial stunning in AF supports the hypothesis of supply-demand ischemia during AF.

\subsubsection{Hibernating myocardium}

When ventricular low-flow ischemia becomes chronic, e.g. in CAD patients, hibernating myocardium becomes apparent ${ }^{4}$. The ventricular myocardium remains viable and cells dedifferentiate as part of "programmed cell-survival", a compensatory mechanism to decrease myocardial energy demand to match the decrease in blood sup- 
ply. It prevents necrosis or apoptosis.

Ausma et al have indicated an important resemblance between the structural changes that occur as a result of AF and the structural changes in the ventricles as a result of chronic low-flow ischemia 2,3,137. The time course and degree of structural changes were investigated in a model of tachypacing induced AF in the goat. Glycogen accumulation, loss of myofibrils, changes in mitochondrial shape, dispersion of nuclear chromatin and remodeling of the contractile apparatus into a more neonatal phenotype 5 were observed progressively in a goat model of lone $\mathrm{AF}^{2,3,8,137,139}$, without any signs of myocardial degeneration ${ }^{2}$ or apoptosis ${ }^{138}$.

\subsubsection{Vascular remodeling}

Vascular remodeling is a component of atrial structural remodeling during AF that is getting more and more attention. As described earlier, hypoxic and angiogenic mar-

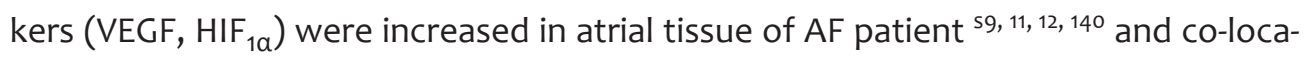
lized in the endothelium of atrial arteries in the AF group ${ }^{10}$. $\mathrm{HIF}_{1 a}$ and VEGF result in atrial angiogenesis and new, stable vessels will improve atrial perfusion. Atrial microvessel size and capillary density were investigated both in experimental AF (CHAPTER 6) and AF patients9, ${ }^{141}$. The capillary density was investigated in the LA posterior wall of control patients, patients with mitral regurgitation (MR) and patient with MR and AF. Patients with MR + AF had a significantly lower capillary density than $M R$ patients without a history of AF and control patients. Similar results were recently observed in our group showing a decrease in capillary density in the left and right atrium after 5 weeks of atrial tachypacing-induced AF in pigs (CHAPTER 6). In the RA appendage, Gramley et al showed opposing results, reporting that microvessel size and density were increased in AF patients ${ }^{9}$. The stabilization of $\mathrm{HIF}_{1 \mathrm{a}} / \mathrm{VEGF}$-induced vessel formation is dependent on the balance between the growth factors angiopoietine 1 (Ang-1) and 2 and (Ang-2). When the balance is in favor of Ang-1, this increased endothelial stability. Ang-2 promotes new vessel sprouting and facilitates the actions of VEGF. Plasma levels of Ang-2 are increased in AF patients shifting the balance to endothelial destabilization ${ }^{140}$. In that case, an increase in capillary density does not necessarily increase functional perfusion. Some functional measurements were performed in clinical $A F^{70}$. Skalidis et al reported coronary flow reserve impairment in lone AF patients when measured during sinus rhythm. They concluded that 
there is microvascular dysfunction ${ }^{70}$.

Endothelial dysfunction is also shown by the release of inflammatory biomarkers from the endothelial tissue. Upregulation of adhesion molecules (e.g. Vascular Cell Adhesion Molecule 1 (VCAM-1), monocyte chemotactic protein-1 (MCP-1), Intercellular Adhesion Molecule 1 (ICAM)) is seen in AF patients ${ }^{142,143}$ and in experimental AF 144. These adhesion molecules attract immune cells and start an immune response in the atrial tissue. The activation of the immune system was associated with post-operative $A F$ in patients undergoing cardiac surgery ${ }^{145}$. In addition, they are associated with thromboembolic events or death in AF patients ${ }^{143}$.

\subsection{Conclusion}

The relationship between AF and ischemia is complex. Distinction can be made between acute (e.g. MI) and chronic (e.g. CAD) ischemia. Especially the role of acute ischemia in AF is obvious and well investigated. In both cases, a sudden or partial decrease in the atrial supply is the cause of an atrial supply-demand mismatch. In addition, AF itself can cause a disturbance of the supply-demand balance. Hypoxic and angiogenic markers are increased in atrial myocardium of $\mathrm{AF}$ patients and animal models of AF. In AF, several types of atrial remodeling have been observed being electrical, contractile, structural ${ }^{146}$, and vascular ${ }^{9,70}$. They can be viewed as energy saving mechanisms in order to restore the supply-demand balance. Atrial remodeling as a result of AF-induced supply-demand ischemia could on its turn contribute to a substrate for AF. This will result in a vicious circle in which AF causes ischemia causes AF and contribute to the self-perpetuating character of AF. More insights on the regulation of the supply-demand balance could prevent ischemia and further atrial remodeling and the stabilization of AF.

\section{REFERENCES}

1. Wijffels MC, Kirchhof CJ, Dorland R, Allessie MA. Atrial fibrillation begets atrial fibrillation. A study in awake chronically instrumented goats. Circulation. 1995;92:1954-1968

2. Ausma J, Litjens N, Lenders MH, Duimel H, Mast F, Wouters L, Ramaekers F, Allessie M, Borgers $\mathrm{M}$. Time course of atrial fibrillation-induced cellular structural remodeling in atria of the goat. Journal of molecular and cellular cardiology. 2001;33:2083-2094 


\section{CHAPTER 2}

3. Ausma J, Wijffels M, Thone F, Wouters L, Allessie M, Borgers M. Structural changes of atrial myocardium due to sustained atrial fibrillation in the goat. Circulation. 1997;96:3157-3163

4. van der Velden HMW, van der Zee L, Wijffels MC, van Leuven C, Dorland R, Vos MA, Jongsma HJ, Allessie MA. Atrial fibrillation in the goat induces changes in monophasic action potential and mrna expression of ion channels involved in repolarization. J Cardiovasc Electrophysiol. 2000;11:1262-1269

5. Ausma J, Borgers M. Dedifferentiation of atrial cardiomyocytes: From in vivo to in vitro. Cardiovasc Res. 2002;55:9-12

6. Rucker-Martin C, Pecker F, Godreau D, Hatem SN. Dedifferentiation of atrial myocytes during atrial fibrillation: Role of fibroblast proliferation in vitro. Cardiovascular research. 2002;55:38-52 7. Thijssen VL, Ausma J, Borgers M. Structural remodelling during chronic atrial fibrillation: Act of programmed cell survival. Cardiovascular research. 2001;52:14-24

8. Thijssen VL, van der Velden HM, van Ankeren EP, Ausma J, Allessie MA, Borgers M, van Eys $\mathrm{GJ}$, Jongsma HJ. Analysis of altered gene expression during sustained atrial fibrillation in the goat. Cardiovasc Res. 2002;54:427-437

9. Gramley F, Lorenzen J, Jedamzik B, Gatter K, Koellensperger E, Munzel T, Pezzella F. Atrial fibrillation is associated with cardiac hypoxia. Cardiovasc Pathol. 2010;19:102-111

10. Ogi H, Nakano Y, Niida S, Dote K, Hirai Y, Suenari K, Tonouchi Y, Oda N, Makita Y, Ueda S, Kajihara K, Imai K, Sueda T, Chayama K, Kihara Y. Is structural remodeling of fibrillated atria the consequence of tissue hypoxia? Circulation journal : official journal of the Japanese Circulation Society. 2010;74:1815-1821

11. Scridon A, Morel E, Nonin-Babary E, Girerd N, Fernandez C, Chevalier P. Increased intracardiac vascular endothelial growth factor levels in patients with paroxysmal, but not persistent atrial fibrillation. Europace. 2012;14:948-953

12. Xu Y, Sharma D, Du F, Liu Y. The role of toll-like receptor 2 and hypoxia-induced transcription factor-1alpha in the atrial structural remodeling of non-valvular atrial fibrillation. Int J Cardiol. 2013

13. Spalteholz W. Die arterien der herzwand. Leipzig: Hirzel. 1924

14. Gross CJ. The blood supply to the heart in its anatomical and clinical aspects. 1921

15. James TN, Burch GE. The atrial coronary arteries in man. Circulation. 1958;17:90-98

16. Smith GT. The anatomy of the coronary circulation. Am J Cardiol. 1962;9:327-342

17. Hromada J, Voboril Z. Arteries of cardiac atria in man. Folia Morphol (Praha). 1970;18:308-

321

18. Busquet J, Fontan F, Anderson RH, Ho SY, Davies MJ. The surgical significance of the atrial branches of the coronary arteries. Int J Cardiol. 1984;6:223-236

19. Williams PL, Warwick R, Dyson M, Bannister L. Gray's anatomy. 1989

20. Keith A, Flack $M$. The form and nature of the muscular connections between the primary divisions of the vertebrate heart. J Anat Physiol. 1907;41:172-189

21. Crainicianu A. Anatomische studien uber die coronararterien und experimentelle unter- 


\section{Atrial tissue perfusion and ischemia in atrial fibrillation}

suchungen uber ihre durchgangigkeit. Virschows Arch. f. path. Anat. 1922;238

22. Schlesinger MJ. An injection plus dissection study of coronary artery occlusions and anastomoses. Am Heart J. 1938;15

23. Stern H, Ranzenhofer ER, Liebow AA. Preparation of vinylite casts of the coronary vessels and cardiac chambers. Lab Invest. 1954;3:337-347

24. Kazzaz D, Shanklin WM. The coronary vessels of the dog demonstrated by colored plastic (vinyl acetate) injections and corrosion. Anat Rec. 1950;107:43-59

25. Pardo Meo J, Scanavacca M, Sosa E, Correia A, Hachul D, Darrieux F, Lara S, Hardy C, Jatene $F$, Jatene $M$. Atrial coronary arteries in areas involved in atrial fibrillation catheter ablation. Circ Arrhythm Electrophysiol.3:600-605

26. Bernard SL, Ewen JR, Barlow CH, Kelly JJ, McKinney S, Frazer DA, Glenny RW. High spatial resolution measurements of organ blood flow in small laboratory animals. American journal of physiology. Heart and circulatory physiology. 2000;279:H2043-2052

27. Spaan JA, ter Wee R, van Teeffelen JW, Streekstra G, Siebes M, Kolyva C, Vink H, Fokkema DS, VanBavel E. Visualisation of intramural coronary vasculature by an imaging cryomicrotome suggests compartmentalisation of myocardial perfusion areas. Med Biol Eng Comput. 2005;43:431-435 28. von Ludinghausen M. Advances in anatomy, embryology and cell biology. Springer; 2003. 29. Soderstrom. Some anatomical and functional data regarding the atria of the heart. Acta medica scandinavica. Supplementum. 1948:27-39.

30. Baroldi G, Scomazzoni G. Coronary circulation in the normal and the pathologic heart. 1967.

31. Saremi F, Abolhoda A, Ashikyan O, Milliken JC, Narula J, Gurudevan SV, Kaushal K, Raney A. Arterial supply to sinuatrial and atrioventricular nodes: Imaging with multidetector ct. Radiology. 2008;246:99-107; discussion 108-109

32. Futami C, Tanuma K, Tanuma Y, Saito T. The arterial blood supply of the conducting system in normal human hearts. Surg Radiol Anat. 2003;25:42-49

33. Kyriakidis MK, Kourouklis CB, Papaioannou JT, Christakos SG, Spanos GP, Avgoustakis DG. Sinus node coronary arteries studied with angiography. Am J Cardiol. 1983;51:749-750

34. Shaw DB, Linker NJ, Heaver PA, Evans R. Chronic sinoatrial disorder (sick sinus syndrome): A possible result of cardiac ischaemia. Br Heart J. 1987;58:598-607

35. Romhilt DW, Hackel DB, Estes EH, Jr. Origin of blood supply to sinoauricular and atrioventricular node. Am Heart J. 1968;75:279-280

36. Pejkovic B, Krajnc I, Anderhuber F, Kosutic D. Anatomical aspects of the arterial blood supply to the sinoatrial and atrioventricular nodes of the human heart. J Int Med Res. 2008;36:691698

37. Tjandrawidjaja MC, Fu Y, Kim DH, Burton JR, Lindholm L, Armstrong PW. Compromised atrial coronary anatomy is associated with atrial arrhythmias and atrioventricular block complicating acute myocardial infarction. J Electrocardiol. 2005;38:271-278

38. Petelenz T. Extracoronary blood supply of the sinu-atrial (keith-flack's) node. Cardiologia. 


\section{CHAPTER 2}

1965;47:57-67

39. Moberg A. Anastomoses between extracardiac vessels and coronary arteries. Acta Med Scand Suppl. 1968;485:5-26

40. Gensini GG, Buonanno C, Palacio A. Anatomy of the coronary circulation in living man. Coronary arteriography. Dis Chest. 1967;52:125-140

41. Hudson CL, Moritz AR, Wearn JT. The extracardiac anastomoses of the coronary arteries. J Exp Med. 1932;56:919-925

42. Seiler C, Stoller M, Pitt B, Meier P. The human coronary collateral circulation: Development and clinical importance. Eur Heart J. 2013

43. Troidl K, Schaper W. Arteriogenesis versus angiogenesis in peripheral artery disease. Diabetes/metabolism research and reviews. 2012;28 Suppl 1:27-29

44. Zoll PM, Wessler S, Schlesinger MJ. Interarterial coronary anastomoses in the human heart, with particular reference to anemia and relative cardiac anoxia. Circulation. 1951;4:797-815

45. Bahar S, Ozdemir V, Eken E, Tipirdamaz S. The distribution of the coronary arteries in the angora rabbit. Anat Histol Embryol. 2007;36:321-327

46. Yalcin B, Kirici Y, Ozan H. The sinus node artery: Anatomic investigations based on injection-corrosion of 60 sheep hearts. Interact Cardiovasc Thorac Surg. 2004;3:249-253

47. Bisaillon A. Gross anatomy of the cardiac blood vessels in the north american beaver (castor canadensis). Anat Anz. 1981;150:248-258

48. Bezuidenhout AJ. The coronary circulation of the heart of the ostrich (struthio camelus). J Anat. 1984;138 ( Pt 3):385-397

49. Buss DD, Hyde DM, Poulos PW, Jr. Coronary artery distribution in bonnet monkeys (macaca radiata). Anat Rec. 1982;203:411-417

50. Duan D, Yu S, Cui Y. Morphological study of the sinus node and its artery in yak. Anat Rec (Hoboken).295:2045-2056

51. Sahni D, Kaur GD, Jit H, Jit I. Anatomy \& distribution of coronary arteries in pig in comparison with man. Indian J Med Res. 2008;127:564-570

52. Weaver ME, Pantely GA, Bristow JD, Ladley HD. A quantitative study of the anatomy and distribution of coronary arteries in swine in comparison with other animals and man. Cardiovasc Res. 1986;20:907-917

53. Christensen GC, Campeti FL. Anatomic and functional studies of the coronary circulation in the dog and pig. Am J Vet Res. 1959;20:18-26

54. Halpern MH. Arterial supply to the nodal tissue in dog heart. Circulation. 1954;9:547-554

55. Hughes GC, Post MJ, Simons M, Annex BH. Translational physiology: Porcine models of human coronary artery disease: Implications for preclinical trials of therapeutic angiogenesis. J Appl Physiol. 2003;94:1689-1701

56. Maxwell MP, Hearse DJ, Yellon DM. Species variation in the coronary collateral circulation during regional myocardial ischaemia: A critical determinant of the rate of evolution and extent of myocardial infarction. Cardiovasc Res. 1987;21:737-746 


\section{Atrial tissue perfusion and ischemia in atrial fibrillation}

57. Kato T, Yasue T, Shoji Y, Shimabukuro S, Ito Y, Goto S, Motooka S, Uno T, Ojima A. Angiographic difference in coronary artery of man, dog, pig, and monkey. Acta pathologica japonica. 1987;37:361-373

58. Yamazaki M, Morgenstern S, Klos M, Campbell K, Buerkel D, Kalifa J. Left atrial coronary perfusion territories in isolated sheep hearts: Implications for atrial fibrillation maintenance. Heart Rhythm. 2010;7:1501-1508

59. White CW, Marcus ML, Abboud FM. Distribution of coronary artery flow to the canine right atrium and sinoatrial node. Circ Res. 1977;40:342-347

6o. Yano A, Igawa O, Adachi M, Miake J, Inoue Y, Ogura K, Kato M, litsuka K, Hisatome I. Left atrial branches of coronary arteries; clinical implications related to linear catheter ablation for atrial fibrillation. J Interv Card Electrophysiol. 2009;25:141-144

61. Nerantzis CE, Anninos H, Couvaris CM. The most vulnerable large atrial arteries during surgery and radiofrequency ablation of the pulmonary veins. Int J Cardiol.160:148-149

62. Castano A, Crawford T, Yamazaki M, Avula UM, Kalifa J. Coronary artery pathophysiology after radiofrequency catheter ablation: Review and perspectives. Heart Rhythm. 2011;8:1975-1980 63. Demaria RG, Page P, Leung TK, Dubuc M, Malo O, Carrier M, Perrault LP. Surgical radiofrequency ablation induces coronary endothelial dysfunction in porcine coronary arteries. European journal of cardio-thoracic surgery : official journal of the European Association for Cardio-thoracic Surgery. 2003;23:277-282

64. Lim HE, Choi CU, Na JO, Choi JI, Kim SH, Kim JW, Kim EJ, Han SW, Park SW, Rha SW, Park CG, Seo HS, Oh DJ, Hwang C, Kim YH. Effects of iatrogenic myocardial injury on coronary microvascular function in patients undergoing radiofrequency catheter ablation of atrial fibrillation. Circ Arrhythm Electrophysiol. 2013;6:318-326

65. Ma J, Cheng G, Xu G, Weng S, Lu X. Effect of radiofrequency catheter ablation on endothelial function and oxidative stress. Acta cardiologica. 2006;61:339-342

66. McHale PA, Greenfield JC, Jr. Origin of atrial coving in canine phasic coronary artery blood flow. Am J Physiol. 1986;251:H774-778

67. Duncker DJ, van Zon NS, Ishibashi Y, Bache RJ. Role of $k+$ atp channels and adenosine in the regulation of coronary blood flow during exercise with normal and restricted coronary blood flow. J Clin Invest. 1996;97:996-1009

68. Kajiya F, Tsujioka K, Ogasawara Y, Hiramatsu O, Wada Y, Goto M, Yanaka M. Analysis of the characteristics of the flow velocity waveforms in left atrial small arteries and veins in the dog. Circ Res. 1989;65:1172-1181

69. Skalidis El, Kochiadakis GE, Igoumenidis NE, Vardakis KE, Vardas PE. Phasic coronary blood flow velocity pattern and flow reserve in the atrium: Regulation of left atrial myocardial perfusion. J Am Coll Cardiol. 2003;41:674-680

70. Skalidis EI, Hamilos MI, Karalis IK, Chlouverakis G, Kochiadakis GE, Vardas PE. Isolated atrial microvascular dysfunction in patients with lone recurrent atrial fibrillation. J Am Coll Cardiol. 2008;51:2053-2057 


\section{CHAPTER 2}

71. van Bragt KA, Nasrallah HM, Kuiper M, Luiken JJ, Schotten U, Verheule S. Atrial supply-demand balance in healthy adult pigs: Coronary blood flow, oxygen extraction, and lactate production during acute atrial fibrillation. Cardiovasc Res. 2014;101:9-19

72. Kimura A, Hiramatsu O, Wada Y, Yada T, Yamamoto T, Goto M, Ogasawara Y, Tsujioka K, Kajiya F. Atrial contractility affects phasic blood flow velocity of atrial small vessels in the dog. Cardiovascular research. 1992;26:1219-1225

73. White CW, Holida MD, Marcus ML. Effects of acute atrial fibrillation on the vasodilator reserve of the canine atrium. Cardiovasc Res. 1986;20:683-689

74. Laughlin MH, Burns JW, Fanton J, Ripperger J, Peterson DF. Coronary blood flow reserve during +gz stress and treadmill exercise in miniature swine. J Appl Physiol. 1988;64:2589-2596

75. Manohar M, Goetz TE, Hutchens E, Coney E. Atrial and ventricular myocardial blood flows in horses at rest and during exercise. Am J Vet Res. 1994;55:1464-1469

76. King RB, Bassingthwaighte JB, Hales JR, Rowell LB. Stability of heterogeneity of myocardial blood flow in normal awake baboons. Circ Res. 1985;57:285-295

77. Neill WA, Sewell D, Gopal M, Oxendine J, Painter L. Independent regulation of atrial coronary blood flow by atrial contraction rate in conscious dogs. Pflugers Arch. 1980;388:193-195

78. Bauman RP, Rembert JC, Greenfield JC, Jr. Regional atrial blood flow in dogs. Effect of hypertrophy on coronary flow reserve. J Clin Invest. 1989;83:1563-1569

79. Bauman RP, Rembert JC, Greenfield JC, Jr. Myocardial blood flow in awake dogs with chronic tricuspid regurgitation. Basic Res Cardiol. 1998;93:63-69

80. Bauman RP, Rembert JC, Greenfield JC, Jr. Regional vascular reserve in canine atria and ventricles during rest and exercise. Am J Physiol. 1995;269:H1578-1582

81. Neill WA, Phelps NC, Oxendine JM, Mahler DJ, Sim DN. Effect of heart rate on coronary blood flow distribution in dogs. Am J Cardiol. 1973;32:306-312

82. Neill WA, Sewell DH, Gosalia KP, Kingsley EM, Oxendine JM. Atrial coronary hyperemia and ischemia in response to variations in atrial pressure in dogs. Am Heart J. 1983;106:554-558

83. Smiseth OA, Mjos OD. Increased left atrial myocardial blood flow during acute ischemic left ventricular failure. Am Heart J. 1986;111:798-799

84. Bauman RP, Rembert JC, Greenfield JC, Jr. Regional blood flow in canine atria during exercise. Am J Physiol. 1993;265:H629-632

85. White CW, Kerber RE, Weiss HR, Marcus ML. The effects of atrial fibrillation on atrial pressure-volume and flow relationships. Circ Res. 1982;51:205-215

86. Hoit BD, Walsh RA, Shao Y, Gabel M, Millard R. Comparative assessment of regional left atrial perfusion by laser doppler and radionuclide microsphere techniques. Cardiovasc Res. 1993;27:508-514

87. McHale PA, Rembert JC, Greenfield JC, Jr. Effect of atrial fibrillation on atrial blood flow in conscious dogs. Am J Cardiol. 1983;51:1722-1727

88. Duncker DJ, Bache RJ. Regulation of coronary blood flow during exercise. Physiological reviews. 2008;88:1009-1086 


\section{Atrial tissue perfusion and ischemia in atrial fibrillation}

89. Krahn AD, Manfreda J, Tate RB, Mathewson FA, Cuddy TE. The natural history of atrial fibrillation: Incidence, risk factors, and prognosis in the manitoba follow-up study. Am J Med. 1995;98:476-484

90. Kannel WB, Benjamin EJ. Status of the epidemiology of atrial fibrillation. The Medical clinics of North America. 2008;92:17-40, ix

91. Kannel WB, Wolf PA, Benjamin EJ, Levy D. Prevalence, incidence, prognosis, and predisposing conditions for atrial fibrillation: Population-based estimates. Am J Cardiol. 1998;82:2N-9N

92. Akao M, Chun YH, Wada H, Esato M, Hashimoto T, Abe M, Hasegawa K, Tsuji H, Furuke K, Fushimi AFRI. Current status of clinical background of patients with atrial fibrillation in a community-based survey: The fushimi af registry. Journal of cardiology. 2013;61:260-266

93. Goldberg RJ, Seeley D, Becker RC, Brady P, Chen ZY, Osganian V, Gore JM, Alpert JS, Dalen JE. Impact of atrial fibrillation on the in-hospital and long-term survival of patients with acute myocardial infarction: A community-wide perspective. Am Heart J. 1990;119:996-1001

94. Lehto M, Snapinn S, Dickstein K, Swedberg K, Nieminen MS, investigators O. Prognostic risk of atrial fibrillation in acute myocardial infarction complicated by left ventricular dysfunction: The optimaal experience. Eur Heart J. 2005;26:350-356

95. Madias JE, Patel DC, Singh D. Atrial fibrillation in acute myocardial infarction: A prospective study based on data from a consecutive series of patients admitted to the coronary care unit. Clinical cardiology. 1996;19:180-186

96. Berton G, Cordiano R, Cucchini F, Cavuto F, Pellegrinet M, Palatini P. Atrial fibrillation during acute myocardial infarction: Association with all-cause mortality and sudden death after 7-year of follow-up. International journal of clinical practice. 2009;63:712-721

97. Rathore SS, Berger AK, Weinfurt KP, Schulman KA, Oetgen WJ, Gersh BJ, Solomon AJ. Acute myocardial infarction complicated by atrial fibrillation in the elderly: Prevalence and outcomes. Circulation. 2000;101:969-974

98. Sakata K, Kurihara H, Iwamori K, Maki A, Yoshino H, Yanagisawa A, Ishikawa K. Clinical and prognostic significance of atrial fibrillation in acute myocardial infarction. Am J Cardiol. 1997;80:1522-1527

99. Kyriakidis M, Barbetseas J, Antonopoulos A, Skouros C, Tentolouris C, Toutouzas P. Early atrial arrhythmias in acute myocardial infarction. Role of the sinus node artery. Chest. 1992;101:944947

100. Pedersen OD, Bagger H, Kober L, Torp-Pedersen C. The occurrence and prognostic significance of atrial fibrillation/-flutter following acute myocardial infarction. Trace study group. Trandolapril cardiac evalution. Eur Heart J. 1999;20:748-754

101. Pizzetti F, Turazza FM, Franzosi MG, Barlera S, Ledda A, Maggioni AP, Santoro L, Tognoni $\mathrm{G}$, Investigators G-. Incidence and prognostic significance of atrial fibrillation in acute myocardial infarction: The gissi-3 data. Heart. 2001;86:527-532

102. Asanin M, Vasiljevic Z, Matic M, Vujisic-Tesic B, Arandjelovic A, Marinkovic J, Ostojic M. Outcome of patients in relation to duration of new-onset atrial fibrillation following acute myocar- 


\section{CHAPTER 2}

dial infarction. Cardiology. 2007;107:197-202

103. Crenshaw BS, Ward SR, Granger CB, Stebbins AL, Topol EJ, Califf RM. Atrial fibrillation in the setting of acute myocardial infarction: The gusto-i experience. Global utilization of streptokinase and tpa for occluded coronary arteries. J Am Coll Cardiol. 1997;30:406-413

104. Bunc M, Starc R, Podbregar M, Brucan A. Conversion of atrial fibrillation into a sinus rhythm by coronary angioplasty in a patient with acute myocardial infarction. Eur J Emerg Med. 2001;8:141-145

105. Blanton RM, Nappi A, Kimmelstiel CD. Conversion of infarction-associated atrial fibrillation by restoration of atrial perfusion. Clinical cardiology. 2010;33:E79-81

106. Hod H, Lew AS, Keltai M, Cercek B, Geft IL, Shah PK, Ganz W. Early atrial fibrillation during evolving myocardial infarction: A consequence of impaired left atrial perfusion. Circulation. 1987;75:146-150

107. Shakir DK, Arafa SO. Right atrial infarction, atrial arrhythmia and inferior myocardial infarction form a missed triad: A case report and review of the literature. Can J Cardiol. 2007;23:995997

108. Cushing EH, Feil HS, Stanton EJ, Wartman WB. Infarction of the cardiac auricles (atria): Clinical, pathological, and experimental studies. Br Heart J. 1942;4:17-34

109. Wartman WB, Souders JC. Localization of myocardial infarcts with respect to the muscle bundles of the heart. Archives of pathology. 1950;50:329-346

110. Lazar EJ, Goldberger J, Peled H, Sherman M, Frishman WH. Atrial infarction: Diagnosis and management. Am Heart J. 1988;116:1058-1063

111. Gardin JM, Singer DH. Atrial infarction. Importance, diagnosis, and localization. Archives of internal medicine. 1981;141:1345-1348

112. Flowers NC, Horan LG. Atrial infarction. Dis Chest. 1966;49:638-640

113. Lin YK, Lai MS, Chen YC, Cheng CC, Huang JH, Chen SA, Chen YJ, Lin Cl. Hypoxia and reoxygenation modulate the arrhythmogenic activity of the pulmonary vein and atrium. Clinical science. 2012;122:121-132

114. Yamazaki M, Avula UM, Bandaru K, Atreya A, Boppana VS, Honjo H, Kodama I, Kamiya K, Kalifa J. Acute regional left atrial ischemia causes acceleration of atrial drivers during atrial fibrillation. Heart Rhythm. 2013;10:901-909

115. Sakabe M, Shiroshita-Takeshita A, Maguy A, Brundel BJ, Fujiki A, Inoue H, Nattel S. Effects of a heat shock protein inducer on the atrial fibrillation substrate caused by acute atrial ischaemia. Cardiovasc Res. 2008;78:63-70

116. Sinno H, Derakhchan K, Libersan D, Merhi Y, Leung TK, Nattel S. Atrial ischemia promotes atrial fibrillation in dogs. Circulation. 2003;107:1930-1936

117. Shiroshita-Takeshita A, Sakabe M, Haugan K, Hennan JK, Nattel S. Model-dependent effects of the gap junction conduction-enhancing antiarrhythmic peptide rotigaptide (zp123) on experimental atrial fibrillation in dogs. Circulation. 2007;115:310-318

118. Rivard L, Sinno H, Shiroshita-Takeshita A, Schram G, Leung TK, Nattel S. The pharmacolo- 


\section{Atrial tissue perfusion and ischemia in atrial fibrillation}

gical response of ischemia-related atrial fibrillation in dogs: Evidence for substrate-specific efficacy. Cardiovasc Res. 2007;74:104-113

119. Nishida K, Qi XY, Wakili R, Comtois P, Chartier D, Harada M, Iwasaki YK, Romeo P, Maguy A, Dobrev D, Michael G, Talajic M, Nattel S. Mechanisms of atrial tachyarrhythmias associated with coronary artery occlusion in a chronic canine model. Circulation. 2011;123:137-146

120. Weijs B, Pisters R, Haest RJ, Kragten JA, Joosen IA, Versteylen M, Timmermans CC, Pison L, Blaauw Y, Hofstra L, Nieuwlaat R, Wildberger J, Crijns HJ. Patients originally diagnosed with idiopathic atrial fibrillation more often suffer from insidious coronary artery disease compared to healthy sinus rhythm controls. Heart Rhythm. 2012;9:1923-1929

121. Senoo K, Suzuki S, Sagara K, Otsuka T, Matsuno S, Uejima T, Oikawa Y, Yajima J, Nagashima K, Kirigaya H, Sawada H, Aizawa T, Lip GY, Yamashita T. Coronary artery diseases in japanese patients with nonvalvular atrial fibrillation. Journal of cardiology. 2014;63:123-127

122. Kakkar AK, Mueller I, Bassand JP, Fitzmaurice DA, Goldhaber SZ, Goto S, Haas S, Hacke W, Lip GY, Mantovani LG, Turpie AG, van Eickels M, Misselwitz F, Rushton-Smith S, Kayani G, Wilkinson $P$, Verheugt FW, Investigators GR. Risk profiles and antithrombotic treatment of patients newly diagnosed with atrial fibrillation at risk of stroke: Perspectives from the international, observational, prospective garfield registry. PloS one. 2013;8:e63479

123. Lip GY, Beevers DG. Abc of atrial fibrillation. History, epidemiology, and importance of atrial fibrillation. Bmj. 1995;311:1361-1363

124. Zusman O, Amit G, Gilutz H, Zahger D. The significance of new onset atrial fibrillation complicating acute myocardial infarction. Clinical research in cardiology : official journal of the German Cardiac Society. 2012;101:17-22

125. Arai AE, Pantely GA, Anselone CG, Bristow J, Bristow JD. Active downregulation of myocardial energy requirements during prolonged moderate ischemia in swine. Circ Res. 1991;69:14581469

126. Gudbjarnason S, Mathes P, Ravens KG. Functional compartmentation of atp and creatine phosphate in heart muscle. Journal of molecular and cellular cardiology. 1970;1:325-339

127. Ausma J, Coumans WA, Duimel H, Van der Vusse GJ, Allessie MA, Borgers M. Atrial high energy phosphate content and mitochondrial enzyme activity during chronic atrial fibrillation. Cardiovasc Res. 2000;47:788-796

128. Wijffels MC, Kirchhof CJ, Dorland R, Power J, Allessie MA. Electrical remodeling due to atrial fibrillation in chronically instrumented conscious goats: Roles of neurohumoral changes, ischemia, atrial stretch, and high rate of electrical activation. Circulation. 1997;96:3710-3720

129. Aronson PS. Kinetic properties of the plasma membrane na+-h+ exchanger. Annual review of physiology. 1985;47:545-560

130. Kimura J, Noma A, Irisawa H. Na-ca exchange current in mammalian heart cells. Nature. 1986;319:596-597

131. Jayachandran JV, Zipes DP, Weksler J, Olgin JE. Role of the na(+)/h(+) exchanger in shortterm atrial electrophysiological remodeling. Circulation. 2000;101:1861-1866 


\section{CHAPTER 2}

132. Altemose GT, Zipes DP, Weksler J, Miller JM, Olgin JE. Inhibition of the na(+)/h(+) exchanger delays the development of rapid pacing-induced atrial contractile dysfunction. Circulation. 2001;103:762-768

133. Blaauw $\mathrm{Y}$, Beier N, van der Voort P, van Hunnik A, Schotten U, Allessie MA. Inhibitors of the na+/h+ exchanger cannot prevent atrial electrical remodeling in the goat. J Cardiovasc Electrophysiol. 2004;15:440-446

134. Shinagawa K, Mitamura H, Ogawa S, Nattel S. Effects of inhibiting na(+)/h(+)-exchange or angiotensin converting enzyme on atrial tachycardia-induced remodeling. Cardiovasc Res. 2002;54:438-446

135. Schotten U, Duytschaever M, Ausma J, Eijsbouts S, Neuberger HR, Allessie M. Electrical and contractile remodeling during the first days of atrial fibrillation go hand in hand. Circulation. 2003;107:1433-1439

136. Weimar T, Watanabe Y, Kazui T, Lee US, Moon MR, Schuessler RB, Damiano RJ, Jr. Differential impact of short periods of rapid atrial pacing on left and right atrial mechanical function. American journal of physiology. Heart and circulatory physiology. 2012;302:H2583-2591

137. Ausma J, Wijffels M, van Eys G, Koide M, Ramaekers F, Allessie M, Borgers M. Dedifferentiation of atrial cardiomyocytes as a result of chronic atrial fibrillation. The American journal of pathology. 1997;151:985-997

138. Dispersyn GD, Ausma J, Thone F, Flameng W, Vanoverschelde JL, Allessie MA, Ramaekers FC, Borgers M. Cardiomyocyte remodelling during myocardial hibernation and atrial fibrillation: Prelude to apoptosis. Cardiovasc Res. 1999;43:947-957

139. Thijssen VL, Ausma J, Liu GS, Allessie MA, van Eys GJ, Borgers M. Structural changes of atrial myocardium during chronic atrial fibrillation. Cardiovasc Pathol. 2000;9:17-28

140. Freestone B, Chong AY, Lim HS, Blann A, Lip GY. Angiogenic factors in atrial fibrillation: A possible role in thrombogenesis? Annals of medicine. 2005;37:365-372

141. Corradi D, Callegari S, Maestri R, Ferrara D, Mangieri D, Alinovi R, Mozzoni P, Pinelli S, Goldoni M, Privitera YA, Bartoli V, Astorri E, Macchi E, Vaglio A, Benussi S, Alfieri O. Differential structural remodeling of the left-atrial posterior wall in patients affected by mitral regurgitation with or without persistent atrial fibrillation: A morphological and molecular study. Journal of cardiovascular electrophysiology. 2012;23:271-279

142. Ehrlich JR, Kaluzny M, Baumann S, Lehmann R, Hohnloser SH. Biomarkers of structural remodelling and endothelial dysfunction for prediction of cardiovascular events or death in patients with atrial fibrillation. Clinical research in cardiology : official journal of the German Cardiac Society. 2011;100:1029-1036

143. Hammwohner M, Ittenson A, Dierkes J, Bukowska A, Klein HU, Lendeckel U, Goette A. Platelet expression of $\mathrm{cd} 40 / \mathrm{cd} 40$ ligand and its relation to inflammatory markers and adhesion molecules in patients with atrial fibrillation. Experimental biology and medicine. 2007;232:581-589

144. Goette A, Bukowska A, Lendeckel U, Erxleben M, Hammwohner M, Strugala D, Pfeiffenberger J, Rohl FW, Huth C, Ebert MP, Klein HU, Rocken C. Angiotensin ii receptor blockade reduces 


\section{Atrial tissue perfusion and ischemia in atrial fibrillation}

tachycardia-induced atrial adhesion molecule expression. Circulation. 2008;117:732-742

145. Bruins P, te Velthuis H, Yazdanbakhsh AP, Jansen PG, van Hardevelt FW, de Beaumont EM, Wildevuur CR, Eijsman L, Trouwborst A, Hack CE. Activation of the complement system during and after cardiopulmonary bypass surgery: Postsurgery activation involves c-reactive protein and is associated with postoperative arrhythmia. Circulation. 1997;96:3542-3548

146. Allessie M, Ausma J, Schotten U. Electrical, contractile and structural remodeling during atrial fibrillation. Cardiovasc Res. 2002;54:230-246 
CHAPTER 3

44 


\section{Anatomy of the atrial vasculature in pigs}

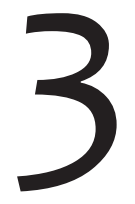

Kelly van Bragt

Pepijn van Horssen

Jeroen P. van den Wijngaard

Hussein M. Nasrallah

Piotr Podziemski

Jos A. Spaan

Ulricht Schotten

Maria Siebes

Sander Verheule

Submitted to Cardiovasc Res. 


\section{ABSTRACT}

BACKGROUND. We have previously reported that acute Atrial Fibrillation (AF) leads to supply-demand ischemia and chronic AF leads to vascular remodeling. The atrial coronary vasculature has not been investigated as extensively as the ventricular circulation. Here, we have investigated porcine atrial vascular anatomy.

METHODS. The atrial vasculature was studied by ink injection $(n=18)$ and corrosion casts $(n=5)$. In a third set of animals, fluorescent microspheres were injected in open chest experiments to assess regional flow distribution during sinus rhythm and AF and 3-dimensional reconstructions of the vasculature were made using videomicrocryotomy $(\mathrm{n}=5)$

RESULTS. Both atria possess a dense capillary network, even in the thinnest parts of the walls. Most of the right (RA) and left atrium (LA) is supplied by branches of the right coronary artery (RCA) and circumflex artery (LCX), respectively, with limited overlap in perfusion territories. In a majority of pigs, the LA free wall was supplied by an 'atrial circumflex', running parallel to the LCx. In addition, bronchial arteries contributed to perfusion of the posterior LA/ superior RA. During AF, LA flow increased by factor $2.5 \pm 0.6(p=0.02)$, without significant regional differences in response. Venous drainage in the LA was conferred by a combination of veins draining into the coronary sinus and Thebesian veins draining into the LA cavity.

CONCLUSIONS. Both atria possess a dense vascular bed from the coronary circulation, with a contribution of the bronchial circulation in some regions. Assessment of the atrial vascular anatomy may be relevant for cardiac surgery and development of ablation strategies. 


\section{INTRODUCTION}

Atrial fibrillation (AF) is the most common arrhythmia in clinical practice. We have previously shown that acute AF leads to an increase in lactate production (CHAPTER 4). In addition, markers of hypoxia and angiogenesis have been identified in experimental ${ }^{1}$ and clinical ${ }^{2-5}$ AF. An increase in atrial high-energy phosphates in short term AF also indicates a mismatch in supply-demand balance ${ }^{6,7}$. Animal models are required to identify the exact role of ischemia in AF. The coronary arterial circulation in pig and humans show strong similarities, both with respect to anatomy and vascular regulation ${ }^{8,9}$. Earlier studies provide a general introduction on atrial coronary anatomy ${ }^{10}$, extracoronary circulation ${ }^{11-13}$ and specifically the supply of the sinus node ${ }^{14}$, ${ }^{15}$ and AV node ${ }^{14,16}$. Here, we give a detailed overview of atrial coronary arteries and extracoronary blood supply in pigs.

\section{METHODS}

All animal procedures were in accordance with national and institutional guidelines. In this study, 28 healthy Dutch Landrace pigs where used with a weight of $68 \pm 4 \mathrm{~kg}$.

\subsection{Ink injections in the coronary circulation}

The anatomy of arterial branches of the left atrium was investigated using ink injections in eleven pigs. The hearts were quickly excised after euthanizing the pigs with Euthasol (20\% pentobarbital 200mg, 200mg/kg I.V.). A catheter was placed into the left coronary circumflex artery (LCx) and blue ink was injected. Branches were investigated by dissection of the LCx.

\subsection{Ink injection in the extracoronary circulation}

To investigate the extracardiac supply, 7 pigs were euthanized using Euthasol and the heart was excised with the closed pericardium, lungs and descending aorta attached. The aorta was closed off above the level of the coronary arteries in order to exclude them from the ink injection. The three major branches in the aortic arch (the brachiocephalic artery, the left common carotid artery and the left subclavian 


\section{CHAPTER 3}

artery) were closed off as well to prevent ink leakage. A catheter was placed into the descending aorta and blue ink was injected in the aorta. The only route that ink could leave the aorta was via small aortic ostia other than the coronary arteries. The most prominent of these is the ostium of the bronchial circulation, found in the inner curve of the aortic arch (Figure 5A), with an approximate diameter of 0.5-1 mm.

\subsection{Corrosion cast of the coronary circulation}

A first 3D visualization of the atrial vasculature was performed in two pigs. The hearts were quickly excised after administration of Euthasol. Cannulas were inserted in the left and right coronary ostia and fixated with purse string sutures. Vessels were maximally dilated with 100ug/l adenosine in PBS, followed by injection of a red low viscosity polymer resin (Batson's \#17 anatomical corrosion kit, Polyscience Inc, Warrington, PA, USA). The heart was left overnight on ice and afterwards all tissue was dissolved in $4 \mathrm{M} \mathrm{KOH}$.

\subsection{Corrosion cast of the extracoronary circulation}

Hearts from three other pigs where excised after administration of Euthasol together with the intact pericardium and the lungs. The coronary arteries and bronchial artery were cannulated and injected with a red and blue resin, respectively (Batson's \#17 anatomical corrosion kit, Polyscience Inc, Warrington, PA, USA).

\subsection{D atrial vasculature and flow distribution}

In five Dutch landrace pigs, anesthesia was induced with Zoletil $(5-8 \mathrm{mg} / \mathrm{kg}$ I.M.) and Thiopenthal (5-15 mg/kg I.V.) and maintained with Midazolam ( $1 \mathrm{mg} / \mathrm{kg} / \mathrm{h}$ ), Sufentanyl $(4 \mathrm{mg} / \mathrm{kg} / \mathrm{h})$ and Propofol $(10 \mathrm{mg} / \mathrm{kg} / \mathrm{h})$. After intubation and the start of mechanical ventilation, pigs were instrumented with a pigtail catheter ( $7 \mathrm{~F}$ Cordis injection catheter) into the left ventricle, to infuse microspheres via the blood stream into the heart tissue. These microspheres (Life Technologies Corporation, Carlsbad, CA, US, $15 \mu \mathrm{m}$ polysterene fluospheres in scarlet, green, yellow and carmine) were used to determine regional blood flow distribution in the heart. Microspheres $\left(4 \mathrm{ml}{ }^{*} 10^{6} \mathrm{mi}-\right.$ crospheres $/ \mathrm{ml}$ ) were gradually injected during sinus rhythm and AF. For AF induction, 
an ablation catheter (RFmarinr, Medtronic, Inc., Minnesota, MA, USA) was placed in the right atrium and used for atrial pacing continuously at $20 \mathrm{~Hz}$, four times stimulation threshold. After instrumentation, a left lateral incision was made, the fifth rib removed, and the pericardium opened to expose the left side of the heart. After the microsphere injections, the heart was excised. The coronary arteries of the explanted heart were cannulated and vessels were maximally dilated by infusion of 100ug/L adenosine in PBS, followed by injection of resin (Batson's \#17 anatomical corrosion kit, Polyscience Inc, Warrington, PA, USA) with UV Blue dye (2-5\% VasQtec, Zürich, Switzerland). The heart was placed on ice overnight and afterwards the cavities were filled with carboxymethylcellulose sodium solvent mixed with $5 \%$ Indian ink and placed in the freezer (-20 degrees Celsius). Episcopic fluorescent imaging using a cryomicrotome, as described earlier by van Horssen et al. ${ }^{17,18}$ and van den Wijngaard et al ${ }^{19}$, was used to gather 3D information on atrial vasculature and flow distribution. In brief, the frozen heart was mounted in a custom developed cryomicrotome system with its long axis perpendicular to the cutting plane. The specimen was sliced by a fully automated cutting mechanism at a set thickness, fixed in the range between 27-30 $\mu \mathrm{m}$ from atrium to ventricular base. After each slice, a black and white reflectance image was taken of the remaining bulk material with an Alta Apogee U16 camera (Apogee Imaging Systems Inc., South Windsor CT, USA 4096×4096 pixels 16 bit greyscale) as well as images from the emission of the four different colors of microspheres and the vasculature filled with UV-blue dye. From the separate images, a high-resolution 3D representation of the entire heart and coronary vessels was generated through interpolation (Amira 3.1, Visage Imaging, Fuerth, Germany and OsiriX 5.9, Pixmeo SARL, Bernex, Switzerland). The location of each microsphere was determined in relation to the vascular structure and anatomical landmarks at high spatial accuracy. The post-processing of 3D data and images was done in Blender 2.71 (Stichting Blender Foundation, Amsterdam, NL).

\subsection{Atrial veins}

The atrial drainage of blood was investigated by injecting ink in the LCx or in the Coronary sinus (CS). The CS is a large vein that collects most of the ventricular blood and drains into the right atrium. To visualize the atrial veins that drain into the CS, retrograde ink injections in the CS ostium were performed and atrial veins were in- 


\section{CHAPTER 3}

vestigated by dissection. To assess the presence of Thebesian veins, that would drain directly into the atrial cavity, an inside-out atrial preparation was produced, and ink was injected into the LCx after all ventricular branches had been ligated.

\section{RESULTS}

\subsection{Main atrial branches of the left circumflex artery}

In two pigs, a corrosion cast was made to visualize the atrial coronary anatomy. Both the left and right atria possessed a dense capillary network, also in the thin epicardial layer overlaying the trabeculated parts of the wall (Figure $1 A$ and $1 B$ ). Several branches of $0.5-1 \mathrm{~mm}$ were found to originate from the LCX and RCA supplying the respective atria (indicated with a red dot in Figure 1). In the 11 pigs investigated with ink injection, no atrial branches were observed originating from the left main stem or LAD to the left atrium. In total, one to five branches ranging from 0.5-1 mm in diameter originated from the $L C x$. Most of the branches originated from the proximal part of the $L C x$, dividing into smaller branches shortly after their origin from the $L C x$ and disappearing into the wall of the left atrial appendage (LAA) supplying the epi- and endocardial tissue of the LAA. The first LA branch $(>0.5 \mathrm{~mm})$ was found on average at $10 \pm 2 \mathrm{~mm}$ from the origin of the $L C X$. The distal part of the $L C X$ often showed almost no atrial branches. The average distance between all the LCx branches was $14 \pm 2 \mathrm{~mm}$. In 9 out of 11 pigs, an atrial branch was found, originating around the level of the obtuse marginal ventricular artery (Indicated with a large red arrow in Figure $1 \mathrm{C}$ and $2 C)$. This branch followed a course parallel to the AV groove, giving numerous smaller branches to the LA, and continued into the left atrial ridge towards Bachmann bundle (Figure $1 \mathrm{E}$ ). In two pigs, this branch originated closer to the left coronary ostium, but continued along the same course as in the other nine pigs. In one of those two pigs, the branch originated immediately after the origin of the LCx and no other branches were found using the ink injection (Figure 1D).

\subsection{D reconstruction of the atrial vasculature}

Figure $2 \mathrm{~A}, \mathrm{~B}$ and $\mathrm{C}$ are aspects of the casts of LA arteries in pigs. In all casts, one or two very early branches were found to ascend towards the LA roof. In one cast, a 


\section{Anatomy of the atrial vasculature in pigs}

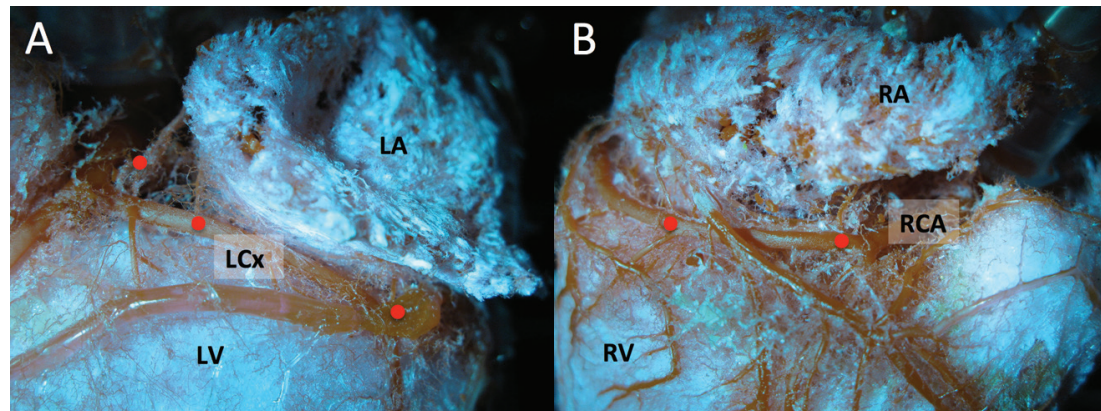

C

D

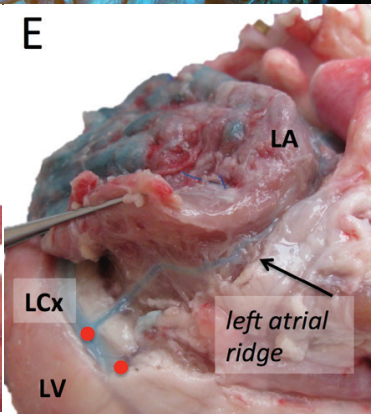

Figure 1: Atrial coronary anatomy.

Representative example of a corrosion cast of the left (A) and right (B) coronary artery and the microvascular network in the respective atria. Representative examples of the ink injections into the left circumflex artery, showing the variability of left atrial branches in number and branching point $(C, D, E)$. Atrial branches are indicated with a red dot. The obtuse marginal ventricular artery is indicated with a large red arrow.

$L A=$ left atrium, $R A=$ right atrium, $L V=$ left ventricle, $R V=$ right ventricle, $L C x=$ left circumflex artery, $R C A=$ right coronary artery.

first branch to the LA originated from the left main stem (Figure $2 \mathrm{C}$ ). In addition, there was an atrial branch running through the LA ridge in all five pigs. This branch always supplied the same atrial region, supplying the posterior LA free wall and giving off several branches to the left atrial wall along its course, but the exact point of origin was variable. The more distal this large artery originated from the $L C x$, the more atrial branches could be found directly from the LCx to supply the atrial appendage and anterior free wall (Figure $2 C$ ). If this artery originated earlier from the $L C x$, it supplied the atrial appendage and anterior free wall and few branches were observed that originated directly from the LCx (Figure 2A and B). Tracing of vascular trees 


\section{CHAPTER 3}

revealed that in general, the perfusion territories of individual atrial branches did not show extensive overlap (Figure 2F). However, in some left atrial regions, arteries do intermingle or form anastomoses, especially in the posterior atrial free wall, indicated with an asterisk in Figure $2 \mathrm{~A}, \mathrm{~B}$ and $\mathrm{C}$.

In the right atrium, a consistent branch was found, branching off from the proximal part of the RCA (Figure 2D and E). In four pigs, the branch was relatively large and ran towards the superior vena cava, likely supplying the sinus node. In one pig, this branch was smaller, and covered a smaller territory, approximately reaching halfway
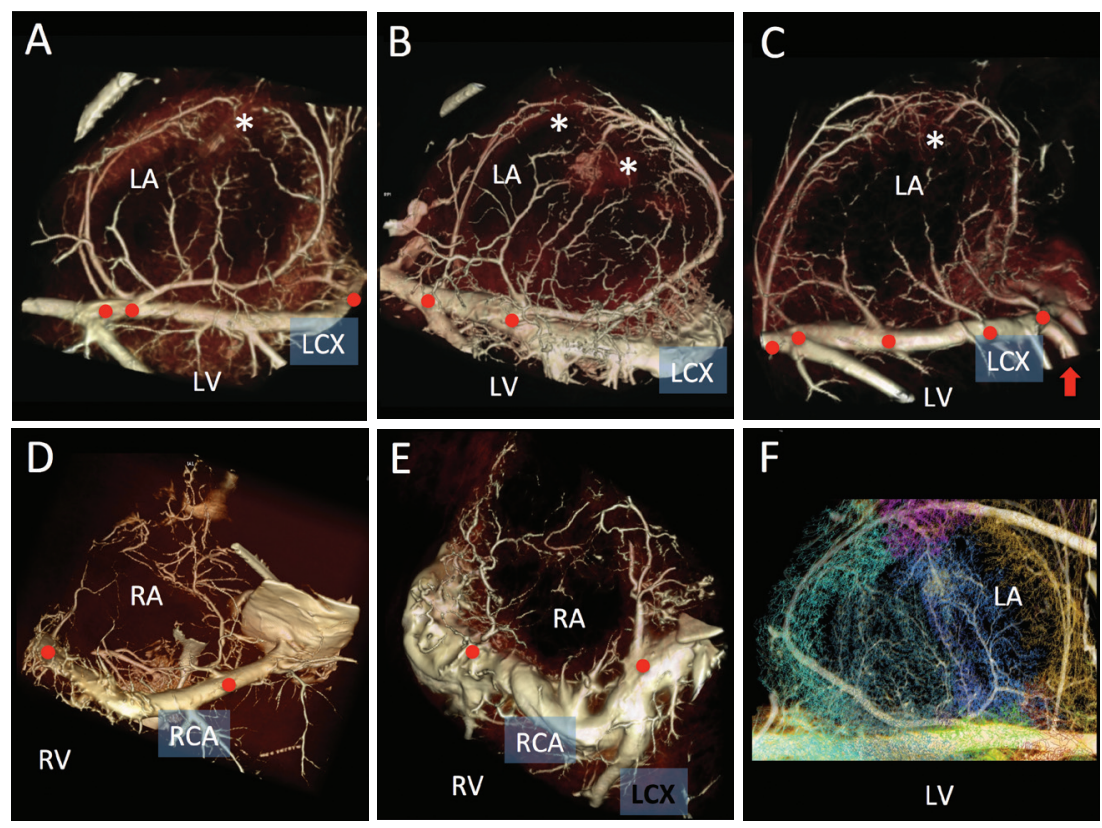

Figure 2: 3D atrial coronary anatomy.

Representative examples of a $3 \mathrm{D}$ digital reconstruction of the corrosion cast of the left atrium ( $A, B$ and $C$ ) and the right atrium ( $D$ and $E$ ), showing the variability of left atrial branches in number and branching point. Atrial branches are indicated with a red dot. The obtuse marginal ventricular artery is indicated with a large red arrow. The asterisk indicates an area of anastomosis on the LA roof. Color representation of the perfusion territory of the different left atrial branches $(F)$. $\mathrm{LA}=$ = left atrium, $\mathrm{RA}$ = right atrium, $\mathrm{LV}=$ left ventricle, $\mathrm{RV}=$ right ventricle, $\mathrm{LCX}=$ left circumflex artery, RCA = right coronary artery. 
the right atrial appendage. In this pig, a large left atrial branch from the proximal LCX was more pronounced, running towards the right atrial roof, to the area of the superior vena cava and sinus node. A second large branch was found in two pigs (Figure $2 \mathrm{E}$ ) originating from the intermediate RCA and coursing over the RA free wall. In the other pigs, the intermediate branch was small (Figure 2D). Most of the RA branches were relatively small and inconsistent in number and branching point. Arteries originating from the RCA seemed to supply a similar area as the branches from the LCX in the posterior atria, the interatrial septum and sinus node area and might form anastomoses here (Figure 3).

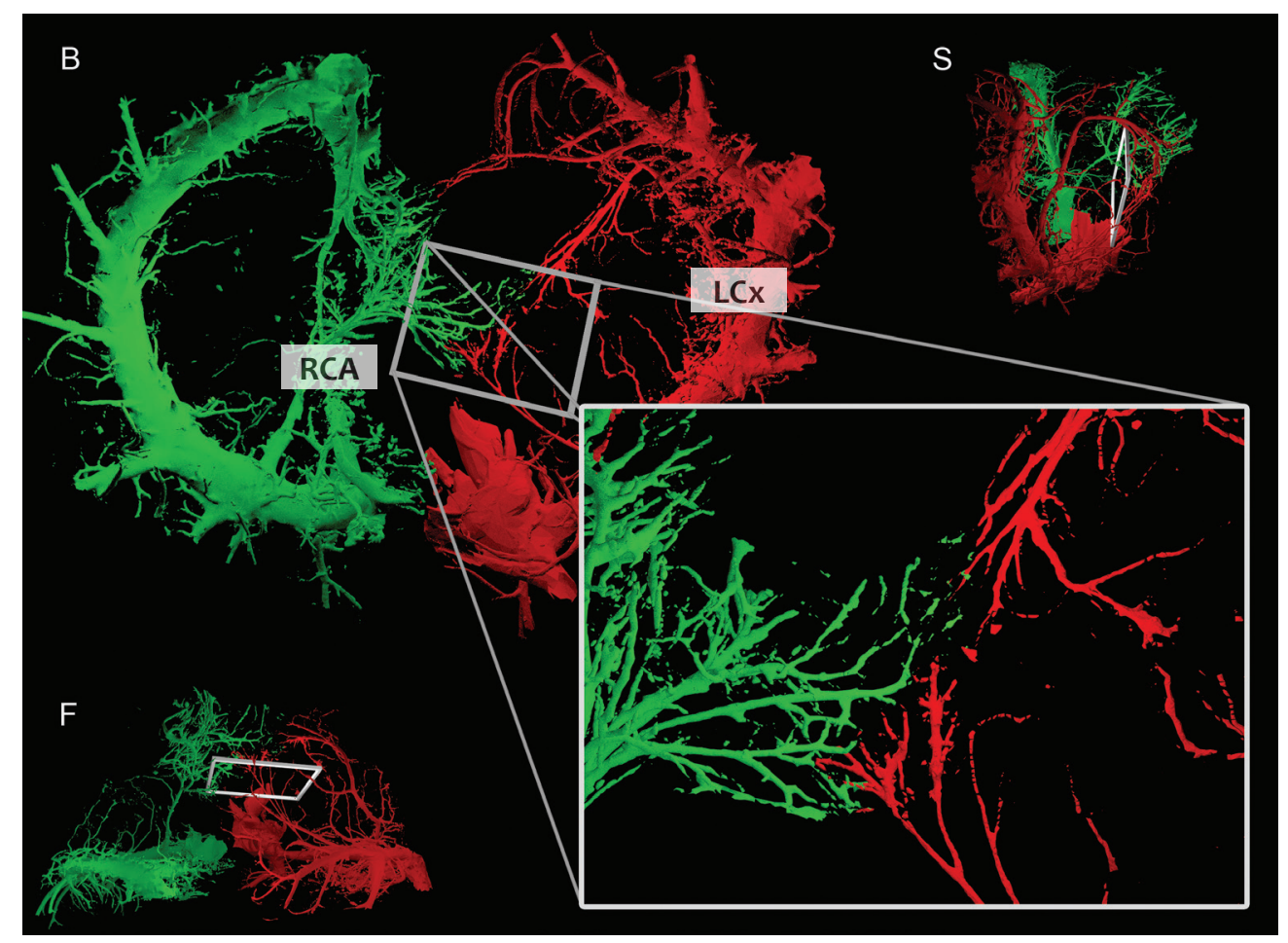

Figure 3: Atrial anastomosis.

Representative example of the anastomoses between the left (red) and right (green) atrial arteries in a bottom (B), front (F) and side (S) view and zoom (white square). LCx = left circumflex artery, $\mathrm{RCA}=$ right coronary artery. 


\subsection{Regional atrial flow distribution}

The regional flow distribution was assessed in the five pigs used in the 3D reconstruction of the coronary anatomy, by determining the position of individual microspheres (Figure 4A). Several regions in the heart where selected and the number of microspheres per voxel was calculated. The \% increase from sinus rhythm to AF is shown for the ventricle (Figure $4 \mathrm{~B}$ ) and atrium (Figure $4 \mathrm{C}$ ). In all areas investigated, there was an increase in microsphere deposition during AF. Although all areas show a similar effect size during AF, some areas showed a large variability between animals in flow increase, and the increase in flow was not significant as a consequence. A significant
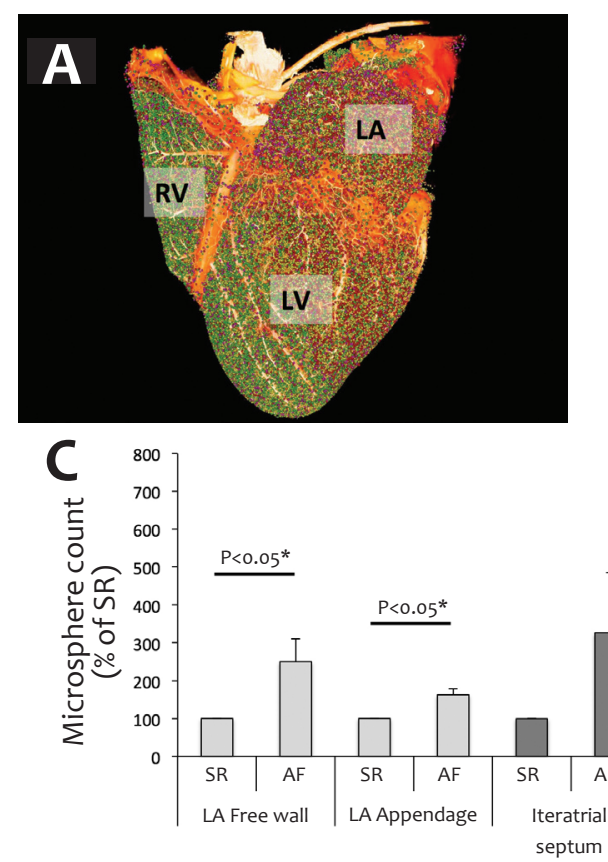

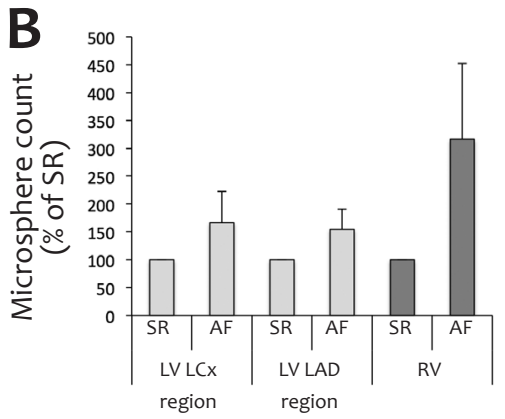

region

region

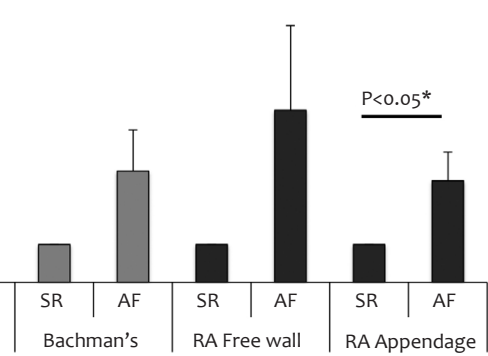
bundle

Figure 4: Atrial microsphere distribution.

(A) Representative example of microsphere visualization in the 3D digital reconstruction of the heart. Microsphere deposition expressed as \% of increase compared to sinus rhythm in different regions of the ventricles $(B)$ and the atria (C). $L A=$ left atrium, $L V=$ left ventricle, $R V=$ right ventricle, $\mathrm{SR}=$ sinus rhythm, $\mathrm{AF}=$ atrial fibrillation, $\mathrm{LCX}=$ left circumflex artery, $\mathrm{LAD}=$ left descending artery. * $p<0.05$ is significantly different vs. sinus rhythm. 
increase from SR to AF was found in the LA free wall, the LA appendage and the RA appendage $(P<0.05$, Figure $4 C)$. In the ventricles, a non-significant trend towards an increase in flow was observed (Figure 4B).

\subsection{Extracoronary contribution to the atrial supply}

In seven pigs, the extracoronary contribution to the atrial vasculature was investigated using ink injections into the descending aorta with blockade of the coronary arteries. Non-coronary branches of the aorta, most importantly the bronchial circulation, supply the conducting airways, pericardium, esophagus, thymus, trachea and aortic wall. Also in the atria, part of the myocardial sleeve of the superior vena cava was stained in about half of the hearts (four out of seven). In addition, part of the posterior LA, the region in between the pulmonary veins was stained in four out of seven animals (Figure $5 A$ and $B$ ). In one pig, part of the endocardium of both LA and RA free wall was stained. In a second pig, the LA free wall showed a staining of both endocardium and epicardium, but no staining of RA free wall. In two pigs, an artery was found containing ink and running over the Bachmann's bundle in the epicardium of the RA appendage to form an anastomosis with the proximal RCA (indicated with a black arrow in Figure $5 \mathrm{C}$ ).

After identifying the bronchial artery as a supplying vessel for the atrial myocardium, its ostium in the inner aortic arch was cannulated and a corrosion cast was made. The combined corrosion casts of the coronary (red) and bronchial (blue) circulations showed that these circulations are closely apposed at the posterior LA (Figure 5D). Removal of the main parts of the lungs revealed a network of small vessels supplied by the bronchial artery covering the posterior left atrium (Figure $5 \mathrm{E}$ ). Also, anastomoses with the proximal and intermediate RCA and posterior LCX were found.

\subsection{Atrial veins}

Retrograde ink injections into the CS showed that the left atrium can have several veins (indicated by blue arrows in Figure 6A and B) that drain into the CS and blood is subsequently drained into the right atrial cavity. Another route of left atrial venous drainage is via Thebesian veins. Thebesian veins in the left atrium were visualized by 


\section{CHAPTER 3}

ink injections into the LCx, illustrating that ink leaked from several small orifices directly into the left atrial cavity (indicated by yellow arrows in Figure 6C).

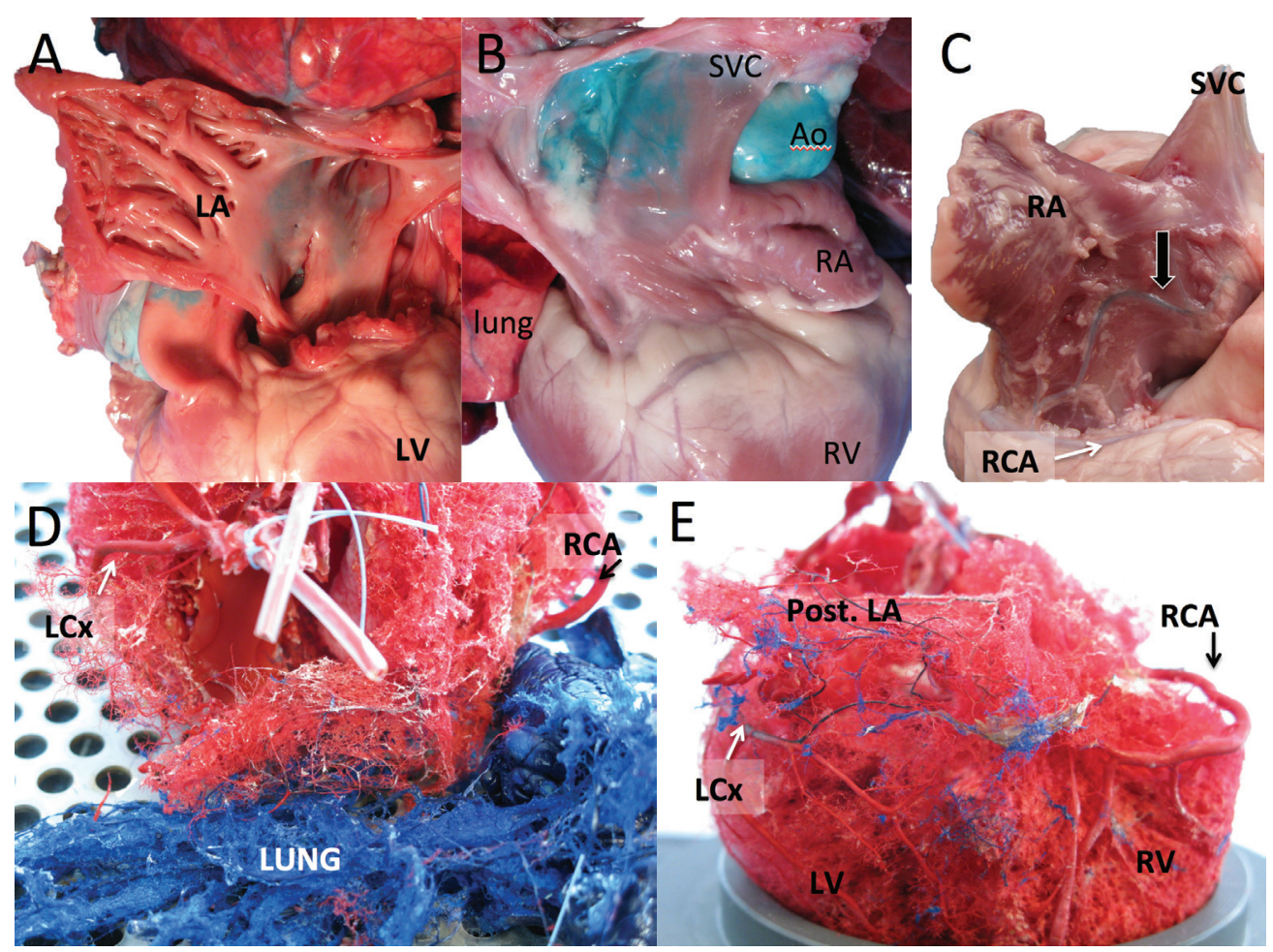

Figure 5: Extracoronary circulation to the atrium.

Representative example of an ink injection in the descending aorta. (A) Representative picture of the left atrium and pulmonary veins, (B) representative picture of the right atrium, superior vena cava and aorta, and (C) picture of the anastomoses between extracoronary circulation and right coronary artery.

Representative example of combined corrosion cast of the coronary (red) and bronchial (blue) circulation with (C) and without (D) the lungs attached. $L V=$ left ventricle, $R V=$ right ventricle, $L C x$ = left circumflex artery, RCA = right coronary artery, SVC = superior vena cava, Ao = aorta 


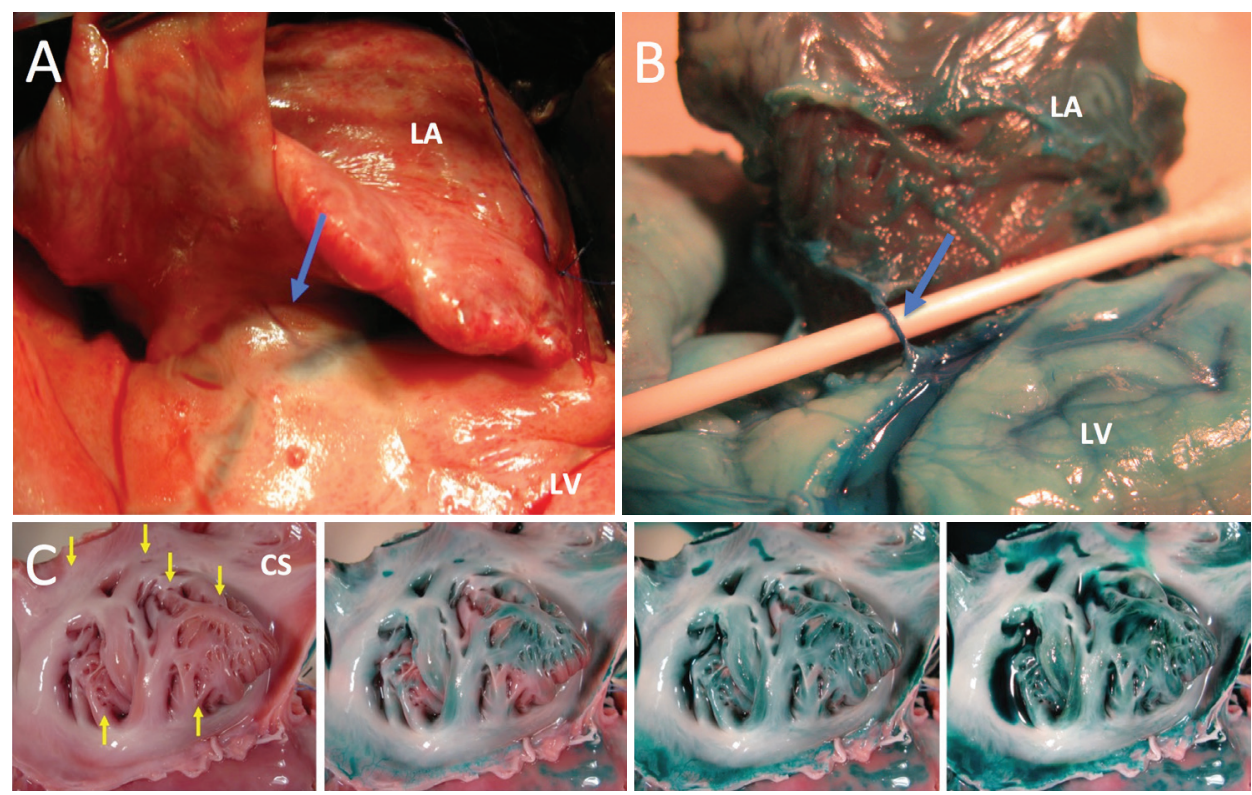

Figure 6: Atrial veins.

(A) LA drainage into the CS in situ, left lateral thoracotomy, (B) explanted heart, after ink injection into CS and dissection, (C) thebesian veins.

Veins that drain into th CS are indicated with a blue arrow, thebesian veins are indicated with a yellow arrow. $\mathrm{LA}=$ left atrium, LV = left ventricle, $C S=$ coronary sinus.

\section{DISCUSSION}

\subsection{Comparison of atrial vascular anatomy in pigs and humans}

In general, the left atrium is supplied by branches form the LCx. We show that in 16 out of 18 pigs, an artery can be found that follows (completely or partially) a course parallel to the LCx, and ascends through the LA ridge. James et al have also described an artery with a highly similar course in humans as one of two atrial arteries in the atria being less variable than others ${ }^{20}$. While Spalteholz described an origin at the intermediate $L C x^{21}$, James and Burch found an origin for this artery often splitting off from the LCx early after the bifurcation of the left main ${ }^{20}$. This phenomenon was de- 


\section{CHAPTER 3}

scribed earlier as a "left atrial circumflex"(LACX), a branch originating from the first few $\mathrm{mm}$ of the LCX or in a rare case from the left main stem or even proximal LAD. James and Gensini have suggested that a LACX is present in most of the hearts, without describing the incidence ${ }^{20,22}$. Tjandrawidjaja found a $L A C X$ in $83 \%$ of patients $(N=454)$. Patients with a compromised perfusion of the LACX had a higher incidence of early atrial arrhythmia's, which supports the role of ischemia in the development of atrial arrhythmias ${ }^{23}$. In our study, we observed that the artery running through the left atrial ridge could originate from the whole length of the LCx; proximal, intermediate or more distal. In our study, two out of 11 pigs had a single LA artery splitting off directly at the origin of the $L C x$, running parallel to the $L C x$ and giving off smaller branches to the LA supplying the parts of the LA free wall, atrial septum and posterior LA wall. According to the original definition of James, these arteries could be considered as a true LACX. In the other pigs, the origin was intermediate, but the artery followed a similar course along the LCX and up through the LA ridge and could also be considered a LACX. In one pig, the origin was very distal and the artery went straight up through the LA ridge. When it originated more proximal, it supplied more branches to the LA wall and less branches were found that originate from the LCx. The more distal its origin, the more branches from the LCX originated from the proximal part of the LCX.

In man, the large artery originating at the LCx and running through the LA groove supplies the sinus node in approx. $10 \%$ of the patients investigated and forms important inter- and intracoronary anastomoses ${ }^{24,25}$. We also observed in at least four out of five $3 \mathrm{D}$ reconstructed hearts that this artery intermingled with proximal and distal branches of the LCX and with branches from the RCA in the atrial roof. In addition, we showed that arteries within the LA wall did not show extensive overlap in perfusion territories. Similar results were found in the left atrium of sheep, where several vessels were injected with ink or ethanol. The ischemic area (after ethanol injection) and ink-stained areas where clearly delineated without significant overlap in perfusion territories ${ }^{26,27}$.

In humans, a large artery is usually present that branches off from the RCA and traverses the RA free wall while dividing into two or three branches ${ }^{20,21}$. This intermediate right atrial artery was not consistently seen in the five pigs in this study. In two pigs, a large intermediate artery was present. In the other pigs, a small branch split 
from the intermediate RCA. Sahni et al has also reported that the arteries branching from the RCA are rather small in pigs ${ }^{15}$.

\subsection{Atrial ischemia in ablation strategies and myocardial infarction}

Several authors have proposed that knowledge of the atrial coronary anatomy may be an important determinant for the success rate of atrial ablation strategies ${ }^{24,25}$, ${ }^{28,29}$. Specifically, the large artery over the LA roof through the left atrial ridge observed in both pigs and humans was implicated in these considerations. In addition to this artery, this LA ridge also contains the remnant of the vein of Marshall and abundant autonomic nerve bundles ${ }^{29}$. This artery is very close to ablation lines as a treatment for atrial fibrillation. Major arteries were also found in the mitral isthmus and LA anterior wall ${ }^{24,28}$. The presence of such large vessels can act as a source of convective heat loss to the blood flow. This could create difficulties in obtaining a transmural lesion and thus electrical isolation of the pulmonary veins. On the other hand, radiofrequency ablation may cause vascular damage, potentially causing coronary artery occlusion and atrial infarction, affecting a much larger atrial region than the direct target of the ablation ${ }^{30-33}$. Meissner et al reported a transient reduction in functional atrial flow reserve in approximately $20 \%$ of patients after radiofrequency ablation ${ }^{34}$. The correlation between coronary artery occlusion and AF can also be observed in myocardial infarctions (MI). In MI patients, 7-11\% suffer from new-onset AF $35-38$ and post-mortem studies show an atrial infarction in $17-42 \%$ of MI cases ${ }^{39-42}$. The anatomical variability in atrial vascular anatomy could explain the variability in ablation outcome. Therefore, an anatomical examination of large atrial arteries (e.g. by angiography) could help in designing a tailor-made ablation strategy in AF patients.

\subsection{Extracoronary supply to the left atrium}

In man, the bronchial circulation is described as a source of extracoronary blood supply to the atria. Bronchial arteries supply the posterior atrial pericardium or enter the pericardium as vasa vasorum of aorta, vena cava and pulmonary veins to form anastomoses with coronary arteries ${ }^{43-50}$. In the pig, the bronchial artery origin and course are similar to humans ${ }^{12}$. In our study in pigs, we show extracoronary supply from the bronchial circulation. Both ink and low viscosity polymer resin injections in 


\section{CHAPTER 3}

the ostium of the bronchial artery showed a clear supply of vena cava, aorta and pulmonary veins and into the posterior walls of both left and right atrium. In addition, anastomoses where found with the intermediate RCA and posterior LCx. Bronchial anastomoses with coronary arteries in pigs were demonstrated earlier ${ }^{11-13}$. It is not known how large the contribution is under normal conditions or whether this contribution changes during pathological conditions. Gade et al reported communications between the bronchial circulation and both coronary arteries in all cases ${ }^{12}$. Our study and the study of Kotoulas et al ${ }^{13}$ report anastomosis in the majority, but not in all pigs, and not always with both coronary arteries. The resin used for the corrosion cast was injected at high pressure. Although we show that overlap and anastomoses between the coronary and bronchial circulation exist, we are unable to determine the functional contribution of the extracoronary supply to atrial perfusion. In fact, the contribution of these anastomoses may be small under normal physiological conditions ${ }^{11}$. The importance of the extracoronary circulation may increase during ischemic conditions. White et al. have described that the extracoronary collateral formation (bronchial and internal mammary artery) with coronary arteries during ischemia in pigs can supply up to $30 \%$ of resting myocardial blood flow ${ }^{11}$. It was proposed in studies on cadavers and during cold cardioplegic cardiac arrest, that patients with severe coronary artery disease have the highest likelihood of extracoronary blood supply ${ }^{51,52}$. The presence of this extracoronary blood flow may cause several problems during open-heart surgery such as the re-excitation of the arrested heart, inhomogeneous cardioplegic delivery, myocardial rewarming, and blood in the operative field ${ }^{53}$. Experiments in dogs, however, suggest that the myocardial perfusion during global ischemia mostly happens through systemic-pulmonary channels and that the contribution of extracoronary myocardial perfusion is low ${ }^{53,54}$.

\section{CONCLUSION}

Atrial anatomy in pigs is very similar to human atrial anatomy. Recognizing the differences and similarities between pigs and humans is important when the pig is used as a model for atrial flow regulation and atrial ischemia. We have used several techniques, including a $3 \mathrm{D}$ reconstruction of heart and vessels, to investigate atrial anatomy and perfusion territories. Even the thinnest parts of the atrial myocardium possess a dense capillary network. The left and right atria are generally supplied by branches 
of the LCx and RCA, respectively. In the left atrium, one large artery was consistently found that courses along the LCx and upwards through the left atrial ridge supplying most of the left atrium. It also formed inter- and intracoronary anastomoses. In all but two pigs, additional posterior, intermediate and distal branches were found supplying the LA. In the right atrium, a proximal and intermediate branch were always found, the other branches were relatively small and variable. The bronchial circulation supplies part of the right and left atrial wall, the posterior right and left atrium and forms anastomoses with both coronary arteries.

\section{REFERENCES}

1. Thijssen VL, van der Velden HM, van Ankeren EP, Ausma J, Allessie MA, Borgers M, van Eys GJ, Jongsma HJ. Analysis of altered gene expression during sustained atrial fibrillation in the goat. Cardiovasc Res. 2002;54:427-437

2. Gramley F, Lorenzen J, Jedamzik B, Gatter K, Koellensperger E, Munzel T, Pezzella F. Atrial fibrillation is associated with cardiac hypoxia. Cardiovasc Pathol. 2010;19:102-111

3. Scridon A, Morel E, Nonin-Babary E, Girerd N, Fernandez C, Chevalier P. Increased intracardiac vascular endothelial growth factor levels in patients with paroxysmal, but not persistent atrial fibrillation. Europace : European pacing, arrhythmias, and cardiac electrophysiology : journal of the working groups on cardiac pacing, arrhythmias, and cardiac cellular electrophysiology of the European Society of Cardiology. 2012;14:948-953

4. Ogi H, Nakano Y, Niida S, Dote K, Hirai Y, Suenari K, Tonouchi Y, Oda N, Makita Y, Ueda S, Kajihara K, Imai K, Sueda T, Chayama K, Kihara Y. Is structural remodeling of fibrillated atria the consequence of tissue hypoxia? Circulation journal : official journal of the Japanese Circulation Society. 2010;74:1815-1821

5. $\quad \mathrm{Xu} \mathrm{Y,} \mathrm{Sharma} \mathrm{D,} \mathrm{Du} \mathrm{F,} \mathrm{Liu} \mathrm{Y.} \mathrm{The} \mathrm{role} \mathrm{of} \mathrm{toll-like} \mathrm{receptor} 2$ and hypoxia-induced transcription factor-1alpha in the atrial structural remodeling of non-valvular atrial fibrillation. Int $J$ Cardiol. 2013

6. Ausma J, Coumans WA, Duimel H, Van der Vusse GJ, Allessie MA, Borgers M. Atrial high energy phosphate content and mitochondrial enzyme activity during chronic atrial fibrillation. Cardiovasc Res. 2000;47:788-796

7. Leistad E, Aksnes G, Verburg E, Christensen G. Atrial contractile dysfunction after shortterm atrial fibrillation is reduced by verapamil but increased by bay k8644. Circulation. 1996;93:17471754

8. Hughes GC, Post MJ, Simons M, Annex BH. Translational physiology: Porcine models of human coronary artery disease: Implications for preclinical trials of therapeutic angiogenesis. Journal of applied physiology. 2003;94:1689-1701 


\section{CHAPTER 3}

9. Lelovas PP, Kostomitsopoulos NG, Xanthos TT. A comparative anatomic and physiologic overview of the porcine heart. Journal of the American Association for Laboratory Animal Science : JAALAS. 2014;53:432-438

10. Christensen GC, Campeti FL. Anatomic and functional studies of the coronary circulation in the dog and pig. Am J Vet Res. 1959;20:18-26

11. White FC, Carroll SM, Magnet A, Bloor CM. Coronary collateral development in swine after coronary artery occlusion. Circulation research. 1992;71:1490-1500

12. Gade J, Norgaard MA, Andersen CB, Pettersson G, Svendsen UG, Olsen PS. The porcine bronchial artery: Surgical and angiographic anatomy. Journal of anatomy. 1999;194 ( Pt 2):241-247

13. Kotoulas C, Karnabatidis D, Kalogeropoulou C, Kokkinis K, Petsas T, Dougenis D. Anastomoses between bronchial and coronary circulation in a porcine model: Computed tomographic and angiographic demonstration. Hellenic journal of cardiology : HJC = Hellenike kardiologike epitheorese. 2006;47:206-210

14. Weaver ME, Pantely GA, Bristow JD, Ladley HD. A quantitative study of the anatomy and distribution of coronary arteries in swine in comparison with other animals and man. Cardiovasc Res. 1986;20:907-917

15. Sahni D, Kaur GD, Jit H, Jit I. Anatomy \& distribution of coronary arteries in pig in comparison with man. Indian J Med Res. 2008;127:564-570

16. Lumb G, Singletary HP. Blood supply to the atrioventricular node and bundle of his: A comparative study in pig, dog, and man. The American journal of pathology. 1962;41:65-75

17. van Horssen P, Siebes M, Spaan JA, Hoefer IE, van den Wijngaard JP. Innate collateral segments are predominantly present in the subendocardium without preferential connectivity within the left ventricular wall. The Journal of physiology. 2014;592:1047-1060

18. van Horssen P, van den Wijngaard JP, Brandt MJ, Hoefer IE, Spaan JA, Siebes M. Perfusion territories subtended by penetrating coronary arteries increase in size and decrease in number toward the subendocardium. American journal of physiology. Heart and circulatory physiology. 2014;306:H496-504

19. van den Wijngaard JP, Schwarz JC, van Horssen P, van Lier MG, Dobbe JG, Spaan JA, Siebes $M .3 d$ imaging of vascular networks for biophysical modeling of perfusion distribution within the heart. Journal of biomechanics. 2013;46:229-239

20. James TN, Burch GE. The atrial coronary arteries in man. Circulation. 1958;17:90-98

21. Spalteholz W. Die arterien der herzwand. Leipzig: Hirzel. 1924

22. Gensini GG, Buonanno C, Palacio A. Anatomy of the coronary circulation in living man. Coronary arteriography. Dis Chest. 1967;52:125-140

23. Tjandrawidjaja MC, Fu Y, Kim DH, Burton JR, Lindholm L, Armstrong PW. Compromised atrial coronary anatomy is associated with atrial arrhythmias and atrioventricular block complicating acute myocardial infarction. J Electrocardiol. 2005;38:271-278

24. Pardo Meo J, Scanavacca M, Sosa E, Correia A, Hachul D, Darrieux F, Lara S, Hardy C, Jatene $\mathrm{F}$, Jatene $\mathrm{M}$. Atrial coronary arteries in areas involved in atrial fibrillation catheter ablation. Circ 


\section{Anatomy of the atrial vasculature in pigs}

Arrhythm Electrophysiol.3:600-605

25. Nerantzis CE, Anninos H, Couvaris CM. The most vulnerable large atrial arteries during surgery and radiofrequency ablation of the pulmonary veins. Int J Cardiol.160:148-149

26. Yamazaki M, Avula UM, Bandaru K, Atreya A, Boppana VS, Honjo H, Kodama I, Kamiya K, Kalifa J. Acute regional left atrial ischemia causes acceleration of atrial drivers during atrial fibrillation. Heart Rhythm. 2013;10:901-909

27. Yamazaki M, Morgenstern S, Klos M, Campbell K, Buerkel D, Kalifa J. Left atrial coronary perfusion territories in isolated sheep hearts: Implications for atrial fibrillation maintenance. Heart Rhythm. 2010;7:1501-1508

28. Yano A, Igawa O, Adachi M, Miake J, Inoue Y, Ogura K, Kato M, litsuka K, Hisatome I. Left atrial branches of coronary arteries; clinical implications related to linear catheter ablation for atrial fibrillation. J Interv Card Electrophysiol. 2009;25:141-144

29. Cabrera JA, Ho SY, Climent V, Sanchez-Quintana D. The architecture of the left lateral atrial wall: A particular anatomic region with implications for ablation of atrial fibrillation. European heart journal. 2008;29:356-362

30. Paul T, Bokenkamp R, Mahnert B, Trappe HJ. Coronary artery involvement early and late after radiofrequency current application in young pigs. American heart journal. 1997;133:436-440 31. Chatelain P, Zimmermann M, Weber R, Campanini C, Adamec R. Acute coronary occlusion secondary to radiofrequency catheter ablation of a left lateral accessory pathway. European heart journal. 1995;16:859-861

32. Caldwell JC, Fath-Odoubadi F, Garratt CJ. Right coronary artery damage during cavotricuspid isthmus ablation. Pacing and clinical electrophysiology : PACE. 2010;33:e110-113

33. Raio N, Cohen TJ, Daggubati R, Marzo K. Acute right coronary artery occlusion following radiofrequency catheter ablation of atrial flutter. The Journal of invasive cardiology. 2005;17:92-93 34. Meissner A, Borchard R, Maagh P, Christ M, van Bracht M, Wickenbrock I, Trappe HJ, Plehn G. Impact of irrigated energy application on the right coronary artery hemodynamics: $\mathrm{Ffr}$ measurement in patients who underwent ablation of common type atrial flutter. J Interv Card Electrophysiol. 2008;21:35-42

35. Berton G, Cordiano R, Cucchini F, Cavuto F, Pellegrinet M, Palatini P. Atrial fibrillation during acute myocardial infarction: Association with all-cause mortality and sudden death after 7-year of follow-up. International journal of clinical practice. 2009;63:712-721

36. Kyriakidis M, Barbetseas J, Antonopoulos A, Skouros C, Tentolouris C, Toutouzas P. Early atrial arrhythmias in acute myocardial infarction. Role of the sinus node artery. Chest. 1992;101:944947

37. Pedersen OD, Bagger H, Kober L, Torp-Pedersen C. The occurrence and prognostic significance of atrial fibrillation/-flutter following acute myocardial infarction. Trace study group. Trandolapril cardiac evalution. European heart journal. 1999;20:748-754

38. Pizzetti F, Turazza FM, Franzosi MG, Barlera S, Ledda A, Maggioni AP, Santoro L, Tognoni $\mathrm{G}$, Investigators G-. Incidence and prognostic significance of atrial fibrillation in acute myocardial 


\section{CHAPTER 3}

infarction: The gissi-3 data. Heart. 2001;86:527-532

39. Shakir DK, Arafa SO. Right atrial infarction, atrial arrhythmia and inferior myocardial infarction form a missed triad: A case report and review of the literature. The Canadian journal of cardiology. 2007;23:995-997

40. Cushing EH, Feil HS, Stanton EJ, Wartman WB. Infarction of the cardiac auricles (atria): Clinical, pathological, and experimental studies. British heart journal. 1942;4:17-34

41. Wartman WB, Souders JC. Localization of myocardial infarcts with respect to the muscle bundles of the heart. Archives of pathology. 1950;50:329-346

42. Lazar EJ, Goldberger J, Peled H, Sherman M, Frishman WH. Atrial infarction: Diagnosis and management. American heart journal. 1988;116:1058-1063

43. Hudson CL, Moritz AR, Wearn JT. The extracardiac anastomoses of the coronary arteries. J Exp Med. 1932;56:919-925

44. Soderstrom. Some anatomical and functional data regarding the atria of the heart. Acta medica scandinavica. Supplementum. 1948:27-39.

45. Smith GT. The anatomy of the coronary circulation. Am J Cardiol. 1962;9:327-342

46. Petelenz T. Extracoronary blood supply of the sinu-atrial (keith-flack's) node. Cardiologia. 1965;47:57-67

47. Bjork L. Anastomoses between the coronary and bronchial arteries. Acta radiologica: diagnosis. 1966;4:93-96

48. Moberg A. Anastomoses between extracardiac vessels and coronary arteries. Acta Med Scand Suppl. 1968;485:5-26

49. Hromada J, Voboril Z. Arteries of cardiac atria in man. Folia Morphol (Praha). 1970;18:308321

50. Williams PL, Warwick R, Dyson M, Bannister L. Gray's anatomy. 1989

51. Hetzer R, Warnecke H, Wittrock H, Engel HJ, Borst HG. Extracoronary collateral myocardial blood flow during cardioplegic arrest. The Thoracic and cardiovascular surgeon. 1980;28:191-196 52. Riquet M, Dupont P, Briere J, Weber S, Hidden G, Debesse B. Anastomoses between bronchial and coronary arteries: Incidence of atheroma. Surgical and radiologic anatomy : SRA. 1991;13:349-351

53. Bolling SF, Kanter KR, Flaherty JT, Gott VL, Gardner TJ. Identification and control of noncoronary collateral blood flow. The Annals of thoracic surgery. 1984;38:232-236

54. Crystal GJ, Downey HF, Bashour FA. Evaluation of noncoronary sources of left ventricular perfusion to intercoronary collateral-dependent myocardium due to chronic major vessel occlusion: Absent contribution of luminal and extracardiac channels. American heart journal. 1981;102:841845 


\section{Atrial supply-demand balance in healthy adult pigs: Coronary blood flow, oxygen extraction and lactate production during acute atrial fibrillation \\ acute atrial fibrillation}

\section{4}

Kelly van Bragt

Hussein M. Nasrallah

Marion Kuiper

Joost J. Luiken

Ulrich Schotten

Sander Verheule
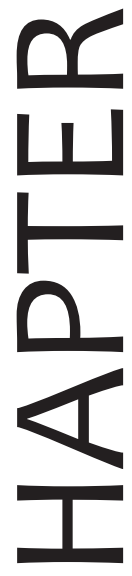

\section{Sander Verheule}

Cardiovasc Res. 2014 Jan 1;101(1):9-19 


\section{ABSTRACT}

AIMS: Little is known about how atrial oxygen supply responds to increased demand, and under which conditions it falls short (supply-demand mismatch). Here, we have investigated the vasodilator response, oxygen extraction and lactate production of the left atrium (LA) and left ventricle (LV) in response to atrial pacing and atrial fibrillation (AF).

METHODS AND RESULTS: Series A ( $\mathrm{n}=9$ Dutch landrace pigs) was instrumented to measure LA and LV vascular conductance in branches of the circumflex artery. Coronary conductance reserve (CCR) was calculated as the ratio between conductance during adenosine infusion and baseline. Series $B(n=7)$ was instrumented with sampling catheters in LA and LV veins for determination of blood gases and lactate levels. LA CCR $(1.76 \pm 0.14)$ was significantly lower than LV CCR (3.16 $\pm 0.27, P=0.002)$. However, basal oxygen extraction was lower in LA $(27 \pm 3 \%)$ than that in the $L V(58 \pm 6 \%, P=0.0006)$, indicating a larger extraction reserve in the $L A$ than that in the LV $(4.68 \pm 0.84 \mathrm{Vs} .1 .88 \pm 0.26, \mathrm{P}=0.01)$. Atrial pacing caused an increase in LA conductance (Series A) and oxygen extraction (Series B). AF increased LA vascular conductance to $177 \pm 14 \%$ at $1 \mathrm{~min}, 168 \pm 14$ at $5 \mathrm{~min}$, and $164 \pm 31 \%$ at $10 \mathrm{~min}$ of $A F(P$ $<0.05 \mathrm{vs}$. baseline). Atrial oxygen extraction also increased from $26 \pm 3 \%$ at baseline to $63 \pm 5 \%(P<0.01)$ at $5 \mathrm{~min}$ and $60 \pm 11 \%(P<0.01)$ at $10 \mathrm{~min}$ of AF. Arterio-venous lactate difference increased significantly $(P=0.02)$ during $A F$.

CONCLUSIONS: In healthy pigs, the LA has a lower CCR, but a higher extraction reserve compared to the LV. Although both reserves were recruited during AF, atrial lactate production increased significantly. 


\section{INTRODUCTION}

Atrial fibrillation (AF) is a common arrhythmia characterized by a fast and irregular activation of the atria. During acute AF, the fast rates of excitation and contraction are likely to increase atrial energy and oxygen demand. In sinus rhythm, the atria receive $5 \%$ of coronary blood flow, and AF increases atrial coronary blood flow ${ }^{1-8}$. However, it is not known whether this increase in atrial supply is sufficient to meet increased atrial demand. If this supply would be insufficient to meet demand, atrial supply-demand ischemia would ensue. Indirect evidence for supply-demand ischemia are decreased atrial phosphocreatine levels and transiently increased expression of $\mathrm{HIF}_{1 \mathrm{a}}$ in the first weeks of AF in a goat model 9, 10. In addition, the atrial structural changes after months of AF are very similar to hibernating ventricular myocardium due to low-flow ischemia ${ }^{11}$.

Here, we have studied the supply-demand balance by investigating the regulation of oxygen supply (coronary flow, oxygen extraction) and lactate production during short periods of increased atrial demand (atrial pacing and AF) in normal healthy adult pigs. Recruitment of coronary conductance reserve and extraction reserve during these interventions are the main determinants of oxygen supply due to increased demand. We report that the LA has a lower CCR than the LV, but a higher extraction reserve. Conductance and extraction ratio are both increased during short-term atrial pacing and AF to meet the increase in LA oxygen consumption. Vascular conductance and oxygen extraction ratio increased less in the LV than in the LA. There is an increase in LA arterio-venous lactate difference during short term AF, despite the recruitment of both the conductance and extraction reserve, indicating supply-demand ischemia during acute AF. This mismatch could form an important trigger for the slower processes of electrical and structural remodeling that have been observed in animal models of AF and in AF patients.

\section{METHODS}

\subsection{Animal model}

Healthy Dutch Landrace pigs weighing $62 \pm 2 \mathrm{~kg}$ were used. All animal procedures were in accordance with national and institutional guidelines and approved by the lo- 


\section{CHAPTER 4}

cal ethical committee. For open chest sacrifice experiments, anesthesia was induced with Zoletil (5-8 mg/kg I.M.) and Thiopenthal (5-15 mg/kg I.V.) and maintained with Midazolam (1.0 mg/kg/h I.V.), Sufentanyl (4 mg/kg/h I.V.) and Propofol (10 mg/kg/h I.V.). After intubation and the start of mechanical ventilation, a left lateral incision was made, the $5^{\text {th }}$ rib removed and the pericardium opened to expose the left side of the heart for further instrumentation.

\subsection{Series A: Coronary flow}

In a first group of animals ( $n=9$ ), we determined LA and LV coronary conductance reserve $(C C R)$ and the recruitment of this reserve during an increase in atrial pacing and acute AF. Doppler flow probes were placed around a LA and LV branch of the left circumflex artery ( $L C X)$, as depicted schematically in Figure $1 \mathrm{~A}$. An example of the atrial branches of the $L C x$ is given in Figure $1 B$ and $1 C$. To calculate vascular conductance, pressures in the right atrium $\left(\mathrm{P}_{\mathrm{RA}}\right)$ and aorta $\left(\mathrm{P}_{\mathrm{AO}}\right)$ were measured using a Millar microtip pressure sensor (Millar Instruments, Houston, $T X$ ) and a Sentron pressure catheter (Sentron Europe BV, Roden, The Netherlands) respectively. Maximal conductance was measured by infusion of adenosine via a JR6 catheter (Cordis Corporation,Bridgewater, $\mathrm{N} J$ ) in the left main coronary artery. $\mathrm{A} 10 \mathrm{ml}$ bolus with an adenosine concentration of $300 \mu \mathrm{g} / \mathrm{ml}$ was given to induce maximal dilatation. Adenosine was administered in increasing concentrations to make sure that the maximal effect was reached. Coronary conductance was calculated as flow divided by the pressure difference across the vascular bed (i.e. between $\mathrm{P}_{\mathrm{AO}_{0}}$ and $\mathrm{P}_{\mathrm{RA}}$ ):

$$
\begin{aligned}
& C_{L A}=Q_{L A} /\left(P_{A 0}-P_{R A}\right) \\
& C_{L V}=Q_{L V} /\left(P_{A 0}-P_{R A}\right)
\end{aligned}
$$

Maximal conductance ( $\left.\mathrm{C}_{\mathrm{MAX}}\right)$ was calculated as conductance during intracoronary adenosine infusion ( $\left.C_{\text {Adenosine }}\right)$ minus the effect of the injection itself ( $\Delta$ Saline $=C_{\text {Saline }}$ - $C_{\text {Baseline}}$ ). In addition, the corrected coronary conductance reserve (CCR) was calculated as $C_{\text {MAX }}$ divided by $C_{\text {Baseline }}$ (Figure 2B).

$$
\begin{gathered}
C_{\text {MAX }}=C_{\text {Adenosine }}-\Delta \text { Saline } \\
C C R=C_{\text {MAX }} / C_{\text {Baseline }}
\end{gathered}
$$




\subsection{Series B: Oxygen extraction and lactate levels}

A second set of experiments $(n=7)$ was performed to determine extraction reserve and lactate production. Instrumentation is shown schematically in Figure 1D and $1 \mathrm{E}$. Arterial blood was sampled from the LV through a dual Ao/LV Millar pressure catheter (Millar Instruments, Houston, TX). LV venous blood was sampled through an I.V. cannula (Braunule, Braun, Melsungen, Germany) that was introduced into a LV vein in the perfusion territory of the LCx. To sample venous blood from the LA, the coronary sinus (CS) was closed off around an atrial vein, creating a small 'sampling pocket' in the CS. A venous sampling catheter (B Braun, Melsungen, Germany) was introduced in the CS pocket. Any ventricular veins ending in the CS pocket were closed off to ensure that the pocket only contained atrial venous blood. The atrial venous blood collected in this CS pocket drains the part of the LA appendage and free wall similar to the area supplied by the atrial arteries measured in series $A$. An example of a left atrial vein draining into the CS is shown in Figure $1 \mathrm{~F}$. To avoid venous congestion in the ventricles, the great cardiac vein was bypassed to a sheet in the jugular vein. Blood gas analysis was performed on these samples on an i-Stat analyzer (Abbott Laboratories, Illinois, U.S.A). Values were obtained for $\mathrm{pH}$, partial arterial and venous oxygen pressure $\left(\mathrm{PO}_{2}\right)$, partial carbon dioxide pressure $\left(\mathrm{PCO}_{2}\right)$, hemoglobin $(\mathrm{Hb})$ concentration and arterial and venous oxygen saturation $\left(\mathrm{SO}_{2}\right)$. Blood lactate concentration was measured in the same blood samples using a Lactate SCOUT+ (Senslab $\mathrm{GmbH}$, Leipzig, Germany). Arterial and venous total oxygen content $\left(\mathrm{CaO}_{2}\right.$ and $\left.\mathrm{CvO}_{2}\right)$ were calculated using the following formula:

Total oxygen content $\left(\mathrm{ml} \mathrm{O}_{2} / 100 \mathrm{ml}\right)=$ oxygen bound to $\mathrm{Hb}$

$$
\begin{aligned}
& \text { + oxygen dissolved in plasma } \\
& =\left(1.36\left(\mathrm{ml} \mathrm{O}_{2} / \mathrm{g} \mathrm{Hb}\right) \times \mathrm{SO}_{2} \times \mathrm{Hb}(\mathrm{g} / 100 \mathrm{ml})\right) \\
& +\left(0.0031 \mathrm{ml} \mathrm{O}_{2} / 100 \mathrm{ml} / \mathrm{mmHg} \times \mathrm{PO}_{2}(\mathrm{mmHg})\right)
\end{aligned}
$$

Oxygen extraction was calculated as the difference between arterial and LA or LV venous oxygen saturation:

$$
\text { Oxygen extraction }(\%)=\left(\mathrm{CaO}_{2}-\mathrm{CvO}_{2}\right) / \mathrm{CaO}_{2} * 100
$$




\section{CHAPTER 4}

The extraction reserve was determined from the arterial oxygen saturation divided by the baseline LA and LV oxygen extraction:

$$
\text { Extraction reserve }=\mathrm{CaO}_{2} /\left(\mathrm{CaO}_{2}-\mathrm{CvO}_{2}\right)
$$

\subsection{Interventions}

In both series $A$ and $B$, measurements were performed during normal sinus rhythm (NSR), right atrial pacing at a basic cycle lengths (BCL) of 500, 450 and $400 \mathrm{~ms}$ and during acute AF maintained by burst pacing (10 $\mathrm{min}$ ). An ablation catheter (RFmarinr, Medtronic Inc, Minnesota, MA, USA) was placed in the RA for pacing and AF induction.

\subsection{Statistics}

The effect of different pacing cycle lengths on conductance and blood gas parameters was investigated at different time points using a two-way ANOVA, with a Bonferroni post-hoc test to compare the mean during pacing with the mean before pacing. For the parameters during AF, a one-way ANOVA was performed for 3 different time points. A post-hoc test (Dunnett's multiple analysis comparison) was performed to compare the values at each time point to baseline values. All measurements during the interventions were compared to a baseline value obtained just before the intervention. To determine differences between basal atrial and ventricular parameters, a paired Student's t-test was performed. To determine the difference between LA and LV during the interventions, a two-way ANOVA was used. P-values smaller than 0.05 were considered significant.

\section{RESULTS}

\subsection{Series A: Coronary vascular conductance}

Corrosion casts of the coronary vasculature show a dense capillary bed in the atrial wall (Figure $1 B$ ). In the LA, this network is supplied by branches of the $L C x$. In series $A$, flow in LA and LV branches of the LCX artery was measured using Doppler flow 


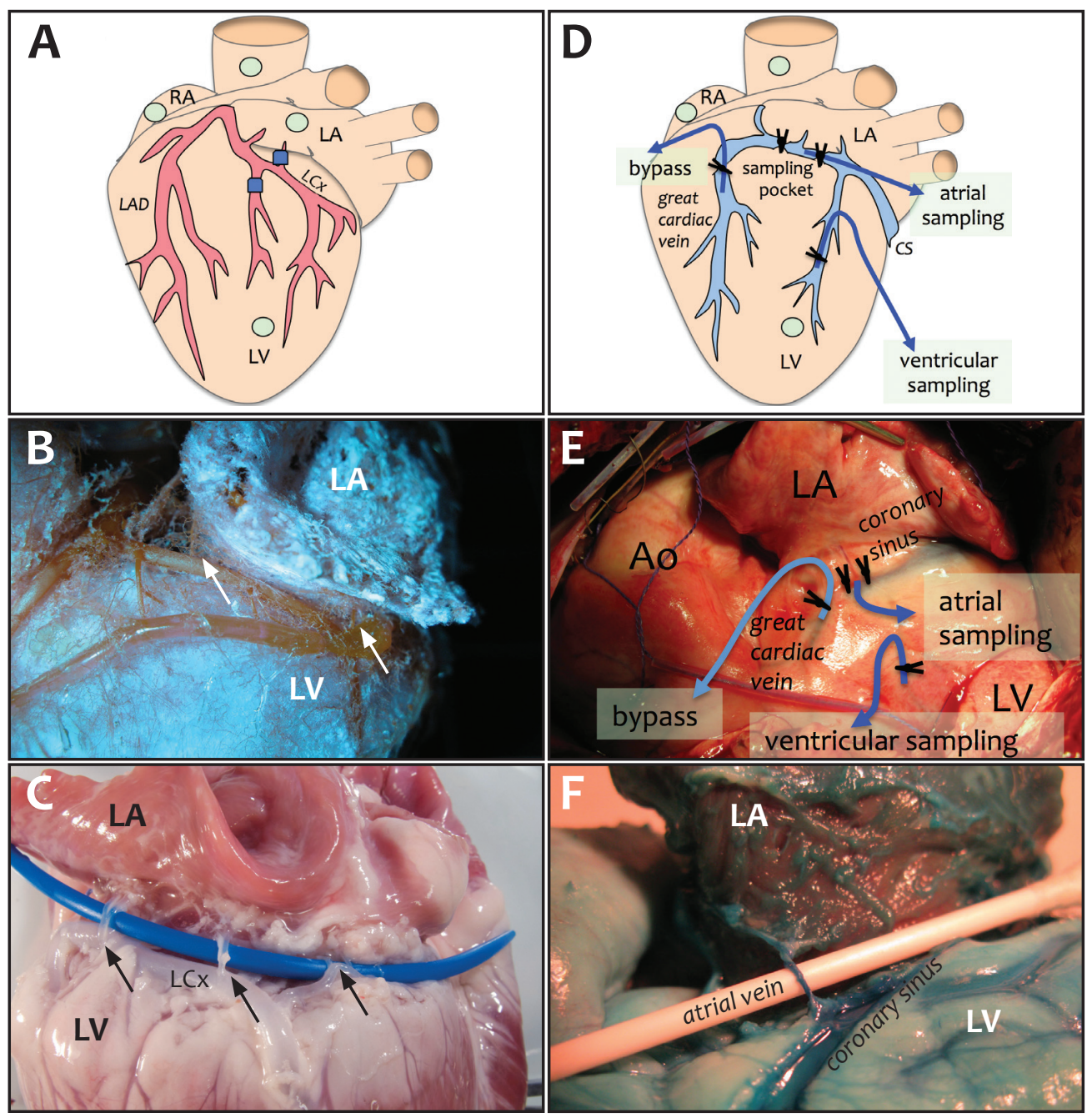

Figure 1: Vascular anatomy and instrumentation. $L A=l$ eft atrium, $R A=$ right atrium, $L V=$ left ventricle, LCX = left circumflex artery, LAD= left anterior descending artery, CS=Coronary sinus A) Schematic representation of the instrumentation during experiment series $A$. Arteries in red, dark blue squares indicate Doppler flow probes, green circles indicate pressure catheters. B) Corrosion cast of coronary vasculature, using Batson's \#17 resin (Polysciences Inc, Warrington PA) injected into the aorta of explanted heart. Atrial arteries indicated with arrows. C) Dissected preparation of LA arteries (arrows). D) Schematic representation of the instrumentation during experiment series $B$. Veins in blue. E) In situ example of instrumentation during experiment series B. F) Dissected preparation of a LA vein draining into the $C S$. 

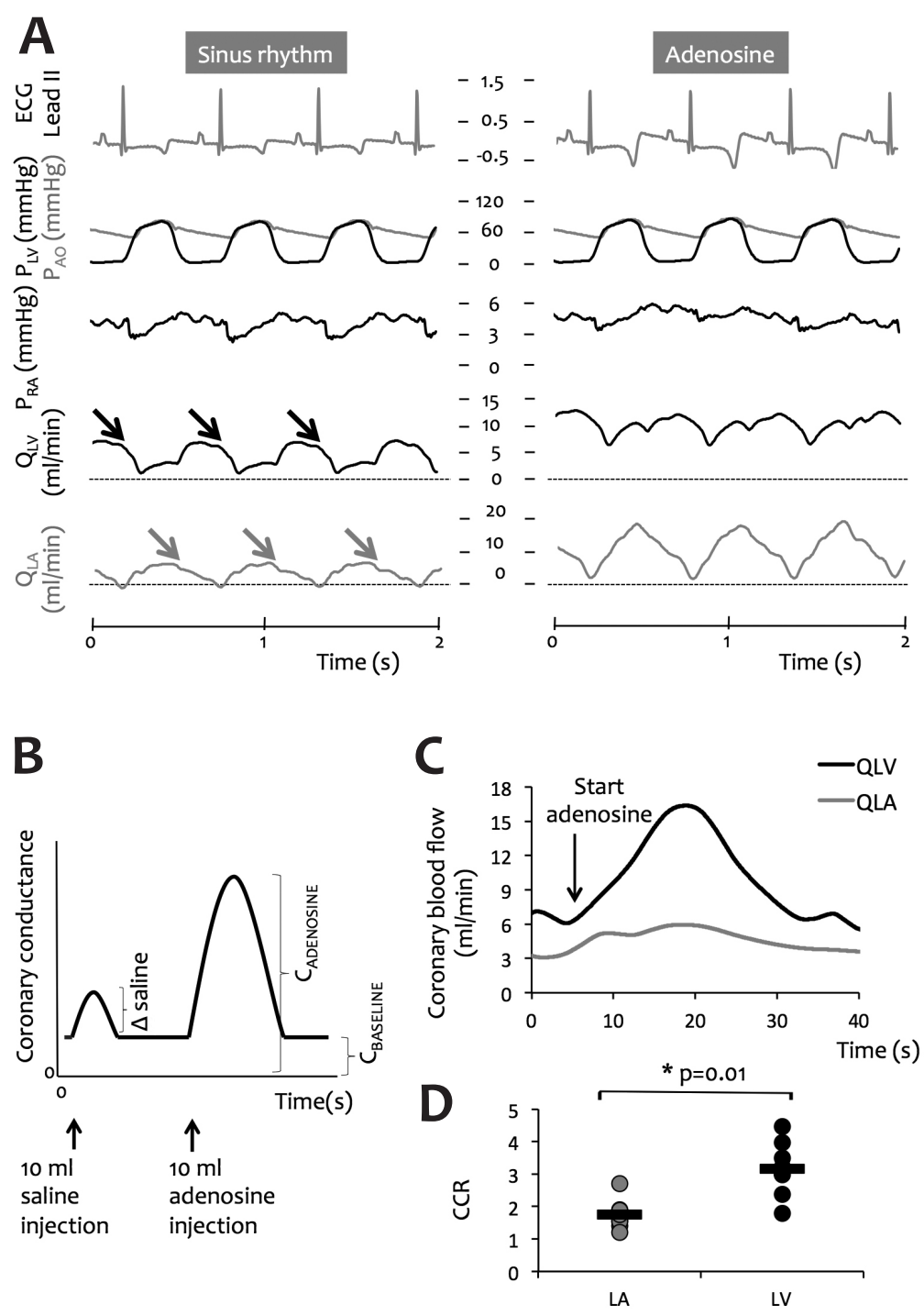

Figure 2: Determination of flow reserve. $A)$ Left ventricular $\left(P_{L V}\right)$ and aortic $\left(P_{A 0}\right)$, left atrial $\left(P_{L A}\right)$ and right atrial $\left(P_{R A}\right)$ pressure, left ventricular $\left(Q_{L V}\right)$ and left atrial $\left(Q_{L A}\right)$ Doppler flow during NSR and adenosine infusion. Arrows indicate the effect of LV (black) and LA (grey) systole on the phasic blood flow pattern. B) For the determination of the coronary conductance reserve (CCR), maximal flow and conductance are corrected for the effect of injection itself ( $\Delta$ saline). C) Average Doppler flow in a LA and LV branch of the circumflex artery during adenosine infusion. The phasic pattern of the cardiac cycle was eliminated using a 10-level wavelet filter, thereby deriving average flow. D) Left atrial and ventricular CCR for all animals in series $A(n=9)$. 
probes. Flow during normal sinus rhythm (NSR) averaged $3.62 \pm 0.86 \mathrm{ml} / \mathrm{min}$ for LA and $6.31 \pm 0.50 \mathrm{ml} / \mathrm{min}$ for LV branches, corresponding to a vascular conductance of $0.05 \pm 0.01 \mathrm{ml} / \mathrm{min} / \mathrm{mmHg}$ and $0.09 \pm 0.01 \mathrm{ml} / \mathrm{min} / \mathrm{mmHg}$, respectively.

The atrial flow pattern showed a consistent decrease during the atrial contraction (grey arrows in Figure $2 \mathrm{~A}$ ), similar to the decrease in LV flow during the ventricular contraction (black arrows in Figure 2A). In most cases, flow in LA arteries reversed (i.e. became negative) during atrial contraction. Because of the asynchrony between atrial and ventricular contraction, the atrial and ventricular flow signals were out of phase.

Intracoronary injection of a bolus of adenosine led to a transient, dose-dependent increase in coronary flow (Figure $2 \mathrm{~B}$ and $2 \mathrm{C}$ ). The maximum flow during adenosine infusion, corrected for the small increase observed during infusion of saline, was used to determine the maximal vascular conductance $\left(C_{M A X}\right)$ and coronary conductance reserve (CCR). The calculated CCR (Figure 2D) was significantly lower in the LA (1.76 \pm 0.14$)$ than in the $\operatorname{LV}(3.16 \pm 0.27, p=0.002)$.

Coronary flow was also measured during right atrial pacing at different pacing rates. An example of LA and LV flow signals during pacing is shown in Figure $3 \mathrm{~A}$ (right panel). An increase in rate causes a change in the phasic pattern of LA and LV flow, and an increase in average LA and LV flow. During atrial pacing, LA and LV coronary flow (Figure $3 \mathrm{~B}$ ) reached a steady state within $30 \mathrm{~s}$ and the response in coronary conductance was calculated at 1 min after the start of pacing. In the LA, a clear frequency-dependent increase in conductance was seen (Figure $3 C$ ). Both at $450 \mathrm{~ms}(135 \pm 9 \%$, $\mathrm{p}<0.001)$ and at $400 \mathrm{~ms}(143 \pm 9 \%, \mathrm{p}<0.001)$, LA vascular conductance was significantly increased compared to baseline. Pacing significantly increased LV conductance at all rates (Figure $3 \mathrm{C}$ ). The increase in LA vascular conductance was significantly larger than the increase in LV conductance at $450 \mathrm{~ms}$ and $400 \mathrm{~ms}$ ( $\mathrm{p}<0.05 \mathrm{LA}$ vs LV).

Calculated as \% of $C_{\text {MAX }}$ (Figure $3 C$ ), there was an overall effect of right atrial pacing on LA ( $p=0.007)$ and LV ( $p=0.03)$ conductance. LA conductance reached approximately $55 \%$ of maximal conductance at baseline, which was significantly higher that the ventricle (approx. $33 \%$ of $C_{\text {MAX }}, \mathrm{p}<0.01$ ). In addition, LA conductance was significantly higher during all $B C L s$ as well. Thus, the LA used significantly more of the conductance reserve at every $B C L$ than the $L V(p<0.001)$.

Flow during $A F$ was measured for 10 min (Figure $4 A$ ). $A F$ resulted in a significant decrease in $\mathrm{P}_{\mathrm{Ao}}$ after 5 min of $\mathrm{AF}$ (Figure $4 \mathrm{~B}$, left panel). The effect of AF on aortic and 
A

岃离
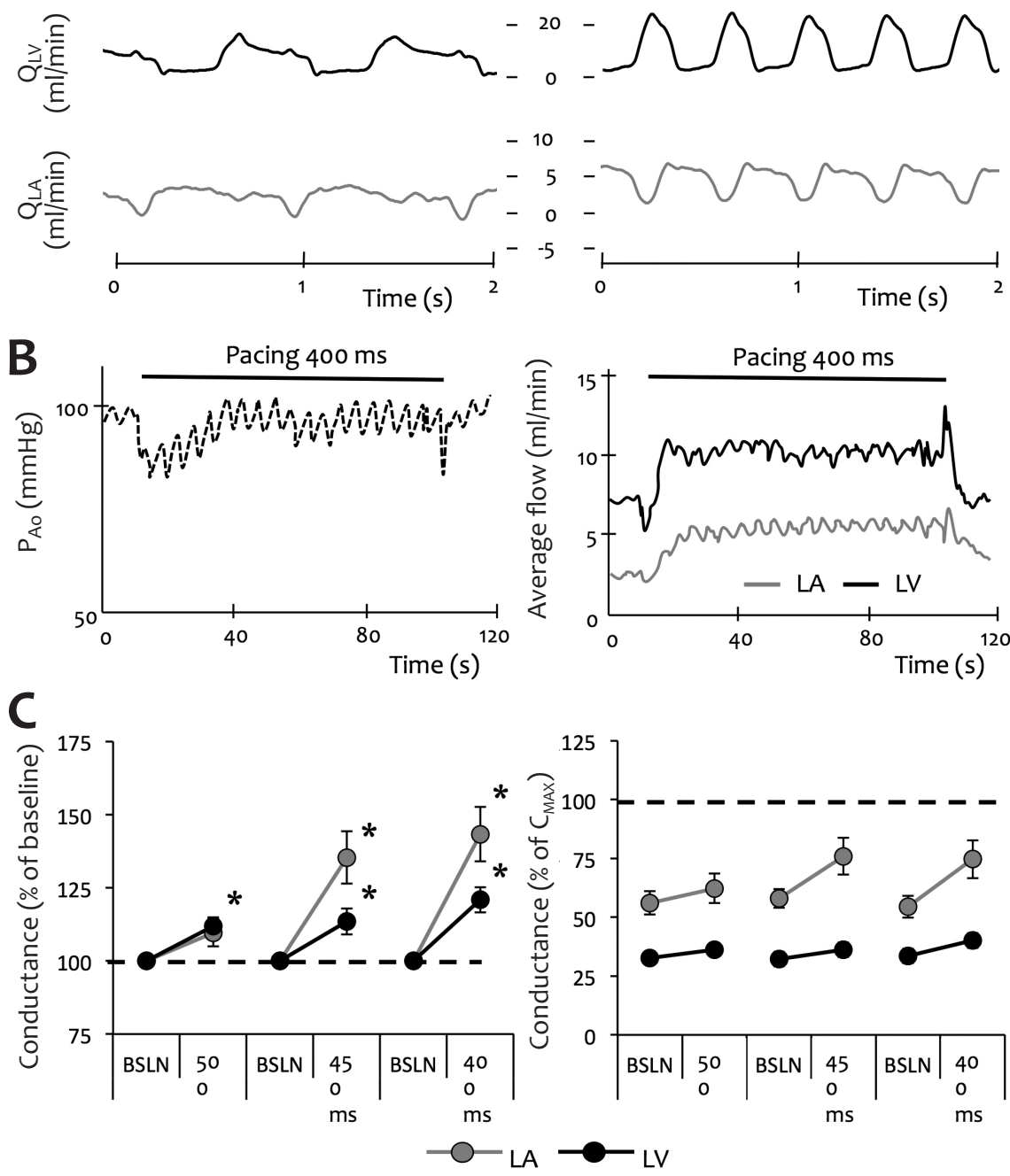

Figure 3: Coronary flow and conductance during pacing. A) ECG lead II and LA and LV Doppler flow patterns during NSR (left) and right atrial pacing at a BCL of $400 \mathrm{~ms}$ (right). B) Mean aortic pressure (left) and Doppler flow for LA and LV (right) at $400 \mathrm{~ms} \mathrm{BCL.} \mathrm{C)} \mathrm{LA} \mathrm{and} \mathrm{LV} \mathrm{conductance} \mathrm{at} \mathrm{different}$ BCLs expressed as \% of baseline conductance (left, $n=9)$ and \% of maximal conductance $\left(C_{\text {MAX }}, n=8\right)$ (right). Values \pm SEM. * $\mathrm{p}<0.05$ intervention vs baseline. 


\section{A Sinus rhythm Atrial fibrillation}
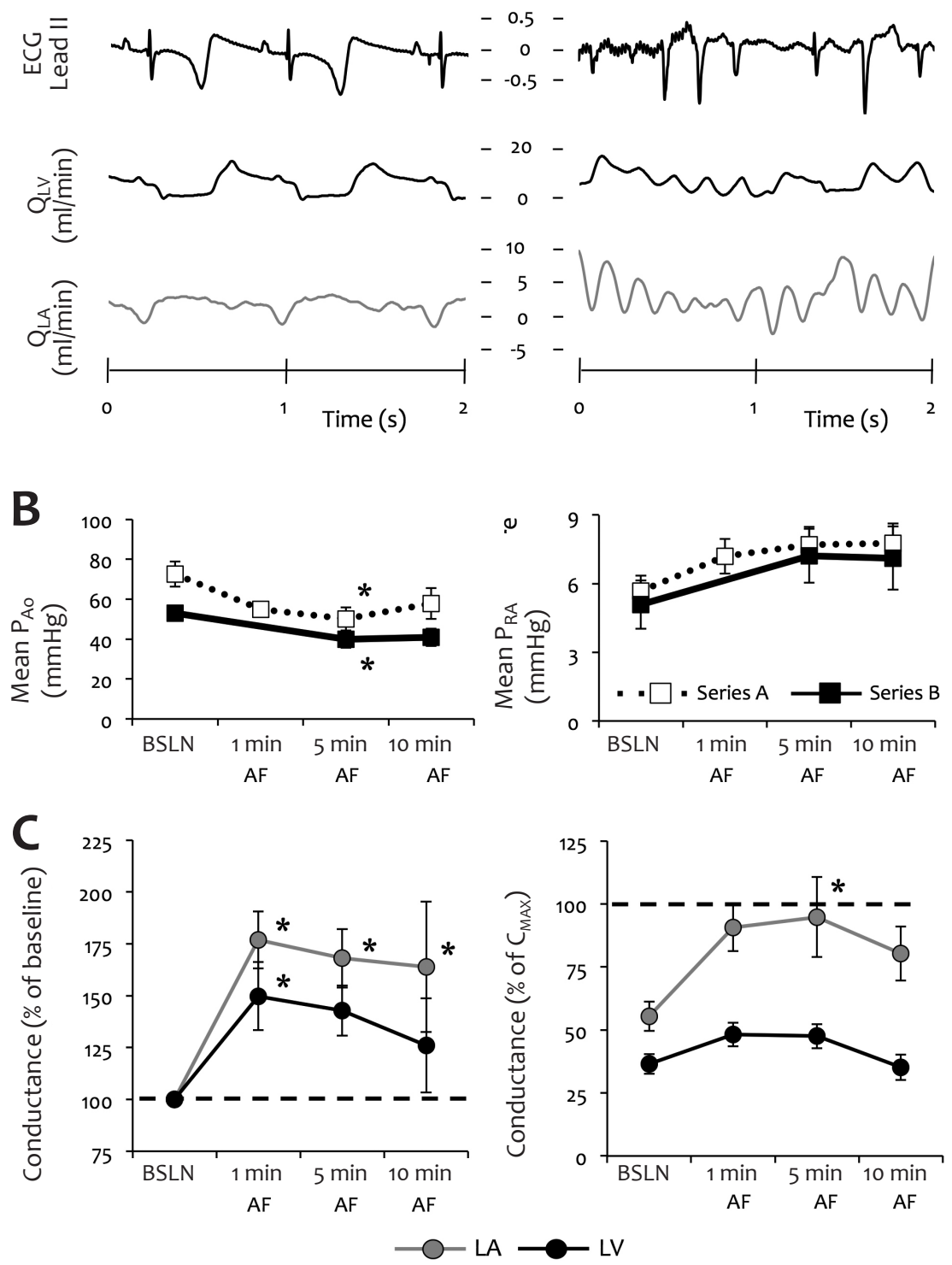

Figure 4: Coronary flow and conductance during AF. A) ECG lead II and LA and LV Doppler flow patterns during NSR (left) and AF (right). $B$ ) Mean aortic pressure ( $\mathrm{P}_{\mathrm{Ao}}$, left) and right atrial pressure ( $P_{R A}$, right) for series $A$ and $B$ during $A F$. C) LA and LV conductance during $A F$ expressed as \% of baseline conductance (left, $n=9$ ) and \% of maximal conductance $\left(C_{\operatorname{MAX}}\right)$ (right, $\left.n=8\right)$. Values $\pm S E M$. * $\mathrm{p}<0.05$ intervention vs baseline. 


\section{CHAPTER 4}

right atrial pressures was similar between series A and B. (Figure 4B). AF caused a rapid rise in $L A$ conductance ( $p=0.02$, Figure $4 C$, left panel), with a significant increase to $177 \pm 14 \%$ at $1 \mathrm{~min}, 168 \pm 14 \%$ at $5 \mathrm{~min}$ and $164 \pm 31 \%$ at $10 \mathrm{~min}$ of $A F$ ( $p<0.05$ vs baseline). In the ventricle, the overall effect of AF on vascular conductance as \% of baseline was not significant ( $p=0.07$ n.s.). However, at $1 \mathrm{~min}$ of AF, LV conductance was significantly higher than baseline $(P<0.05)$. No significant effect of AF was found on LA $(p=0.07)$ or LV $(p=0.1)$ conductance expressed as \% of $C_{\text {MAX }}$. LA conductance approached $C_{\text {MAX }}$ (Figure $4 C$, right panel) by $91 \pm 9 \%$ (n.s.), $95 \pm 16 \%$ ( $p=<0.05$ vs baseline) and $80 \pm 11 \%$ (n.s.) at 1,5 and 10 min of AF, respectively. In contrast, LV conductance did not even reach half of its $C_{\text {MAX }}$ at the same time point of AF. Thus, the LA used a substantially larger part of the conductance reserve than the LV at every time point during $A F(p<0.01)$.

\subsection{Series B: Oxygen extraction and lactate levels}

LA venous oxygen saturation was higher at baseline compared to the LV $(74 \pm 3 \%$ vs $43 \pm 7 \%$ respectively, $\mathrm{p}<0.001)$. Correspondingly, the extraction reserve was larger in the LA than in the LV $(4.68 \pm 0.84$ vs $1.88 \pm 0.26, p=0.01)$. The same interventions as in series $A$ were used to establish to which extent this reserve in oxygen extraction was utilized.

Venous blood gas analysis was performed during pacing. There were no significant overall effects on venous and arterial $\mathrm{PO}_{2}$ and $\mathrm{PCO}_{2}$ (Figure $5 \mathrm{~A}$ and $5 \mathrm{~B}$ ). However, atrial venous $\mathrm{PO}_{2}$ decreased significantly at $400 \mathrm{~ms} \mathrm{BCL}$ from $38 \pm 7 \mathrm{mmHg}$ at baseline to $24 \pm 6 \mathrm{mmHg}$ at $5 \mathrm{~min}$ and to $28 \pm 6 \mathrm{mmHg}$ at $10 \mathrm{~min}$ of pacing (Figure $5 \mathrm{~A}$ ). LA total oxygen concentration ( $\mathrm{CvO} 2$ ), but not $\mathrm{LV} \mathrm{CvO}_{2}$ or $\mathrm{CaO}_{2}$, showed a frequency-dependent decrease (data not shown). LA extraction ratio was strongly increased at $400 \mathrm{~ms}$ pacing from $25 \pm 5 \%$ before pacing to $55 \pm 12 \%$ at $5 \mathrm{~min}(\mathrm{p}<0.05)$ and $53 \pm 9 \%(\mathrm{p}<0.05)$ at 10 min of pacing (Figure $5 \mathrm{C}$ ). $\mathrm{LV} \mathrm{O}_{2}$ extraction remained unchanged during pacing at all BCLs.

During AF, LA venous $\mathrm{PO}_{2}$ significantly decreased at the $5 \mathrm{~min}$, but not the 10 min time point (Figure $5 A$ ). AF resulted in a significant increase in $L A$ venous $\mathrm{PCO}_{2}$ after 10 min (Figure $5 \mathrm{~B}$ ), rising from $43 \pm 2 \mathrm{mmHg}$ at baseline to $58 \pm 4 \mathrm{mmHg}$ ( $\mathrm{p}<0.05$ vs NSR). LV venous and arterial $\mathrm{PO}_{2}$ and $\mathrm{PCO}_{2}$ remained statistically unaltered during $\mathrm{AF}$. A large decrease in $\mathrm{LA} \mathrm{CvO}_{2}$ was seen from $10.9 \pm 0.5 \mathrm{ml} \mathrm{O}_{2} / 100 \mathrm{ml}$ just before $A F$ induction to $5.0 \pm 0.7 \mathrm{ml} \mathrm{O}_{2} / 100 \mathrm{ml}$ at $5 \mathrm{~min}(\mathrm{p}<0.01)$ and $5.8 \pm 1.7 \mathrm{ml} \mathrm{O}_{2} / 100 \mathrm{ml}$ at $10 \mathrm{~min}$ of $\mathrm{AF}$ 

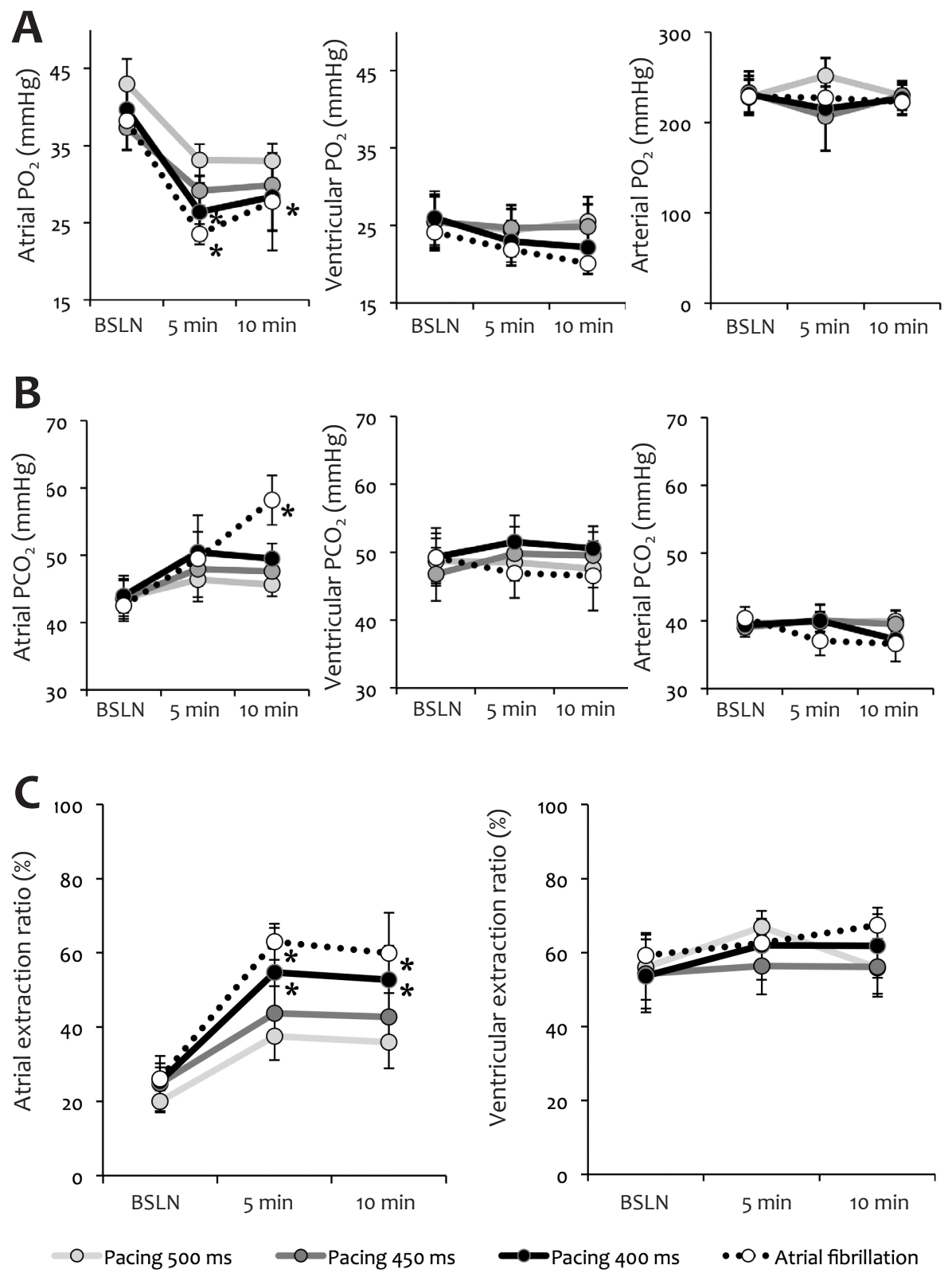

Figure 5: Blood gas analysis during pacing and AF. A) LA venous, LV venous and arterial partial oxygen pressure $\left(\mathrm{PO}_{2}\right)$ and $B$ ) carbon dioxide pressures $\left.\left(\mathrm{PCO}_{2}\right) \mathrm{C}\right) \mathrm{LA}$ and $\mathrm{LV}$ oxygen extraction ratio $(n=6)$ during pacing at a $B C L$ of 500,450 and $400 \mathrm{~ms}$ and during AF. Values \pm SEM. ${ }^{*} p<0.05$ intervention vs NSR. 
A
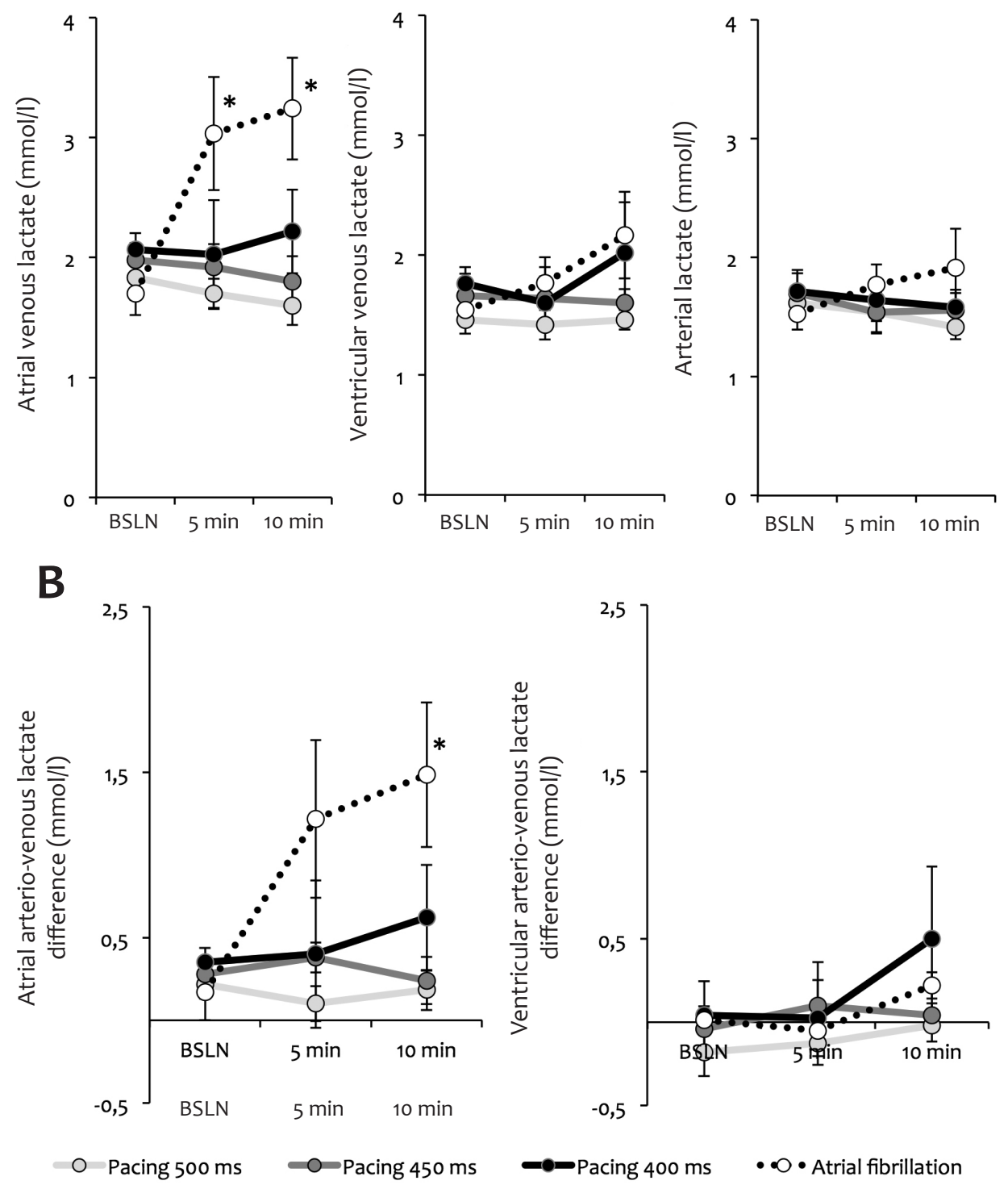

Figure 6: Lactate levels. A) LA venous, LV venous and arterial lactate concentration and B) arterio-venous concentration difference during pacing at a $\mathrm{BCL}$ of 500,450 and $400 \mathrm{~ms}$ and during $\mathrm{AF}$ $(n=6)$. Values \pm SEM. * $p<0.05$ intervention vs NSR. 
$(p<0.01$, data not shown). Correspondingly, LA oxygen extraction ratio was high during $A F$ (Figure $5 C$ ), increasing significantly from $26 \pm 3 \%$ at baseline to $63 \pm 5 \%(p<0.01)$ at $5 \mathrm{~min}$ and $60 \pm 11 \%(\mathrm{p}<0.01)$ at $10 \mathrm{~min}$ of AF. AF did not change LV extraction ratio. In summary, LA oxygen extraction reserve was recruited to a considerable degree both during pacing at $400 \mathrm{~ms}$ and during $\mathrm{AF}$.

During NSR, LA venous blood lactate concentration was comparable to LV venous lactate concentration $(1.7 \pm 0.2 \mathrm{mmol} / \mathrm{L}$ vs $1.4 \pm 0.1 \mathrm{mmol} / \mathrm{L}, \mathrm{p}=0.11)$. Arterial lactate concentration was $1.5 \pm 0.1 \mathrm{mmol} / \mathrm{L}$. Myocardial arterio-venous lactate difference shows that little lactate is produced or consumed by either the LA or LV during NSR.

Pacing did not significantly affect venous or arterial lactate levels (Figure 6A).

AF caused atrial venous lactate levels to increase from $1.7 \pm 0.2 \mathrm{mmol} / \mathrm{L}$ before $A F$ to $3.0 \pm 0.5 \mathrm{mmol} / \mathrm{L}$ at $5 \mathrm{~min}$ and $3.2 \pm 0.4 \mathrm{mmol} / \mathrm{L}$ at $10 \mathrm{~min}$ of $\mathrm{AF}$ without an increase in ventricular venous or arterial lactate levels (Figure 6A). The LA arterio-venous lactate difference showed a significant increase at $10 \mathrm{~min}$ of $A F$ (from $0.2 \pm 0.2 \mathrm{mmol} / \mathrm{L}$ to $1.5 \pm 0.4 \mathrm{mmol} / \mathrm{L}, \mathrm{p}<0.05 \mathrm{vs} \mathrm{NSR}$, Figure $6 \mathrm{~B}$ ), but it remained unchanged in the LV during 10 min of AF. Thus, despite the recruitment of the LA conductance and extraction reserve, lactate is produced in the LA during acute AF.

\section{DISCUSSION}

Because of its obvious relevance to ischemic heart disease, the ventricular vasculature has been extensively studied. In comparison, very little is known about atrial vasculature and atrial balance between oxygen supply and demand.

Most of our knowledge of the regulation of atrial coronary flow derives from experiments on dogs. However, both in (ventricular) coronary flow regulation and vascular anatomy, pigs are more similar to humans than dogs are ${ }^{12-16}$.

In this study, we investigate the recruitment of coronary conductance reserve and oxygen extraction reserve of the left atrium and ventricle during pacing and $A F$ in anesthetized healthy pigs.

\subsection{Coronary vascular conductance}

The coronary conductance reserve was larger in the LV $(3.16 \pm 0.27)$ than the LA $(1.76 \pm 0.14)$. An increase in RA pacing rate and acute AF resulted in a stronger 


\section{CHAPTER 4}

increase in coronary conductance in the LA than in the LV. As a result, the LA came closer to its conductance reserve during these interventions than the LV. Our data in series $A$ agree with earlier findings in dogs showing that an increase in atrial rate caused an increase in atrial myocardial blood flow ${ }^{1,2,8,17}$. In dogs, atrial blood flow increased by a factor 1.5 to 3 during the first minutes of $\mathrm{AF}^{1,2,8,17}$. Ventricular myocardial blood flow in dogs was not significantly or only slightly increased due to AF, despite an increase in ventricular rate ${ }^{1,2,8}$.

\subsection{Oxygen extraction and lactate production}

Few data are available on atrial oxygen consumption and extraction in animal models, and none in humans. In a study in dogs, Wichmann et al reported that AF caused a decrease in coronary sinus (CS) oxygen saturation from $26 \pm 2 \%$ to $22 \pm 1 \%$, but the specific contributions for LA and LV could not be determined ${ }^{18}$. Using a microspectrophotometric technique on frozen vessels, White et al determined the atrial venous and arterial oxygen saturation in tissue samples from anesthetized dogs 1. They reported an arterial oxygen saturation of $87 \pm 1.5 \%$ and an atrial venous saturation of $61 \pm 1 \%$, corresponding to an LA extraction of approximately $26 \%$. Acute AF in the anesthetized dogs caused a slight increase in atrial oxygen extraction to approximately $31 \%{ }^{1}$.

Our technique of collecting venous blood samples allows taking repeated samples under various conditions and conventional blood gas analysis. For the LV we found comparable extraction values to other studies in dogs under anesthesia (approximately $60 \%)^{19}$. Oxygen extraction ratio during NSR was lower in the LA $(25 \pm 3 \%)$ than in the LV (59 $\pm 6 \%, p=0.002)$. Therefore, atrial oxygen extraction reserve was higher than in the ventricle during NSR (4.68 \pm 0.84 vs $1.88 \pm 0.26, p=0.01)$. Atrial pacing and AF caused an increase in LA oxygen extraction ratio, but had a much smaller effect on LV extraction ratio.

In summary, the LA recruited both conductance and extraction reserve to increase atrial oxygen supply during atrial pacing and short term AF. To determine whether this is sufficient to meet atrial oxygen demand, we have measured lactate production, which is a hallmark response to acute supply-demand ischemia ${ }^{20-23}$. Previous studies have shown that ventricular ischemia resulted in a peak lactate production at 5-15 $\min ^{20-22}$. Ventricular lactate production correlated with the severity of ische- 
$\mathrm{mia}^{24}$. Our results show a significant increase in LA arterio-venous lactate difference during acute AF. This indicates that during acute AF, atrial oxygen demand increases more than oxygen supply, potentially leading to a supply-demand mismatch. The atrial arterio-venous lactate difference we observed during AF (1.2-1.5 mM) approaches ventricular values during acute moderate ischemia in isolated rat hearts $(2 \mathrm{mM}$ after $3 \mathrm{~min})^{25}$ and in anesthetized pigs ( $4.2 \mathrm{mM}$ after $\left.5 \mathrm{~min}\right)^{26}$. Therefore, we conclude that the severity of the atrial supply-demand mismatch induced by AF is comparable to mild-to-moderate ventricular ischemia.

\subsection{Relevance}

The rapid electrical and mechanical activation rates during AF are likely to increase the energy expenditure of the atrial myocardium. Several studies have shown a concomitant increase in atrial myocardial blood flow ${ }^{1,3,8}$. Our study shows that, in addition to an increase in LA coronary conductance, atrial oxygen extraction also increased during AF. Despite the recruitment of both atrial coronary conductance reserve and extraction reserve, the atrial oxygen supply is insufficient to fully match increased atrial oxygen demand during acute AF. This is reflected in the increase in atrial venous lactate levels during short term AF in a healthy heart. Supply-demand ischemia may also explain the rapid decrease in atrial contractility that has been reported after 5 min of $A F$ in goats ${ }^{17}$ and after $1 \mathrm{~h}$ of $A F$ in pigs ${ }^{27}$. This may be comparable with the response to ischemia in the ventricles, where a fast decline in contractility has been proposed to constitute an active adaptation to downregulate myocardial energy demand $^{22}$. The occurrence of atrial ischemia during AF is further supported by increased expression of hypoxia and angiogenesis markers $\left(\mathrm{HIF}_{1 \alpha}, \mathrm{HIF}_{2 \alpha}, \mathrm{VEGF}\right)$ that has been found in $\mathrm{AF}$ patients ${ }^{28}$. In a goat model of $\mathrm{AF}$, a reduction in phosphocreatine and an increase in $\mathrm{HIF}_{1 \alpha}$ have been observed ${ }^{9,10}$. In addition, gene expression profiles in a pig model showed changes indicative of energy depletion after $7 \mathrm{~h}$ of $A F^{29}$. Supply-demand ischemia may form the trigger for the slow process of atrial structural remodeling, the first signs of which can be observed at the ultrastructural level after one week of AF in goats 9, 30 . Several aspects of atrial structural remodeling (myolysis and myocyte dedifferentiation) in AF patients and in a goat AF model are consistent with chronic ischemia and are strongly reminiscent of hibernating ventricular myocardium due to chronic low-flow ischemia ${ }^{11,31-33}$. 


\section{CHAPTER 4}

During prolonged AF, atrial remodeling may reduce the energy expenditure and oxygen demand of the atria. Electrical remodeling, especially the reduction in calcium current, strongly decreases atrial contractility. In the ventricles, low-flow ischemia and heart failure lead to metabolic remodeling, hallmarked by a shift from fatty acid to glucose utilization that increases oxygen-efficiency ${ }^{34}$. Whether this shift also takes place in the atria during prolonged $\mathrm{AF}$ is unknown at present, but expression profiles show marked changes in the expression of metabolism-related genes after $24 \mathrm{~h}$ of rapid atrial pacing in dogs 35 . In addition, structural remodeling leads to a hibernating phenotype of atrial myocytes that can also be interpreted as an energyconserving adaptation to ischemia ${ }^{11,31,36}$. Because of adaptive electrical/contractile, metabolic and structural remodeling, the phase of atrial supply-demand ischemia may be transient. Indeed, the decrease in atrial phosphocreatine levels, an indicator of supply-demand ischemia and increased expression of $\mathrm{HIF}_{1 \alpha}$, a common response to oxygen shortage were both observed in the first weeks of AF, but had disappeared at later stages in a goat model of 'lone' AF 9 . Nevertheless, these adaptive processes contribute to the formation of a substrate for AF. In this context, it is relevant that in patients AF initially is often paroxysmal. Typically, the time spent in NSR between paroxysms would be sufficient for full reversal of electrical remodeling ${ }^{17}$. Under such conditions, atrial supply-demand ischemia might occur during successive paroxysms, and any resulting damage to the atrial myocardium could be cumulative.

Prevention of atrial supply-demand ischemia may represent a valuable therapeutic target. Its occurrence would present a window of opportunity for interventions that improve oxygen efficiency (such as trimetazidine or ranolazine) ${ }^{37}$, thereby reducing supply-demand ischemia and possibly preventing the progression of AF.

\subsection{Limitations}

We propose that the results of our study are relevant for AF patients, and in this respect, there are several potential limitations.

Firstly, this study was performed in pigs. Ventricular flow regulation in pigs is similar to humans, but the similarity in atrial flow regulation cannot be ascertained at present. Opportunities to measure atrial coronary blood flow in humans are limited. However, one study using a Doppler guide wire has reported phasic flow patterns similar to our recordings ${ }^{38}$. In addition, an elevated heart rate increased atrial blood 
flow more than ventricular (LCX) blood flow, in agreement with our data in pigs. Secondly, the recordings were performed under anesthesia. The anesthesia used allowed stable recording of flow and pressure over a time course of several hours. However, the activity of the autonomic nervous system is likely to be lower under anesthesia, which may exacerbate blood pressure fluctuations, for example during acute AF. Nevertheless, our data show that under these conditions, the atria are more vulnerable to supply-demand ischemia than the ventricles. In addition, reported values for $L V$ venous oxygen saturation tend to be somewhat higher in anesthetized animals than in awake animals (40\% in our study vs. $20 \%$ in awake pigs ${ }^{39}$ ). No venous oxygen saturation has been reported for the LA in awake animals, but if it were similarly lower, this would actually decrease atrial extraction reserve and thus increase the vulnerability to supply-demand ischemia.

\section{CONCLUSION}

The LA has a lower coronary conductance reserve than the LV, but a higher oxygen extraction reserve. Although, both reserves are recruited during short term AF, a supply-demand mismatch still arises in the LA. This imbalance may represent a pivotal trigger that induces atrial structural changes on the longer term, thereby contributing to the progressive stabilization of AF.

\section{FUNDING SOURCES}

This work was supported by the Foundation Leducq (07CVD03), and the European Union (European Network for Translational Network in Atrial Fibrillation, EUTRAF, grant no.261057).

\section{REFERENCES}

1. White CW, Kerber RE, Weiss HR, Marcus ML. The effects of atrial fibrillation on atrial pressure-volume and flow relationships. Circulation research. 1982;51:205-215

2. White CW, Holida MD, Marcus ML. Effects of acute atrial fibrillation on the vasodilator reserve of the canine atrium. Cardiovascular research. 1986;20:683-689

3. McHale PA, Rembert JC, Greenfield JC, Jr. Effect of atrial fibrillation on atrial blood flow in conscious dogs. Am J Cardiol. 1983;51:1722-1727 


\section{CHAPTER 4}

4. $\quad$ Neill WA, Phelps NC, Oxendine JM, Mahler DJ, Sim DN. Effect of heart rate on coronary blood flow distribution in dogs. Am J Cardiol. 1973;32:306-312

5. Neill WA, Sewell D, Gopal M, Oxendine J, Painter L. Independent regulation of atrial coronary blood flow by atrial contraction rate in conscious dogs. Pflugers Arch. 1980;388:193-195

6. Bauman RP, Rembert JC, Greenfield JC, Jr. Regional blood flow in canine atria during exercise. Am J Physiol. 1993;265:H629-632

7. Manohar M, Goetz TE, Hutchens E, Coney E. Atrial and ventricular myocardial blood flows in horses at rest and during exercise. Am J Vet Res. 1994;55:1464-1469

8. Friedman HS, O'Connor J, Kottmeier S, Shaughnessy E, McGuinn R. The effects of atrial fibrillation on regional blood flow in the awake dog. Can J Cardiol. 1987;3:240-245

9. Ausma J, Coumans WA, Duimel H, Van der Vusse GJ, Allessie MA, Borgers M. Atrial high energy phosphate content and mitochondrial enzyme activity during chronic atrial fibrillation. Cardiovascular research. 2000;47:788-796

10. Thijssen VL, van der Velden HM, van Ankeren EP, Ausma J, Allessie MA, Borgers M, van Eys $\mathrm{GJ}$, Jongsma HJ. Analysis of altered gene expression during sustained atrial fibrillation in the goat. Cardiovasc Res. 2002;54:427-437

11. Dispersyn GD, Ausma J, Thone F, Flameng W, Vanoverschelde JL, Allessie MA, Ramaekers FC, Borgers M. Cardiomyocyte remodelling during myocardial hibernation and atrial fibrillation: Prelude to apoptosis. Cardiovasc Res. 1999;43:947-957

12. Duncker DJ, Bache RJ. Regulation of coronary blood flow during exercise. Physiol Rev. 2008;88:1009-1086

13. Duncker DJ, Bache RJ, Merkus D. Regulation of coronary resistance vessel tone in response to exercise. J Mol Cell Cardiol. 2012;52:802-813

14. Weaver ME, Pantely GA, Bristow JD, Ladley HD. A quantitative study of the anatomy and distribution of coronary arteries in swine in comparison with other animals and man. Cardiovasc Res. 1986;20:907-917

15. Hughes GC, Post MJ, Simons M, Annex BH. Translational physiology: Porcine models of human coronary artery disease: Implications for preclinical trials of therapeutic angiogenesis. J Appl Physiol. 2003;94:1689-1701

16. Swindle MM, Horneffer PJ, Gardner TJ, Gott VL, Hall TS, Stuart RS, Baumgartner WA, Borkon AM, Galloway E, Reitz BA. Anatomic and anesthetic considerations in experimental cardiopulmonary surgery in swine. Lab Anim Sci. 1986;36:357-361

17. Schotten U, Duytschaever M, Ausma J, Eijsbouts S, Neuberger HR, Allessie M. Electrical and contractile remodeling during the first days of atrial fibrillation go hand in hand. Circulation. 2003;107:1433-1439

18. Wichmann J, Ertl G, Rudolph G, Kochsiek K. Effect of experimentally induced atrial fibrillation on coronary circulation in dogs. Basic Res Cardiol. 1983;78:473-491

19. Kusachi S, Nishiyama O, Yasuhara K, Saito D, Haraoka S, Nagashima H. Right and left ventricular oxygen metabolism in open-chest dogs. Am J Physiol. 1982;243:H761-766 


\section{Atrial supply-demand balance in healthy adult pigs}

20. Fedele FA, Gewirtz H, Capone RJ, Sharaf B, Most AS. Metabolic response to prolonged reduction of myocardial blood flow distal to a severe coronary artery stenosis. Circulation. 1988;78:729-735

21. Apstein CS, Gravino F, Hood WB, Jr. Limitations of lactate production as an index of myocardial ischemia. Circulation. 1979;60:877-888

22. Arai AE, Pantely GA, Anselone CG, Bristow J, Bristow JD. Active downregulation of myocardial energy requirements during prolonged moderate ischemia in swine. Circ Res. 1991;69:14581469

23. Willigers HM, Prinzen FW, Roekaerts PM, de Lange S, Durieux ME. Dexmedetomidine decreases perioperative myocardial lactate release in dogs. Anesth Analg. 2003;96:657-664, table of contents

24. Apstein CS, Deckelbaum L, Hagopian L, Hood WB, Jr. Acute cardiac ischemia and reperfusion: Contractility, relaxation, and glycolysis. Am J Physiol. 1978;235:H637-648

25. Apstein CS, Deckelbaum L, Mueller M, Hagopian L, Hood WB, Jr. Graded global ischemia and reperfusion. Cardiac function and lactate metabolism. Circulation. 1977;55:864-872

26. Martin C, Schulz R, Rose J, Heusch G. Inorganic phosphate content and free energy change of atp hydrolysis in regional short-term hibernating myocardium. Cardiovasc Res. 1998;39:318326

27. Weimar T, Watanabe Y, Kazui T, Lee US, Moon MR, Schuessler RB, Damiano RJ, Jr. Differential impact of short periods of rapid atrial pacing on left and right atrial mechanical function. Am J Physiol Heart Circ Physiol. 2012;302:H2583-2591

28. Gramley F, Lorenzen J, Jedamzik B, Gatter K, Koellensperger E, Munzel T, Pezzella F. Atrial fibrillation is associated with cardiac hypoxia. Cardiovascular pathology : the official journal of the Society for Cardiovascular Pathology. 2010;19:102-111

29. Chilukoti RK, Mostertz J, Bukowska A, Aderkast C, Felix SB, Busch M, Volker U, Goette A, Wolke C, Homuth G, Lendeckel U. Effects of irbesartan on gene expression revealed by transcriptome analysis of left atrial tissue in a porcine model of acute rapid pacing in vivo. Int J Cardiol. 2013 30. Ausma J, Litjens N, Lenders MH, Duimel H, Mast F, Wouters L, Ramaekers F, Allessie M, Borgers M. Time course of atrial fibrillation-induced cellular structural remodeling in atria of the goat. Journal of molecular and cellular cardiology. 2001;33:2083-2094

31. Thijssen VL, Ausma J, Liu GS, Allessie MA, van Eys GJ, Borgers M. Structural changes of atrial myocardium during chronic atrial fibrillation. Cardiovasc Pathol. 2000;9:17-28

32. Ausma J, Wijffels M, Thone F, Wouters L, Allessie M, Borgers M. Structural changes of atrial myocardium due to sustained atrial fibrillation in the goat. Circulation. 1997;96:3157-3163

33. Ausma J, Wijffels M, van Eys G, Koide M, Ramaekers F, Allessie M, Borgers M. Dedifferentiation of atrial cardiomyocytes as a result of chronic atrial fibrillation. The American journal of pathology. 1997;151:985-997

34. Ashrafian H, Frenneaux MP, Opie LH. Metabolic mechanisms in heart failure. Circulation. 2007;116:434-448 


\section{CHAPTER 4}

35. Cardin S, Libby E, Pelletier P, Le Bouter S, Shiroshita-Takeshita A, Le Meur N, Leger J, Demolombe S, Ponton A, Glass L, Nattel S. Contrasting gene expression profiles in two canine models of atrial fibrillation. Circulation research. 2007;100:425-433

36. Thijssen VL, Ausma J, Borgers M. Structural remodelling during chronic atrial fibrillation: Act of programmed cell survival. Cardiovascular research. 2001;52:14-24

37. Horowitz JD, Chirkov YY, Kennedy JA, Sverdlov AL. Modulation of myocardial metabolism: An emerging therapeutic principle. Curr Opin Cardiol. 2010;25:329-334

38. Skalidis El, Kochiadakis GE, Igoumenidis NE, Vardakis KE, Vardas PE. Phasic coronary blood flow velocity pattern and flow reserve in the atrium: Regulation of left atrial myocardial perfusion. $J$ Am Coll Cardiol. 2003;41:674-680

39. Merkus D, Haitsma DB, Sorop O, Boomsma F, de Beer VJ, Lamers JM, Verdouw PD, Duncker DJ. Coronary vasoconstrictor influence of angiotensin ii is reduced in remodeled myocardium after myocardial infarction. Am J Physiol Heart Circ Physiol. 2006;291:H2082-2089 


\section{Dynamic regulation of atrial coronary blood flow in healthy adult pigs}

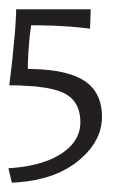

Kelly van Bragt

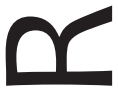

Hussein M. Nasrallah

Marion Kuiper

Arne van Hunnik

Nico H.L. Kuijpers

Ulrich Schotten

Sander Verheule

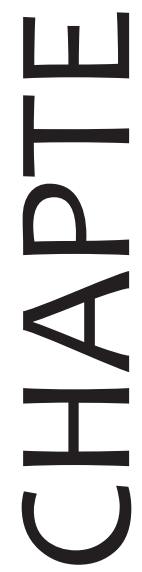

Heart Rhythm. 2015 May;12(5):991-1000 


\section{ABSTRACT}

BACKGROUND: There are several indications for a mismatch between atrial oxygen supply and demand during atrial fibrillation (AF), but atrial coronary flow regulation has not been investigated extensively.

OBJECTIVE: This study was designed to characterize the dynamic regulation of atrial coronary flow in pigs. Methods: In anesthetized open-chest pigs, Doppler flow probes were placed around LA and LV branches of the circumflex artery. Pressures and work indices were measured simultaneously. Systolic and diastolic flow contribution, flow response kinetics and relationship between pressures, work and flow were investigated during sinus rhythm, atrial pacing and acute AF.

RESULTS: During atrial systole, LA flow decreased. Only $2 \%$ of total LA flow occurred during atrial systole. Pacing with 2:1 AV-block and infusion of acetylcholine revealed that the atrial contraction itself impedes atrial coronary flow. The response to sudden changes in heart rate was slower in LA compared to LV. Both LA and LV vascular conductance were positively correlated with work. After the cessation of acute AF, the LA showed a more pronounced phase of supranormal vascular conductance than the LV, indicating a period of atrial reactive hyperemia.

CONCLUSION: In healthy adult pigs, atrial coronary flow is impeded by atrial contraction. Although atrial coronary blood flow is positively correlated with atrial external work, it reacts more slowly to changes in rate than ventricular flow. The occurrence of a pronounced hyperemic phase after acute AF supports the notion of a significant supply-demand mismatch during AF. 


\section{Dynamic regulation of atrial coronary blood flow in healthy adult pigs}

\section{INTRODUCTION}

Atrial fibrillation (AF), the most common tachyarrhythmia in clinical practice, is associated with increased morbidity and mortality ${ }^{1-3}$. The rapid and irregular rate of excitation and contraction during AF is likely to lead to increased atrial energy demand. Indeed, several studies using microspheres in healthy animals have shown that an increased atrial demand, such as short-term atrial pacing, exercise and atrial fibrillation resulted in increased atrial coronary blood flow ${ }^{4-11}$. However, if this increase in supply were insufficient to meet the increased demand, a state of supply-demand ischemia would ensue. In the goat model of AF, the occurrence of supply-demand ischemia over a longer period is supported by decreased phosphocreatine levels ${ }^{12}$. In addition, $\mathrm{HIF}_{1 a}$ and VEGF expression were increased in atrial biopsies of both goats in $\mathrm{AF}^{13}$ and AF patients ${ }^{14}$. Because its (ventricular) coronary anatomy and flow regulation are similar to those in humans ${ }^{15}$, we have chosen pigs to study atrial coronary flow regulation. We have recently shown that, although atrial arteries dilate and atrial oxygen extraction increases in response to acute AF in healthy pigs, atrial lactate production increases, indicative of supply-demand ischemia ${ }^{16}$.

Understanding the dynamic regulation of atrial coronary flow will help in understanding the role of ischemia in the onset and perpetuation of AF. In this study, we have studied the dynamic regulation of atrial coronary blood flow in normal healthy pigs. The phasic coronary flow pattern was analyzed and the kinetics of flow regulation were investigated. To this end, simultaneous measurements of atrial work and atrial flow were performed under different circumstances that influence atrial energy demand.

\section{METHODS}

\subsection{Animal preparation}

Eleven healthy Dutch Landrace pigs weighing $66 \pm 3 \mathrm{~kg}$ were studied. Some aspects of the measurements in these animals have been reported previously ${ }^{17}$. For the present study, three additional animals were included, and additional analysis, interventions and parameters are described. All animal procedures were in accordance with national and institutional guidelines. Anesthesia was induced with Zoletil (5-8 mg/kg I.M.) 


\section{CHAPTER 5}

and Thiopenthal (5-15 mg/kg I.V.) and maintained with Midazolam (0.8 mg/kg/h), Sufentanyl $(6 \mu \mathrm{g} / \mathrm{kg} / \mathrm{h})$ and Propofol $(2.5-10 \mathrm{mg} / \mathrm{kg} / \mathrm{h})$. A left lateral incision was made with removal of the $5^{\text {th }}$ rib and the pericardium was opened to expose the LA and LV.

\subsection{Instrumentation}

Pigs were instrumented as shown in Figure 1B. To measure atrial and ventricular flow, Doppler flow probes (Transonic Systems Inc., Ithaca, NY) were placed around a left atrial (LA) and left ventricular (LV) branch of the left circumflex artery (LCX). Flow signals were recorded during sinus rhythm (SR), atrial pacing at different pacing cycle lengths (500,450 and $400 \mathrm{~ms}$ ) and AF. For this purpose, a pacemaker lead (5568, Medtronic Inc, Minneapolis, MN) was placed endocardially in the RA to pace and record local electrograms.

Because the stability of AF was low in healthy pigs, continuous rapid burst pacing at $20 \mathrm{~Hz}$ (4x diastolic threshold) was used to artificially maintain the arrhythmia for recordings during AF. AF episodes had approximately the same duration in each ani-

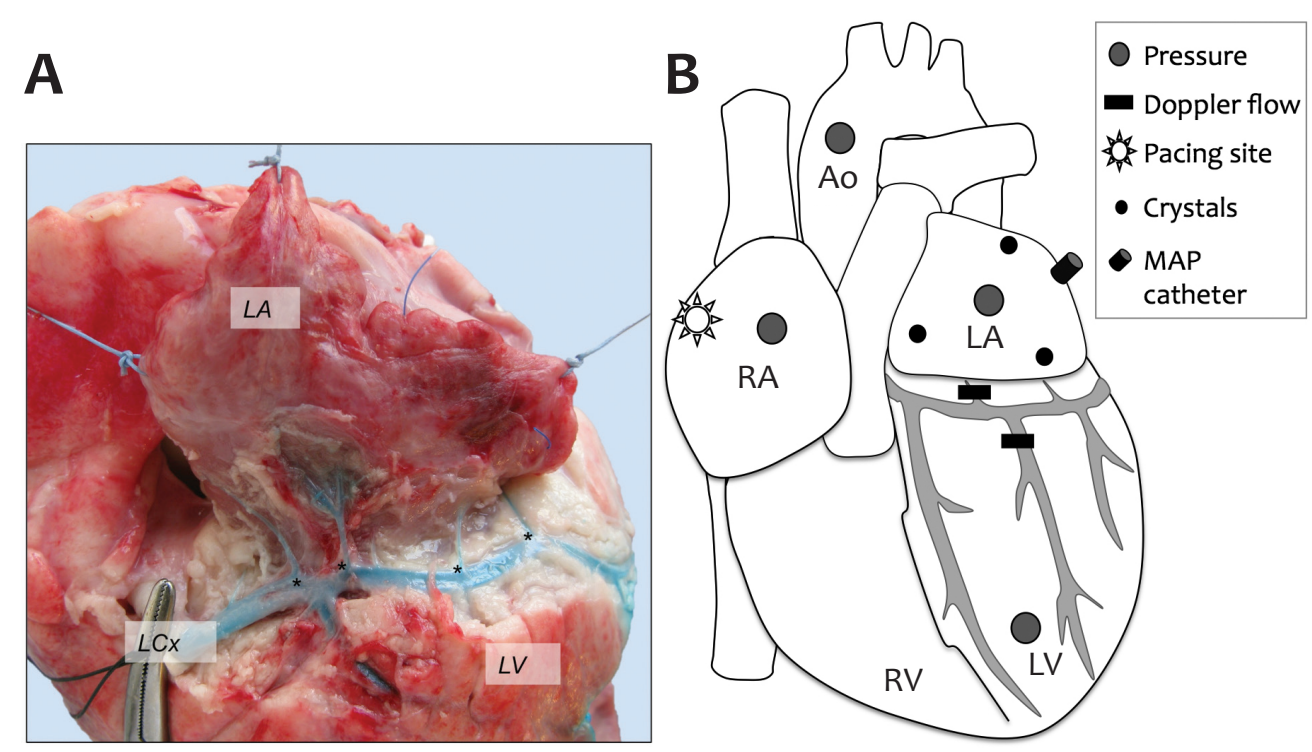

Figure 1: Instrumentation. A) Ink injection into the left circumflex artery (LCX). Atrial branches are indicated with an asterisk. B) Instrumentation in aorta (Ao), left ventricle (LV), left atrium (LA) and right atrium (RA). 


\section{Dynamic regulation of atrial coronary blood flow in healthy adult pigs}

mal, because pigs spontaneously converted to sinus rhythm within seconds of cessation of burst pacing.

To analyze the phasic flow pattern, the diastolic and systolic phases of the flow signal were defined (see section "Calculation of diastolic and systolic fraction"). To analyze the trends in the coronary flow pattern, the response kinetics of the flow signal were determined during atrial pacing (See section "Calculation of flow response kinetics"). LA and LV work indices were measured simultaneously with coronary flow signals. Left atrial work index (LAWI) was estimated using LA dimensions and pressure (see section "Calculation of atrial and ventricular work"). Three piezo-electric crystals (Sonometrics, London, Ontario, Canada) were introduced through the LA free wall into the LA lumen in a triangular orientation (Figure 1B) in order to measure atrial dimensions. To measure LA pressures $\left(\mathrm{P}_{\mathrm{LA}}\right)$, a Millar microtip pressure sensor (Millar Instruments, Houston, TX, USA) was inserted through the LA free wall into the LA lumen. Left ventricular work index (LVWI) was determined using a Sentron conductance catheter (Sentron Europe BV, Roden, The Netherlands) to measure LV volume and pressure $\left(\mathrm{P}_{\mathrm{LV}}\right)$. In order to calculate vascular conductance, aortic (Sentron Europe BV, Roden, The Netherlands) and RA (Millar Instruments, Houston, TX, USA) pressures were measured. Conductance was then calculated by dividing coronary flow by the pressure difference over the coronary vascular bed $\left(\mathrm{P}_{\mathrm{Ao}}-\mathrm{P}_{\mathrm{RA}}\right)$. Atrial work and flow were measured during atrial pacing at a cycle length of $500 \mathrm{~ms}, 450 \mathrm{~ms}$ and $400 \mathrm{~ms}$ and during short term AF (10 min). The same parameters were measured during intracoronary infusion of acetylcholine (ACh) via a JR6 catheter (Cordis Corporation, Bridgewater, NJ, USA) in the left main coronary artery. Prior to and during ACh infusion, monophasic action potentials (MAP) were recorded using a monophasic action potential catheter (7F MAP-4801, Harvard Apparatus, Holliston, MA, USA). After 1 min of pacing or steady state ACh infusion, a 10 s period was analyzed to calculate the average atrial and ventricular conductance and work indices.

\subsection{Calculation of diastolic and systolic fraction of flow}

Left ventricular systolic flow was calculated as the flow occurring between the onset of ventricular contraction (i.e. the start of the increase in LV pressure) and the onset of ventricular relaxation (i.e. the start of the decrease in LV pressure, illustrated in 


\section{CHAPTER 5}

Figure 3A). Left atrial systolic flow was defined as period between the start of the atrial contraction (i.e. the increase in LA pressure following the start of the $P$ wave in the ECG), and the start of atrial relaxation (i.e. the decrease in LA pressure, illustrated in Figure 3B). The time-flow integrals were calculated for 5 consecutive beats during systole (TFIs) and diastole (TFId). The systolic fraction (SF, in \%) of total flow per beat was calculated as:

$$
\mathrm{SF}=(\text { TFIs } /(\text { TFIs }+ \text { TFId })) * 100
$$

\subsection{Calculation of flow response kinetics}

The response kinetics of the average flow signal over time was compared between the LA and LV branches. To this end, the flow signal was filtered using a 10-level wavelet filter to eliminate the phasic pattern of the cardiac cycle, thereby deriving average flow. For 3 different pacing cycle lengths, the time to reach the half-maximal flow increase ( $T_{1 / 2}$ MAX $)$ from the baseline was calculated. In addition, the time to the half-maximal flow decrease $\left(T_{1 / 2}\right.$ bsln $)$ from the maximum after the cessation of pacing was determined (illustrated in Figure 4A). To quantify the hyperemic phase after cessation of acute $A F$, the ratio between the time integral of the total conductance and the baseline over the same time period were calculated.

\subsection{Calculation of work indices}

Ventricular work indices were determined by integrating all completed LV pressure-volume loops during periods of $10 \mathrm{~s}$. Atrial work indices were assumed to be proportional to the integral of pressure-distance loops during the atrial contraction ${ }^{18}$. Atrial pressure-distance loops result from both passive and active atrial emptying. The active atrial work starts at the moment of LA pressure rise and followed by shortening of the atrial distance (indicated with a star in Figure $5 \mathrm{~A}$ ). The atrial active work loop ends when the same atrial diameter is reached again. Three distances were recorded on the LA free wall and work index was calculated by the average value from the three pressure-distance loops. LAWI was normalized with respect to heart rate, by multiplying the work per beat times the number of heartbeats per second and was expressed as $\mathrm{mm} * \mathrm{mmHg} / \mathrm{s}$. 


\section{Dynamic regulation of atrial coronary blood flow in healthy adult pigs}

\subsection{Statistical analysis}

Results are expressed as mean \pm SEM. Statistical analysis was performed using a 1-way ANOVA to assess the effects of different interventions on work indices and conductance. Values were compared to baseline using a post-hoc test (Dunnett's Multiple Comparison). LA and LV values were compared with a 2-way ANOVA followed by a post-hoc Dunnett test. Correlation between work indices and conductance was tested using a linear mixed model analysis. We have applied three linear mixed models and chose the one with the lowest Akaike's Information Criterion (AIC). A p-value $<0.05$ was considered statistically significant.
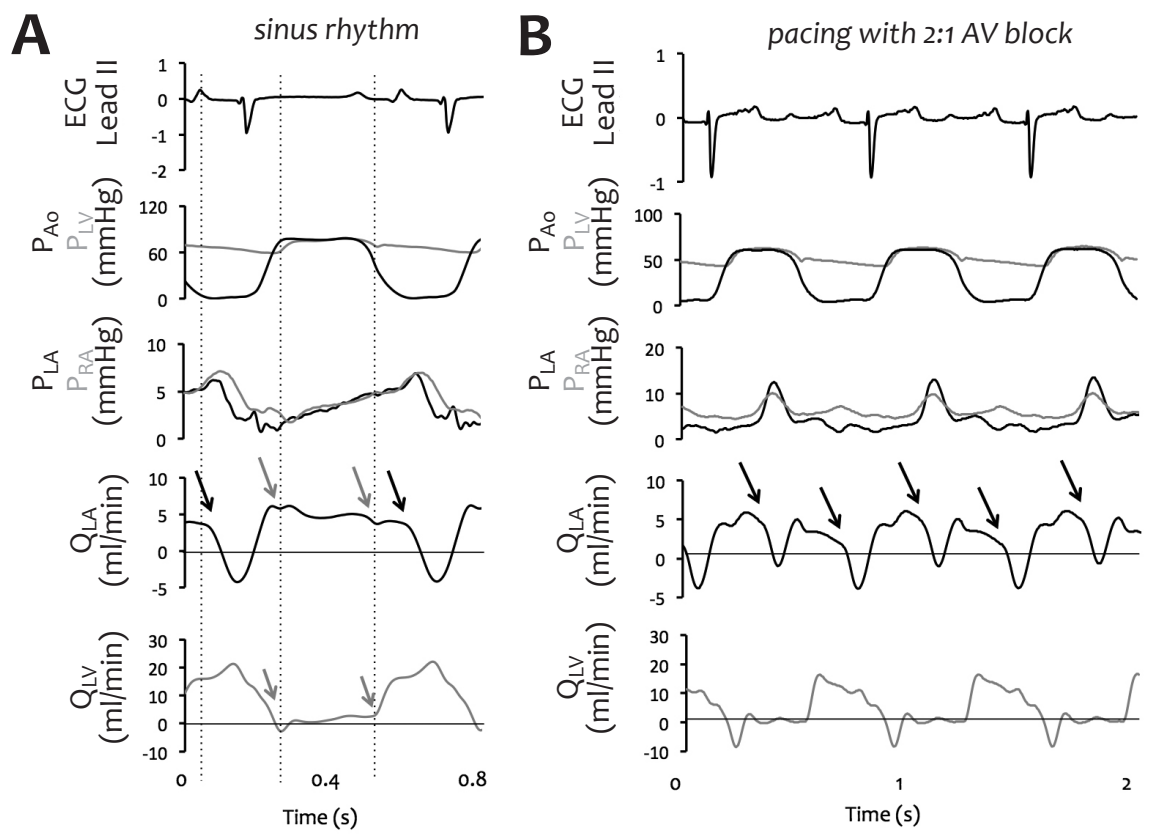

Figure 2: Phasic flow pattern during sinus rhythm (A) and 2:1 AV block (B). Black arrows indicate the decrease in atrial flow during atrial systole. Grey arrows indicate the timing of aortic valve opening and closure. 


\section{RESULTS}

\subsection{The phasic atrial flow pattern}

The atrial flow signal showed a phasic pattern during every cardiac cycle. Both atrial and ventricular flow patterns consistently showed a small decrease during the opening and closing of the aortic valve (Figure $2 \mathrm{~A}$, indicated with gray arrows). As expected, ventricular flow decreased during ventricular systole ${ }^{19,20}$. Similarly, a consistent decrease in atrial flow was observed during atrial activation (Figure $2 \mathrm{~A}$, indicated

A

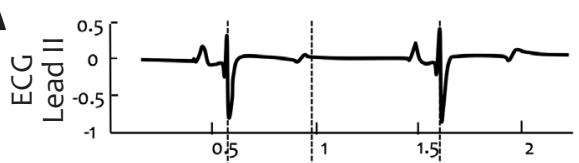

B
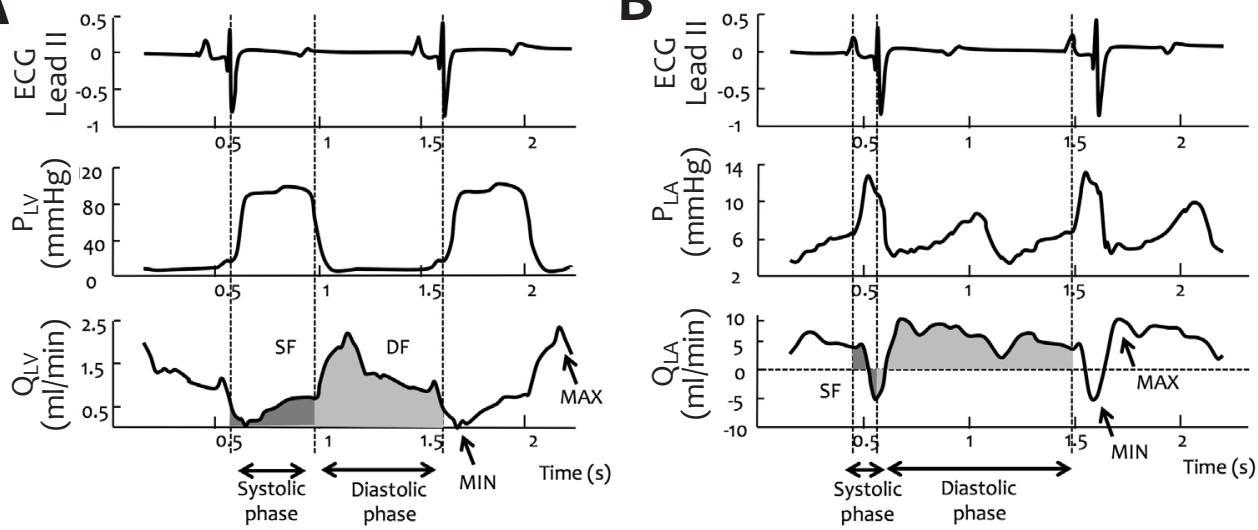

C

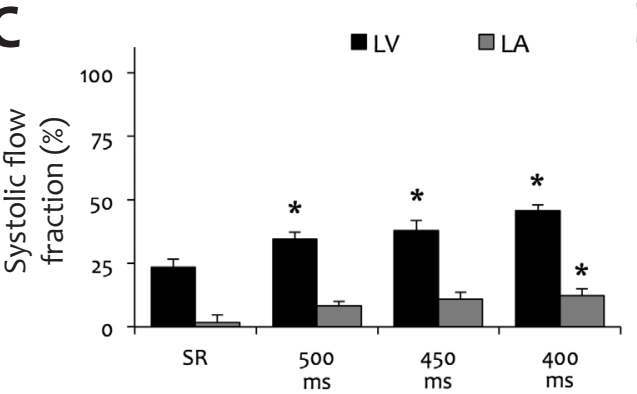

D

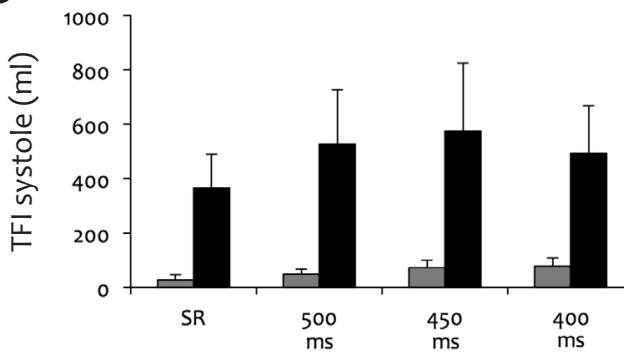

Figure 3: Calculation of systolic and diastolic fraction of flow. Systolic phase in indicated in dark grey, diastolic phase in light gray in the LV (A) and LA (B) phasic flow pattern. Minimum (MIN) and maximum (MAX) flow are indicated in the flow signal. From the flow signal of LV and LA, systolic flow fraction (C) and time-flow integral during systole (TFIs) (D) were calculated. * $p \leq 0.05$ vs baseline. 


\section{Dynamic regulation of atrial coronary blood flow in healthy adult pigs}

with a black arrow). In principle, the decrease in atrial flow during atrial activation could be caused either by the increase in atrial pressure during the atrial contraction or by the atrial contraction itself. When 2:1 AV block occurred during atrial pacing, the atrial pressure alternated between large increases, when the atria contracted against a closed mitral valve (isovolumetric contraction), and much smaller increases, when the atria contracted with an open mitral valve, as illustrated in Figure $2 \mathrm{~B}$. The decrease in atrial coronary flow was comparable for both types of contractions, indicating that the atrial contraction itself impedes atrial coronary blood flow (Figure $2 \mathrm{~B}$, black arrows). In 8 out of 11 animals, atrial flow reversed during atrial contraction. The minimum in atrial flow $(-0.76 \pm 0.64 \mathrm{ml} / \mathrm{min}$ during SR) was reached at the end of atrial systole (Figure $3 \mathrm{~B}$ ). In the LV, flow reversed in 4 out of 11 animals (minimum flow during SR $-0.2 \pm 0.9 \mathrm{ml} / \mathrm{min}$ ). Both in the LA and LV, maximal flow was reached in the early diastolic phase (Figure $3 \mathrm{~A}$ and $3 \mathrm{~B}$ ). The atrial systole is short compared to the ventricular systole. In the LA, $1.8 \pm 2.9 \%$ of the total coronary flow occurred during atrial systole (Figure $3 \mathrm{C}$ ) and $98.2 \pm 2.9 \%$ during diastole. In the LV, $23.5 \pm 3.3 \%$ of total ventricular flow occurs during ventricular systole and $76.5 \pm 3.3 \%$ during diastole. The $\mathrm{TFI}$ during systole is depicted in Figure 3D.

\subsection{Response to atrial pacing}

As the heart rate increases, the diastolic period becomes significantly shorter in both LA and LV. LV diastolic time per heart beat was 52 $\pm 3 \%$ during SR, $41 \pm 2 \%$ during 500 $\mathrm{ms}, 37 \pm 2 \%$ during $450 \mathrm{~ms}$ and $35 \pm 2 \%$ during $400 \mathrm{~ms}$ pacing, $\mathrm{p}<0.01 \mathrm{vs} \mathrm{SR}$. The TFI was calculated during diastole and systole (Figure 3D) for both LA and LV. TFIs showed a trend towards an increase in both LA and LV with incremental pacing, but this was not statistically significant. The contribution of the systolic flow fraction gradually increased with pacing rate, both in the LA and in the LV (Figure $3 \mathrm{C}$ ), and correspondingly, the contribution of diastolic flow decreased.

We have previously shown that the average atrial and ventricular coronary flow increases with increasing pacing rate ${ }^{16}$. Figure $4 \mathrm{~A}$ and $\mathrm{B}$ show the time course with which atrial and ventricular coronary flow respond to a period of pacing at a basic cycle length $(B C L)$ of $400 \mathrm{~ms}$. Left atrial flow reacted to pacing by increasing $120 \pm 6 \%$, $143 \pm 16 \%$ and $146 \pm 21 \%$ of baseline flow at 500,450 and 400 ms respectively. Left ventricular flow increased $125 \pm 10 \%, 125 \pm 12 \%$ and $121 \pm 11 \%$ at the same respective cycle lengths. 


\section{CHAPTER 5}

Both after the onset and cessation of pacing, the response of atrial flow appears to be slower than that of ventricular flow (Figure 4A vs. B).

At the start of pacing, the half time was calculated to reach the steady state coronary flow during pacing $\left(\mathrm{T}_{1 / 2 \mathrm{MAX}}\right.$, Figure $\left.4 \mathrm{~A}\right)$. After the cessation of pacing, the half time to return to baseline coronary flow $\left(T_{1 / 2}\right.$ bsln , Figure $\left.4 A\right)$ was calculated. At all pacing cycle lengths investigated, the response time of flow to pacing was significantly slower in the LA than in the LV, both after the onset and after cessation of pacing (Figure $4 \mathrm{C}$ and D).

\subsection{Relation between flow and work}

To investigate the relation between atrial work and atrial vascular tone, pressure-distance loops were measured simultaneously with coronary flow measurements. The LAWI was $13 \pm 4 \mathrm{~mm} * \mathrm{mmHg} / \mathrm{s}$ during SR and showed a cycle length dependent increase $(p=0.0059)$, with a LAWI of $58 \pm 16,93 \pm 29$ and $154 \pm 39 \mathrm{~mm} * \mathrm{mmHg} / \mathrm{s}$ at $500 \mathrm{~ms}, 450$
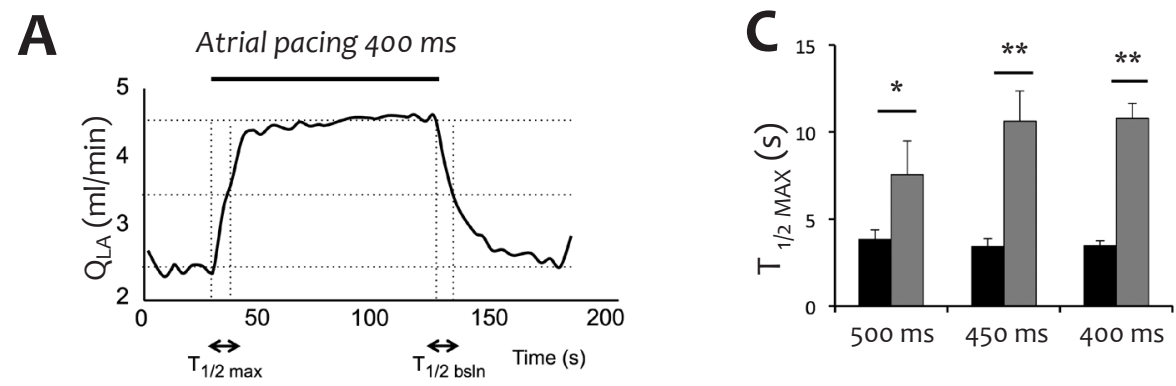

B
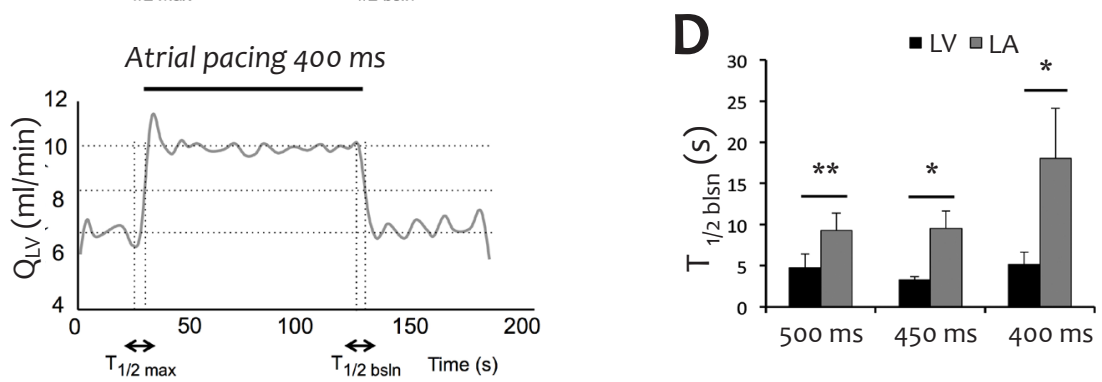

Figure 4: Kinetics of flow during pacing. A) Example of filtered flow signal in the LA (A) and LV (B) upon atrial pacing at $400 \mathrm{~ms}$. The time to reach half $\max \left(T_{1 / 2 \mathrm{MAX}}\right)$ and half baseline $\left(T_{1 / 2 \mathrm{bsln}}\right)$ of the flow signal are indicated in the signal. Calculation of $\mathrm{T}_{1 / 2 \mathrm{MAX}}(\mathrm{C})$ and $\mathrm{T}_{1 / 2 \mathrm{bs} \ln }(\mathrm{D})$ during pacing at 500 ms, 450 ms and 400 ms cycle length. * $p \leq 0.05,{ }^{* *} p \leq 0.01$ vs LA. 


\section{Dynamic regulation of atrial coronary blood flow in healthy adult pigs}

ms and $400 \mathrm{~ms} B C L$ respectively (Figure $5 B$ left panel). LVWI was significantly higher during SR and at every pacing rate compared to LAWI $(p<0.001$, Figure 5B right panel). The average conductance was $0.042 \pm 0.007 \mathrm{ml} / \mathrm{min} / \mathrm{mmHg}$ in the LA branch and $0.078 \pm 0.011 \mathrm{ml} / \mathrm{min} / \mathrm{mmHg}$ in the LV branch. In agreement with the increase in LAWI, atrial pacing significantly increased LA conductance (data not shown, $p<0.001$ ) from $100 \%$ at baseline to $112 \pm 4 \%$ at $500 \mathrm{~ms}$ ( $p>0.05$, n.s.), $140 \pm 9 \%$ at $450 \mathrm{~ms}(p<0.001)$ and $156 \pm 13 \%$ at $400 \mathrm{~ms}(\mathrm{p}<0.001)$. Also LV conductance increased significantly by pacing $(p<0.001)$. A positive correlation was found during right atrial pacing between LAWI and the increase in LA conductance (Figure 5C upper panel). The slope $0.052(95 \% \mathrm{Cl}$ : $0.016,0.088)$ is significantly different from zero $(p=0.012)$. As expected, LVWI and LV conductance also correlated significantly with a slope of 0.288 (95\% Cl: $0.112,0.464$, $\mathrm{p}=0.003$, Figure 5 ( lower panel).

A

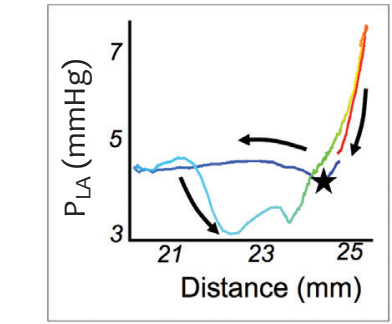

B

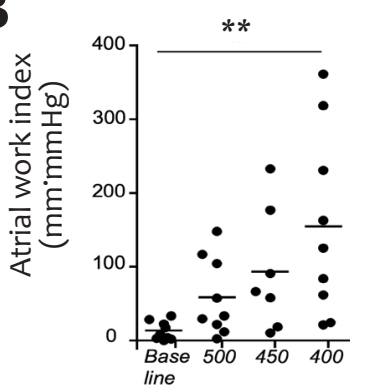

Atrial pacing

(450 ms)
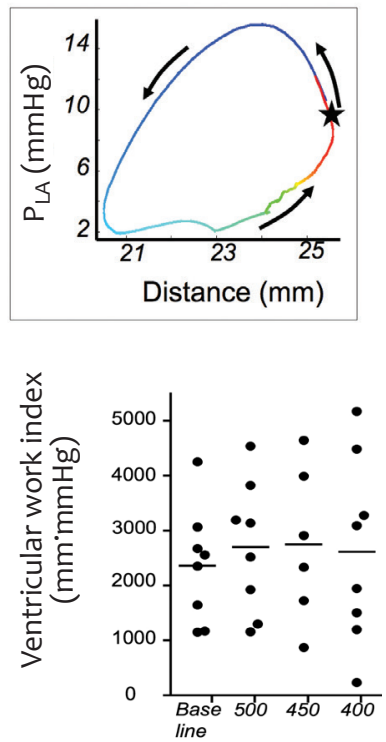

Basic cycle length (ms)
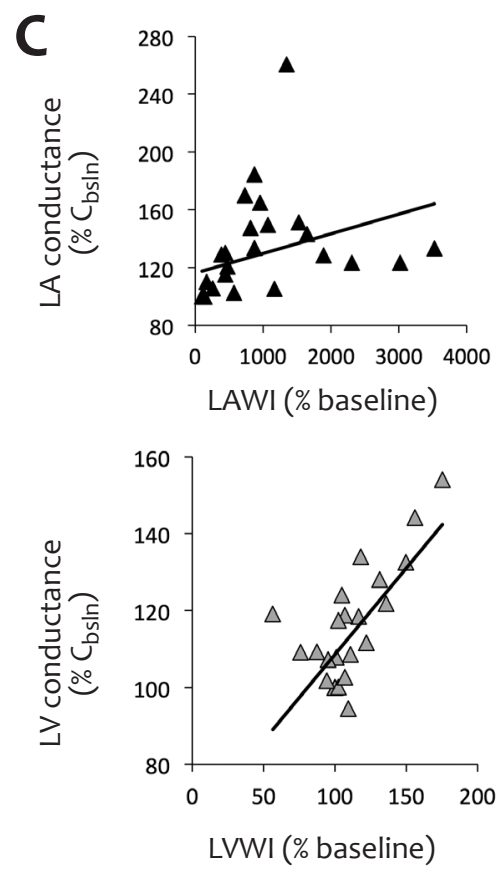

Figure 5: Work-conductance relationship during pacing. A) Example of atrial distance-pressure relationship. B) Atrial work index during baseline and atrial pacing at $500 \mathrm{~ms}, 450 \mathrm{~ms}$ and $400 \mathrm{~ms}$ cycle length. C) Correlation between left atrial work index (LAWI) and LA conductance expressed as \% of baseline. D) Correlation between left atrial work index (LVWI) and LV conductance expressed as \% of baseline. ${ }^{* *} \mathrm{p} \leq 0.01 \mathrm{vs}$ baseline. 


\section{CHAPTER 5}

Secondly, the relationship between atrial workload and coronary conductance was investigated by administration of acetylcholine (ACh) during atrial pacing at $450 \mathrm{~ms}$. The ACh-induced reduction in atrial contractility greatly reduced the phasic decrease in the atrial blood flow pattern (Figure 6A). During ACh infusion, atrial monophasic action potentials from the LA endocardial free wall were recorded. ACh administration resulted in a shortening of the action potential (Figure 6B, inset), thereby reducing atrial contractility and the active atrial work. The correlation between atrial work index and conductance had a slope of 1.01 (Figure 6B, 95\% Cl: $0.83-1.20, \mathrm{p}<0.001$ ). At the same concentration of $\mathrm{ACh}$, the ventricular action potential duration was not affected, as indicated by the lack of effect on QT time $(236 \pm 15 \mathrm{~ms}$ for baseline vs. $230 \pm 18$ ms during ACh infusion, $p=0.78)$. The atrial conductance was compared between baseline condition and the concentration of ACh that resulted in approximately a $50 \%$ reduction in LAWI (Figure 6B). A reduction in APD 80 to $33 \pm 15 \%$ of baseline $(p=0.02)$ resulted in a reduction in LAWI to $47 \pm 2 \%$ of baseline (Figure $6 C)$. This was accompanied by a decrease in LA vascular conductance to $24 \pm 8 \%$ of baseline (Figure 6D). $P_{R A}$ and $P_{A o}$ did not change significantly, but $P_{L A}$ was increased significantly from $6.20 \pm 1.01 \mathrm{mmHg}$ to $7.07 \pm 1.11 \mathrm{mmHg}(\mathrm{p}=0.03)$. The effect of $A C h$ on ventricular systolic function was evaluated by calculating the slope of the positive upstroke of the LV pressure curve $(+\mathrm{dP} / \mathrm{dt})$. The $+\mathrm{dP} / \mathrm{dt}$ was unchanged, as was the LV work index (data not shown). Accordingly, the LV conductance was not significantly influenced by ACh administration, as expected from the lack of effect on LV work.

\subsection{Response to atrial fibrillation}

During atrial fibrillation, the atrial flow pattern was irregular (Figure $7 \mathrm{~A}$ ). The average atrial conductance increased significantly during the first few minutes of AF. There was a trend towards an increase in LV conductance as well, but this was not statistically significant. The kinetics of the response in average conductance were measured for LA and LV flow after cessation of AF. The LA vascular conductance was transiently elevated above baseline values (i.e. the period preceding the induced AF episode), reflecting a hyperemic phase (Figure $7 B$ ). By contrast, the LV vascular conductance did not display a hyperemic phase. The ratio between the integrals of the area above and below baseline conductance was significantly higher for the LA compared to the LV (Figure $7 \mathrm{C}, \mathrm{p}=0.04)$. 


\section{Dynamic regulation of atrial coronary blood flow in healthy adult pigs}
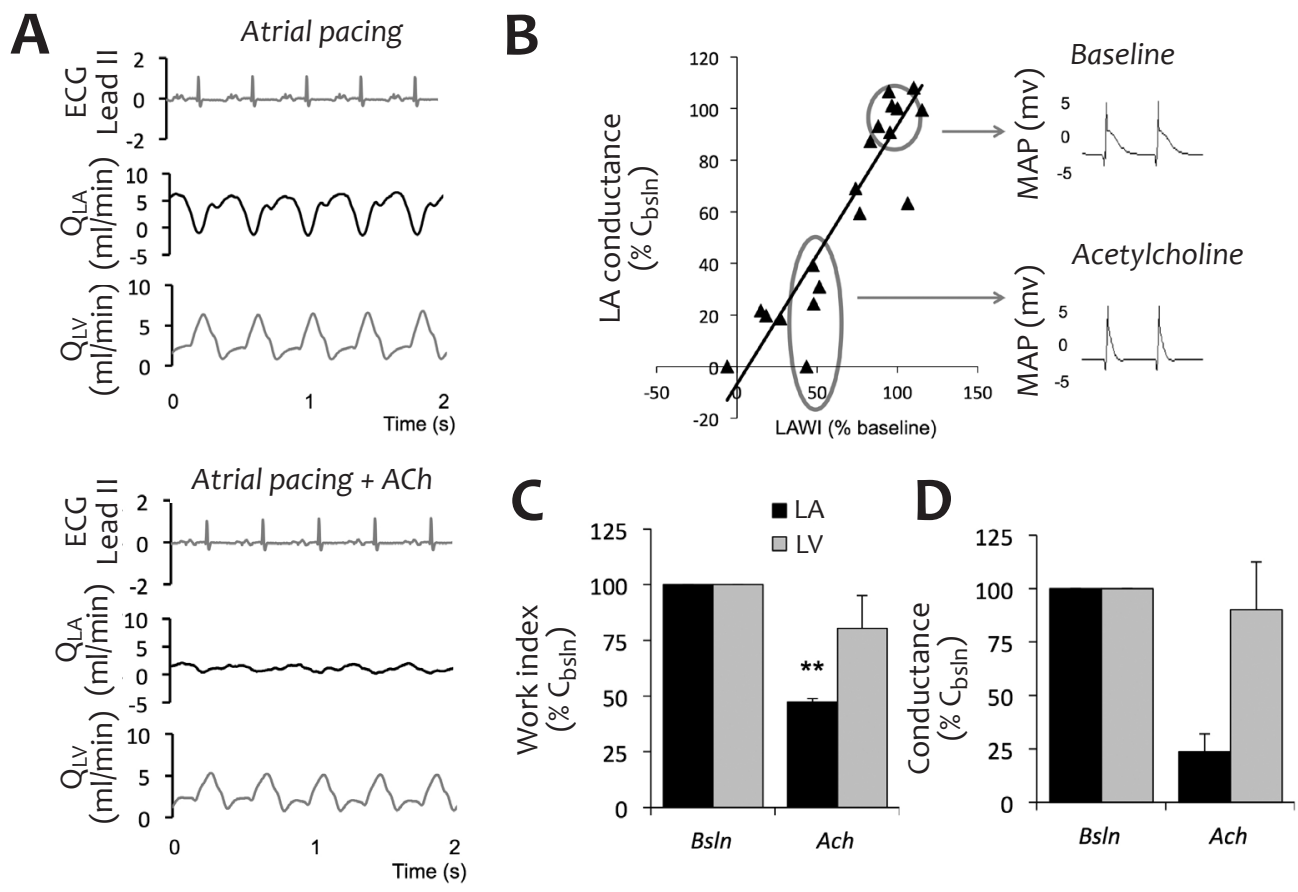

Figure 6: Work-conductance relationship during acetylcholine infusion. A) Correlation between LA work index (LAWI) and conductance during acetylcholine (Ach). Data points were divided in two groups: baseline and 50\% reduction in LAWI. Examples of monophasic action potentials (MAP) are given for the two groups. Work index expressed as \% of baseline (B), conductance expressed as \% of baseline and an example of atrial and ventricular flow (C) in the baseline groups and Ach group. $* * p \leq 0.01$ vs baseline.

\section{DISCUSSION}

In this study, we have investigated the dynamic regulation of the atrial coronary blood flow in detail and compared it to the ventricle in normal adult pigs. The atrial coronary flow pattern was assessed during sinus rhythm, atrial pacing and acute AF.

\subsection{Atrial flow pattern}

A consistent decrease in atrial flow was observed during the atrial contraction. This pattern is similar to the pattern found in other studies on left atrial branches in patients and dogs measured by a Doppler guide wire, Doppler crystals and laser Dop- 


\section{CHAPTER 5}

pler optical fibers ${ }^{6,21-23}$. In principle, this phasic decrease could be caused to the rise in atrial pressure or by the atrial contraction itself. However, when 2:1 AV block occurred during atrial pacing, every atrial contraction resulted in a similar decrease in atrial flow while atrial pressure alternated depending on whether the atrium contracted against an open or closed mitral valve. In addition, we show that during acetylcholine administration the decrease in atrial contractility led to the disappearance of the decrease in atrial flow during atrial contraction. This is in agreement with studies in dogs where premature ventricular stimulation caused a fluctuation in atrial pressure without affecting atrial coronary flow and where increasing atrial contractility by administration of isoproterenol affected atrial flow, but not atrial pressure ${ }^{23,24}$. In most pigs in our study, atrial flow reversed during atrial contraction. In an earlier study on dogs, reversal of atrial flow during the atrial contraction was only observed during administration of isoproterenol and not under baseline conditions ${ }^{23}$.

In the LV, where the decrease of coronary flow during contraction has been investigated extensively, the intramyocardial pump action is the major factor impeding systolic flow ${ }^{25,26}$. Our results are consistent with a similar mechanism affecting flow in the LA, which may have important consequences during AF. We have recently reported that acute AF leads to a supply-demand mismatch, resulting in atrial lactate production. While organized atrial contractility is absent during AF, the local contraction rate increases dramatically. Because atrial energy demand increases during AF, the negative effect of rapid local contractions on local flow may exacerbate the supply-demand mismatch.

The systolic contribution to total coronary flow was calculated for atrium and ventricle. The systolic fraction of total ventricular flow during ventricular contraction was $23.5 \pm 3.3 \%$, comparable to values in literature $(25 \%-35 \%)^{21,27}$. In the LA, flow during atrial systole contributes $1.8 \pm 2.9 \%$ to total atrial flow. Our results on phasic atrial flow show that atrial systole is responsible for the transient decrease in atrial flow, often leading to a reversal of atrial flow and, consequently, it only constitutes a small fraction of total atrial coronary flow.

\subsection{Relation between coronary flow and myocardial work}

In the LA, the diastolic time was much longer than in the LV, as mentioned above flow was strongly diminished during atrial systole. As a consequence, the relative 


\section{Dynamic regulation of atrial coronary blood flow in healthy adult pigs}

contribution of systolic flow to total flow was smaller in the LA, although it increased gradually with an increased heart rate. During atrial pacing, the LAWI increased in a cycle length dependent manner, in agreement with an earlier study in goats using distance-pressure loops for the RA that are similar to the LA loops in our study ${ }^{28}$. The increase in work index during pacing would be expected to increase atrial demand and thus lead to an increase in atrial coronary flow. Indeed, we observed a positive correlation between LA vascular conductance and work index.

The total amount of myocardial work performed is the sum of external and internal work. External work reflects mechanical work during atrial or ventricular contraction to pump blood and is the calculated as the area within a pressure-volume loop. Internal work is used to elongate elastic and viscous elements in sarcomeres and connective tissue and is therefore proportional to wall stress. In addition to mechanical work, energy is used within cells to maintain ion homeostasis.

The response time of coronary flow to an increase in heart rate was significantly slo-
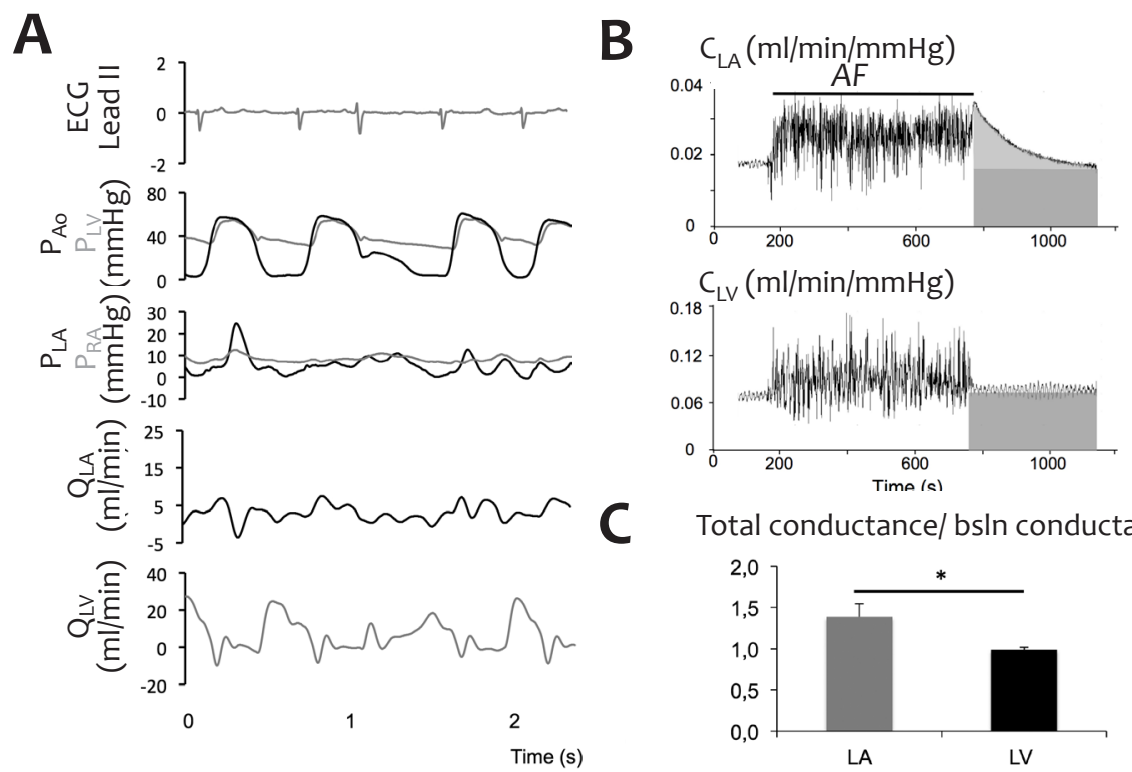

Total conductance/ bsin conductance

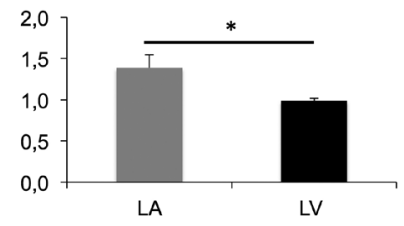

Figure 7: Atrial fibrillation. A) Example of flow signals during atrial fibrillation. B) Conductance in a $L A$ and $L V$ artery before, during and after an episode of acute AF. The hyperemic phase after cessation of AF was determined as the ratio of the time integral of the total flow (light gray + dark gray area) to the baseline flow (dark gray area). C) The hyperemic phase was significantly larger in the LA than in the $\operatorname{LV}\left({ }^{*} \mathrm{p}=0.04\right)$. 


\section{CHAPTER 5}

wer in the LA than in the LV. This may indicate either a difference in the rate of metabolic changes, or a difference in the rate of response to a metabolic change. We have recently shown that compared to the LV, the LA has a lower coronary flow reserve, but a higher oxygen extraction reserve (due to a lower atrial extraction under baseline conditions). Pacing led to an increase in both atrial coronary flow and oxygen extraction ${ }^{16}$. Although the time resolution of oxygen extraction measurements was low, it is conceivable that in response to an increase in atrial demand, atrial oxygen extraction increases more rapidly than atrial coronary flow.

During intracoronary infusion of $\mathrm{ACh}$, ventricular vascular conductance, ventricular contractility and the QT time were not affected, whereas the atrial APD, contractility and coronary flow were reduced. However, in the pig ventricle, ACh has a direct vasoconstrictor effect ${ }^{29}$, and we have indeed observed a reduction in ventricular vascular conductance at much higher ACh concentrations. Therefore, our interpretation that the decrease in atrial work during ACh infusion causes the reduction in atrial flow would be incorrect if the atrial vasculature is more sensitive to ACh than the ventricular vasculature.

\subsection{Atrial fibrillation}

We have recently shown that AF causes an increase in atrial coronary vascular conductance in pigs ${ }^{16}$. Interestingly, White et al have reported that increasing wall stress by volume expansion to the same level observed during AF caused significantly less increase in atrial myocardial blood flow compared to $\mathrm{AF}^{6}$. This indicates that the total energy expenditure, rather than wall stress per se, is the major determinant of atrial coronary blood flow during AF. The rapid and irregular contraction of the atrial cardiomyocytes during AF are likely to contribute greatly to atrial energy expenditure, while virtually no useful external work is delivered.

The time required for atrial coronary blood flow to return to baseline values after AF was significantly longer than after atrial pacing with a basic cycle length of $400 \mathrm{~ms}$. After a short episode of AF, atrial vascular conductance remained elevated above the baseline level for a prolonged time. This reflects a hyperemic phase after an episode of AF. We have shown previously that short-term AF causes a supply-demand mismatch, marked by an increase in atrial lactate production ${ }^{16}$. During AF, the active atrial pump function is abolished, but atrial myocytes are contracting rapidly, increasing 


\section{Dynamic regulation of atrial coronary blood flow in healthy adult pigs}

energy expenditure. We have showed that atrial contraction in itself impedes atrial flow. It could be expected that the local atrial contractions during AF impede atrial flow by local compression of the vessel wall. In addition, the diastolic phase, which normally provides most of atrial myocardial perfusion, is very short and irregular during AF. This resulting impediment of atrial flow may contribute to the occurrence of oxygen debt during $\mathrm{AF}$ and result in a hyperemic period after the return to normal sinus rhythm. After the cessation of AF, the impediment of atrial flow is relieved immediately while the oxygen debt persists, resulting in a transient elevation of vascular conductance.

\subsection{Limitations}

The experiments are performed in open-chest experiments under anesthesia. Opening of the pericardium may influence atrial wall stress and therefore atrial energy consumption and blood flow, as well as the mechanical interactions between the cardiac chambers ${ }^{30}$. Nevertheless, the waveform characteristics found in this study under open-chest conditions are very similar to the ones measured in humans using a Doppler guide-wire in a closed chest setting.

\subsection{Clinical perspective}

Regulation of the atrial blood supply is essential in maintaining the supply-demand balance, especially during periods of increased atrial demand such as atrial fibrillation. In this study, we have investigated the dynamic regulation of atrial coronary blood flow in healthy pigs. Atrial coronary flow is positively correlated to atrial workload, but responds more slowly to increased heart rate than ventricular flow. The atrial contraction itself strongly impedes atrial flow. After a period of acute atrial fibrillation, atrial flow shows a phase of reactive hyperemia, consistent with the occurrence of supply-demand ischemia. A fuller understanding of the conditions under which atrial supply falls short of demand may lead to novel strategies to prevent atrial remodeling and the progression of AF. 


\section{CHAPTER 5}

\section{CONCLUSION}

The atrial flow pattern showed a consistent decrease during atrial systole. This was caused by the atrial contraction itself rather than atrial pressure. Not only did atrial systole cause flow to decrease, it even reversed in most animals. The systolic phase contributes to only $2 \%$ of total atrial flow. However, the contribution of systolic flow fraction to total flow increased with increasing heart rate in both atrium and ventricle. Atrial vascular conductance is correlated with the performed external work. The flow response to acute changes in heart rate, however, was slower in the atrium compared to the ventricle. In addition, the occurrence of hyperemia after the cessation of short term AF in healthy pigs supports our earlier findings of a supply-demand mismatch in AF.

\section{FUNDING SOURCES}

This work was supported by the Foundation Leducq (07 CVD 03), and the European Union (European Network for Translational Network in Atrial Fibrillation, EUTRAF, grant no. 261057).

\section{REFERENCES}

1. Krahn AD, Manfreda J, Tate RB, Mathewson FA, Cuddy TE. The natural history of atrial fibrillation: incidence, risk factors, and prognosis in the Manitoba Follow-Up Study. Am J Med 1995;98:476-484.

2. Kannel WB, Wolf PA, Benjamin EJ, Levy D. Prevalence, incidence, prognosis, and predisposing conditions for atrial fibrillation: population-based estimates. Am J Cardiol 1998;82:2N-9N.

3. Benjamin EJ, Wolf PA, D'Agostino RB, Silbershatz H, Kannel WB, Levy D. Impact of atrial fibrillation on the risk of death: the Framingham Heart Study. Circulation 1998;98:946-952.

4. MCHale PA, Rembert JC, Greenfield JC, Jr. Effect of atrial fibrillation on atrial blood flow in conscious dogs. Am J Cardiol 1983;51:1722-1727.

5. White CW, Holida MD, Marcus ML. Effects of acute atrial fibrillation on the vasodilator reserve of the canine atrium. Cardiovasc Res 1986;20:683-689.

6. White CW, Kerber RE, Weiss HR, Marcus ML. The effects of atrial fibrillation on atrial pressure-volume and flow relationships. Circ Res 1982;51:205-215.

7. Neill WA, Phelps NC, Oxendine JM, Mahler DJ, Sim DN. Effect of heart rate on coronary blood flow distribution in dogs. Am J Cardiol 1973;32:306-312. 


\section{Dynamic regulation of atrial coronary blood flow in healthy adult pigs}

8. Neill WA, Sewell D, Gopal M, Oxendine J, Painter L. Independent regulation of atrial coronary blood flow by atrial contraction rate in conscious dogs. Pflugers Arch 1980;388:193-195.

9. Bauman RP, Rembert JC, Greenfield JC, Jr. Regional blood flow in canine atria during exercise. The American journal of physiology 1993;265:H629-632.

10. Manohar M, Goetz TE, Hutchens E, Coney E. Atrial and ventricular myocardial blood flows in horses at rest and during exercise. Am J Vet Res 1994;55:1464-1469.

11. Friedman HS, O'Connor J, Kottmeier S, Shaughnessy E, McGuinn R. The effects of atrial fibrillation on regional blood flow in the awake dog. Can J Cardiol 1987;3:240-245.

12. Ausma J, Coumans WA, Duimel H, Van der Vusse GJ, Allessie MA, Borgers M. Atrial high energy phosphate content and mitochondrial enzyme activity during chronic atrial fibrillation. Cardiovasc Res 2000;47:788-796.

13. Thijssen VL, van der Velden HM, van Ankeren EP, Ausma J, Allessie MA, Borgers M, van Eys $\mathrm{GJ}$, Jongsma HJ. Analysis of altered gene expression during sustained atrial fibrillation in the goat. Cardiovasc Res 2002;54:427-437.

14. Ogi $\mathrm{H}, \mathrm{Nakano} \mathrm{Y}, \mathrm{Niida} \mathrm{S}$, et al. Is structural remodeling of fibrillated atria the consequence of tissue hypoxia? Circ J 2010;74:1815-1821.

15. Duncker DJ, Bache RJ. Regulation of coronary blood flow during exercise. Physiol Rev 2008;88:1009-1086.

16. van Bragt KA, Nasrallah HM, Kuiper M, Luiken JJ, Schotten U, Verheule S. Atrial supply-demand balance in healthy adult pigs: coronary blood flow, oxygen extraction, and lactate production during acute atrial fibrillation. Cardiovasc Res 2014;101:9-19.

17. van Bragt KA, Nasrallah HM, Kuiper M, Luiken Ulrich Schotten JJ, Verheule S. Atrial supply-demand balance in healthy adult pigs: Coronary blood flow, oxygen extraction and lactate production during acute atrial fibrillation. Cardiovasc Res 2013.

18. Schotten U, Duytschaever M, Ausma J, Eijsbouts S, Neuberger HR, Allessie M. Electrical and contractile remodeling during the first days of atrial fibrillation go hand in hand. Circulation 2003;107:1433-1439.

19. Chilian WM, Marcus ML. Phasic coronary blood flow velocity in intramural and epicardial coronary arteries. Circ Res 1982;50:775-781.

20. Kajiya F, Tomonaga G, Tsujioka K, Ogasawara Y, Nishihara H. Evaluation of local blood flow velocity in proximal and distal coronary arteries by laser Doppler method. J Biomech Eng 1985;107:10-15.

21. Skalidis El, Kochiadakis GE, Igoumenidis NE, Vardakis KE, Vardas PE. Phasic coronary blood flow velocity pattern and flow reserve in the atrium: regulation of left atrial myocardial perfusion. $J$ Am Coll Cardiol 2003;41:674-680.

22. Skalidis EI, Hamilos MI, Karalis IK, Chlouverakis G, Kochiadakis GE, Vardas PE. Isolated atrial microvascular dysfunction in patients with lone recurrent atrial fibrillation. J Am Coll Cardiol 2008;51:2053-2057.

23. Kajiya F, Tsujioka K, Ogasawara Y, Hiramatsu O, Wada Y, Goto M, Yanaka M. Analysis of 


\section{CHAPTER 5}

the characteristics of the flow velocity waveforms in left atrial small arteries and veins in the dog. Circ Res 1989;65:1172-1181.

24. Kimura A, Hiramatsu O, Wada Y, Yada T, Yamamoto T, Goto M, Ogasawara Y, Tsujioka K, Kajiya F. Atrial contractility affects phasic blood flow velocity of atrial small vessels in the dog. Cardiovasc Res 1992;26:1219-1225.

25. Westerhof N, Boer C, Lamberts RR, Sipkema P. Cross-talk between cardiac muscle and coronary vasculature. Physiol Rev 2006;86:1263-1308.

26. Spaan JA, Breuls NP, Laird JD. Diastolic-systolic coronary flow differences are caused by intramyocardial pump action in the anesthetized dog. Circ Res 1981;49:584-593.

27. Kondo M, Kawata K, Azuma A, Yamada H, Kohno H, Yagi T, Sawada T, Tatsukawa H, Sugihara $\mathrm{H}$, Nakagawa $\mathrm{M}$. Relationship between coronary blood flow velocity waveform and transmural distribution of myocardial blood flow in coronary artery. Jpn Heart J 1999;40:783-790.

28. Schotten U, de Haan S, Neuberger HR, Eijsbouts S, Blaauw $Y$, Tieleman R, Allessie M. Loss of atrial contractility is primary cause of atrial dilatation during first days of atrial fibrillation. Am J Physiol Heart Circ Physiol 2004;287:H2324-2331.

29. Oltman CL, Parker JL, Adams HR, Laughlin MH. Effects of exercise training on vasomotor reactivity of porcine coronary arteries. The American journal of physiology 1992;263:H372-382.

30. Maruyama Y, Ashikawa K, Isoyama S, Kanatsuka H, Ino-Oka E, Takishima T. Mechanical interactions between four heart chambers with and without the pericardium in canine hearts. Circ Res 1982;50:86-100. 


\section{The impact of persistent atrial fibrillation on the atrial supply-demand balance}

Kelly van Bragt

Hussein M. Nasrallah

Marion Kuiper

Joost J. Luiken

Ulrich Schotten

Sander Verheule

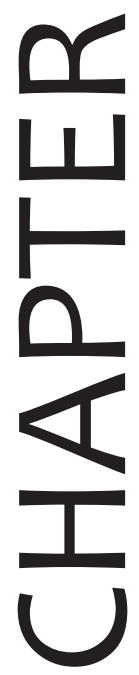

Submitted to Cardiovasc Res. 


\section{ABSTRACT}

BACKGROUND: Atrial fibrillation (AF) leads to atrial remodeling that contributes to the perpetuation of the arrhythmia. We have recently shown that acute AF leads to supply-demand ischemia in pigs. Some aspects of atrial remodeling processes can be viewed as adaptation to energy shortage. Here, we have compared atrial coronary flow regulation, oxygen extraction and lactate production between control pigs and pigs with chronic AF.

METHODS AND RESULTS: AF was induced by rapid atrial pacing (RAP, using digoxin to control ventricular rate) in twelve Dutch Landrace pigs (62 $23 \mathrm{~kg}$ ) and compared to fifteen controls (61 $\pm 2 \mathrm{~kg}$ ). To characterize the model, alterations in AF stability, hemodynamics and tissue structure were assessed. Atrial and ventricular extraction, conductance and lactate were measured. Five weeks of RAP resulted in an increase in AF inducibility and duration. Myocyte hypertrophy in left and right atria (LA and RA) and increased interstitial fibrosis in the RA were observed. The capillary density was decreased by $51 \%$ in the LA and $57 \%$ in the RA. Coronary conductance reserve (determined as the response to intracoronary adenosine infusion) was not different between the groups. The response of atrial vascular conductance and oxygen extraction to atrial pacing and AF was similar between RAP and control pigs. The increase in lactate production that was observed after 5 minutes of AF in control animals was not present in the RAP group.

CONCLUSIONS: At 5 weeks of sustained AF in pigs, the supply-demand balance is restored and atrial ischemia during $A F$ is prevented. Atrial remodeling can be seen as a successful adaptation to energy shortage. 
1. INTRODUCTION

$\mathrm{AF}$ is the most common tachyarrhythmia in clinical practice. AF is self-perpetuating since it causes atrial remodeling processes that in turn increase AF stability. Rapid atrial pacing (RAP), either with or without ventricular rhythm control, has been widely used in animal models to represent AF without preexisting structural heart disease. In these models, different aspects of atrial remodeling have been described. Electrical remodeling, i.e. a shortening of the atrial action potential duration (ADP) and effective refractory period (AERP) ${ }^{1,2}$, is a relatively fast process, developing over 1-2 days. In a goat model of AF, electrical remodeling increased the duration of induced AF episodes from seconds to minutes. The underlying downregulation of the L-type calcium current $\left(\mathrm{ICa}_{\mathrm{L}}\right)$ not only contributes to APD shortening, but also to the observed reduction in atrial contractility, because entry of calcium through $\mathrm{ICa}_{\mathrm{L}}$ initiates the contraction ${ }^{3,4}$. Structural remodeling is a much slower process, evolving gradually over a time course of weeks to years ${ }^{5,6}$. The AF-induced structural changes include myocyte hypertrophy, glycogen accumulation, loss of sarcomeres (myolysis), alterations in connexin expression, changes in mitochondrial shape, fragmentation of sarcoplasmic reticulum, redistribution of nuclear chromatin and changes in quantity and localization of structural cellular proteins ${ }^{7}$. Ausma et al have described these changes as 'hibernation', proposing that they reflect dedifferentiation into a more fetal phenotype, and resembling the changes in ventricular myocytes during chronic low flow ischemia $6,8,9$.

We have recently shown that acute AF in pigs leads to an increase in atrial coronary flow and oxygen extraction. Nevertheless, supply-demand ischemia occurred within minutes, as evidenced by increased atrial lactate production (CHAPTER 4) ${ }^{10}$. On the longer term, the occurrence of atrial ischemia during AF is supported by decreased phosphocreatine levels in the first weeks of AF in goats ${ }^{11,12}$. In addition, markers of hypoxia and angiogenesis $\left(\mathrm{HIF}_{1 \alpha}, \mathrm{HIF}_{2 \alpha}, \mathrm{VEGF}\right)$ are increased in goats with $\mathrm{AF}$ and in AF patients ${ }^{13,14}$. Some aspects of atrial remodeling can be viewed as adaptation to energy shortage, i.e. decreased APD and contractility and hibernation of myocytes. The effect of chronic AF on atrial vascular structure and atrial supply-demand balance has not been investigated extensively. Here, we have investigated the effect of 5 weeks sustained AF on atrial vascular structure, function, oxygen extraction and lactate production. 


\section{METHODS}

\subsection{Model}

Twelve Dutch Landrace pigs (62 $53 \mathrm{~kg}$ ), were anesthetized as described below, intubated and mechanically ventilated. An endocardial lead (J-Leads Capsurefix 5568 - 53 $\mathrm{cm}$, Medtronic Inc, Minneapolis, Minnesota) was implanted in the right atrium and connected to a subcutaneous pacemaker (Itrel II, Medtronic, Minneapolis, MN). Pigs were allowed one week recovery after implantation before the pacemaker was switched on at a rate of $10 \mathrm{~Hz}$ for 5 weeks (rapid atrial pacing, RAP). Ventricular rate was controlled by digoxin $10 \mathrm{~g} \mu \mathrm{g} / \mathrm{kg}$ for 1 week, followed by $5 \mu \mathrm{gg} / \mathrm{kg}$ for 4 weeks (Timeline Figure $1 \mathrm{~A}$ ). Digoxin was stopped 3 days before the sacrifice experiment in order to reach plasma levels $<0.5 \mu \mathrm{g} / \mathrm{ml}$ during the measurements. Fifteen healthy control pigs ( $61 \pm 2 \mathrm{~kg}$ ) served as a control group. All animal procedures were conducted in accordance with institutional and national guidelines.

\subsection{Study protocol}

For open-chest sacrifice experiments, anesthesia was induced with Zoletil ( $5-8 \mathrm{mg} / \mathrm{kg}$ I.M.) and Thiopenthal (5-15 mg/kg I.V.) and maintained with an intravenous infusion of Midazolam (1.0 mg/kg/h), Sufentanyl (4 mg/kg/h) and Propofol (2.5-10 mg/kg/h). Cardiac output was measured during normal sinus rhythm (NSR) using thermodilution with a closed chest to compare control and RAP animals. Also aortic pressure $\left(P_{A o}\right)$ and left ventricular pressure $\left(P_{L V}\right)$ were recorded during NSR with a closed chest. From these signals, end-diastolic pressure, heart rate, $\mathrm{dP} / \mathrm{dt}$ max and mean $\mathrm{P}_{\mathrm{Ao}}$ were calculated offline using custom software.

All RAP pigs converted to NSR spontaneously during the induction of anesthesia. A left lateral incision was made, the $5^{\text {th }}$ rib was removed and the pericardium was opened to expose the left side of the heart for further instrumentation. Subsequently, monophasic action potentials were recorded using a MAP-4801 monophasic action potential and stimulation catheter (7 FR, Hugo Sachs Elektronics, Harvard Apparatus, March-Hugstetten, Germany) and the action potential duration (APD) was calcula- 
ted. The APD50 and APD80 were calculated to determine the degree of electrical remodeling in the RAP pigs. They reflect the time for the action potential to repolarize to $50 \%$ and $20 \%$ of the maximum amplitude respectively. In addition, atrial epicardial conduction was measured on the LA and RA free walls using a round high density mapping electrode array of $4 \mathrm{~cm}$ in diameter, consisting of 234 unipolar recording electrodes with an interelectrode distance of $2.4 \mathrm{~mm}$, connected to a 256-channel amplifier (sampling rate $1 \mathrm{kHz}$, filtering bandwidth $0.5-500 \mathrm{~Hz}$ ). AF was induced 5 times by $5 \mathrm{~s} 20 \mathrm{~Hz}$ burst pacing at 4 times stimulation threshold in the RA. Sustained AF was defined as a rapid, irregular atrial activation pattern lasting more than $5 \mathrm{~min}$. AF was terminated by electrical cardioversion if it lasted $>30 \mathrm{~min}$. Using custom software, time points of maximum negative $\mathrm{dV} / \mathrm{dt}$ were determined for each electrode to determine local activation times. After epicardial mapping, pigs were randomly assigned to experimental series $A$ or $B$ or both experiments were performed in succession. In both series $A$ and $B$, an ablation catheter in the RA was used for pacing and $A F$ induction. During NSR, pacing at basic cycle lengths $(B C L)$ of 500, 450 and $400 \mathrm{~ms}$ and during acute $\mathrm{AF}$, atrial and ventricular coronary blood flow (series $A$ ) or oxygen extraction and lactate production (series B) were investigated.

\section{Series A: Coronary vascular conductance}

RAP $(\mathrm{N}=8)$ and control $(\mathrm{N}=9)$ animals were instrumented with a Doppler flow probe (Transonic Systems Inc, Ithaca, NY) around a left atrial (LA) and left ventricular (LV) branch of the left circumflex artery (LCX), as previously described (CHAPTER 4) ${ }^{10}$. Conductance was calculated by dividing the flow in the atrial $\left(Q_{L A}\right)$ and ventricular $\left(Q_{L V}\right)$ branch by the pressure difference over the vascular bed $\left(P_{A o}-P_{R A}\right)$. To calculate the pressure difference, a right atrial pressure $\left(P_{R A}\right.$, micro tip pressure sensor, Millar Instruments, Houston, $\mathrm{TX})$ and aortic pressure $\left(\mathrm{P}_{\mathrm{AO}}\right.$, pressure catheter, Sentron Europe BV, Roden, The Netherlands) were recorded simultaneously with the Doppler flow signals. In addition, left ventricular pressure $\left(P_{\mathrm{LV}}\right)$ was measured with a Sentron conductance catheter (Sentron Europe BV, Roden, The Netherlands). The maximal vascular conductance was calculated during a $10 \mathrm{ml}$ intracoronary bolus of $300 \mu \mathrm{g}$ adenosine infusion as described previously (CHAPTER 4) ${ }^{10}$ and was used to determine the coronary conductance reserve $(C C R): C C R=$ maximal conductance $\left(C_{\text {MAX }}\right)$ / baseline conductance $\left(\mathrm{C}_{\mathrm{BSLN}}\right)$ 
Series B: Extraction and lactate levels

Blood was collected from an atrial and ventricular vein in $\operatorname{RAP}(\mathrm{N}=9)$ and control $(\mathrm{N}=7)$ animals as was previously described (CHAPTER 4) ${ }^{10}$. Arterial blood was sampled from the LV through a double AO/LV Millar pressure catheter (Millar Instruments, Houston, TX). An i-Stat analyzer (Abbott Laboratories, Illinois, U.S.A, with EG7+ cartridges) was used for blood gas analysis of venous and arterial blood samples. Blood lactate levels were measured in the same blood samples using a Lactate SCOUT+ (Senslab GmbH, Leipzig, Germany). Total arterial and venous oxygen content $\left(\mathrm{CaO}_{2}\right.$ and $\left.\mathrm{CvO}_{2}\right)$, oxygen extraction ratio, extraction reserve and lactate production were calculated using the following formulas:

- $\mathrm{CaO}_{2} / \mathrm{CvO}_{2}\left(\mathrm{ml} \mathrm{O}_{2} / 100 \mathrm{ml}\right)=\left(1.36 \times \mathrm{O}_{2}\right.$ saturation $(\%) \times$ Hemoglobin $\left.(\mathrm{g} / \mathrm{dL})\right)+$ (0.0031 x partial $\mathrm{O}_{2}$ pressure $(\mathrm{mmHg})$ )

- $\quad$ Extraction ratio $=\left(\mathrm{CaO}_{2}-\mathrm{CvO}_{2}\right) / \mathrm{CaO}_{2} *_{100}$

- $\quad$ Extraction reserve $=\mathrm{CaO}_{2} /\left(\mathrm{CaO}_{2}-\mathrm{CvO}_{2}\right)$

- $\quad$ Lactate production = arterial lactate concentration - venous lactate concentration

\subsection{Histology}

After the open chest experiment, the heart was rapidly excised and rinsed with saline solution. Tissue samples of the LA and RA were stored in $4 \%$ formaldehyde for at least $24 \mathrm{~h}$, embedded in paraffin and cut into $5 \mu \mathrm{m}$ tissue sections. Heamatoxilin \& Eosin (H\&E), and Sirius Red staining were performed to measure cell diameter and interstitial fibrosis, respectively, and to provide information on the degree of atrial structural remodeling. Cell diameter was analyzed on one H\&E section ( 3 to 4 locations per slide) at a 400x magnification in transversely cut cardiomyocytes at the level of the nucleus. Overall fibrosis was measured in 3 to 4 locations per Sirius Red-stained slide at 200x magnification. For this analysis, the epicardial and endocardial fibrous layer and perivacular fibrosis were excluded, and a color threshold was set to determine the relative surface area of red pixels (fibrosis) per tissue area. From the same Sirius Red stanings, larger vessels were photographed at higher magnification. In these images, the degree of perivascular fibrosis was quantified as the area of fibrous 
tissue around a vessel to the area of the vessel wall. Griffonia Simplicifolia I (GSI) staining was used to label vessels and thus quantify capillary density. Vessels were detected using a trainable Weka segmentation software, and counted using 'particle analysis' function in Fiji (www.fiji.sc/Fiji). All other histological analyses with ImageJ (http://fiji.sc/ImageJ).

\subsection{Statistical analysis}

To compare mean values for pressures, heart rate, body and heart weight, AF parameters, CCR and extraction reserve between control and RAP animals, a t-test was used. Histological parameters were analyzed with a mixed model analysis. AF inducibility was tested with a $\chi^{2}$ test. AF duration was analyzed using a Mann-Whitney $U$ test. Values are expressed as mean \pm SEM.
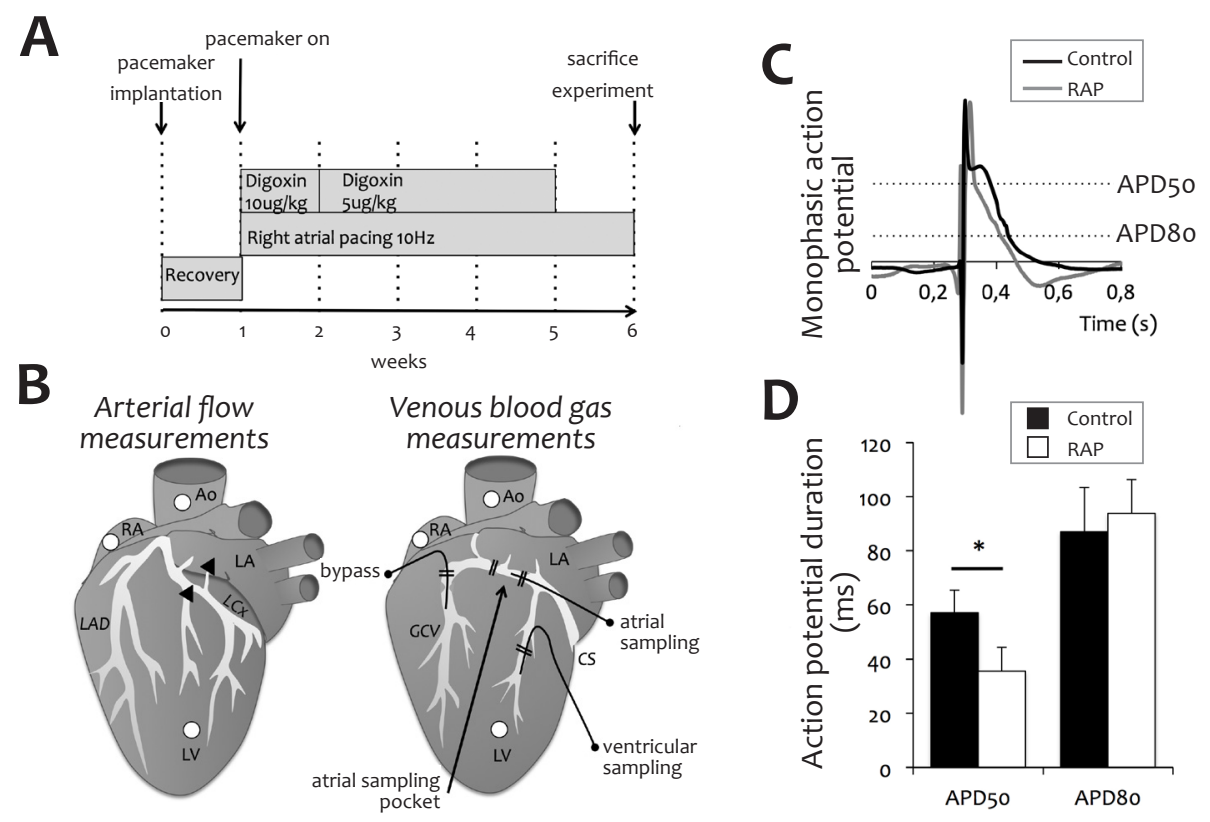

Figure 1: Rapid atrial pacing model. A) Time line of the protocol. B) Graphic representation of arterial flow measurements (left) ad venous blood gas measurement (right). Ao= aorta, RA=right atrium, $\mathrm{LA}=$ left atrium, $\mathrm{CS}=$ coronary sinus, $\mathrm{GVC}=$ great cardiac vein, $\mathrm{LV}=$ =let ventricular, white circles indicate pressure catheters, black triangles represent flow probes. C) Representative action potential of control (black) and RAP (grey) pig and D) Calculation of action potential duration (APD) at $50 \%$ and $80 \%$ recovery in control (black, $\mathrm{N}=5$ ) and RAP (white, $\mathrm{N}=6$ ). 


\section{RESULTS}

\subsection{Characterization of the RAP model}

3.1.1. Hemodynamic parameters

A comparison of hemodynamic parameters in control and RAP pigs is provided in Table 1. There were no significant differences between the two groups in body weight, heart weight, cardiac output, heart rate and end-diastolic pressure. Mean aortic pressure and left ventricular dP/dt max were significantly lower in the RAP group compared to control.

\subsubsection{Electrophysiological parameters}

The morphology of monophasic action potentials differed between control and RAP animals (Figure $1 \mathrm{C}$ ). Although the APD80 was similar, the plateau phase was less pronounced in the RAP group, reflected in a significant decrease in APD50 (Figure $1 C$ and $\mathrm{D} ; 36 \pm 9 \mathrm{~ms}$ in $\mathrm{RAP}(\mathrm{N}=6)$ vs. $57 \pm 18 \mathrm{~ms}$ in control $(\mathrm{N}=5), \mathrm{p}=0.03)$.

In the RAP group the average for the longest AF episode observed in each animal was significantly higher than in the control group (Figure $2 \mathrm{~A}$ and $2 \mathrm{~B}$ ). AF was not

\begin{tabular}{llll}
\hline & Control & RAP & P-value \\
\hline Body weight $(\mathrm{kg})$ & $61 \pm 2$ & $62 \pm 3$ & $\mathrm{~ns}$ \\
Heart weight $(\mathrm{g})$ & $352 \pm 21$ & $362 \pm 20$ & $\mathrm{~ns}$ \\
Heart weight/ body weight $(\mathrm{g} / \mathrm{kg})$ & 5.8 & 5.8 & $\mathrm{~ns}$ \\
Heart rate (bpm) & $78 \pm 6$ & $69 \pm 2$ & $\mathrm{~ns}$ \\
Cardiac output during NSR (ml/min) & $4.93 \pm 0.48$ & $4.24 \pm 0.26$ & $\mathrm{~ns}$ \\
Mean aortic pressure (mmHg) & $83.0 \pm 3.8$ & $63.9 \pm 1.5$ & $\mathrm{p}<0.001$ \\
dP/dT max (mmHg/s) & $1861 \pm 127$ & $1053 \pm 21$ & $\mathrm{p}<0.001$ \\
End diastolic pressure (mmHg) & $11.8 \pm 1.4$ & $12.0 \pm 1.3$ & $\mathrm{~ns}$ \\
\hline
\end{tabular}

Table 1: Characteristics of control $(\mathrm{N}=15)$ and RAP $(\mathrm{N}=12)$ pigs. Values expressed as mean $\pm \mathrm{SEM}$. *P<0.05 control vs. RAP. 
sustained in any of the animals in the control group, but was sustained (i.e. lasting $>5$ $\mathrm{min}$ ) in 11 out of 12 RAP pigs (Figure 2B). Although AF was sustained in the RAP group, the average $A F$ cycle length was longer in the RAP group than in the control group, both in the LA ( $219 \pm 10$ vs $153 \pm 18$ ms respectively, $p=0.002$ ) and RA (208 \pm 14 vs $159 \pm 26$ $m$ s respectively, $p=0.046$ ) as shown in Figure $2 C$.
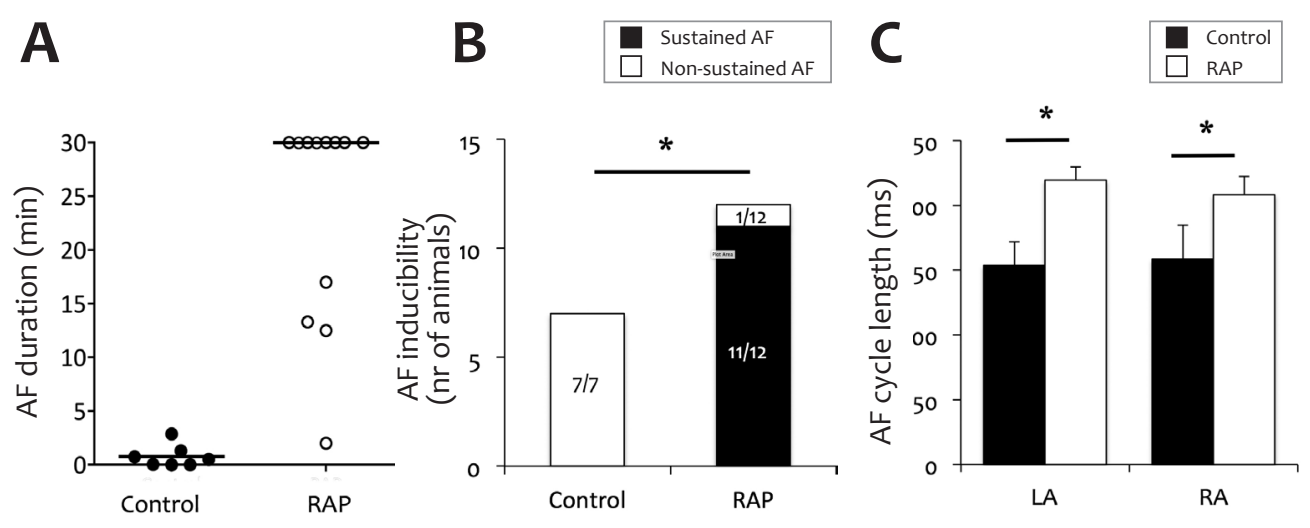

Figure 2: Characteristics of atrial fibrillation (AF). A) AF duration in control (black, N=7) vs. RAP (white, $\mathrm{N}=12)$. B) AF inducibility in control $(\mathrm{N}=7)$ and $\mathrm{RAP}(\mathrm{N}=12)$. C) AF cycle length in control (black, $\mathrm{N}=5$ ) and RAP (white, $\mathrm{N}=9$ ). Values for $A F$ cycle length in mean $\pm S E M, * \mathrm{p}<0.05$ control vs. RAP 0.05 control vs. RAP

\subsubsection{Histological parameters}

RAP resulted in atrial hypertrophy (Figure $3 \mathrm{~A}$ ) in both the left and right atrium. Cell diameter was increased significantly from $10.8 \pm 0.6 \mu \mathrm{m}(\mathrm{N}=10)$ in the $L A$ of control animals to $12.5 \pm 0.7 \mu \mathrm{m}(\mathrm{N}=11)$ in the LA RAP animals $(\mathrm{p}=0.032)$. In the RA, cell diameter was 10.9 $\pm 1.9 \mu \mathrm{m}(\mathrm{N}=8)$ in the control group compared to $16.2 \pm 1.2 \mu \mathrm{m}(\mathrm{N}=11)$ in the RAP group $(p=0.009)$. RAP resulted in the induction of fibrosis formation (Figure 3B). Interstitial fibrosis (\%) per myocardial area in the LA of AF animals was not significantly different from control $(p=0.35)$. However, in the RA, a significant increase in interstitial fibrosis was found in the AF animals $(23 \pm 2 \%, \mathrm{~N}=11)$ compared to control animals $(16 \pm 2 \%, \mathrm{~N}=8, \mathrm{p}=0.01)$. 

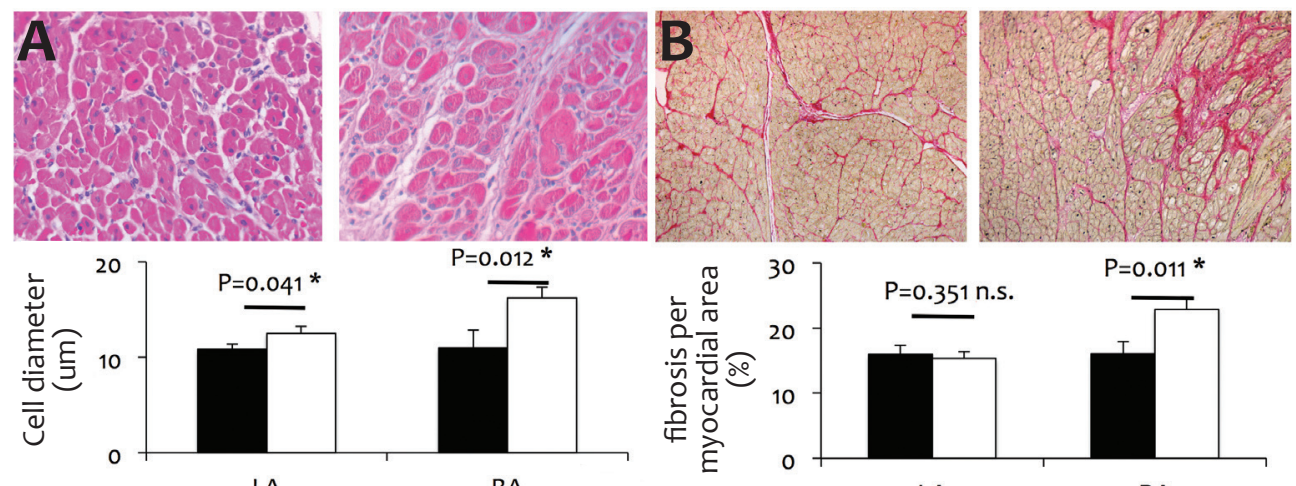

LA

RA

LA

RA
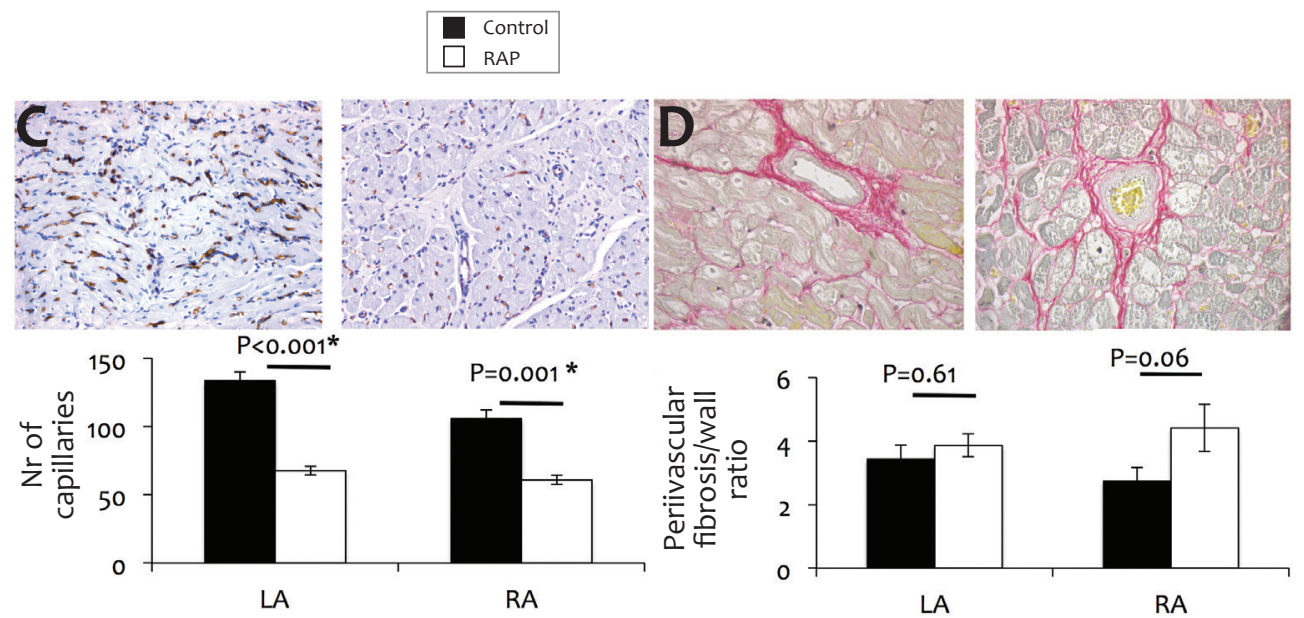

$P=\underline{0.06}$

Figure 3: Histology. A) Representative images of Hematoxiline \& Eosine staining in the right atrial (RA) of control (left) and RAP (right) and calculation of cell diameter $(\mu \mathrm{m})$ in left (LA) and right (RA) atrium. B) Representative images of Sirius Red staining in the right atrial (RA) of control (left) and RAP (right) and calculation of interstitial fibrosis per myocardial area (\%) in left (LA) and right (RA) atrium. C) Representative images of $C D 36$ staining in the right atrial (RA) of control (left) and RAP (right) and calculation of capillary density per field of view in left (LA) and right (RA) atrium. D) Representative images of Sirius Red staining in the right atrial (RA) around small vessels of control (left) and RAP (right) and calculation of perivascular fibrosis/wall area ratio in left (LA) and right (RA) atrium. $P<0.05$ control vs. RAP 


\section{The impact of persistent atrial fibrillation on the atrial supply-demand balance}

\subsection{Vascular structure and function}

\subsubsection{Vascular remodeling}

A histological analysis was performed to identify changes in vasculature structure induced by long-term AF. There was a significant decrease in the capillary density (the number of vessel per field of view) in both the LA and RA of RAP pigs compared to control (Figure $3 C p<0.001$ ). Larger arteries with sizes in the range of conduit arteries and resistances arterioles were photographed separately at higher magnification to quantify perivascular fibrosis (Figure 3D). The ratio between the areas occupied by perivascular fibrosis and vascular wall was not different between the groups for the LA ( $p=0.61)$, although there was a trend towards an increase in the RA ( $p=0.06)$.

\subsubsection{Atrial coronary flow regulation}

In both groups, the phasic pattern in the atrial coronary flow showed a decrease during atrial activation (Figure $4 \mathrm{~A}$ and $\mathrm{B}$ ). However, this decrease was smaller in the RAP group than in the control group. In 7 out of 9 control animals, atrial flow reversed during atrial contraction, whereas a reversal of atrial flow was only observed in 2 out of 7 RAP pigs. In accordance with this observation, the systolic flow fraction (i.e. the relative contribution of systolic flow to total flow) was higher in the RAP group than in the control group (Figure $4 \mathrm{C}, \mathrm{p}=0.048$ ).

Flow measurements with Doppler flow probes were performed in comparable atrial branches supplying the LA free wall in all animals. The baseline flow during NSR was not different between the control and RAP groups $(3.5 \pm 0.9 \mathrm{ml} / \mathrm{min}$ vs. $3.3 \pm 0.8 \mathrm{ml} /$ $\mathrm{min}, \mathrm{p}=0.43$ ). Flow during maximum vasodilatation (i.e. infusion of adenosine into the circumflex artery) was similar between the control and RAP pigs $(7.2 \pm 1.5 \mathrm{ml} / \mathrm{min}$ vs. $11.0 \pm 3.9 \mathrm{ml} / \mathrm{min}, \mathrm{p}=0.16)$. The coronary conductance reserve was calculated from the $L A$ and $L V$ vascular conductance (i.e. $\mathrm{Q} /\left(\mathrm{P}_{\mathrm{Ao}}-\mathrm{P}_{\mathrm{RA}}\right)$ at baseline and maximum dilatation. Both the LA ( $1.76 \pm 0.14 \mathrm{vs} .2 .41 \pm 0.57 \mathrm{ml} / \mathrm{min} / \mathrm{mmHg}$ respectively, $\mathrm{p}=0.3)$ and LV CCR ( $3.16 \pm 0.27$ vs. $4.24 \pm 0.64 \mathrm{ml} / \mathrm{min} / \mathrm{mmHg}, p=0.2)$ were not different between the control and RAP group (Figure 4D).

We have shown before that in normal pigs, the external work performed by the atrium increases during atrial pacing (CHAPTER 5) ${ }^{15}$. To investigate the effect of 
increased workload on vascular conduction in both groups, the atrium was paced at 500, 450 and $400 \mathrm{~ms}$. Normalized to the vascular conductance during NSR, there was a significant increase at 450 and $400 \mathrm{~ms}$ in both the control and RAP groups (Figure $5 A)$. This response was not different between the groups $(p=0.4)$. In the LV, pacing had a larger effect on the conductance in RAP animals compared to control ( $p<0.0001)$. In both RAP and control animals pacing induced a significant increase in LV conductance at every pacing rate (Figure $5 \mathrm{~B}$ ). During AF, atrial conductance in RAP animals showed a similar increase as in control animals ( $p=0.2$, Figure $5 C$ ). In the LV, vascular conductance increased during AF in the RAP group, but not in the control group (Figure 5D).

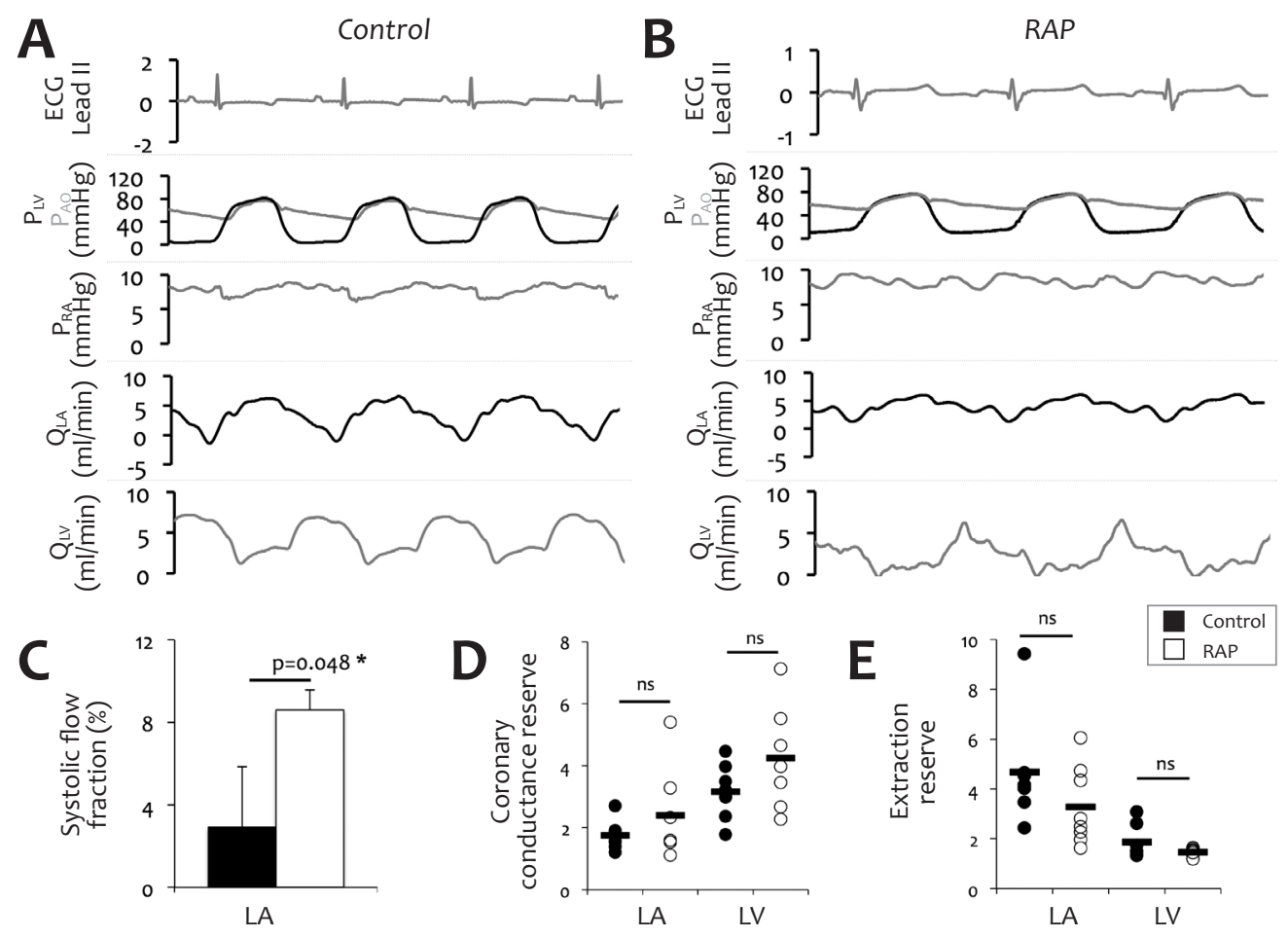

Figure 4: Analysis of coronary flow, conductance and extraction. Representative flow signals of $A$ ) control and $B$ ) RAP pigs. $P A O=$ aortic pressure, $P L V=l e f t$ ventricular pressure, $P R A=$ right atrial pressure, QLA= left atrial flow, QLV=left ventricular flow. C) Calculation of the contribution of flow during systolic flow to total flow in control (black, $N=9$ ) and RAP (white, $N=7$ ). Values in mean $\pm S E M$, ${ }^{*} \mathrm{p}<0.05$ control vs. RAP. D) Coronary conductance reserve and $E$ ) extraction reserve in control (black) and RAP (white) in the left atrium (LA) and left ventricle (LV) 


\section{The impact of persistent atrial fibrillation on the atrial supply-demand balance}
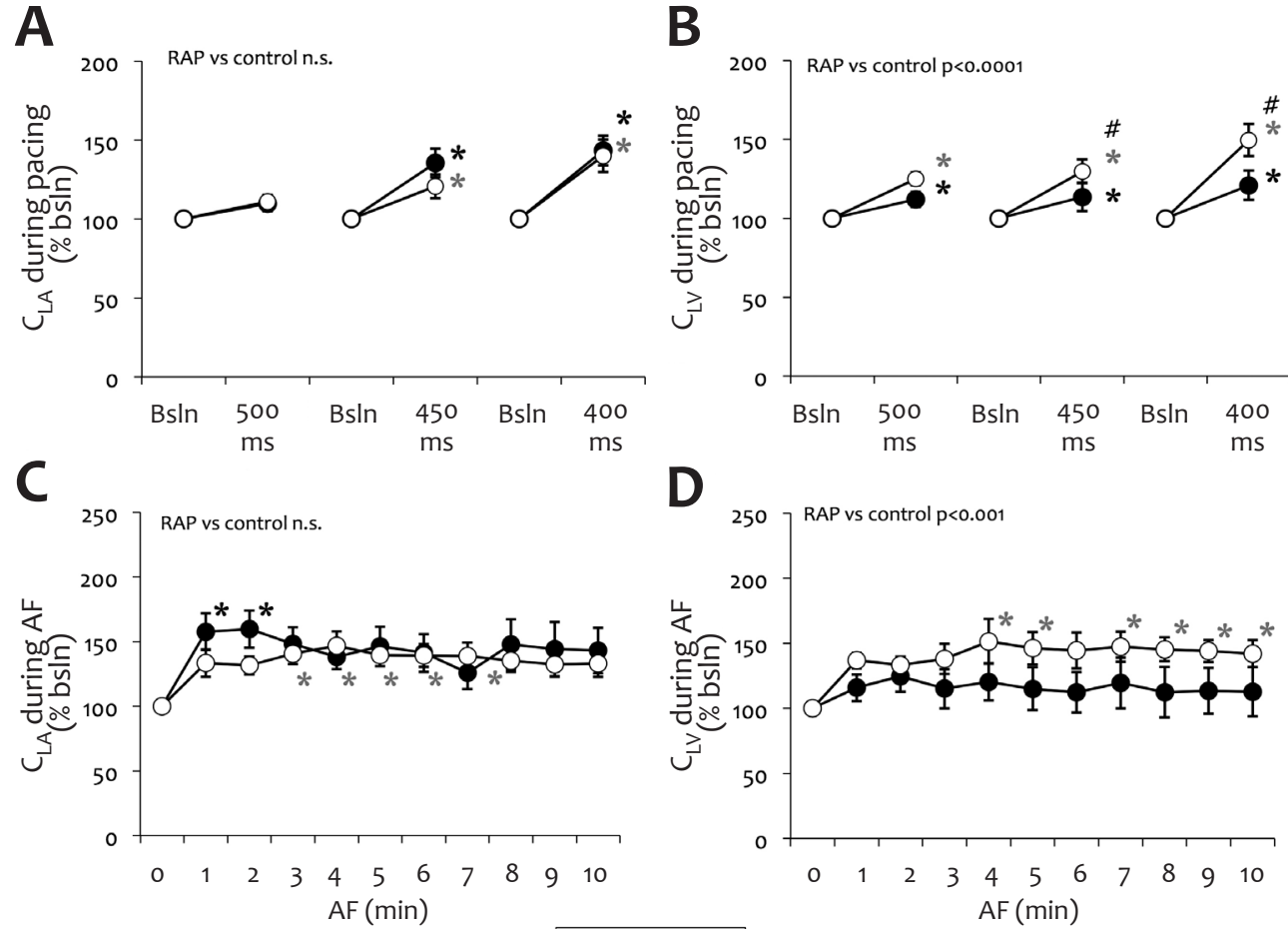

Control $-\mathrm{O}$ - RAP

Figure 5: Coronary conductance during pacing and $A F$. A) Left atrial conductance $\left(C_{L A}\right)$ and $\left.B\right)$ left ventricular conductance $\left(C_{\mathrm{LV}}\right)$ during pacing at 500, 450 and $400 \mathrm{~ms}$ expressed as \% of baseline in control (black, $N=9$ ) and RAP (white, $N=7$ ). C) $C_{L A}$ and $D$ ) $C_{L V}$ during 10 min of AF expressed as \% of baseline in control (black, $\mathrm{N}=9$ ) and RAP (white, $\mathrm{N}=6$ ). Values are expressed as mean $\pm \mathrm{SEM}$, black * $p<0.05$ vs. baseline for control, grey * $p<0.05$ vs. baseline for RAP, \# $p<0.05$ control vs. RAP

\subsubsection{Atrial oxygen extraction and lactate production}

As depicted in Figure 4E, the oxygen extraction reserve tended to be higher in the control group than in the RAP group in the LA ( $4.68 \pm 0.84$ vs. 3.29 $\pm 0.55, p=0.2)$ and LV (1.88 \pm 0.26 vs. $1.47 \pm 0.05, p=0.2$ ).

Oxygen extraction was also measured in the LA and LV during pacing at $500 \mathrm{~ms}, 450$ ms and $400 \mathrm{~ms}$ and during $\mathrm{AF}$ (Fig. 6A and 6B). At $400 \mathrm{~ms} \mathrm{BCL}$ and $\mathrm{AF}$, a significant increase in atrial extraction was seen in control animals at 5 and $10 \mathrm{~min}$. In the RAP animals, there was also a trend towards an increase in atrial extraction, but this was 
not significant at any intervention. There was also no significant difference found between the two groups. Ventricular extraction was not affected in control nor in RAP animals.

Lactate concentrations were measured during the same interventions. During AF, the arterio-venous lactate difference was significantly increased in the LA of control animals from $0.17 \pm 0.17 \mathrm{mmol} / \mathrm{l}$ to $1.22 \pm 0.48 \mathrm{mmol} / \mathrm{l}$ at $5 \mathrm{~min}$ and $1.48 \pm 0.44 \mathrm{mmol} / \mathrm{l}$ at 10 min (Figure $7 A$ ). This was significantly lower in the atrium of RAP pigs. In the RAP group, arterio-venous lactate difference was $0.20 \pm 0.12 \mathrm{mmol} / \mathrm{l}$ at baseline and did not significantly increase at $5 \mathrm{~min}(0.28 \pm 0.07 \mathrm{mmol} / \mathrm{l})$ and $10 \mathrm{~min}(0.43 \pm 0.18 \mathrm{mmol} / \mathrm{l})$ of $A F$. In the ventricle, no increase in arterio-venous lactate difference was observed in control or RAP group under any intervention (Figure $7 \mathrm{~B}$ ).
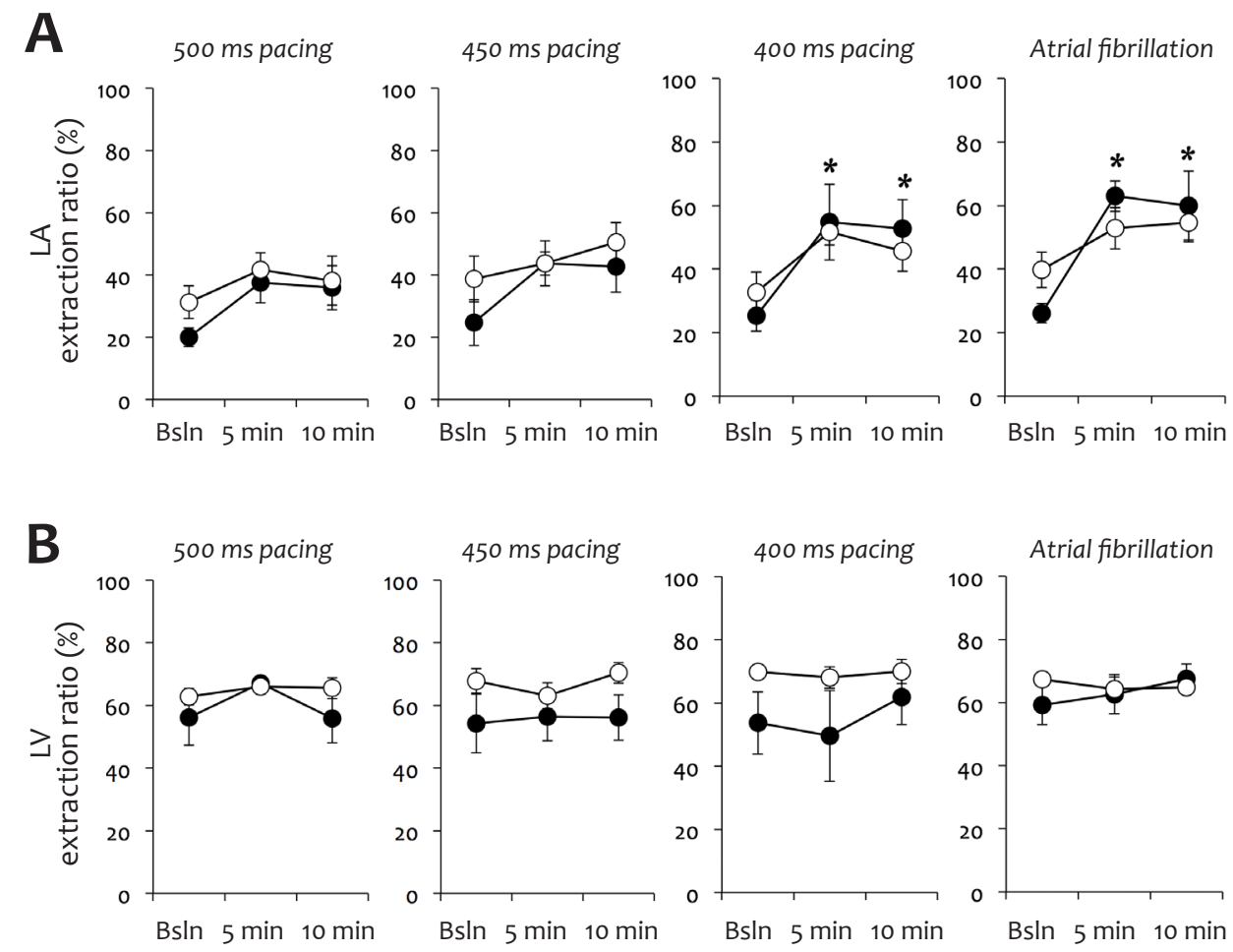

- Control -O-RAP

Figure 6: Extraction during pacing and AF. A) Left atrial (LA) and B) left ventricular (LV) extraction in control (black, $\mathrm{N}=7$ ) and RAP (white, $\mathrm{N}=8$ ). * Values are expressed as mean $\pm \mathrm{SEM}, \mathrm{p}<0.05$ vs. baseline. 


\section{DISCUSSION}

\subsection{RAP in pigs as a model for $A F$}

In this study, we have used rapid atrial pacing in pigs as a model for AF without preexisting structural heart disease. Although dogs and goats with RAP have been more extensively characterized as models for AF, atrial coronary vessels are poorly accessible in goats and there are significant differences in (ventricular) coronary anatomy and regulation between dogs and humans ${ }^{16-18}$. Pigs were chosen as a species because the anatomy and regulation of the coronary vasculature is known to be similar to humans ${ }^{18-20}$. RAP in goats without ventricular rate control does not lead to congestive heart failure (CHF) within 6 months ${ }^{21}$. By contrast, dogs ${ }^{22}$ and pigs ${ }^{23}$ do develop CHF as a result of RAP, evidenced by a decrease in $L V$ ejection fraction, cardiac output, an increase in LV end diastolic, LA and RA pressures, along with clinical signs of $\mathrm{CHF}^{23,24}$. The heart weight to bodyweight is reported to increase from $4.9 \pm 0.6$ to $7.3 \pm 0.4$ after RAP in dogs ${ }^{23}$. CHF by itself, in the absence of $\mathrm{AF}$, can also cause structural changes in the atrium ${ }^{25}$. In order to prevent the development of $\mathrm{CHF}$, pigs received oral digoxin to inhibit AV conduction. In the RAP group, two pigs showed mild ascites, while all other clinical signs were normal in all pigs. Cardiac output was measured with closed chest and was not decreased compared to the control group. Heart weight to total body weight ratio was 5.8 in the control group, and not altered in the RAP group. These parameters indicate that the development of $\mathrm{CHF}$ is at most modest. However, mean arterial pressure and the ventricular $\mathrm{dP} / \mathrm{dt}$ max, a measure for LV contractility, were significantly decreased in the RAP group, indicating a degree of ventricular systolic dysfunction, although the cardiac output was maintained.

In several species, AF (artificially maintained by RAP) leads to electrical and structural remodeling, resembling the remodeling processes in AF patients 5 . In goats, the relatively fast process of electrical remodeling (1-2 days) leads to a decrease in APD, ERP and a concomitant decrease in AFCL ${ }^{1,2,26}$. Similarly, APD, ERP and AFCL decreased in a dog model of RAP with controlled ventricular rate (AV block + ventricular pacing) ${ }^{27}$. The decrease in APD during electrical remodeling coincides with a down-regulation of $\mathrm{ICa}_{\mathrm{L}}$ and $\mathrm{I}_{\mathrm{to}}$ currents ${ }^{1,28,29}$ but also an upregulation of $\mathrm{I}_{\mathrm{K} 1}$ current ${ }^{30}$. Mathematical modeling suggests the latter is the most important determinant of APD shortening ${ }^{30}$. 


\section{CHAPTER 6}

The decrease in atrial contractility during electrical remodeling closely parallels the decrease in $\mathrm{ICa}_{\mathrm{L}}$ current density ${ }^{3}$. The relatively slow process of structural remodeling as a result of RAP has also been characterized in several species. The presence of fibrosis is different in different models of AF. In dogs, 6-8 weeks of RAP with a controlled ventricular rate (AV block + ventricular pacing) did not lead to an increase in overall fibrosis ${ }^{27}$. However, an increase in LA and RA interstitial fibrosis and extracellular matrix proteins was described previously in a pig model after 6 wks of RAP with controlled ventricular rate (digoxin) ${ }^{25}$. RAP without controlled ventricular rate did lead to degenerative structural remodeling in dogs, including fibrosis ${ }^{31}$. In goats, overall fibrosis does not increase as a result of RAP, but interstitial fibrosis in the epicardial layer does increase ${ }^{32}$. Also in the goat model atrial structural changes
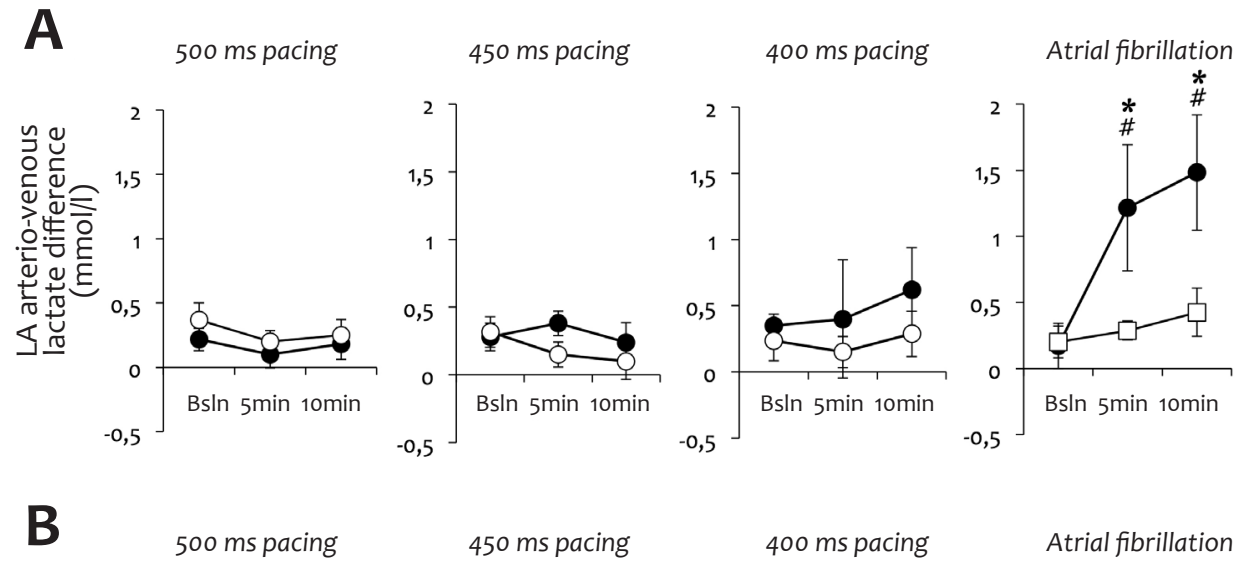

450 ms pacing

400 ms pacing

Atrial fibrillation
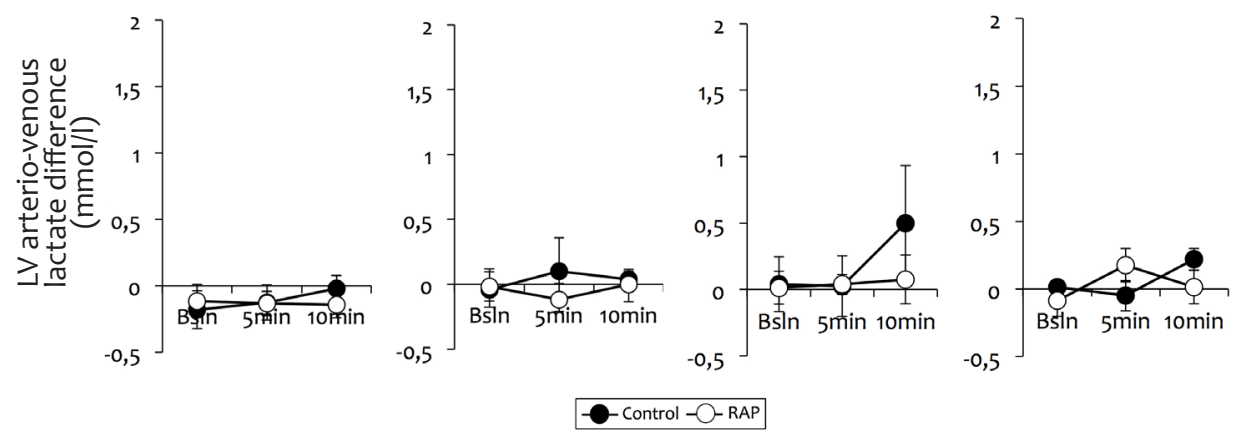

Figure 7: Lactate production during pacing and AF. A) Left atrial (LA) and B) left ventricular (LV) arterio-venous lactate control in control (black, $\mathrm{N}=7$ ) and RAP (white, $\mathrm{N}=8$ ) during pacing and $\mathrm{AF}$. * Values are expressed as mean $\pm S E M, p<0.05$ vs. baseline, $\# p<0.05$ control vs RAP. 
seem to depend to some extent on a rapid ventricular response ${ }^{22}$.

In this study, we show a change in the action potential morphology, a decrease in the plateau phase, reflected in a decrease in APD50, without a significant change in APD80. AF episodes were very short in the control group, but sustained AF was seen in all but one RAP animals, and AF inducibility was increased in the RAP group, as in a previous study in pigs ${ }^{33}$. Increased inducibility of AF and AF duration were also previously shown in dogs ${ }^{27,33}$ and goats ${ }^{2}$ as a result of RAP. Despite the increase in AF stability and inducibility, AFCL was increased. Our data indicates that electrical remodeling is not a major factor in AF stabilization in pigs within 6 weeks of RAP. A discrepancy in time course of electrical remodeling and AF stabilization was already shown earlier by Wijffels et al ${ }^{2}$. Structural remodeling was also seen to some extend in our 6 months RAP model. Myocyte hypertrophy was present in both atria and interstitial fibrosis was significantly increased in the RA, but not in the LA. As atrial fibrosis seems to be related to ventricular rate, the level of digoxin in the pig model could influence the degree in atrial fibrosis found.

\subsection{Atrial supply-demand balance}

We have previously shown that acute AF in normal, anesthetized pigs leads to supply-demand ischemia, as evidenced by an increase in atrial lactate production within 5-10 min of AF (CHAPTER 4) ${ }^{10}$ although atrial vessels dilated and oxygen extraction increased. Apparently, the increased demand caused by rapid rates of electrical activation and mechanical contraction during acute AF cannot be accommodated by the increase in supply. Several studies in other species support the occurrence of atrial ischemia during AF. Atrial creatine phosphate levels are decreased in the first weeks of $A F^{11,12}$. In addition, the atria produce markers of hypoxia and angiogenesis (e.g. $\left.\mathrm{HIF}_{1 \alpha}, \mathrm{VEGF}, \mathrm{KDR}\right)^{14,34-36}$. During AF, a more indirect argument is that many aspects of atrial structural remodeling resemble ventricular hibernating myocardium resulting from chronic low-flow ischemia ${ }^{6,9}$.

Adaptation to supply-demand ischemia may involve a decrease in atrial energy/oxygen demand and/or an increase in atrial energy/oxygen supply. In this study, we have investigated both factors by measuring vascular remodeling, coronary blood flow, oxygen extraction and lactate production.

The atrial flow signal in the RAP model was similar to that in controls. However, the 


\section{CHAPTER 6}

decrease in atrial flow during atrial activation was smaller in the RAP group compared to control. The phasic decrease in the atrial flow pattern is caused by the atrial contraction itself (CHAPTER 5) 15, 37, 38. AF causes contractile remodeling, resulting in a decrease in contractile force $3,39,40$. Although APD80 did not decrease in RAP pigs, the decrease in APD50 reduced plateau potential is consistent with a decrease in calcium current amplitude and thus a reduced contractile force. This would explain the alteration in atrial flow pattern and increased contribution of flow during atrial systole in the RAP group. As an important consequence, a reduction in atrial contractility would decrease the atrial demand.

To assess atrial coronary supply, we have investigated both atrial vascular structure and regulation. Fibrosis around conduit/resistance arterioles may reduce their capacity to dilate. However, the degree of perivascular fibrosis around conduit/resistance arterioles was not significantly different between the control and RAP groups. The capillary density was significantly lower in both atria in the RAP group. Clinical studies on capillary density showed a decreased capillary density in AF patients compared to controls in the sinus node area ${ }^{41}$, LA appendage, free wall ${ }^{42}$ and posterior wall ${ }^{43}$. A decreased capillary density increases oxygen diffusion distances ${ }^{42}$ and could exacerbate atrial ischemia during AF. The decrease in capillary density may seem at odds with the increase of angiogenic markers that has also been observed in AF patients. However, the stability of newly formed capillaries is influenced by growth factors

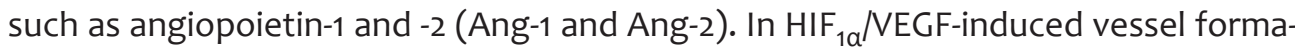
tion, Ang-1 favors endothelial stability by interaction with pericytes, whereas Ang-2 promotes new vessel sprouting and facilitates the actions of VEGF ${ }^{44}$. Plasma levels of Ang-2 were found to be increased in AF patients, which would shift the balance to endothelial destabilization and capillary rarefaction ${ }^{36}$.

Our functional measurements indicate that vascular regulation is intact after 5 weeks of RAP. The vasodilator response to adenosine and coronary conductance reserve were not different between the control and RAP groups. During pacing and AF, the LA vascular conductance and oxygen extraction both increase, indicating that these interventions cause an increase in atrial demand and a concomitant increase in supply. In control pigs, the mobilization of conductance and extraction reserve was insufficient to prevent supply-demand ischemia, and atrial lactate production increased within 5-10 minutes of acute AF. By contrast, a similar recruitment of conductance and extraction reserve in RAP is sufficient to prevent lactate production. This 
supports the hypothesis by Ausma et al that the remodeling processes taking place in the atria during prolonged $A F$ represent energy saving mechanisms ${ }^{6,8}$. Indeed, in a goat model of AF, the phosphocreatine level is decreased and $\mathrm{HIF}_{1 \alpha}$ expression is increased in the first weeks of AF, but they subsequently recover ${ }^{12,13}$. Remodeling processes in the atrium thus lead to an amelioration of supply-demand ischemia, and can be viewed as a successful adaptation to energy shortage during AF. The loss of capillary density may become particularly relevant in patients with paroxysmal AF. Paroxysms of AF may cause vascular remodeling and capillary rarefaction. In a study on AF patients (with 2 or more episodes of AF in the previous year), Skalidis et al did indeed observe a decrease in coronary reserve compared to controls ${ }^{45}$. In between paroxysms, the atria rapidly recover from electrical remodeling and atrial contractility recovers to a large degree ${ }^{3}$, which would increase atrial energy expenditure.

\section{CONCLUSIONS}

Five weeks of chronic AF in pigs results in atrial structural remodeling. Electrical remodeling was investigated and indicates that the decrease in APD and AFCL is not a prerequisite for increased AF stability. Functional flow measurements show that vascular regulation is intact after 5 weeks of RAP, despite the observed decrease in capillary density. The coronary conductance reserve was comparable between the control and RAP groups. During pacing and AF, the LA vascular conductance and oxygen extraction both increase similarly to control pigs. As opposed to acute AF in controls, chronic AF does not result in lactate production with a similar increase in atrial flow and extraction. Atrial remodeling can be seen as an energy saving adaptation to supply-demand ischemia.

\section{REFERENCES}

1. van der Velden HMW, van der Zee L, Wijffels MC, van Leuven C, Dorland R, Vos MA, Jongsma $\mathrm{HJ}$, Allessie MA. Atrial fibrillation in the goat induces changes in monophasic action potential and mRNA expression of ion channels involved in repolarization. J Cardiovasc Electrophysiol 2000;11:1262-1269.

2. Wijffels MC, Kirchhof CJ, Dorland R, Allessie MA. Atrial fibrillation begets atrial fibrillation. 


\section{CHAPTER 6}

A study in awake chronically instrumented goats. Circulation 1995;92:1954-1968.

3. Schotten U, Duytschaever M, Ausma J, Eijsbouts S, Neuberger HR, Allessie M. Electrical and contractile remodeling during the first days of atrial fibrillation go hand in hand. Circulation 2003;107:1433-1439.

4. Yue L, Feng J, Gaspo R, Li GR, Wang Z, Nattel S. Ionic remodeling underlying action potential changes in a canine model of atrial fibrillation. Circ Res 1997;81:512-525.

5. Schotten U, Verheule S, Kirchhof P, Goette A. Pathophysiological mechanisms of atrial fibrillation: a translational appraisal. Physiol Rev 2011;91:265-325.

6. Ausma J, Litjens N, Lenders MH, Duimel H, Mast F, Wouters L, Ramaekers F, Allessie M, Borgers M. Time course of atrial fibrillation-induced cellular structural remodeling in atria of the goat. J Mol Cell Cardiol 2001;33:2083-2094.

7. Allessie M, Ausma J, Schotten U. Electrical, contractile and structural remodeling during atrial fibrillation. Cardiovasc Res 2002;54:230-246.

8. Ausma J, Wijffels M, Thone F, Wouters L, Allessie M, Borgers M. Structural changes of atrial myocardium due to sustained atrial fibrillation in the goat. Circulation 1997;96:3157-3163.

9. Ausma J, Wijffels M, van Eys G, Koide M, Ramaekers F, Allessie M, Borgers M. Dedifferentiation of atrial cardiomyocytes as a result of chronic atrial fibrillation. Am J Pathol 1997;151:985-997. 10. van Bragt KA, Nasrallah HM, Kuiper M, Luiken JJ, Schotten U, Verheule S. Atrial supply-demand balance in healthy adult pigs: coronary blood flow, oxygen extraction, and lactate production during acute atrial fibrillation. Cardiovasc Res 2014;101:9-19.

11. Leistad E, Aksnes G, Verburg E, Christensen G. Atrial contractile dysfunction after shortterm atrial fibrillation is reduced by verapamil but increased by BAY K8644. Circulation 1996;93:17471754 .

12. Ausma J, Coumans WA, Duimel H, Van der Vusse GJ, Allessie MA, Borgers M. Atrial high energy phosphate content and mitochondrial enzyme activity during chronic atrial fibrillation. Cardiovasc Res 2000;47:788-796.

13. Thijssen VL, van der Velden HM, van Ankeren EP, Ausma J, Allessie MA, Borgers M, van Eys $\mathrm{GJ}$, Jongsma HJ. Analysis of altered gene expression during sustained atrial fibrillation in the goat. Cardiovasc Res 2002;54:427-437.

14. Gramley F, Lorenzen J, Jedamzik B, Gatter K, Koellensperger E, Munzel T, Pezzella F. Atrial fibrillation is associated with cardiac hypoxia. Cardiovasc Pathol 2010;19:102-111.

15. van Bragt KA, Nasrallah HM, Kuiper M, van Hunnik A, Kuijpers NH, Schotten U, Verheule S. Dynamic regulation of atrial coronary blood flow in healthy adult pigs. Heart rhythm : the official journal of the Heart Rhythm Society 2015.

16. Kato T, Yasue T, Shoji Y, Shimabukuro S, Ito Y, Goto S, Motooka S, Uno T, Ojima A. Angiographic difference in coronary artery of man, dog, pig, and monkey. Acta pathologica japonica 1987;37:361-373.

17. Maxwell MP, Hearse DJ, Yellon DM. Species variation in the coronary collateral circulation during regional myocardial ischaemia: a critical determinant of the rate of evolution and extent of 


\section{The impact of persistent atrial fibrillation on the atrial supply-demand balance}

myocardial infarction. Cardiovascular research 1987;21:737-746.

18. Duncker DJ, Bache RJ. Regulation of coronary blood flow during exercise. Physiological reviews 2008;88:1009-1086.

19. Lelovas PP, Kostomitsopoulos NG, Xanthos TT. A comparative anatomic and physiologic overview of the porcine heart. Journal of the American Association for Laboratory Animal Science : JAALAS 2014;53:432-438.

20. Hughes GC, Post MJ, Simons M, Annex BH. Translational physiology: porcine models of human coronary artery disease: implications for preclinical trials of therapeutic angiogenesis. Journal of applied physiology 2003;94:1689-1701.

21. Verheule S, Tuyls E, van Hunnik A, Kuiper M, Schotten U, Allessie M. Fibrillatory conduction in the atrial free walls of goats in persistent and permanent atrial fibrillation. Circulation Arrhythmia and electrophysiology 2010;3:590-599.

22. Schoonderwoerd BA, Ausma J, Crijns HJ, Van Veldhuisen DJ, Blaauw EH, Van Gelder IC. Atrial ultrastructural changes during experimental atrial tachycardia depend on high ventricular rate. J Cardiovasc Electrophysiol 2004;15:1167-1174.

23. Bauer A, McDonald AD, Donahue JK. Pathophysiological findings in a model of persistent atrial fibrillation and severe congestive heart failure. Cardiovasc Res 2004;61:764-770.

24. Kjekshus H, Smiseth OA, Klinge R, Oie E, Hystad ME, Attramadal H. Regulation of ET: pulmonary release of ET contributes to increased plasma ET levels and vasoconstriction in CHF. American journal of physiology Heart and circulatory physiology 2000;278:H1299-1310.

25. Lin CS, Lai LP, Lin JL, Sun YL, Hsu CW, Chen CL, Mao SJ, Huang SK. Increased expression of extracellular matrix proteins in rapid atrial pacing-induced atrial fibrillation. Heart rhythm : the official journal of the Heart Rhythm Society 2007;4:938-949.

26. Wijffels MC, Kirchhof CJ, Dorland R, Power J, Allessie MA. Electrical remodeling due to atrial fibrillation in chronically instrumented conscious goats: roles of neurohumoral changes, ischemia, atrial stretch, and high rate of electrical activation. Circulation 1997;96:3710-3720.

27. Li D, Fareh S, Leung TK, Nattel S. Promotion of atrial fibrillation by heart failure in dogs: atrial remodeling of a different sort. Circulation 1999;100:87-95.

28. Cha TJ, Ehrlich JR, Zhang L, Nattel S. Atrial ionic remodeling induced by atrial tachycardia in the presence of congestive heart failure. Circulation 2004;110:1520-1526.

29. Cha TJ, Ehrlich JR, Zhang L, Chartier D, Leung TK, Nattel S. Atrial tachycardia remodeling of pulmonary vein cardiomyocytes: comparison with left atrium and potential relation to arrhythmogenesis. Circulation 2005;111:728-735.

30. Zhang H, Garratt CJ, Zhu J, Holden AV. Role of up-regulation of IK1 in action potential shortening associated with atrial fibrillation in humans. Cardiovascular research 2005;66:493-502.

31. Morillo CA, Klein GJ, Jones DL, Guiraudon CM. Chronic rapid atrial pacing. Structural, functional, and electrophysiological characteristics of a new model of sustained atrial fibrillation. Circulation 1995;91:1588-1595.

32. Verheule S, Tuyls E, Gharaviri A, Hulsmans S, van Hunnik A, Kuiper M, Serroyen J, Zeeme- 


\section{CHAPTER 6}

ring S, Kuijpers NH, Schotten U. Loss of continuity in the thin epicardial layer because of endomysial fibrosis increases the complexity of atrial fibrillatory conduction. Circ Arrhythm Electrophysiol 2013;6:202-211.

33. Lin JL, Lai LP, Lin CS, Du CC, Wu TJ, Chen SP, Lee WC, Yang PC, Tseng YZ, Lien WP, Huang SK. Electrophysiological mapping and histological examinations of the swine atrium with sustained ( $>$ or $=24 \mathrm{~h}$ ) atrial fibrillation: a suitable animal model for studying human atrial fibrillation. Cardiology 2003;99:78-84.

34. Scridon A, Morel E, Nonin-Babary E, Girerd N, Fernandez C, Chevalier P. Increased intracardiac vascular endothelial growth factor levels in patients with paroxysmal, but not persistent atrial fibrillation. Europace 2012;14:948-953.

35. Xu Y, Sharma D, Du F, Liu Y. The role of Toll-like receptor 2 and hypoxia-induced transcription factor-1alpha in the atrial structural remodeling of non-valvular atrial fibrillation. Int J Cardiol 2013.

36. Freestone B, Chong AY, Lim HS, Blann A, Lip GY. Angiogenic factors in atrial fibrillation: a possible role in thrombogenesis? Ann Med 2005;37:365-372.

37. Kimura A, Hiramatsu O, Wada Y, Yada T, Yamamoto T, Goto M, Ogasawara Y, Tsujioka K, Kajiya F. Atrial contractility affects phasic blood flow velocity of atrial small vessels in the dog. Cardiovasc Res 1992;26:1219-1225.

38. Kajiya F, Tsujioka K, Ogasawara Y, Hiramatsu O, Wada Y, Goto M, Yanaka M. Analysis of the characteristics of the flow velocity waveforms in left atrial small arteries and veins in the dog. Circ Res 1989;65:1172-1181.

39. Schotten U, de Haan S, Neuberger HR, Eijsbouts S, Blaauw Y, Tieleman R, Allessie M. Loss of atrial contractility is primary cause of atrial dilatation during first days of atrial fibrillation. Am J Physiol Heart Circ Physiol 2004;287:H2324-2331.

40. Weimar T, Watanabe Y, Kazui T, Lee US, Moon MR, Schuessler RB, Damiano RJ, Jr. Differential impact of short periods of rapid atrial pacing on left and right atrial mechanical function. Am J Physiol Heart Circ Physiol 2012;302:H2583-2591.

41. Hurle A, Sanchez-Quintana D, Ho SY, Bernabeu E, Murillo M, Climent V. Capillary supply to the sinus node in subjects with long-term atrial fibrillation. Ann Thorac Surg 2010;89:38-43.

42. Corradi D, Callegari S, Benussi S, Nascimbene S, Pastori P, Calvi S, Maestri R, Astorri E, Pappone C, Alfieri O. Regional left atrial interstitial remodeling in patients with chronic atrial fibrillation undergoing mitral-valve surgery. Virchows Arch 2004;445:498-505.

43. Corradi D, Callegari S, Maestri R, Ferrara D, Mangieri D, Alinovi R, Mozzoni P, Pinelli S, Goldoni M, Privitera YA, Bartoli V, Astorri E, Macchi E, Vaglio A, Benussi S, Alfieri O. Differential structural remodeling of the left-atrial posterior wall in patients affected by mitral regurgitation with or without persistent atrial fibrillation: a morphological and molecular study. J Cardiovasc Electrophysiol 2012;23:271-279.

44. Rabelink TJ, de Boer HC, van Zonneveld AJ. Endothelial activation and circulating markers of endothelial activation in kidney disease. Nature reviews Nephrology 2010;6:404-414. 
The impact of persistent atrial fibrillation on the atrial supply-demand balance

45. Skalidis El, Hamilos MI, Karalis IK, Chlouverakis G, Kochiadakis GE, Vardas PE. Isolated atrial microvascular dysfunction in patients with lone recurrent atrial fibrillation. J Am Coll Cardiol 2008;51:2053-2057. 
CHAPTER 7

130 


\section{General discussion}

Kelly van Bragt
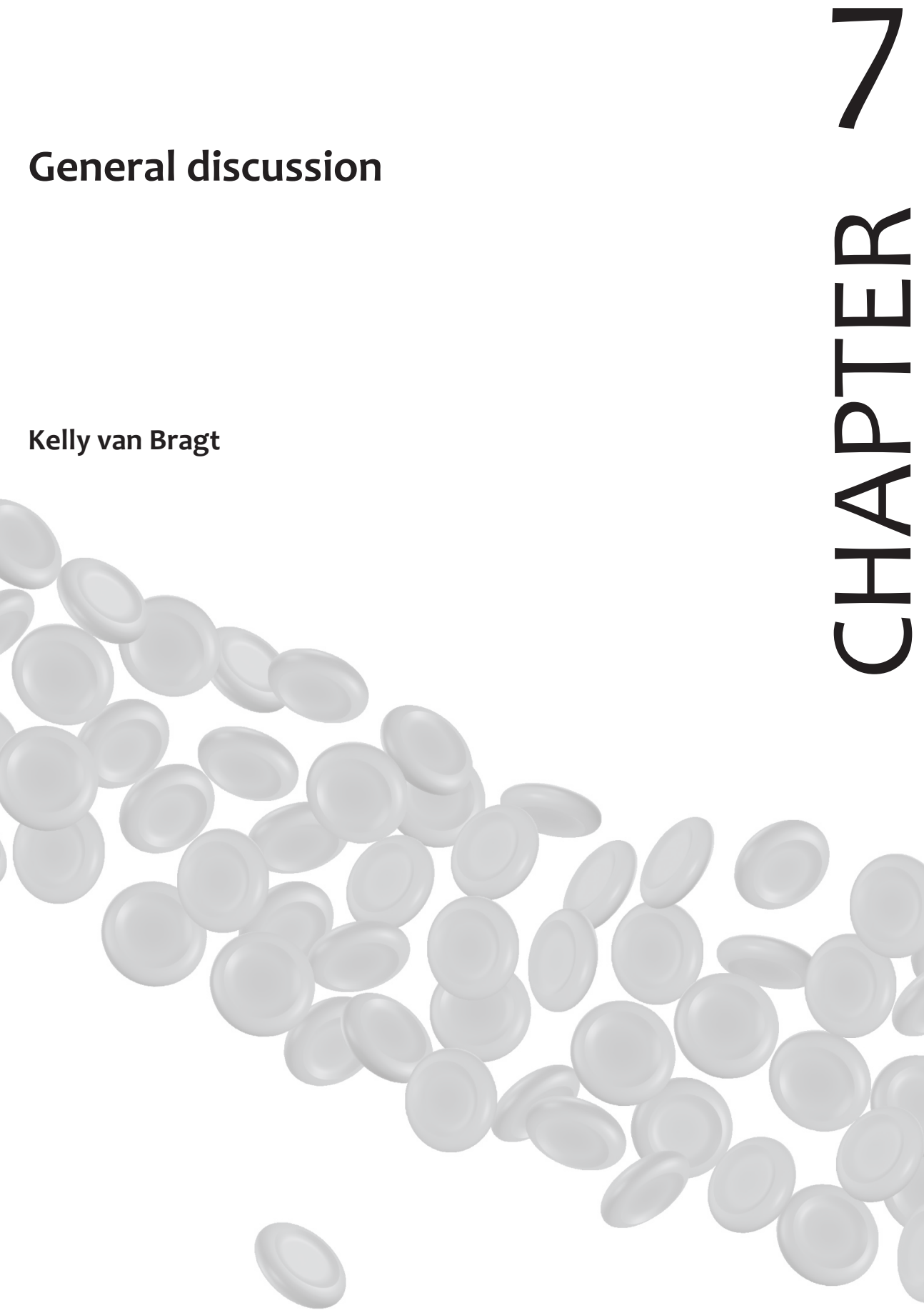
1. INTRODUCTION

Atrial fibrillation is the most common cardiac arrhythmia in clinical practice. It is a self-perpetuating disease. In AF patients, structural, electrophysiological and contractile changes are observed. Action potential duration and effective refractory period (ERP) are shortened, and the rate-dependent effect on ERP is lost in human atria during $A F^{1}$. In addition, short-term AF (minutes) in humans was shown to be sufficient to cause contractile dysfunction ${ }^{2}$. Fibrosis may ${ }^{3-5}$ or may not ${ }^{6}$ be significantly increased in AF patients. Other structural changes as a result of AF include e.g. mitochondrial abnormalities, glycogen accumulation, change in structure of the sarcoplasmic reticulum, loss of myofibrils 7,8 . The structural remodeling process is an important determinant in AF stability ${ }^{9,10}$. However, the origin of these structural changes is not completely understood.

Ausma et al were the first to point out that the changes in atrial ultrastructure resemble the changes seen in hibernating myocardium during ventricular low-flow ischemia ${ }^{4,11-13}$. Cells return to a more fetal phenotype, which can be interpreted as an adaptive mechanism to energy shortage ${ }^{14}$. Further circumstantial evidence is available that suggests a role for supply-demand ischemia in AF. Markers of hypoxia (e.g. Hypoxia Inducible Factor $1 \alpha\left(\mathrm{HIF}_{1 \alpha}\right)$ ) and angiogenesis (e.g. Vascular Endothelial Growth Factor (VEGF)) were found in AF patients ${ }^{15-18}$. Also in animal models of $A F$, evidence for supply-demand ischemia was found. After 1 week of AF, an increase in gene expression of $\mathrm{HIF}_{1 \alpha}{ }^{19}$ and a 60\% decrease in the high-energy phosphate phosphocreatine $(\mathrm{PCr})^{20}$ were observed. However, both $\mathrm{HIF}_{1 \alpha}$ gene expression and $\mathrm{PCr}$ levels return to baseline after a few weeks of AF. These data suggest that the atrial supply-demand ischemia occurs in an early phase and is transient, suggesting a successful adaptation to restore supply-demand balance. In this thesis, we have aimed to describe regulation of the atrial supply-demand balance during acute and chronic AF. In addition, we have provided a comprehensive description of the atrial vascular anatomy and the changes in vascular structure that are caused by AF. 


\section{ANIMAL MODELS OF ATRIAL FIBRILLATION}

In order to understand the processes resulting in the perpetuation of AF and investigate the relation to atrial ischemia, there is a need for appropriate animal models. In the past, pigs, dogs and goats have been used as models for chronic atrial fibrillation induced by rapid atrial pacing (RAP). Atrial electrophysiological, structural and contractility parameters were extensively investigated in the goat and dog model of $\mathrm{AF}$ and were comparable to the pathophysiological changes identified in AF patients ${ }^{10}$. Electrical remodeling, i.e. shortening of the effective refractory period and shortening of the action potential, was shown to be complete within the first hours to days ${ }^{21-23}$. It was also shown that the downregulation of the L-type calcium current $\left(\mathrm{IC} \mathrm{a}_{\mathrm{L}}\right)$ not only contributes to shortening of the action potential, but also resulted in a decrease in atrial contractility. This aspect was further elucidated in the goat model and it was shown that atrial contractility was almost completely abolished after 2 days of $\mathrm{AF}^{24}$. The identified electrical and contractile changes were fully reversible after restoration of sinus rhythm ${ }^{21}$. Structural remodeling like myocyte hypertrophy, loss of sarcomeres, accumulation of glycogen, and mitochondrial abnormalities were observed in the goat model ${ }^{12}$. Total fibrosis was not increased in the atria of AF goats ${ }^{12}$ and dogs ${ }^{22}$, but an increase was observed in the amount of extracellular matrix per myocytes (interstitial fibrosis/microfibrosis) ${ }^{12}$ and in transverse intermyocyte distances within bundles (endomysial fibrosis) ${ }^{25}$. In contrast to electrical and contractile remodeling, reversal of structural remodeling after restoration to sinus rhythm was slow and incomplete ${ }^{26}$.

In order to investigate the role of supply-demand atrial ischemia, an animal model is needed with a coronary anatomy similar to humans. Coronary and bronchial arteries supplying the pig heart are very similar to humans ${ }^{27-29}$. A characterization of atrial pathological changes during AF is given in CHAPTER 6 of this thesis. From earlier studies in pigs it became evident that rapid atrial pacing caused a significant increase in ventricular rate, with congestive heart failure (CHF) as a major consequence ${ }^{30-32}$. As discussed in CHAPTER 6, pigs were subjected to rapid atrial pacing with a controlled ventricular rate by the administration of oral digoxin. In this pig model of AF, we observed significant interstitial fibrosis in the left atrium and myocardial hypertrophy 


\section{CHAPTER 7}

in left and right atrium. The action potential duration did not shorten as was seen in the goat, but the action potential morphology changed as the plateau phase disappeared in AF pigs. AF episodes were longer and easier to induce than in controls. The development of $\mathrm{CHF}$ was modest at most. The pig was chosen as species to further elucidate the relationship between AF and ischemia (CHAPTERS 4-6) and a detailed description of the atrial blood supply in the pig is provided in this thesis (CHAPTER 3 ).

\section{ATRIAL CORONARY ANATOMY IN PIGS}

In the early 1900's, scientists have identified the presence of arteries branching off from the left and right coronary arteries into the atrial myocardium ${ }^{33-38}$. Also the extracoronary circulation (e.g. bronchial circulation) appeared to play a role in atrial blood supply, forming anastomoses with large atrial vessels ${ }^{36-41}$. With more and more circumstantial evidence for a role of atrial ischemia in the perpetuation of AF, a detailed and comprehensive investigation of the anatomy of the atrial vasculature was necessary. In CHAPTER 3, we have used new techniques and experiments to elucidate the anatomy of the atrial blood supply. In this chapter, a detailed overview was given of pig atrial coronary anatomy. Large vessels branching off from the coronary and bronchial circulation were identified as described earlier. Knowledge of the anatomy of atrial arteries may be relevant during heart transplants and AF ablation strategies. Ablation lines running through (or in very close proximity of) major atrial arteries could cause ischemia, thereby increasing the chance of AF recurrence. In addition, we have visualized the extensive atrial capillary network (CHAPTER 3). Despite the fact that the atrial wall is very thin and in close contact with the blood in the atrial cavity, there is a considerable blood-supply network in place that is tightly regulated to maintain supply-demand balance in the atria.

\section{ATRIAL FLOW REGULATION}

Changes in vascular diameter, especially in the small arteries and arterioles (resistance vessels), determine the total amount of blood flow (thus oxygen delivery) to the tissue downstream. Vascular resistance is partly regulated by the autonomic 
nervous system and the circulating vasoactive hormones like angiotensine II, (nor-) epinephrine, vasopressin, atrial natriuretic peptide and endothelin. Changes in these vasoactive hormones are observed in AF. For example, increased atrial protein and gene-expression levels of Endothelin-1 are associated with atrial dilatation, fibrosis, hypertrophy and AF in patients ${ }^{42,}{ }^{43}$. In addition, elevated baseline plasma levels of Endothelin-1 are a predictor for recurrent AF after ablation ${ }^{44,45}$. Another important factor is the local regulation of the vascular resistance. Vasodilators and vasoconstrictors are secreted by the cardiomyocytes to meet their metabolic needs and by the vascular endothelium. During contraction of the heart muscle, extravascular forces cause a compression of the vasculature, which is an additional determinant of total vascular resistance.

\subsection{Phasic pattern of atrial flow}

Earlier microsphere measurements provide information on average blood flow per region ${ }^{46-51}$. To obtain detailed information on blood flow regulation over time, we measured coronary flow with Doppler flow probes, as described in CHAPTER 4 and 5 of this thesis. The atrial flow pattern in pigs was described in CHAPTER 4 and was very similar to that in humans ${ }^{52,53}$. During atrial systole, a decrease, or even a reversal of flow, is observed. Both our study (2:1 AV block and acetylcholine administration) and earlier studies 54,55 (isoproterenol) confirm that it is atrial contraction, rather than the increase in atrial pressure during systole, which causes the decrease in atrial flow. Atrial systole is short and $98 \%$ of total flow takes place during the atrial diastole. During short-term AF, the active pump function of the atria is abolished, but the local activation and contraction are very fast and irregular. These irregular and local contractions result in a very irregular atrial flow pattern during AF, but did not reverse atrial flow in any of the pigs as was seen during synchronous atrial contraction in sinus rhythm or pacing. However, they could continuously impede local flow, thereby aggravating the supply-demand mismatch. 
4.2. Regional regulation of atrial flow

CHAPTER 2 includes a literature overview about myocardial blood flow distribution measured with microspheres. Blood flow is higher in the left side of the heart compared to the right side during sinus rhythm ${ }^{47,51,56-60}$. Changes in myocardial workload result in a redistribution of myocardial blood flow. An increase in atrial pressure or rhythm results in a larger portion of total flow going to the atria $56,57,60$. Atrial fibrillation is an even more potent stimulus than atrial pacing to increase atrial flow $46,51,61$. During AF, ventricular flow was not significantly affected in these microsphere experiments. Within the atria, differences in flow distribution also exist. Myocardial blood flow in the atrial appendages is lower than in the atrial free wall during rest ${ }^{59}$. During $\mathrm{AF}^{49}$ and exercise ${ }^{60}$, this flow distribution changes and the appendages will receive more myocardial flow. We have found similar results in healthy pigs. AF caused in increase in all area's investigated (atrial free walls, appendages, interatrial septum and Bachmann's bundle), but was only significant in LA free wall, LA appendage and RA appendage (CHAPTER 3).

\subsection{Dynamic regulation of atrial flow}

Atrial flow regulation was further investigated in CHAPTER 4 and 5 of this thesis in healthy pigs. A first set of experiments showed results consistent with microspheres studies. During pacing, conductance in a LA and LV branch of the left circumflex artery (LCX) increased. Since Doppler flow measurements plot flow against time, kinetics of flow regulation could be further investigated (CHAPTER 5). An immediate change in atrial and ventricular rhythm results in immediate increase in atrial conductance and the opposite was found when atrial pacing ceased. However, the atrial response to a quick change in rhythm was slower than in a ventricular artery. Atrial vascular conductance during AF increased even more than during atrial pacing and almost reached maximal conductance of the atrial vasculature. In the LV, an early increase (first minutes) was also observed during short-term AF, but this slowly decreased back to baseline values over time. In CHAPTER 5, we show that atrial conductance is positively correlated with atrial workload, as was shown in an earlier goat study, 
but the correlation is weaker than in the ventricle. The atrial work calculated here, determined by calculating the area of the atrial distance-pressure loops, reflects the mechanical atrial work. In addition to mechanical work, cellular processes like ion homeostasis also require energy and thus contribute to the total energy demand in the atria. Although the distance-pressure loops collapse during AF, individual cells are contracting at a very high rate and atrial work and energy expenditure per cell are high. This could explain the large increase in atrial conductance and flow during AF.

\subsection{Atrial flow as a limiting factor during $A F$}

Cessation of AF did not result in an immediate decrease, but rather an increase of conductance compared to the period before and during AF, which was not seen in the LV artery (CHAPTER 5). This reactive hyperemia is another indicator for atrial supply-demand ischemia during and shortly after atrial fibrillation. The diastolic period in $A F$ is very short and the constantly contracting tissue could exert mechanical stress on the atrial arteries and limit atrial blood flow, even if they are fully dilated. A decrease in mechanical force on the vascular wall after restoration of sinus rhythm would still result in an increase in atrial coronary conductance if the need for oxygen supply would remain high.

\section{ATRIAL OXYGEN EXTRACTION}

In addition to the regulation of atrial blood flow, the amount of oxygen extracted from the blood also plays an important role in maintaining the supply-demand balance. Oxygen extraction in the atrium was low $(\sim 25 \%)$ during normal sinus rhythm, whereas the values found for the ventricle ( $60 \%)$ were very comparable to values in other studies under general anesthesia (CHAPTER 5). During pacing (150 beats per minute) and $A F$, we observed a significant increase in atrial extraction, while ventricular extraction remained unchanged. To our knowledge, this is the first study to measure atrial arterial and venous oxygen saturation in fresh blood samples. White et al measured saturation in frozen vessels and found an atrial arterial saturation of only $87 \pm 1.5 \%$ and a venous saturation of $61 \%{ }^{61}$. Oxygen extraction during sinus rhy- 


\section{CHAPTER 7}

thm $(\sim 26 \%)$ was very comparable to our results and was increased slightly, but not significantly during $\operatorname{AF}(\sim 31 \%)$.

\section{ATRIAL ISCHEMIA DURING ATRIAL FIBRILLATION}

An overview of literature on AF and ischemia was given in CHAPTER 2 and will be further discussed in terms of new findings in this chapter. CHAPTER 3, 4 and 5 aimed to describe the regulation of atrial supply-demand balance in healthy animals. During atrial fibrillation, oxygen demand is high, but the coronary conductance and extraction reserve are used to increase oxygen supply to the atrial myocardial tissue. The atrial conductance reserve turned out to be a limiting factor in oxygen supply and the hyperemic phase after the cessation of AF indicated a supply-demand mismatch. To determine whether a mismatch in supply-demand balance existed in short-term AF, atrial lactate production was measured in CHAPTER 4 of this thesis. Lactate production is an indicator for tissue supply-demand mismatch. The main fuel for ATP production in the heart are fatty acids. A second, but smaller source for ATP production in the ventricle is glucose that is converted through glycolysis and lactate into pyruvate that can enter the mitochondria for oxidation. Fatty acid oxidation is a strong inhibitor of glycolysis. However, when oxygen shortage arises, fatty acid oxidation is slowed down and glycolysis is stimulated. During oxygen shortage, mitochondria are not able to burn all pyruvate and the excess is converted to lactate in the cytoplasm. Subsequently, lactate is released and can be measured in the venous blood. Atrial arterio-venous lactate differences in healthy pigs showed a significant production of lactate after 5 and 10 minutes of AF, indicating supply-demand ischemia (CHAPTER 5). To investigate the effects of AF-induced remodeling on this supply-demand mismatch, a second group of animals was tested after 5 weeks of AF (CHAPTER 6). The atria had undergone significant electrophysiological and structural remodeling. Flow regulation was similar to control animals and oxygen extraction was even slightly lower in RAP pigs during sinus rhythm. However, during AF, no lactate was produced in the atria, showing that the adaptive mechanism are to some extent able to restore supply-demand after 5 weeks of continuous AF in pigs. 


\section{VASCULAR REMODELING}

In 2008, Skalidis et al reported that patients with lone recurrent AF suffered from microvascular dysfunction. They observed a significant impairment of atrial coronary flow when measured during sinus rhythm ${ }^{53}$. Vascular remodeling in pigs was further elucidated in CHAPTER 6 of this thesis. In the pigs that underwent rapid atrial pacing for 5 weeks no functional impairment in coronary conductance reserve was observed. In addition, capillary density and perivascular fibrosis were calculated to assess the effect of 5 weeks AF on atrial vasculature. Capillary density was significantly decreased in both left and right atrium in pigs subjected to 5 weeks of rapid atrial pacing compared to control pigs. Perivascular fibrosis was, however, not increased in both left and right atrium compared to controls. Decreased capillary density could result in a decreased oxygen delivery capacity. Similar results were found in patients: AF patients showed a significantly lower capillary density than in patients without a history of $A F^{62,63}$. However, Gramley et al reported an opposing observation. In AF patients, capillary density and microvessel size were increased compared to patients without a history of $\mathrm{AF}^{15}$. It should be noted that these patients were all in persistent AF and paroxysmal AF patients were excluded from the study. It is likely to assume that capillary destabilization is also an early and transient phase that is dependent on the balance of circulating factors like HIF $_{1 \alpha}$, VEGF, angiopoietin-1 and angiopoietin-2 64. During this process, the time point of measurement and type of AF will determine the effect of AF on capillary density.

\section{ATRIAL ISCHEMIA IN PAROXYSMAL AF VS. PERSISTENT AF}

Our conclusions and speculations on the atrial supply-demand balance during acute, paroxysmal and persistent AF are represented in Figure 1. We propose that atrial supply-demand ischemia plays an early role in AF (CHAPTER 4), but supply-demand balance is restored after a few weeks as a result of atrial remodeling (CHAPTER 6). Atrial ischemia could thus be an important driver for early electrical and contractile remodeling. If AF episodes last for days to weeks, this supply-demand mismatch could also drive structural remodeling processes (e.g. fibrosis and vascular remode- 


\section{CHAPTER 7}

ling). These remodeling processes can be considered as energy-saving, adaptive mechanisms, reducing the atrial energy demand.

The interactions between these processes may be particularly relevant for paroxysmal AF patients. As discussed in paragraph 2 of this chapter, electrophysiological changes and contractile dysfunction quickly recover after restoration of sinus rhythm. However, structural changes like loss of capillaries and increased fibrosis may recover much more slowly or not at all. In patients with paroxysmal AF, episodes of AF may induce progressive vascular (e.g. rarefaction) and structural remodeling. In ensuing periods of sinus rhythm, electrical and contractile remodeling are known to reverses quickly ${ }^{24}$. This would increase atrial work and energy/oxygen demand. Subsequent periods of $\mathrm{AF}$ would then again lead to supply-demand ischemia. In these patients, every AF episode would thus lead to ischemia in the atria and the associated damage would be cumulative. To some extent, this view is supported by the observation of an increase in Vascular Endothelial Growth Factor (VEGF) in patients with paroxysmal AF, but not in persistent AF patients ${ }^{16}$. In a study on goats with $A F$, the increase in $\mathrm{HIF}_{1 \alpha}$ was also transient and $\mathrm{HIF}_{1 \alpha}$ gene expression was increased only in the first week of rapid atrial pacing ${ }^{19}$. Interestingly, in AF patients, $\mathrm{HIF}_{1 a}$ was still increased after (longstanding) persistent AF, suggesting that the phase of ischemia may be much longer in those patients than in the goat model of $A F^{15,17}$.

\section{FUTURE PERSPECTIVES}

Our data show that there is a transient phase of atrial ischemia during AF. Understanding the changes in supply-demand balance during AF is merely the tip of the 'metabolic iceberg'. Although it is plausible that atrial ischemia could drive the electrical, contractile and structural remodeling processes, this is not yet shown. Also the role of atrial ischemia in the stabilization of AF should be further elucidated.

Reducing the supply-demand mismatch could be clinically relevant in the prevention of the subsequent remodeling processes and the perpetuation of AF. To improve oxygen efficiency in the atrium during $A F$, it is important to further investigate the underlying processes like metabolic and vascular remodeling. In the ventricle it is shown that low-flow ischemia and heart failure lead to metabolic remodeling, hall- 


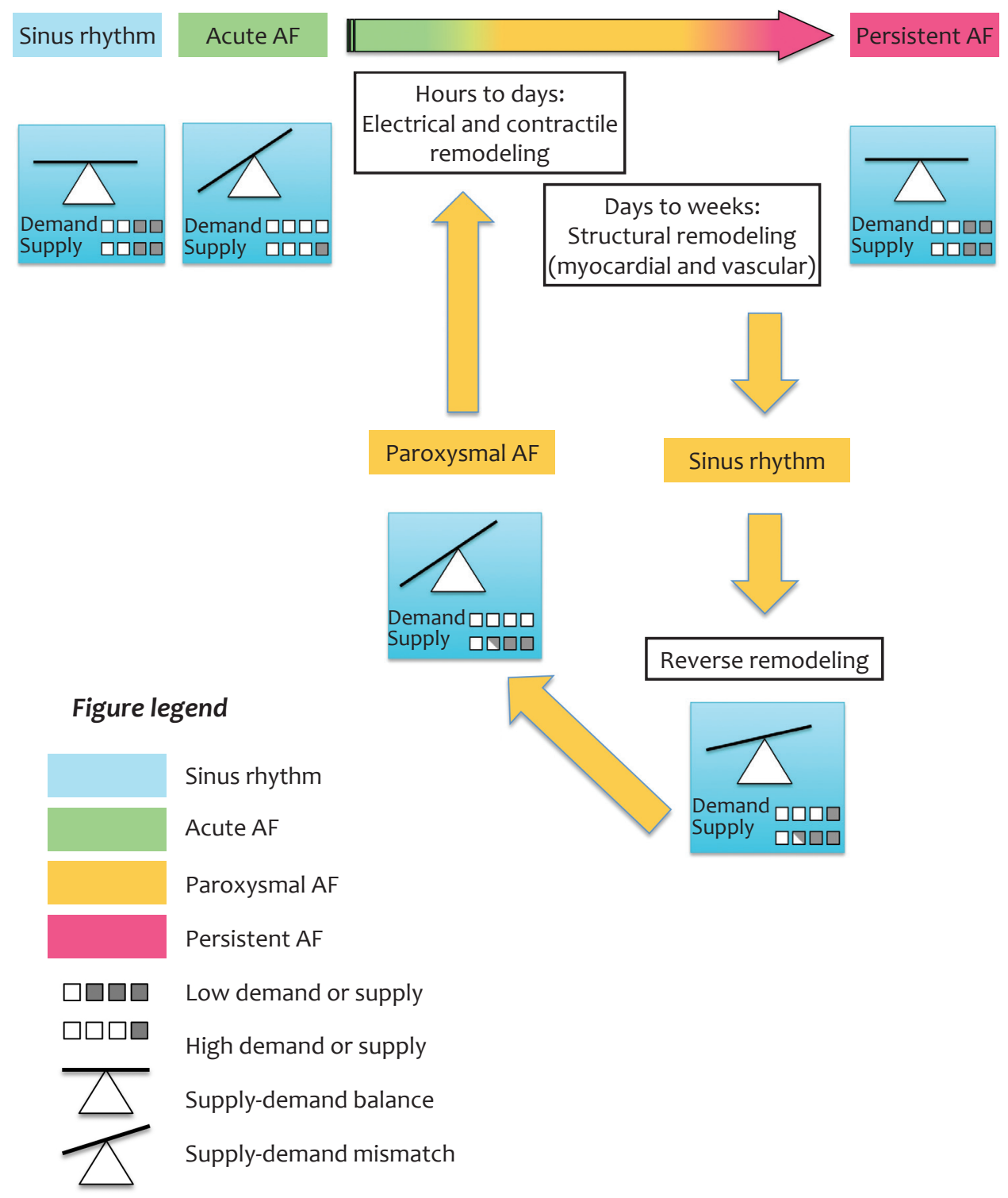

Figure 1: Conclusions and speculations on atrial supply-demand balnce in acute, paroxysmal and persistent atrial fibrillation (AF) 
marked by a shift from fatty acids to glucose utilization ${ }^{65}$. Whether or not metabolic remodeling plays a role in $\mathrm{AF}$ is unknown, but gene expression profiles show marked changes in metabolism related genes after $24 \mathrm{~h}$ of rapid atrial pacing in dogs ${ }^{66}$. The use of metabolic shifters like ranolazine and trimetazidine ${ }^{67}$ could be useful interventions to improve oxygen efficiency. As discussed earlier in of this chapter, AF is associated with microvascular dysfunction and decreased capillary density that could aggravate ischemia during AF. Identifying new potential targets in the vascular remodeling process could also contribute to improved oxygen delivery and the prevention of supply-demand mismatch during AF. Furthermore, knowledge of atrial coronary anatomy and specifically the location of large atrial vessels may be important in the development of ablation strategies.

\section{REFERENCES}

1. Workman AJ, Kane KA, Rankin AC. The contribution of ionic currents to changes in refractoriness of human atrial myocytes associated with chronic atrial fibrillation. Cardiovascular research. 2001;52:226-235

2. Daoud EG, Marcovitz P, Knight BP, Goyal R, Man KC, Strickberger SA, Armstrong WF, Morady $\mathrm{F}$. Short-term effect of atrial fibrillation on atrial contractile function in humans. Circulation. 1999;99:3024-3027

3. Aime-Sempe C, Folliguet T, Rucker-Martin C, Krajewska M, Krajewska S, Heimburger M, Aubier M, Mercadier JJ, Reed JC, Hatem SN. Myocardial cell death in fibrillating and dilated human right atria. J Am Coll Cardiol. 1999;34:1577-1586

4. Rucker-Martin C, Pecker F, Godreau D, Hatem SN. Dedifferentiation of atrial myocytes during atrial fibrillation: Role of fibroblast proliferation in vitro. Cardiovascular research. 2002;55:38-52 5. $\quad$ Anne $W$, Willems R, Roskams $T$, Sergeant $P$, Herijgers $P$, Holemans $P$, Ector $H$, Heidbuchel $\mathrm{H}$. Matrix metalloproteinases and atrial remodeling in patients with mitral valve disease and atrial fibrillation. Cardiovascular research. 2005;67:655-666

6. van Brakel TJ, van der Krieken T, Westra SW, van der Laak JA, Smeets JL, van Swieten HA. Fibrosis and electrophysiological characteristics of the atrial appendage in patients with atrial fibrillation and structural heart disease. Journal of interventional cardiac electrophysiology : an international journal of arrhythmias and pacing. 2013;38:85-93

7. Mary-Rabine L, Albert A, Pham TD, Hordof A, Fenoglio JJ, Jr., Malm JR, Rosen MR. The relationship of human atrial cellular electrophysiology to clinical function and ultrastructure. Circulation research. 1983;52:188-199

8. Thiedemann KU, Ferrans VJ. Left atrial ultrastructure in mitral valvular disease. The American journal of pathology. 1977;89:575-604 
9. Allessie M, Ausma J, Schotten U. Electrical, contractile and structural remodeling during atrial fibrillation. Cardiovascular research. 2002;54:230-246

10. Schotten U, Verheule S, Kirchhof P, Goette A. Pathophysiological mechanisms of atrial fibrillation: A translational appraisal. Physiological reviews. 2011;91:265-325

11. Ausma J, Litjens N, Lenders MH, Duimel H, Mast F, Wouters L, Ramaekers F, Allessie M, Borgers $M$. Time course of atrial fibrillation-induced cellular structural remodeling in atria of the goat. Journal of molecular and cellular cardiology. 2001;33:2083-2094

12. Ausma J, Wijffels M, Thone F, Wouters L, Allessie M, Borgers M. Structural changes of atrial myocardium due to sustained atrial fibrillation in the goat. Circulation. 1997;96:3157-3163

13. Ausma J, Wijffels M, van Eys G, Koide M, Ramaekers F, Allessie M, Borgers M. Dedifferentiation of atrial cardiomyocytes as a result of chronic atrial fibrillation. The American journal of pathology. 1997;151:985-997

14. Thijssen VL, Ausma J, Borgers M. Structural remodelling during chronic atrial fibrillation: Act of programmed cell survival. Cardiovascular research. 2001;52:14-24

15. Gramley F, Lorenzen J, Jedamzik B, Gatter K, Koellensperger E, Munzel T, Pezzella F. Atrial fibrillation is associated with cardiac hypoxia. Cardiovascular pathology : the official journal of the Society for Cardiovascular Pathology. 2010;19:102-111

16. Scridon A, Morel E, Nonin-Babary E, Girerd N, Fernandez C, Chevalier P. Increased intracardiac vascular endothelial growth factor levels in patients with paroxysmal, but not persistent atrial fibrillation. Europace : European pacing, arrhythmias, and cardiac electrophysiology : journal of the working groups on cardiac pacing, arrhythmias, and cardiac cellular electrophysiology of the European Society of Cardiology. 2012;14:948-953

17. Xu Y, Sharma D, Du F, Liu Y. The role of toll-like receptor 2 and hypoxia-induced transcription factor-1alpha in the atrial structural remodeling of non-valvular atrial fibrillation. International journal of cardiology. 2013

18. Ogi H, Nakano Y, Niida S, Dote K, Hirai Y, Suenari K, Tonouchi Y, Oda N, Makita Y, Ueda S, Kajihara K, Imai K, Sueda T, Chayama K, Kihara Y. Is structural remodeling of fibrillated atria the consequence of tissue hypoxia? Circulation journal : official journal of the Japanese Circulation Society. 2010;74:1815-1821

19. Thijssen VL, van der Velden HM, van Ankeren EP, Ausma J, Allessie MA, Borgers M, van Eys GJ, Jongsma HJ. Analysis of altered gene expression during sustained atrial fibrillation in the goat. Cardiovascular research. 2002;54:427-437

20. Ausma J, Coumans WA, Duimel H, Van der Vusse GJ, Allessie MA, Borgers M. Atrial high energy phosphate content and mitochondrial enzyme activity during chronic atrial fibrillation. Cardiovascular research. 2000;47:788-796

21. Wijffels MC, Kirchhof CJ, Dorland R, Allessie MA. Atrial fibrillation begets atrial fibrillation. A study in awake chronically instrumented goats. Circulation. 1995;92:1954-1968

22. Li D, Fareh S, Leung TK, Nattel S. Promotion of atrial fibrillation by heart failure in dogs: Atrial remodeling of a different sort. Circulation. 1999;100:87-95

23. Yue L, Feng J, Gaspo R, Li GR, Wang Z, Nattel S. Ionic remodeling underlying action poten- 
tial changes in a canine model of atrial fibrillation. Circulation research. 1997;81:512-525

24. Schotten U, Duytschaever M, Ausma J, Eijsbouts S, Neuberger HR, Allessie M. Electrical and contractile remodeling during the first days of atrial fibrillation go hand in hand. Circulation. 2003;107:1433-1439

25. Verheule S, Tuyls E, van Hunnik A, Kuiper M, Schotten U, Allessie M. Fibrillatory conduction in the atrial free walls of goats in persistent and permanent atrial fibrillation. Circulation. Arrhythmia and electrophysiology. 2010;3:590-599

26. Ausma J, van der Velden HM, Lenders MH, van Ankeren EP, Jongsma HJ, Ramaekers FC, Borgers M, Allessie MA. Reverse structural and gap-junctional remodeling after prolonged atrial fibrillation in the goat. Circulation. 2003;107:2051-2058

27. Gade J, Norgaard MA, Andersen CB, Pettersson G, Svendsen UG, Olsen PS. The porcine bronchial artery: Surgical and angiographic anatomy. Journal of anatomy. 1999;194 ( Pt 2):241-247 28. Hughes GC, Post MJ, Simons M, Annex BH. Translational physiology: Porcine models of human coronary artery disease: Implications for preclinical trials of therapeutic angiogenesis. Journal of applied physiology. 2003;94:1689-1701

29. Weaver ME, Pantely GA, Bristow JD, Ladley HD. A quantitative study of the anatomy and distribution of coronary arteries in swine in comparison with other animals and man. Cardiovascular research. 1986;20:907-917

30. Hystad ME, Klinge R, Spurkland A, Attramadal H, Hall C. Contrasting cardiac regional responses of a-type and b-type natriuretic peptide to experimental chronic heart failure. Scandinavian journal of clinical and laboratory investigation. 2000;60:299-309

31. Kjekshus H, Smiseth OA, Klinge R, Oie E, Hystad ME, Attramadal H. Regulation of et: Pulmonary release of et contributes to increased plasma et levels and vasoconstriction in chf. American journal of physiology. Heart and circulatory physiology. 2000;278:H1299-1310

32. Bauer A, McDonald AD, Donahue JK. Pathophysiological findings in a model of persistent atrial fibrillation and severe congestive heart failure. Cardiovascular research. 2004;61:764-770

33. Spalteholz W. Die arterien der herzwand. Leipzig: Hirzel. 1924

34. Gross CJ. The blood supply to the heart in its anatomical and clinical aspects. 1921

35. James TN, Burch GE. The atrial coronary arteries in man. Circulation. 1958;17:90-98

36. Smith GT. The anatomy of the coronary circulation. Am J Cardiol. 1962;9:327-342

37. Hromada J, Voboril Z. Arteries of cardiac atria in man. Folia Morphol (Praha). 1970;18:308-

321

38. Williams PL, Warwick R, Dyson M, Bannister L. Gray's anatomy. 1989

39. Soderstrom. Some anatomical and functional data regarding the atria of the heart. Acta medica scandinavica. Supplementum. 1948:27-39.

40. Hudson CL, Moritz AR, Wearn JT. The extracardiac anastomoses of the coronary arteries. J Exp Med. 1932;56:919-925

41. Moberg A. Anastomoses between extracardiac vessels and coronary arteries. Acta Med Scand Suppl. 1968;485:5-26

42. Brundel BJ, Van Gelder IC, Tuinenburg AE, Wietses M, Van Veldhuisen DJ, Van Gilst WH, 
Crijns HJ, Henning RH. Endothelin system in human persistent and paroxysmal atrial fibrillation. Journal of cardiovascular electrophysiology. 2001;12:737-742

43. Mayyas F, Niebauer M, Zurick A, Barnard J, Gillinov AM, Chung MK, Van Wagoner DR. Association of left atrial endothelin-1 with atrial rhythm, size, and fibrosis in patients with structural heart disease. Circulation. Arrhythmia and electrophysiology. 2010;3:369-379

44. Wang H, Liu J, Fang P, Lei S, Li X, Hou Y, Zhang S. Big endothelin-1 as a predictor of atrial fibrillation recurrence after primary ablation only in patients with paroxysmal atrial fibrillation. Herz. 2012;37:919-925

45. Nakazawa Y, Ashihara T, Tsutamoto T, Ito M, Horie M. Endothelin-1 as a predictor of atrial fibrillation recurrence after pulmonary vein isolation. Heart rhythm : the official journal of the Heart Rhythm Society. 2009;6:725-730

46. McHale PA, Rembert JC, Greenfield JC, Jr. Effect of atrial fibrillation on atrial blood flow in conscious dogs. Am J Cardiol. 1983;51:1722-1727

47. Neill WA, Phelps NC, Oxendine JM, Mahler DJ, Sim DN. Effect of heart rate on coronary blood flow distribution in dogs. Am J Cardiol. 1973;32:306-312

48. Neill WA, Sewell D, Gopal M, Oxendine J, Painter L. Independent regulation of atrial coronary blood flow by atrial contraction rate in conscious dogs. Pflugers Arch. 1980;388:193-195

49. Bauman RP, Rembert JC, Greenfield JC, Jr. Regional atrial blood flow in dogs. Effect of hypertrophy on coronary flow reserve. J Clin Invest. 1989;83:1563-1569

50. Bauman RP, Rembert JC, Greenfield JC, Jr. Regional vascular reserve in canine atria and ventricles during rest and exercise. Am J Physiol. 1995;269:H1578-1582

51. White CW, Holida MD, Marcus ML. Effects of acute atrial fibrillation on the vasodilator reserve of the canine atrium. Cardiovascular research. 1986;20:683-689

52. Skalidis EI, Kochiadakis GE, Igoumenidis NE, Vardakis KE, Vardas PE. Phasic coronary blood flow velocity pattern and flow reserve in the atrium: Regulation of left atrial myocardial perfusion. J Am Coll Cardiol. 2003;41:674-680

53. Skalidis EI, Hamilos MI, Karalis IK, Chlouverakis G, Kochiadakis GE, Vardas PE. Isolated atrial microvascular dysfunction in patients with lone recurrent atrial fibrillation. J Am Coll Cardiol. 2008;51:2053-2057

54. Kajiya F, Tsujioka K, Ogasawara Y, Hiramatsu O, Wada Y, Goto M, Yanaka M. Analysis of the characteristics of the flow velocity waveforms in left atrial small arteries and veins in the dog. Circulation research. 1989;65:1172-1181

55. Kimura A, Hiramatsu O, Wada Y, Yada T, Yamamoto T, Goto M, Ogasawara Y, Tsujioka K, Kajiya F. Atrial contractility affects phasic blood flow velocity of atrial small vessels in the dog. Cardiovascular research. 1992;26:1219-1225

56. Manohar M, Goetz TE, Hutchens E, Coney E. Atrial and ventricular myocardial blood flows in horses at rest and during exercise. Am J Vet Res. 1994;55:1464-1469

57. Neill WA, Sewell DH, Gosalia KP, Kingsley EM, Oxendine JM. Atrial coronary hyperemia and ischemia in response to variations in atrial pressure in dogs. American heart journal. 1983;106:554558 


\section{CHAPTER 7}

58. Smiseth OA, Mjos OD. Increased left atrial myocardial blood flow during acute ischemic left ventricular failure. American heart journal. 1986;111:798-799

59. White CW, Marcus ML, Abboud FM. Distribution of coronary artery flow to the canine right atrium and sinoatrial node. Circulation research. 1977;40:342-347

60. Bauman RP, Rembert JC, Greenfield JC, Jr. Regional blood flow in canine atria during exercise. Am J Physiol. 1993;265:H629-632

61. White CW, Kerber RE, Weiss HR, Marcus ML. The effects of atrial fibrillation on atrial pressure-volume and flow relationships. Circulation research. 1982;51:205-215

62. Corradi D, Callegari S, Maestri R, Ferrara D, Mangieri D, Alinovi R, Mozzoni P, Pinelli S, Goldoni M, Privitera YA, Bartoli V, Astorri E, Macchi E, Vaglio A, Benussi S, Alfieri O. Differential structural remodeling of the left-atrial posterior wall in patients affected by mitral regurgitation with or without persistent atrial fibrillation: A morphological and molecular study. Journal of cardiovascular electrophysiology. 2012;23:271-279

63. Hurle A, Sanchez-Quintana D, Ho SY, Bernabeu E, Murillo M, Climent V. Capillary supply to the sinus node in subjects with long-term atrial fibrillation. The Annals of thoracic surgery. 2010;89:38-43

64. Rabelink TJ, de Boer HC, van Zonneveld AJ. Endothelial activation and circulating markers of endothelial activation in kidney disease. Nature reviews. Nephrology. 2010;6:404-414

65. Ashrafian H, Frenneaux MP, Opie LH. Metabolic mechanisms in heart failure. Circulation. 2007;116:434-448

66. Cardin S, Libby E, Pelletier P, Le Bouter S, Shiroshita-Takeshita A, Le Meur N, Leger J, Demolombe S, Ponton A, Glass L, Nattel S. Contrasting gene expression profiles in two canine models of atrial fibrillation. Circulation research. 2007;100:425-433

67. Horowitz JD, Chirkov YY, Kennedy JA, Sverdlov AL. Modulation of myocardial metabolism: An emerging therapeutic principle. Current opinion in cardiology. 2010;25:329-334 

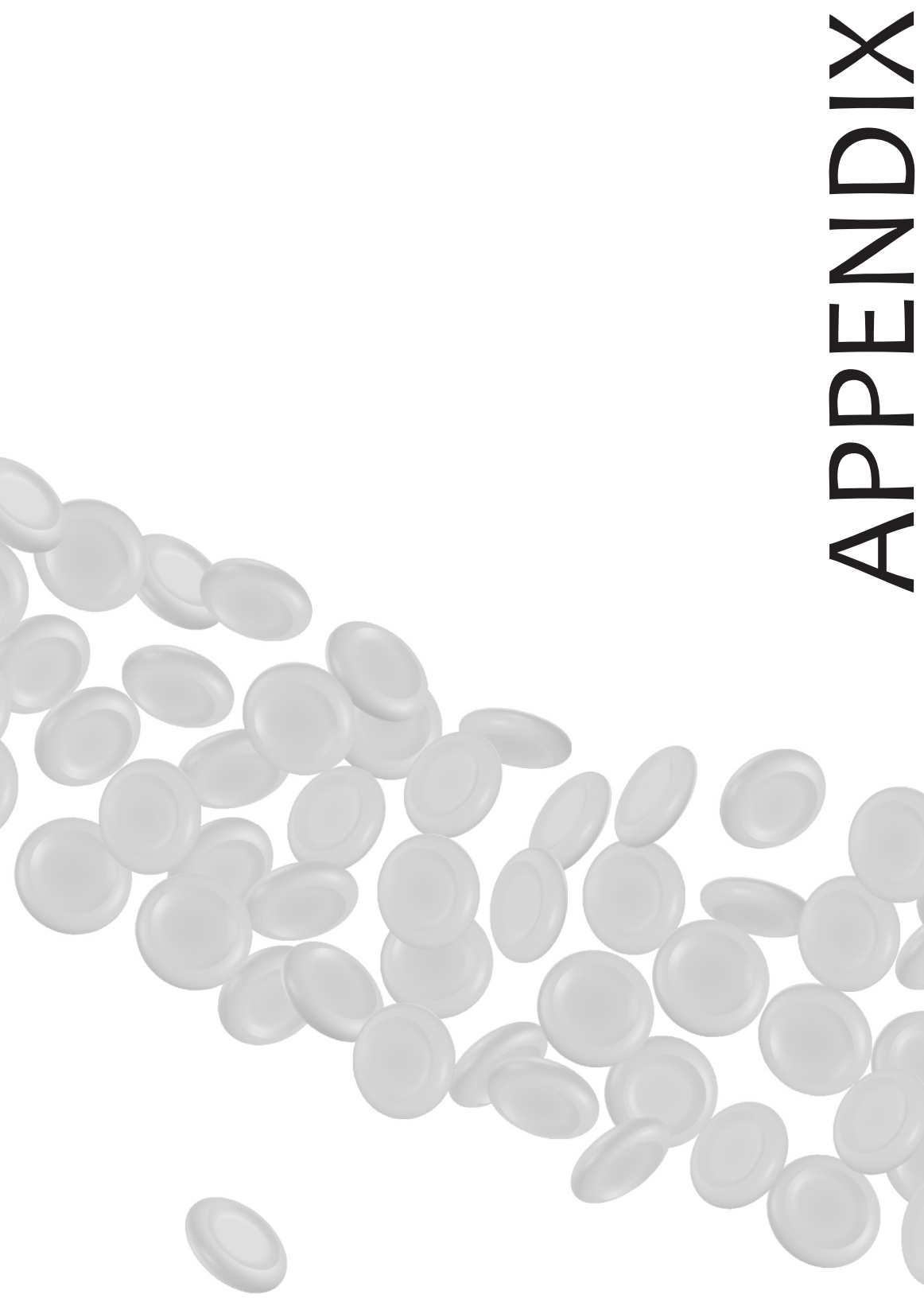


\section{APPENDIX}

\section{SUMMARY}

Atrial fibrillation (AF) is a self-perpetuating arrhythmia characterized by fast and irregular activation of the atria. Structural, electrophysiological, contractile and metabolic remodeling takes place in the atrial tissue as a result of AF. The exact trigger for these atrial changes is unknown, but indirect evidence suggests a role for energy shortage in the perpetuation of AF. The ultrastructural changes seen in the atria during AF resemble hibernating ventricular myocardium due to low flow ischemia. In addition, markers of hypoxia and angiogenesis are increased in animal models of AF and in AF patients.

To prevent a supply-demand mismatch during AF, atrial supply should be increased or atrial demand should be decreased. This thesis aims to describe the different aspects of supply-demand balance in the atrium during sinus rhythm and acute and chronic AF. The atrial vascular anatomy of the pig was investigated in CHAPTER 3 and an extensive atrial vascular network was observed. Through this vascular network, the atria receive about $5 \%$ of total coronary blood flow during sinus rhythm. Very limited overlap in atrial perfusion territories was observed, which makes the atrium susceptible to ischemia. Both atrial coronary blood flow and atrial oxygen extraction can be recruited to match changes in atrial oxygen demand and maintain supplydemand balance. In CHAPTER 5, we show that an increased atrial rate resulted in an increased atrial workload. Atrial pacing and the induction of AF in healthy pigs resulted in an immediate increase in atrial coronary blood supply. After the cessation of $\mathrm{AF}$, atrial flow did not immediately return to baseline values, which is a first indication for a shortage of oxygen during AF. An increase in atrial oxygen extraction was also observed during acute AF (CHAPTER 4). Despite recruitment of both flow reserve and extraction reserve in the atrium during AF, lactate was produced, showing that a supply-demand mismatch occurred.

In a goat model of AF, the increase in gene expression of hypoxia marker $\mathrm{HIF}_{1 \alpha}$ was temporary and returned to baseline values after 1 week of AF. Also phospocreatine, a tell-tale sign for supply-demand ischemia, was only increased in the first week of AF 
in goats. In addition, angiogenesis marker VEGF was only increased in patients with paroxysmal AF, but restored in permanent AF patients. To further determine the effect of chronic AF, a pig model of 5 weeks (chronic) AF was developed and supply-demand balance was investigated (CHAPTER 6). In the pig model of chronic AF, electrical and structural remodeling was observed and AF stability was increased compared to healthy controls. Coronary flow reserve and extraction reserve were comparable to healthy controls. In addition, flow and extraction increased in similar amounts during $A F$. As opposed to acute $A F$ in controls, chronic AF did not result in increased lactate production, indicating that the AF-induced remodeling processes are to some extent able to restore the supply-demand balance. The most likely mechanism for this adaptation is probably a decrease in demand during AF resulting from loss of contractility and myocyte hibernation. The capillary density was markedly decreased after 5 weeks of AF. This process of atrial 'vascular remodeling' may maintain atrial susceptibility to ischemia, limiting the capacity of the atrial myocardium to respond to fluctuations in demand. 


\section{NEDERLANDSE SAMENVATTING}

Boezemfibrilleren of atriumfibrilleren (AF) is een hartritmestoornis die gekarakteriseerd wordt door een snelle en onregelmatige activatie van de boezems. Structurele, elektrofysiologische, contractiele en metabolische veranderingen in de atria worden geobserveerd in de atria van AF patiënten. De exacte oorzaak voor deze veranderingen is onbekend, maar er is indirect bewijs voor een energie tekort in de atria tijdens AF. De ultrastructurele veranderingen in atriale cellen tijdens AF zijn vergelijkbaar met hibernerende cellen tijdens lage-perfusie ischemie in de ventrikels. Ook zijn er aanwijzingen van hypoxie en angiogenese in diermodellen van AF en in AF patiënten.

De disbalans tussen zuurstof vraag en zuurstof aanbod wordt supply-demand mismatch of supply-demand ischemie genoemd. Om supply-demand ischemie te voorkomen tijdens AF, moet het aanbod stijgen of de vraag dalen. In deze thesis werden de verschillende aspecten van de supply-demand balans in het atrium besproken tijdens sinus ritme en acuut en chronisch AF. De anatomie van de atriale vaat-boom werd beschreven in HOOFDSTUK 3 en een dicht netwerk van vaten werd geobserveerd. Ongeveer $5 \%$ van de totale bloedstroom naar het hart gaat via dit dichte netwerk naar de atria. Aangezien er weinig overlap is tussen de perfusie gebieden van de atriale vaten, zijn de atria erg gevoelig voor ischemie. Zowel de atriale bloedstroom als de atriale zuurstof extractie kunnen worden aangesproken indien de vraag naar zuurstof stijgt in de atria. In HOOFDSTUK 5 toonden we aan dat de atriale arbeid toeneemt als het ritme in de atria stijgt. Een verhoging van het atriale ritme en de inductie van AF doormiddel van een pacemaker in de atria resulteerde in een directe toename van de atriale bloedstroom. Zodra het atriaal ritme omsloeg van AF naar sinus ritme, had dit niet direct een daling in de bloedstroom tot gevolg. Dat was een eerste indicatie voor een zuurstof tekort tijdens AF (HOOFDSTUK 4). Ondanks de toename in bloedstroom en zuurstof extractie tijdens AF, werd een toename in melkzuur (lactaat) aangetoond in de atria tijdens AF. Dit is een directe indicatie voor supply-demand ischemie tijdens AF. 
In het geitenmodel van AF werd een tijdelijke toename in $\mathrm{HIF}_{1 a}$ gezien, die terugkeertde naar de originele waarden na 1 week AF. Ook werd er een toename in phosphocreatine aangetoond in het geitenmodel na 1 week AF. Een toename in de angiogenese marker VEGF werd gezien in paroxysmaal AF en niet in persistent (chronisch) AF patiënten. Om het chronische effect van AF verder te onderzoeken, hebben we een model van 5 weken chronisch AF in varkens ontwikkeld (HOOFDSTUK 6). In dit varkensmodel werden structurele en elektrische veranderingen gevonden en $A F$ was meer stabiel dan in controle dieren. De bloedstroom reserve en extractie reserve waren vergelijkbaar in beide modellen. Daarnaast was de toename in bloedstroom en extractie tijdens AF even groot. In tegenstelling tot acuut AF in controle dieren, zagen we geen toename in lactaat in het 5 -weken AF model tijdens AF. Dit toont aan dat de veranderingen in het atriaal weefsel die optreden tijdens AF tot op zekere hoogte de supply-demand balans in het atrium kunnen herstellen, waarschijnlijk doordat de vraag naar zuurstof afneemt bij bijvoorbeeld cellulaire hibernatie of een daling in de contractiliteit. De capillaire dichtheid was sterk verlaagd na 5 weken AF. Door de veranderingen in de vaatboom is het atriale weefsel juist extra vatbaar voor een zuurstoftekort en is er in het atrium een beperkte capaciteit om te reageren op fluctuaties in zuurstofvraag. 


\section{OPPORTUNITIES FOR VALORIZATION}

The aim of this chapter is to identify opportunities to valorize the research findings of this thesis. Knowledge valorization refers to the "process of creating value from knowledge, by making knowledge suitable and/or available for social (and/or economic) use, and by making knowledge suitable for translation into competitive products, services, processes and new commercial activities" (adapted definition based on the National Valorization Committee 2011:8). According to this definition, scientific research is valued by its direct socio-economic impact. Although the socio-economic impact of basic research is difficult to quantify, increasing knowledge of complex (patho)physiolocial processes is pivotal to future innovations.

\section{Societal conditions}

As described in CHAPTER 1 of this thesis, atrial fibrillation (AF) is the most common arrhythmia in clinical practice and the prevalence of AF increases with age ${ }^{1-3}$. AF significantly increases the risk for all cause mortality, cardiovascular mortality, stroke and congestive heart failure ${ }^{3}$. In the Netherlands, an estimated 300.000 people suffer from AF. With the ageing of the population, this number is expected to increase to 1.000 .000 in 2050. Thus, AF represents a significant socio-economic burden. Current $A F$ treatment involves maintaining patients with paroxysmal and persistent $A F$ in sinus rhythm (rhythm control) or controlling the ventricular rate (rate control). In addition, patients are treated with anti-coagulation therapy to decrease the risk of stroke ${ }^{4}$. However, anti-coagulation therapy has potentially harmful side effects, such as an increased risk of bleeding, and therefore needs to be carefully controlled. Except for anti-coagulation therapy, so far there is no treatment available that substantially improves the prognosis of AF patients ${ }^{5}$. In AF patients, the arrhythmia is often progressive, with a gradual increase in the duration of AF episodes. AF causes structural remodeling of the atrial myocardium, and it is generally accepted that this process is responsible for AF progression. By causing structural remodeling that increases the stability of the arrhythmia, AF is self-perpetuating. Although various aspects of structural remodeling, e.g. fibrosis, myocyte hypertrophy and hibernati- 
on, have been characterized extensively, the factors leading to structural remodeling are still poorly understood. Insight into these pathogenic factors is essential for the development of successful upstream therapy, i.e. therapy preventing structural remodeling and thereby inhibiting AF progression.

\section{Novelty of the concept}

Several potentially important pathogenic factors have been proposed in AF progression, e.g. atrial dilatation/ stretch, calcium overload, oxidative stress, inflammation and altered neurohumoral signaling. Although atrial ischemia has been mentioned as a possible contributor ${ }^{6-12}$, its occurrence and role has not been investigated systematically. Nevertheless, it is likely that the rapid rates occurring during AF represent a substantial increase in atrial energy expenditure. If this increase cannot be met by an increase in atrial coronary supply, a state of supply-demand ischemia will develop. In this thesis, we have investigated the structure of the atrial vasculature (CHAPTER 3), the regulation of atrial coronary blood flow (CHAPTER 5) and the occurrence of supply-demand ischemia (CHAPTER 4 and 6). Several remodeling processes observed in AF (e.g. myocyte hibernation) can be viewed as energy saving mechanisms to restore the supply-demand balance. To our knowledge, this is the first study to show atrial supply-demand ischemia induced by acute AF (CHAPTER 4). We have also shown that after a few weeks of AF, atrial supply-demand balance is restored, although accompanied by potentially detrimental vascular remodeling (CHAPTER 6).

\section{Road to product}

A logical next step to evaluate the role of atrial ischemia as a pathogenic factor leading to structural remodeling is to test interventions that would reduce supply-demand ischemia. Both inventions that affect atrial metabolism (leading to conservation of energy) and the atrial vasculature (leading to improvement of supply) would be suitable candidates for upstream therapy. These would first have to be tested in a suitable large animal model of AF. If such a therapy would prove successful in inhibiting structural remodeling and AF progression in an animal model, they 


\section{APPENDIX}

could be considered a treatment option for patients with AF or patients at risk for developing AF. Targeting supply-demand ischemia may prove particularly suitable in patients with paroxysmal AF, where episodes of AF and sinus rhythm alternate, and where each AF paroxysm may represent an ischemic insult that leads to an accumulation of damage to the atrial myocardium.

\section{Conclusions}

On the short term, the research findings in this thesis about supply-demand balance in the atrium will be of value to researchers in directly related fields. In addition, knowledge about the atrial vascular anatomy may be relevant in cardiac surgery and the development of new ablation strategies, as described in CHAPTER 3 of this thesis in the paragraph "atrial ischemia in ablation strategies and myocardial infarction". On the long term, these findings may lead to the development of new strategies for upstream treatment of AF. If atrial supply-demand ischemia indeed proves to be an important pathogenic factor in the development of a substrate for AF, then it is likely that vascular or metabolic interventions can inhibit the progression of AF.

\section{REFERENCES}

1. Feinberg WM, Blackshear JL, Laupacis A, Kronmal R, Hart RG. Prevalence, age distribution, and gender of patients with atrial fibrillation. Analysis and implications. Archives of internal medicine. 1995;155:469-473

2. Go AS, Hylek EM, Phillips KA, Chang Y, Henault LE, Selby JV, Singer DE. Prevalence of diagnosed atrial fibrillation in adults: National implications for rhythm management and stroke prevention: The anticoagulation and risk factors in atrial fibrillation (atria) study. JAMA : the journal of the American Medical Association. 2001;285:2370-2375

3. Krahn AD, Manfreda J, Tate RB, Mathewson FA, Cuddy TE. The natural history of atrial fibrillation: Incidence, risk factors, and prognosis in the manitoba follow-up study. Am J Med. 1995;98:476-484

4. Potpara TS, Polovina MM, Licina MM, Stojanovic RM, Prostran MS, Lip GY. Novel oral anticoagulants for stroke prevention in atrial fibrillation: Focus on apixaban. Advances in therapy. 2012;29:491-507

5. Schotten U, Verheule S, Kirchhof P, Goette A. Pathophysiological mechanisms of atrial fibrillation: A translational appraisal. Physiological reviews. 2011;91:265-325 
6. Ausma J, Coumans WA, Duimel H, Van der Vusse GJ, Allessie MA, Borgers M. Atrial high energy phosphate content and mitochondrial enzyme activity during chronic atrial fibrillation. Cardiovascular research. 2000;47:788-796

7. Dispersyn GD, Ausma J, Thone F, Flameng W, Vanoverschelde JL, Allessie MA, Ramaekers FC, Borgers M. Cardiomyocyte remodelling during myocardial hibernation and atrial fibrillation: Prelude to apoptosis. Cardiovascular research. 1999;43:947-957

8. Gramley F, Lorenzen J, Jedamzik B, Gatter K, Koellensperger E, Munzel T, Pezzella F. Atrial fibrillation is associated with cardiac hypoxia. Cardiovasc Pathol. 2010;19:102-111

9. Scridon A, Morel E, Nonin-Babary E, Girerd N, Fernandez C, Chevalier P. Increased intracardiac vascular endothelial growth factor levels in patients with paroxysmal, but not persistent atrial fibrillation. Europace : European pacing, arrhythmias, and cardiac electrophysiology : journal of the working groups on cardiac pacing, arrhythmias, and cardiac cellular electrophysiology of the European Society of Cardiology. 2012;14:948-953

10. Thijssen VL, Ausma J, Borgers M. Structural remodelling during chronic atrial fibrillation: Act of programmed cell survival. Cardiovascular research. 2001;52:14-24

11. Thijssen VL, van der Velden HM, van Ankeren EP, Ausma J, Allessie MA, Borgers M, van Eys GJ, Jongsma HJ. Analysis of altered gene expression during sustained atrial fibrillation in the goat. Cardiovascular research. 2002;54:427-437

12. Xu Y, Sharma D, Du F, Liu Y. The role of toll-like receptor 2 and hypoxia-induced transcription factor-1alpha in the atrial structural remodeling of non-valvular atrial fibrillation. International journal of cardiology. 2013 


\section{ABOUT THE AUTHOR}

Kelly van Bragt was born on the $23^{\text {rd }}$ of January 1985 in Roermond. In 1999 she moved with her family to Maasmechelen, Belgium where she graduated from Heilig Hart College high school in 2004 with the profile Science and Mathematics.

She started at Maastricht University in 2004 to follow the Bachelor program Molecular Life Sciences. After obtaining her Bachelor degree in 2007, she attended a two-year Research Master program in Cardiovascular Biology and Medicine organized by the Cardiovascular Research Institute Maastricht (CARIM). During this Master program she became interested in electrophysiology of the heart and did two internships at the Department of Physiology under supervision of Prof. Schotten and Dr. Verheule. After her internships, she presented her work and future perspectives to a jury of university staff members and CARIM board members and was rewarded with a PhD grant within CARIM. She joined the Physiology department as a PhD in 2009, supervised by Prof. Schotten en Dr. Verheule, where she was involved in determining the project plan and developing a variety of new techniques. In 2010 and 2011, the author joined the organizing committee of the Dutch Association for Physiology. The obtained data from her research at Maastricht University resulted in several publications in peer- reviewed scientific journals. With the presentation of her work, she won two poster awards and an oral presentation award on international symposia.

After her PhD, she started working as a Clinical Research Specialist at the Medtronic Bakken Research Center. 


\section{APPENDIX}

\section{LIST OF PUBLICATIONS}

van Bragt KA, Nasrallah HM, Kuiper M, van Hunnik A, Kuijpers NH, Schotten U, Verheule $S$. Dynamic regulation of atrial coronary blood flow in healthy adult pigs.

Heart Rhythm. 2015 May;12(5):991-1000

\section{Editorial commentary}

Wijesurendra R, Casadei B. Atrial supply-demand mismatch in atrial fibrillation: The missing link between rapid rate and atrial remodeling?

Heart Rhythm. 2015 May;12(5):1001-2

van Bragt KA, Nasrallah HM, Kuiper M, Luiken JJ, Schotten U, Verheule S. Atrial supply-demand balance in healthy adult pigs: coronary blood flow, oxygen extraction, and lactate production during acute atrial fibrillation.

Cardiovasc Res. 2014 Jan 1;101(1):9-19

Blana A, Kaese S, Fortmüller L, Laakmann S, Damke D, van Bragt K, Eckstein J, Piccini I, Kirchhefer U, Nattel S, Breithardt G, Carmeliet P, Carmeliet E, Schotten U, Verheule S, Kirchhof P, Fabritz L. Knock-in gain-of-function sodium channel mutation prolongs atrial action potentials and alters atrial vulnerability.

Heart Rhythm. 2010 Dec;7(12):1862-9

Submitted to Cardiovasc Res

van Bragt KA, van Horssen P, van den Wijngaard JP, Nasrallah HM, Podziemski P, Spaan JA, Schotten U, Siebes M, Verheule S Anatomy of the atrial vasculature in pigs

Submitted to Cardiovasc Res

van Bragt KA, Nasrallah HM, Kuiper M, Luiken JJ, Schotten U, Verheule S

The impact of persistent atrial fibrillation on the atrial supply-demand balance 


\section{List of publications}

To be submitted

Nasrallah HM, van Bragt KA, Kuiper M, van Hunnik A, Schotten U, Verheule S. Left atrial oxygen supply in a pig model of congestive heart failure: vascular remodeling, atrial contractile dysfunction and reduced oxygen efficiency 


\section{APPENDIX}

\section{DANKWOORD}

En zo schrijf ik ineens mijn laatste hoofdstuk, het dankwoord. Wetenschappelijk gezien wellicht het minst relevant, maar wat is een promovendus zonder de steun van collega's, vrienden en familie. Ik wil graag iedereen bedanken die mij tijdens dit leerzame avontuur heeft geholpen en gesteund.

Allereerst wil ik graag mijn promotor, Prof. Ulrich Schotten bedanken. Beste Uli, hartelijk dank voor jouw hulp bij het tot stand komen van mijn proefschrift. Je hebt me altijd gestimuleerd kritisch te blijven en vragen te stellen bij mijn onderzoek. Ook een grote dank aan mijn co-promotoren Dr. Sander Verheule en Dr. Joost Luiken. Beste Sander, het is nu bijna 8 jaar geleden dat jij onze onderwijsgroep binnenliep met een artikel van Li et al. Toen wist ik het zeker, ik wilde verder in de elektrofysiologie en dat vond jij okay. Met veel enthousiasme hebben we samen kunnen sparren over nieuwe vraagstellingen, nieuwe technieken en nieuwe modellen. Dankzij jou heb ik geleerd dat bijna niets onmogelijk is. Ik heb daar vaak aan getwijfeld tijdens het gepriegel met piepkleine vaatjes op een kloppend hart en de experimenten tot 3 uur 's nachts. Soms dacht ik ook dat er nooit een einde zou komen aan het her-schrijven van een artikel of het her-analyseren van de data. Door jouw vertrouwen en geduld is het onderzoek naar een hoger niveau getild. Bedankt daarvoor. Beste Joost, jouw deur stond altijd open voor overleg, welke kant mijn onderzoek ook op ging. Ik vond het erg plezierig om twee afdelingen en onderzoeksvelden met elkaar te kunnen verbinden. Bedankt dat ik die kans heb gekregen.

Leden van de lezerscommissie, Prof. Crijns, Prof. Duncker, Prof. Prinzen, hartelijk dank voor het beoordelen van dit proefschrift. Ik heb met eenieder van jullie interessante gesprekken gehad die mijn onderzoek vorm en richting hebben gegeven. Ook daarvoor grote dank.

Mijn liefste paranimfjes, Frauke Swieringa en Dr. Anneleen Daniels, bedankt voor alle tijd die we samen hebben doorgebracht op de uni en daarbuiten en jullie steun bij het afronden van deze mijlpaal. Frauke, mede-prinses, mijn grote steun en toe- 
verlaat, waar zou ik zijn zonder jou. Bedankt voor de Disney-films, de feestjes, de etentjes, de ATP-grappen, je advies, jouw kritisch oog op mijn onderzoek en bij het uitzoeken van de promotie-jurk natuurlijk. Anneleen, wonder woman, ik-doe-welefkes-alles-tegelijk-woman. Jouw doorzettingsvermogen is een voorbeeld voor me. Bedankt voor de vele professionele en persoonlijke gesprekken die we hebben gehad onder het genot van een kopje koffie, zowel op de uni als bij Medtronic. Het is een plezier met je te werken. Over jullie zou ik door kunnen schrijven, voor jullie heb ik nooit woorden (maar wel pagina's) tekort. Bedankt dat jullie mijn paranimfen zijn.

Uiteraard wil ik ook mijn collega's van de elektrofysiologie bedanken. Marion, bedankt voor de fijne gesprekken tijdens de lunch en tot in de late uurtjes aan de OK tafel. Je bent de koningin van het vaatjes prepareren, zonder jou was het niet gelukt zoveel geslaagde experimenten te doen. Arne, jouw vakkundige kennis heeft zeker bijgedragen aan de kwaliteit van de experimenten. Sophie, bedankt voor de leuke tijd en al je hulp op de OK. Stijn, Hussein and BG, my roommates, thanks for the laughter, the stories, the hummus and wine, thanks for opening the door when I forgot my key (again). Hussein, thank you for your big contribution to the experiments and data-analysis and good luck with finishing your thesis. BG, thank you for our inpirational conversations. And Stijn, who let the dogs out? Maura en Jens, you were a great help during my internship, thank you for teaching me about echo's, cell isolations and the ins-and-outs of a good scientist. Bart, Stef, Dominic, Ali, Pawel, I had a great time with you during our lunches, days out, BBQs etc. Piotr, we only had a few encounters, but I want to thank you for your magical touch on the 3D representations of the coronary anatomy. I would also like to thank our students Linda, Qimei and Malte for their contribution to my thesis. Linda, de tijd in Vancouver was onvergetelijk!

Hartelijk dank ook aan de Dr. Pepijn van Horssen, Dr. Jeroen van den Wijngaard, Prof. Spaan en Dr. Siebes voor de visualisatie en anayse van de atriale vasculatuur en flow.

Ook dank aan Dr. Nico Kuijpers voor het schrijven van algoritmes voor het analyse- 


\section{APPENDIX}

ren van de atriale distance-pressure loops.

Ook mag ik de andere AIO's en collega's van de fysiologie niet vergeten. Ik heb me altijd welkom gevoeld, voor een gesprek van AIO tot AIO, om iets te lenen, voor goed wetenschappelijk advies, een kopje koffie en een grap. Bart (Eskens), bedankt voor onze dagelijkse gesprekken, ijsjes en koffie, artikelen schrijven met een biertje aan de Maas. Ik vond het erg gezellig. Aan die gezelligheid mochten ook Anneleen, Bart Heijnen, Mark (Vries), Irma (Ila), Vincenza, Chantal en Felix (Flix) niet ontbreken. De fysiologie-uitjes, Papendal, zomer in het park, het Preuvenemint en Chess after work, ik heb erg genoten van de leuke tijd met jullie.

Alhoewel zo'n promotie behoorlijk wat tijd vergt, is de tijd buiten de uni minstens net zo belangrijk geweest. Ik wil iedereen bedanken voor de fijne herinneringen uit deze periode, in het bijzonder Marti, Frauke, Patrick, Dennis, Saartje, Melanie, Lindsay, Jill, Jackie, Joris en Pieter. Jullie zorgden altijd voor voldoende afleiding, een steun in de rug, een goed gesprek en vooral veel plezier, dat zal ik niet vergeten.

Ten laatste wil ik mijn familie bedanken, de stabiele factor in mijn leven en onmiskenbaar de meest belangrijke.

Mama, bedankt voor je goede zorgen en je onvoorwaardelijke steun. Ik heb erg genoten van onze gezellige lunches thuis en in de stad. Hans, bedankt voor je geduld en onze gesprekken over het leven. Ik vind altijd veel rust bij jullie. Ik wens jullie heel veel succes tijdens jullie nieuwe avontuur in Duitsland. Met de huidige technologie zijn we gelukkig altijd dichtbij.

Papa, bedankt voor je oprechte interesse in mijn onderzoek. De klus/knutselkennis die ik bij jou heb opgedaan, kwam nog goed van pas in het fysiologie lab. Olga, bedankt voor je luisterend oor, de onderonsjes en het paardrij-avontuur. Bij jullie is er altijd afleiding en plezier. Chrissie en Nicky, jullie zijn de zonnestraaltjes in mijn leven. Bedankt voor de tekeningen en pannekoeken, het dansen en lachen. 
Stephanie, lieve zus, ik had je nog gewaarschuwd, zo'n PhD traject is zwaar! Maar eigenwijs als je was, ging jij er ook aan beginnen. En met succes! Binnenkort zal ook jij je proefschrift verdedigen. Ik heb ervan genoten deze speciale tijd met mijn zus en mede-promovendus te kunnen delen, jij begreep me als geen ander. Ik ben ontzettend trots op je! Go get'em, tiger.

Met veel plezier kijk ik terug op alle fijne herinneringen en alles wat ik geleerd heb in deze periode. Mijn promotie traject is een ontdekkingsreis geweest in het lab en de OK, in de wetenschap en in mijzelf als persoon. Het is tijd om dit hoofdstuk af te sluiten. 